UNIVERSIDADE DE SÃO PAULO

FACULDADE DE FILOSOFIA LETRAS E CIÊNCIAS HUMANAS

DEPARTAMENTO DE LINGUÍSTICA

PROGRAMA DE PÓS-GRADUAÇÃO EM SEMIÓTICA E LINGUÍSTICA GERAL

Karin Camolese Vivanco

\title{
Perguntas QU-, orações subordinadas e ordem de palavras em Karitiana
}

VERSÃO CORRIGIDA

Brasil

2018 

UNIVERSIDADE DE SÃO PAULO

FACULDADE DE FILOSOFIA LETRAS E CIÊNCIAS HUMANAS

DEPARTAMENTO DE LINGUÍSTICA

PROGRAMA DE PÓS-GRADUAÇÃO EM SEMIÓTICA E LINGUÍSTICA GERAL

\title{
Perguntas QU-, orações subordinadas e ordem de palavras em Karitiana
}

\author{
Karin Camolese Vivanco \\ Tese apresentada ao Programa de Semiótica \\ e Linguística Geral da Faculdade de Filoso- \\ fia, Letras e Ciências Humanas da Universi- \\ dade de São Paulo para obtenção do título \\ de Doutor em Linguística \\ Orientador: Prof. ${ }^{a}$ Dr. ${ }^{a}$ Luciana Raccanello \\ Storto
}

VERSÃO CORRIGIDA

Brasil

2018 



\section{ENTREGA DO EXEMPLAR CORRIGIDO DA DISSERTAÇÃO/TESE}

\section{Termo de Ciência e Concordância do (a) orientador (a)}

Nome do (a) aluno (a): Karin Camolese Vivanco

Data da defesa: $26 / 10 / 2018$

Nome do Prof. (a) orientador (a): Luciana Raccanello Storto

Nos termos da legislação vigente, declaro ESTAR CIENTE do conteúdo deste EXEMPLAR CORRIGIDO elaborado em atenção às sugestões dos membros da comissão Julgadora na sessão de defesa do trabalho, manifestando-me plenamente favorável ao seu encaminhamento e publicação no Portal Digital de Teses da USP.

São Paulo, 15/01/2019

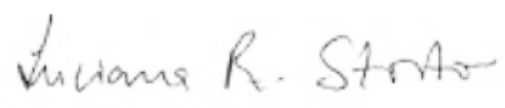


Autorizo a reprodução e divulgação total ou parcial deste trabalho, por qualquer meio convencional ou eletrônico, para fins de estudo e pesquisa, desde que citada a fonte.

Catalogação na Publicação

Serviço de Biblioteca e Documentação

Faculdade de Filosofia, Letras e Ciências Humanas da Universidade de São Paulo

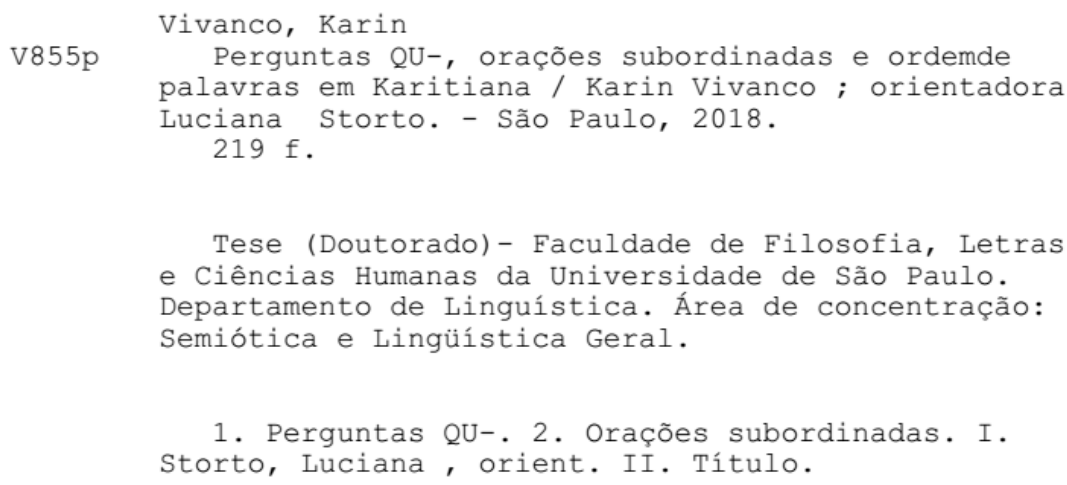




\section{Karin Camolese Vivanco}

\section{Perguntas QU-, orações subordinadas e ordem de palavras em Karitiana}

Tese apresentada ao Programa de Semiótica e Linguística Geral da Faculdade de Filosofia, Letras e Ciências Humanas da Universidade de São Paulo para obtenção do título de Doutor em Linguística

Área de Concentração: Linguística

Brasil, 13 de agosto de 2018

BANCA EXAMINADORA

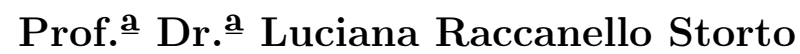

Orientador

Maria Filomena Spatti Sandalo

Universidade Estadual de Campinas

Suzi Oliveira de Lima

Universidade de Toronto/Universidade Federal do Rio de Janeiro

Ana Lúcia de Paula Müller

Universidade de São Paulo 



\section{Agradecimentos}

Antes de tudo, gostaria de iniciar com dois agradecimentos especiais àqueles foram fundamentais para a existência deste trabalho. Primeiramente, agradeço à Fundação de Amparo à Pesquisa do Estado de São Paulo por todo apoio financeiro para a realização desta pesquisa (número dos processos: 2014/15141-1 e 2016/07643-2) Em segundo lugar, devo meus sinceros agradecimentos à comunidade Karitiana, que durante todo esse tempo se disponibilizou em compartilhar comigo sua língua e seu conhecimento de vida. Agradeço o apoio das lideranças e professores que me ajudaram durante todo este tempo: Cizino Karitiana, Nelson Karitiana, Inácio Karitiana, Antônio José Karitiana, Walmir Karitiana, Orlando Karitiana, Luís Karitiana, Reinaldo Karitiana, Elivar Karitiana, João Karitiana, Cledson Karitiana, Maria de Fátima Karitiana, Cláudio Karitiana, Reinaldo Karitiana e Edelaine Karitiana. Não menos importante, agradeço a todos os outros membros da comunidade, que muito pacientemente me ensinarem não só sua língua, mas também o respeito e a consideração pelos outros. Yryhodn, yota!

Outra pessoa fundamental para este trabalho foi a minha orientadora, a prof. ${ }^{\text {a }}$ Luciana Storto. A Luciana me acolheu como sua aluna logo no início da graduação e desde então tem me incentivado e apoiado sempre. A Luciana foi peça fundamental em todas as minhas conquistas e a agradeço muito por me ensinar, por me orientar e também por me acalmar em momentos de grande aflição. Considero que sou uma pessoa de grande sorte, já que contei com o apoio de uma pesquisadora que admiro muito, mas que é também uma pessoa que sabe tratar os outros de uma forma muito humana e caridosa.

Em segundo lugar, agradeço muito ao meu orientador no exterior, o prof. Norvin Richards. O Norvin me acolheu no MIT e acompanhou praticamente todos os aspectos de minha pesquisa em reuniões semanais. Admiro sua paciência e generosidade, e o agradeço muito por me auxiliar em questões acadêmicas e burocráticas mesmo sendo um pesquisador tão requisitado.

Outra professora de grande importância para a realização deste trabalho foi a prof. a Ana Müller, que tem praticamente atuado como minha co-orientadora durante todos estes anos. Agradeço por todo o apoio e também pelos valiosos comentários durante o exame de qualificação. Também agradeço ao prof. Jairo Nunes, por ter discutido este trabalho durante a qualificação e em muitas outras ocasiões. Outros professores que também me ajudaram durante o processo e a quem eu gostaria de agradecer são Shigeru Miyagawa, Edward Flemming, Sabine Iatridou, David Pesetsky, Marcello Modesto, Elaine Grolla, Esmeralda Negrão, Flaviane Fernandes-Svartman, Didier Demolin, Andres Salanova, Evani Viotti, Fábio Bomfim e Thomas Finbow. Por fim, agradeço também a Filomena Sandalo e Suzi Lima pela leitura cuidadosa e por todas as suas contribuições a este trabalho. 
Durante todo esse percurso, pude contar com a amizade e colaboração de diversos colegas pós-graduandos, que gostaria de citar aqui. Primeiramente, agradeço a Ivan Rocha e Luciana Sanchez-Mendes, meus grandes colegas de campo. Agradeço tudo que me ensinaram, a companhia durante os momentos de tensão, as risadas e os perrengues inesquecíveis. Também agradeço aos meus novos colegas de campo, Thiago Alexandre, Luís Fernando Ferreira e Tarcísio Dias. Também agradeço especialmente à querida Karolin Obert, por toda amizade e auxílio nessa jornada. Além disso, gostaria de agradecer aos meus colegas da USP Fernanda Nogueira, Janayna Carvalho, Paula Armelin, Aline Takahira, João Paulo Cyrino, Rafael Minussi, Indaiá Bassani, Lara Frutos, Letícia Evelyn, Cláudia Souza, Vítor Nóbrega, Bruna Polachini, Fernanda Rosa, Wânia Miranda, Edu Santos, Stela Danna, Mayara Spadaro, Paulo Jefferson, Fernanda Canever, Íris Araújo, Júlia Fernandez, Lucas Shimoda, Camila Rezende, Kalyne Melo, Aline Benevides, Marcelo Rangel, Carol Alves, Joana Autuori, Juliana Vignado, Iolanda Dias, Lucas Ciola, Jéssica Viana, Raíssa Santana, Andressa Toni, Monique Amaral, Jéssica Costa, Wallace Andrade. Outros colegas de fora da USP que eu gostaria de agradecer são Ricardo Castro, Adam Singerman, Myriam Lapierre e Bernat Bardagil Mas.

Nos EUA, agradeço principalmente a quatro pessoas que me ajudaram em alguns dos meus momentos mais difíceis. Primeiro, à Mar Bassa, que foi praticamente minha família durante todo sanduíche e será para toda vida; à Lilla Magyar, que foi minha querida companheira e grande confidente, à Maísa (e Lucas!) por toda a força e amizade; e à Suzana Fong, pelas valiosas dicas, conselhos e por toda a generosidade. Agradeço também a Newell Lewey, por ter me ensinado tanto e ampliado meu mundo, e a Talia Fox, Milena Sisovics, Abdul-Razak Sulemana, Carrie Spadine, aos colegas do Syntax Square e a todos os outros amigos e colegas que me ajudaram durante a minha estadia em Cambridge.

Por toda ajuda em Porto Velho, agradeço também ao apoio de Leonildo e Márcia, da SEDUC, e de Luciana Borges e sua família.

Fora do âmbito acadêmico, agradeço também às queridas Fernanda Belarmino e Nathaschka Martiniuk (e ao Thiago também!) por serem as pessoas maravilhosas que são. Agradeço também às minhas amigas Bianca Lopez e Camila Belotti, cuja amizade tem me acompanhado durante todos estes anos.

Por fim, nada disso teria sido possível sem o apoio incondicional da minha família, que me apoiou e incentivou mesmo nos momentos mais difíceis. Aos meus pais, Mirian e Francisco, que são os melhores pais do mundo, ao meu querido irmão Bruno, minha vó Eunice, e meus tios, sogros e cunhadas. Não menos importante, ao Marcelo, cuja companhia tem deixado toda essa jornada mais leve e colorida 


\section{Resumo}

VIVANCO, K.C. Perguntas QU-, orações subordinadas e ordem de palavras em Karitiana. 2018. 209 f. Tese (Doutorado) - Faculdade de Filosofia, Letras e Ciências Humanas, Universidade de São Paulo, São Paulo, 2018.

Este trabalho descreve diversos aspectos da formação de perguntas complexas, orações subordinadas e ordem de palavras no Karitiana, uma língua Tupi da família Arikém. Primeiramente, descrevemos a formação de perguntas bi-oracionais como perguntas indiretas e perguntas de longa-distância. No primeiro caso, argumentamos que perguntas indiretas strictu sensu não existem em Karitiana, pois pronomes interrogativos não são em geral permitidos dentro de orações subordinadas. Já perguntas de longa-distância são possíveis na língua, mas sua formação inclui uma estratégia conhecida como pied-piping de larga-escala, na qual a oração subordinada inteira contendo o pronome interrogativo é movida para a posição inicial da sentença. Argumentamos que estes dois fatos podem ser capturados se assumirmos uma estrutura para orações subordinadas (1) que não contém certos núcleos oracionais, como C; e (2) que é a projeção de um núcleo nominalizador $n$. Essas propriedades seriam capazes de explicar o comportamento ambíguo destas construções, que ora se comportam como orações, ora como sintagmas nominais. Além disso, essa proposta também explica outros fenômenos aparentemente não relacionadas, como a ausência de tough-constructions, a extração com verbos factivos, a cliticização em subordinadas e a presença de relativas de núcleo interno. Propomos ainda que este núcleo $n$ de caráter nominal teria como uma possível realização fonética um sufixo - $a$, que pode ser detectado em diversos ambientes nominais da língua e que possivelmente teria conexões históricas com o nominalizador - $a$ presente em outras línguas Tupi. $\mathrm{Na}$ segunda parte deste trabalho, discutimos ainda construções com o morfema de voz inversa ti-, reanalisadas aqui como configurações de redobro de clítico. Essa proposta é capaz de explicar diversas propriedades deste morfema, como sua emergência em diferentes construções, o padrão de concordância excêntrica disparado por ele, a distribuição complementar com a passiva e a leitura pressuposicional do tema nestes ambientes. Por fim, discutimos ainda dois fenômenos prosódicos - o sufixo -o e a intonação de relativas de objeto com ti- - que poderiam constituir argumentos adicionais para as análises desenvolvidas neste trabalho.

Palavras-chaves: Perguntas QU-, Orações Subordinadas, Voz inversa, Nominalização, Karitiana 



\section{Abstract}

VIVANCO, K.C. WH- questions, embedded clauses, and word order in Karitiana. 2018. 209 p. Dissertation (Ph.D in Linguistics) - Faculdade de Filosofia, Letras e Ciências Humanas, Universidade de São Paulo, São Paulo, 2018.

This dissertation investigates aspects of question formation, embedded clauses, and word order in Karitiana, a Tupi-Arikém language spoken in Brazil. Firstly, the formation of bi-clausal questions such as indirect questions and long-distance questions is described. Regarding indirect questions, our claim is that there are no indirect questions in Karitiana, as interrogative pronouns are usually disallowed inside embedded clauses. On the other hand, the language has long-distance questions, but they obligatorily involve a strategy known as clausal/large-scale pied-piping - i.e., fronting of the whole embedded clause containing the interrogative pronoun. These two facts can be explained if one assumes a structure for embedded clauses that does not contain certain clausal projections, such as $\mathrm{CP}$, and that includes a nominalizing head $n$. These properties also account for the mixed behavior of these constructions, which exhibit a clausal template while manifesting several nominal features. Moreover, the proposed analysis also explains other apparently non-related properties of the language, such as the lack of tough-constructions, extraction with factive verbs, obligatory cliticization, and internally-headed relative clauses. Additionally, we claim that this nominal head has a phonetic realization as a suffix - $a$, detected in several nominal phrases and which is possibly linked to a Tupian nominalizer of the same form. In part II, we discuss constructions with the inverse voice morpheme $t i-$, claiming that these can be reanalyzed as cases of clitic-doubling. This analysis accounts for several properties of this preffix, such as its presence in cases of WHmovement, the eccentric pattern of agreement that it triggers, the complementary distribution with the passive, and the pressupositional reading of the theme in these constructions. Finally, two prosodic phenomena - the suffix - $o$ and the intonational pattern of object relative clauses with $t i-$ - are describedin detail and it will be shown how these provide additional evidence for the analyses developed in this dissertation.

Key-words: WH- questions, Embedded clauses, Inverse voice, Nominalization, Karitiana 



\section{Lista de ilustrações}

Figura 1 - Grande mudança vocálica (STORTO; BALDI, 1994) . . . . . . . . . . 32

Figura 2 - Figura utilizada para elicitação . . . . . . . . . . . . . . 52

Figura 3 - Figura utilizada para elicitação . . . . . . . . . . . . . . 52

Figura 4 - Figura utilizada para elicitação . . . . . . . . . . . . . . 71

Figura 5 - Figura utilizada para elicitação . . . . . . . . . . . . . . 71

Figura 6 - Figura utilizada para elicitação . . . . . . . . . . . . . . . 71

Figura 7 - Figura utilizada para elicitação . . . . . . . . . . . . . 72

Figura 8 - Figura utilizada para elicitação . . . . . . . . . . . . . . 72

Figura 9 - Grande mudança vocálica (STORTO; BALDI, 1994) . . . . . . . 125

Figura 10 - Curva intonacional para "Pyry'a sarytyn keerep Gokyp"("Gokyp") . . . 194

Figura 11 -Curva intonacional para "Yn naakat iso'oot... Maria gok amangaty." . 195

Figura 12 -Curva intonacional para "Dez dias yjakat.." . . . . . . . . . . . . 196

Figura 13 -Curva intonacional para "Ewosiit itihyrãt" (dado de Valin et al. (s.d.)) 197

Figura 14 - Curva intonacional para "Yn naakat ipyting 'irip saara ti'yty" . . . . . 198

Figura 15 - Curva intonacional para "Yn naakt ipyting Luciana pykyp tipipãramaty"199

Figura 16 - Curva intonacional para "Yn naakt ipyting sosy kinda'o ti'yty" . . . . . 200

Figura 17 - Curva intonacional para "Yn naakat ipyting jonso ombaky timity" . . . 200

Figura 18 -Curva intonacional para "Yn naakat ipyting ambi jonso tim'aty." . . . 201

Figura 19 - Curva intonacional para "Yn naakat ipyting 'irip saara ti'yty" . . . . . 202

Figura 20 - Curva intonacional para "Yn naakat ipyting boet Luciana tim'aty" . . . 202

Figura 21 - Curva intonacional para "Ivan naakat isondyp São Paulopip Luciana titataty" . . . . . . . . . . . . . . . . . . . . 205 



\section{Lista de tabelas}

Tabela 1 - Variação na pronúncia de fonemas nasais (STORTO, 1999) . . . . . . . 23

Tabela 2 - Número de orações subordinadas em textos naturalísticos . . . . . . . 29

Tabela 3 - Cognatos em línguas Tupi (RODRIGUES, 1986) . . . . . . . . . 32

Tabela 4 - Prefixos de pessoa . . . . . . . . . . . . 33

Tabela 5 - Sufixos de tempo . . . . . . . . . . . . . . 34

Tabela 6 - Morfologia de perguntas QU- . . . . . . . . . . . 46

Tabela 7 - Cognatos de 'penereg' em Tupi (DIETRICH, 2009) . . . . . . . . . 126

Tabela 8 - Vogal $[$ o] na lista de Nimuendajú . . . . . . . . . . . . . . 127

Tabela 9 - Enfático - o na lista de Nimuendajú . . . . . . . . . . . . 127

Tabela 10 -Sufixo - a na lista de Nimuendajú . . . . . . . . . . . . . . . . 127

Tabela 11 -Variação entre - o e - a na lista de Nimuendajú . . . . . . . . . . . . . 128

Tabela 12 -Variação entre - o e - a na lista de Nimuendajú . . . . . . . . . . . . . 128

Tabela 13 -Semelhança entre pronomes livres e afixos de concordância . . . . . . 151

Tabela 14 -Sistema tonal do Karitiana . . . . . . . . . . . . . . . 197 



\section{Lista de abreviaturas e siglas}

\begin{tabular}{|c|c|}
\hline $1 \mathrm{~s}$ & $1^{\mathrm{a}}$ pessoa singular \\
\hline $2 \mathrm{~s}$ & $2^{\mathrm{a}}$ pessoa singular \\
\hline $1 \mathrm{PL}$ & $1^{\mathrm{a}}$ pessoa plural \\
\hline $2 \mathrm{PL}$ & $2^{\mathrm{a}}$ pessoa plural \\
\hline 3 & $3^{\mathrm{a}}$ pessoa \\
\hline ANAPH & $3^{\mathrm{a}}$ pessoa anafórica \\
\hline ADJZ & adjetivizador \\
\hline ADVZ & adverbializador \\
\hline ASS & modo assertivo \\
\hline ASP.REF & aspecto referencial \\
\hline ASP & aspecto \\
\hline CAUS & causativizador \\
\hline CIT & citativo \\
\hline COMIT & comitativo \\
\hline COMP & comparativo \\
\hline COND & condicional \\
\hline $\mathrm{COP}$ & cópula \\
\hline CON.COP & concordância de cópula \\
\hline DECL & modo declarativo \\
\hline DEM & demonstrativo \\
\hline DEO & deôntico \\
\hline DES & desiderativo \\
\hline EPEN & epêntese \\
\hline EVID.DIR & evidencial direto \\
\hline EVID.IND & evidencial indireto \\
\hline FUTURO & futuro \\
\hline IMPERF & imperfectivo \\
\hline INV & voz inversa \\
\hline INV.DECL & voz inversa declarativa \\
\hline INTERR & partícula interrogativa \\
\hline INT.COP & copula interrogativa \\
\hline IMPERF.SEN. & modo imperfectivo (sentado) \\
\hline IMPERF.MOV & modo imperfectivo (em movimento) \\
\hline IMPERF.POS & imperfectivo posterior \\
\hline LAT & lativo \\
\hline LOC & locativo \\
\hline $\mathrm{N}$ & núcleo nominalizador $n$ \\
\hline
\end{tabular}




$\begin{array}{ll}\text { NEG } & \text { negação } \\ \text { NEG.EXIS } & \text { negação existencial } \\ \text { NFUT } & \text { não futuro } \\ \text { NMZ } & \text { nominalizador } \\ \text { OBL } & \text { oblíquo } \\ \text { PASS } & \text { voz passiva } \\ \text { PERF } & \text { perfectivo } \\ \text { RED } & \text { reduplicação } \\ \text { QU } & \text { pronome interrogativo }\end{array}$




\section{Sumário}

I Perguntas e orações subordinadas $\quad 25$

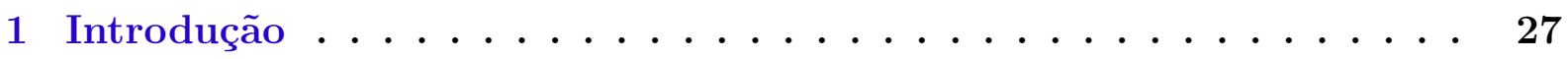

1.1 Questões metodológicas . . . . . . . . . . . . . . . . . 28

1.2 Localização e classificação . . . . . . . . . . . . . . . . . . . . 31

1.3 Aspectos gramaticais relevantes . . . . . . . . . . . . . . . 33

1.3.1 Morfologia verbal . . . . . . . . . . . . . . . . . . . 33

1.3 .2 Caso . . . . . . . . . . . . . . . . . . . . . 34

1.3.3 Estrutura argumental . . . . . . . . . . . . . . . 35

1.3.4 Ordem de palavras . . . . . . . . . . . . . . . 38

1.3.5 Orações subordinadas . . . . . . . . . . . . . . . . . . . 40

1.3.6 Perguntas QU- . . . . . . . . . . . . . . . . 45

1.4 Resumo do capítulo . . . . . . . . . . . . . . . . . . . . . 47

2 Perguntas indiretas ........................... 49

2.1 Metodologia . . . . . . . . . . . . . . . . . 51

2.2 Dados naturalísticos . . . . . . . . . . . . . . . . 53

2.3 Dados de elicitação . . . . . . . . . . . . . . . . . . . 54

2.3.1 Duas estratégias para perguntas indiretas . . . . . . . . . . . 54

2.3.2 O status marginal de perguntas indiretas com QU- . . . . . . . 58

2.3.2.1 Estatuto dos QU- . . . . . . . . . . . . . . 59

2.3.2.2 Recorte sociolinguístico . . . . . . . . . . . . 65

2.4 Resumo do capítulo . . . . . . . . . . . . . . . . . . . . . . 68

3 Perguntas QU- de longa distância . . . . . . . . . . . . 69

3.1 Introdução . . . . . . . . . . . . . . . . . . . . 69

3.2 Metodologia . . . . . . . . . . . . . . . . . 70

3.3 Perguntas QU- de longa distância e pied-piping de larga escala . . . . . . . 73

3.3.1 Pied-piping de larga-escala . . . . . . . . . . . . . . . 76

3.3 .2 Focalização . . . . . . . . . . . . . . . . . . 78

3.3.3 Topicalização . . . . . . . . . . . . . . . . . . . . 79

3.3.4 Movimento interno do QU- . . . . . . . . . . . . . . 81

3.4 Resumo do capítulo . . . . . . . . . . . . . . . . . . . 85

4 Estrutura das orações subordinadas . . . . . . . . . . . . 87

4.1 Propriedades das orações subordinadas . . . . . . . . . . . . . . . . 87

4.2 Proposta . . . . . . . . . . . . . . . . . . . . . . 95 
4.3 A estrutura das subordinadas e perguntas bi-oracionais . . . . . . . . . 98

4.3.1 Perguntas indiretas . . . . . . . . . . . . . . . . . . . . . . 99

4.3 .2 QU- de longa distância . . . . . . . . . . . . . . . . . 100

4.3.2.1 Orações subordinadas adverbiais . . . . . . . . . . . . . 104

4.4 Argumentos independentes . . . . . . . . . . . . . . . . . . . . 107

4.4.1 Ausência de 'tough-constructions' . . . . . . . . . . . . . . . . 107

4.4.2 Extração com verbos factivos . . . . . . . . . . . . . . . . 108

4.4 .3 Cliticização em subordinadas . . . . . . . . . . . . . . . . . 109

4.4 .4 Relativas de núcleo interno . . . . . . . . . . . . . . . . . . 111

4.5 Efeito $\mathrm{V} 2 \ldots \ldots \ldots \ldots 112$

4.6 Resumo do capítulo . . . . . . . . . . . . . . . . . . . . . . 113

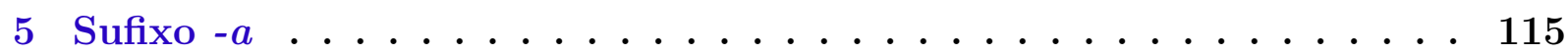

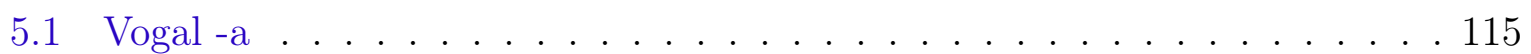

5.2 Outras análises de $-a \ldots \ldots \ldots$. . . . . . . . . . . . . . . . . . . .

$5.3-a$ em sintagmas nominais complexos . . . . . . . . . . . . 118

$5.4 \quad-a$ com verbos flexionados . . . . . . . . . . . . . . 120

5.5 -a e seus cognatos em outras línguas . . . . . . . . . . . . . . . . 121

5.5.1 Grande mudança vocálica e o enfático -o . . . . . . . . . . . . . . . 124

5.6 Resumo do capítulo . . . . . . . . . . . . . . . . . . . . . 130

II Outros fenômenos 131

6 Morfema de voz inversa ti- . . . . . . . . . . . . . 133

6.1 Propriedades . . . . . . . . . . . . . . . . . . . 134

6.1 .1 ti-só prefixa verbos transitivos . . . . . . . . . . . 135

6.1 .2 ti-V é intransitivo . . . . . . . . . . . . . . . . 136

6.1.3 ti- tem traços de $3^{\text {a }}$ pessoa . . . . . . . . . . . . . . . . 139

6.2 Outras análises possíveis . . . . . . . . . . . . . . . . . . . 139

6.2 .1 ti- marca frontalização . . . . . . . . . . . . . . . . . . . 140

6.2.2 ti- marca movimento QU- . . . . . . . . . . . . . . . 141

6.2.3 ti-como uma antipassiva espúria . . . . . . . . . . . . . 143

6.2 .4 ti-como passiva . . . . . . . . . . . . . . . . . . . 145

6.2 .5 ti- como concordância ． . . . . . . . . . . . . . . . . 147

6.2 .6 Resumo da seção . . . . . . . . . . . . . . . . . . . . . . . . . . 148

6.3 Proposta . . . . . . . . . . . . . . . . . . . . . . 149

6.3.1 Natureza pronominal de $t i^{-}$. . . . . . . . . . . . . . . . . . . . 150

6.3.2 Tema é gerado como complemento de V . . . . . . . . . . . . . 153

6.3.3 Resumo da proposta . . . . . . . . . . . . . . . . . 155 
6.4 Redobro de clítico e propriedades de ti- . . . . . . . . . . . . . . . 155

6.4.1 Perguntas QU-, construções de foco e relativas de objeto . . . . . . 155

6.4.2 Concordância excêntrica . . . . . . . . . . . . . . . . . . . . 159

6.4 .3 ti- e a passivização . . . . . . . . . . . . . . . . . . 159

6.4.4 Efeito semântico . . . . . . . . . . . . . . . . 160

6.5 Problemas com a proposta de redobro de clítico . . . . . . . . . . . . . 169

6.5.1 Redobro de clítico e weak crossover . . . . . . . . . . . . . . . 169

6.5.2 Redobro de clítico e sintagmas nominais não referencias . . . . . . . . 172

6.5.3 Resumo da seção . . . . . . . . . . . . . . . . . . . . . 176

6.6 Resumo do capítulo . . . . . . . . . . . . . . . . . 176

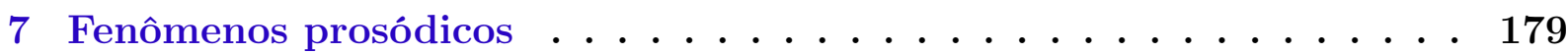

7.1 Hierarquia prosódica . . . . . . . . . . . . . . . . . . . . . . . 179

7.2 Sufixo -o em orações subordinadas . . . . . . . . . . . . . . . . . . 181

7.2.1 Vogal -o como epêntese . . . . . . . . . . . . . . . . . . . . 182

7.2 .2 Vogal -o como enfático . . . . . . . . . . . . . . . . . . . . 187

7.2 .3 Resumo da seção . . . . . . . . . . . . . . . . . . . . . . . . . . . . 189

7.3 Entonação das subordinadas com ti $\ldots$. . . . . . . . . . . . 190

7.3.1 Fonologia Intonacional Autossegmental-Métrica . . . . . . . . . . 190

7.3.2 Gramática entoacional do Karitiana . . . . . . . . . . . . . . . . . . 193

7.3.2.1 Contorno ascendente de continuação . . . . . . . . . . 195

7.3.3 Entonação em relativas de objeto . . . . . . . . . . . . . . . . 197

7.3.3.1 Prosódia e argumentos em relativas de objeto . . . . . . . 203

7.4 Resumo do capítulo . . . . . . . . . . . . . . . . . . . . 206

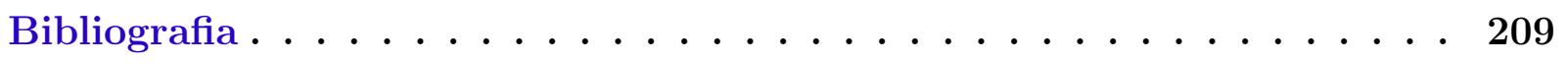





\section{Forma de apresentação dos dados}

Os dados da língua Karitiana serão apresentados aqui em sua forma ortográfica e, quando necessário, serão acompanhados por sua transcrição fonética. Optamos por representar os dados em sua forma ortográfica para que eles sejam acessíveis para os próprios falantes da língua, que muitas vezes desconhecem os símbolos da transcrição fonética. Afinal, um dos objetivos de um trabalho na área de língua indígenas não é somente a investigação de um ou vários tópicos gramaticais de uma determinada língua; deve-se considerar que um trabalho em linguística é também um importante instrumento de documentação.

A primeira ortografia do Karitiana foi elaborada por David Landin, um missionário do Summer Institute of Linguistics que também discorreu sobre diversos aspectos gramaticais da língua. Esta ortografia foi empregada no primeiro dicionário do Karitiana, publicado em 1983 e distribuído digitalmente em 2005 (D. LANDIN, 2005). A ortografia de Landin, que era principalmente de base fonêmica, foi reformulada por Luciana Storto na década de 90 a pedido dos próprios falantes (STORTO, 1996). Desde então, essa ortografia foi adotada nas escolas Karitiana e a cartilha elaborada por ela é usada pelos professores indígenas como material de apoio para alfabetização em língua materna.

Por essa ortografia ser amplamente empregada pelos falantes e professores indígenas, optamos por utilizá-la também na transcrição de nossos dados. Porém, é preciso mencionar que, atualmente, alguns professores indígenas iniciaram um movimento com o intuito de modificar a grafia de algumas palavras específicas. Por exemplo, Karitiana exibe uma alto grau de alomorfia com fonemas nasais e um mesmo falante pode empregar diversas pronúncias de uma mesma palavra, como se vê na tabela abaixo para as palavras 'casa' e 'coisa':

Tabela 1 - Variação na pronúncia de fonemas nasais (STORTO, 1999)

\begin{tabular}{|c|c|c|c|}
\hline & L. Karitiana & C. Karitiana & ORTOGRAFIA \\
\hline 'casa' & {$\left[a ̃ m^{b} \mathrm{i}\right]$ e [abi] } & {$\left[a m^{b} \mathrm{i}\right]$ e $\left[\mathrm{a}^{\mathrm{b}} \mathrm{m}^{\mathrm{b}} \mathrm{i}\right]$} & $a m b i$ \\
\hline 'coisa' & [kîn $\left.{ }^{\mathrm{d}} \mathrm{a}\right]$ e [kida] & [kida] e [ki $\left.{ }^{\mathrm{d}} \mathrm{n}^{\mathrm{d}} \mathrm{a}\right]$ & kinda \\
\hline
\end{tabular}

Na ortografia proposta por Storto, optou-se por grafar essas palavras como 'ambi' e 'kinda', respectivamente. Essas representações ortográficas de fato se aproximam de pronúncias empregadas pelos próprios falantes. Alguns professores, contudo, desejam que a representação ortográfica reflita a pronúncia da variante mais prestigiada, a saber, 'abi' e 'kida'. Além disso, os professores indígenas também optam por empregar as letras $d j$ em vez de $j$ para o som [d3] em início de palavra - assim, 'djekỹy'ep' é usado no lugar de 'jeký'ep' proposto em Storto (1996). Contudo, como essa nova reforma ortográfica ainda 
não foi oficializada em nenhuma publicação, optamos por empregar as formas de acordo com a norma ortográfica vigente.

Todos os dados e glosas serão sempre apresentados da seguinte forma:

(1) Descrição do dado

[língua]

Dado (segmentação morfêmica)

glosa

"tradução"

(referência)

Quando se tratar de um dado de Karitiana, Português ou Inglês, o item [língua] será omitido. Além disso, também omitiremos o item (referência) sempre o dado for original e não retirado do trabalho de terceiros. Em exemplos que contêm os sub-itens (a), (b), (c), etc., a referência aparecerá apenas ao final do último item.

As glosas empregadas aqui seguem em geral as diretrizes do Departamento de Linguística do Instituto Max Planck (2015). A única diferença com relação a essa normatização é em relação à epêntese, que aparecerá na glosa como um morfema à parte. A principal razão para tanto é que, em alguns momentos, o status de uma vogal epentética ainda estará sob investigação, como no capítulo 7. Quanto ao fraseamento de constituintes, empregamos os símbolos '[l' para designar agrupamentos sintáticos, enquanto os parênteses '()' são reservados para agrupamentos prosódicos.

Nos dados de Karitiana coletados por terceiros, incluímos a informação 'adaptado' no item (referência) sempre que o exemplo original fora modificado de alguma forma. Tais modificações podem se dar por diferenças na forma de transcrição do dado (i.e., se ortografia ou transcrição fonética) ou por uma segmentação morfêmica diferente daquela que assumimos. Por fim, os exemplos de terceiros em outras línguas incluem sempre as glosas originais fornecidas pelos autores. Caso as abreviaturas sejam em Inglês, as traduzimos minimamente apenas para que elas fossem suficientemente explícitas em Português.

Para indicar o nível de aceitação das sentenças coletadas, utilizamos o sistema de símbolos empregados na linguística formal, a saber: o asterisco $(*)$ para sentenças rejeitadas por um número expressivo de colaboradores e a cerquilha (\#) para indicar a impossibilidade semântica de uma sentença em um determinado contexto. Além disso, empregaremos também a interrogação (?) para casos em que o julgamento de gramaticalidade não é óbvio, principalmente para aqueles em que uma determinada sentença é aceita por um número razoável de falantes e rejeitada por muitos outros. 


\section{Parte I}

\section{Perguntas e orações subordinadas}





\section{Introdução}

Segundo Aryon Rodrigues (1966), uma das principais tarefas da linguística brasileira é o estudo das línguas indígenas faladas em território nacional. ${ }^{1}$ Assim, nosso trabalho se ocupa em descrever e analisar aspectos de uma língua indígena, o Karitiana. Como veremos à frente, essa língua é a única remanescente da família Arikém, uma das dez famílias que compõem o tronco Tupi.

Essa tese se debruça sobre diversos aspectos dessa língua em ambientes sintaticamente complexos - incluindo alguns que não haviam sido descritos antes na literatura sobre ela. Nossa investigação descreve fenômenos envolvendo orações subordinadas, como a formação de perguntas indiretas e perguntas QU- de longa distância. Discutiremos esses dados à luz de nossa proposta de que as orações subordinadas do Karitiana seriam nominalizadas em um certo grau. Essa proposta abre uma possibilidade de análise para outros elementos da língua que não tinham sido suficientemente investigados antes, como o sufixo - a. Além disso, discutimos também fenômenos de variação de ordem em ambientes complexos - como aqueles desencadeados pelo morfema de voz inversa $t i$ - - e apresentamos ainda alguns fenômenos prosódicos que podem constituir evidências adicionais para as análises desenvolvidas em nosso trabalho.

Para as análises morfossintáticas, nosso investigação pressupõe os desenvolvimentos mais atuais da teoria gerativa, tal como proposta por Noam Chomsky em uma série de trabalhos $(1977 ; 1986 ; 1986 ; 2001)$. Além disso, assumimos também as conexões entre a estrutura sintática e o aparato da semântica formal, tal como formalizado em Heim e Kratzer (1998). No entanto, apesar de se tratar de um trabalho com embasamento teórico da linguística formal, nosso intuito aqui não é restringi-lo apenas para os pesquisadores destas áreas, mas sim torná-lo acessível para qualquer leitor interessado nos tópicos aqui descritos. Assim, incluímos sempre que possível uma explanação detalhada dos pontos teóricos de que nos valemos na discussão.

Assim como muitas teses na área de línguas indígenas, este trabalho não possui uma ideia central que norteará toda discussão. Nosso objetivo aqui é descrever diversas construções e oferecer uma análise que explique seu comportamento e distribuição. No entanto, como o leitor poderá verificar ao final de sua leitura, a maioria dos tópicos explorados aqui se complementa e se sobrepõe, ao ponto que, em última estância, o grande fio coesivo deste trabalho se encontra na própria essência da língua, que manifesta sua natureza de diversas formas.

1 O número exato de línguas faladas no Brasil ainda é incerto, pois, conforme o conhecimento dessas línguas se adensa, as fronteiras entre línguas e dialetos tendem a ficar mais claras. Rodrigues (2005) cita 181 línguas, enquanto Moore (2007) afirma que seriam 154 ou menos. Crucialmente, Moore afirma que cerca de $23 \%$ destas línguas estão ameaçadas de extinção em curto prazo. 
Os capítulos desta tese dividem-se em duas partes. A primeira parte se dedicará ao estudo da estrutura das orações subordinadas, com especial ênfase na formação de perguntas em ambientes complexos. No capítulo 2, descrevemos as perguntas indiretas no Karitiana, isto é, construções nas quais uma pergunta é o complemento de um verbo dicendi como e.g., 'O João quer saber quando a Maria vai chegar'. Argumentamos que, em Karitiana, perguntas indiretas tal como no Português ou Inglês não parecem existir, pois a língua em geral não permite elementos QU- com força quantificacional em ambientes encaixados. No capítulo 3, descrevemos a formação de perguntas complexas nas quais o pronome interrogativo é um constituinte da oração subordinada (e.g., 'Quem você acha que foi à festa?') e veremos que, em Karitiana, toda a oração subordinada parece ser frontalizada nestas construções. Esses dois aspectos da língua e diversos outros serão retomados no capítulo 4, no qual argumentamos que essas propriedades podem ser acomodadas em uma estrutura para as subordinadas que contenha (1) menos núcleos funcionais tipicamente oracionais e (2) um núcleo nominalizador $n$. Além disso, argumentamos no capítulo 5 que existe na língua um possível candidato à realização fonológica do núcleo $n$ : o sufixo $-a$.

Na parte II, discutimos alguns outros fenômenos relacionados a orações subordinadas, mas que têm como principal característica a modificação da ordem de constituintes e o estatuto dos sintagmas nominais. Especificamente, discutimos o morfema de voz inversa $t i$-, que afeta o objeto em diversos ambientes, no capítulo 6. Nele, apresentamos nossa análise das orações com ti- como configurações de redobro de clítico e discutimos como essa proposta é capaz de explicar diversas propriedades destas construções. Por fim, apresentamos também alguns fenômenos prosódicos relacionados à ordem de palavras em ambientes subordinadas no capítulo 7, no qual veremos como dados de epêntese e intonação podem constituir argumentos adicionais para as estruturas que propomos nos capítulos 4 e 6.

\subsection{Questões metodológicas}

Nossa pesquisa se valerá de dados de diversas fontes. Primeiramente, utilizamos dados coletados por outros autores que se ocuparam em descrever e analisar aspectos da língua Karitiana antes de nós. Como mencionamos anteriormente, os dados de terceiros contêm sempre uma referência explícita aos pesquisadores que os coletaram e, a menos que indicado, também incluem as glosas originais fornecidas por eles.

Além disso, nos valemos também de textos naturalísticos orais como as narrativas tradicionais contadas por falantes nativos, que foram coletadas e transcritas pela linguista Luciana Storto na década de 90. Eles são: "Botyj̃ Pynhadna" ("História de Deus"), "Gokyp" ("Sol"), "O encontro entre os Capivari e os Karitiana", "Ritos funerários"e "Osiipo". Também tivemos acesso às gravações em K7 dessas narrativas, que foram digitalizadas por 
nós. Dessa forma, utilizamos sempre que possível a pronúncia original para análise, além do texto transcrito e traduzido.

Acreditamos que o emprego de textos naturalísticos enriquece a análise de dados, pois, nestas casos, o risco de incorrermos na artificialidade de uma construção é potencialmente menor do que em uma elicitação. Contudo, o uso exclusivo deste tipo de fonte é insuficiente para examinarmos todos os aspectos de uma língua (veja Matthewson (2004)). Especificamente, a própria natureza de certos tipos de construções dificulta o uso de dados provenientes de produções espontâneas. Como exposto na seção anterior, um de nossos objetos de investigação são orações subordinadas. Por uma questão de memória de trabalho, textos falados costumam conter menos orações dependentes do que textos escritos (O'DONNELL, 1974). Isso possivelmente ocorre devido à possibilidade de um tempo maior de planejamento no momento da escrita. Ademais, outras línguas podem, por diversos fatores, exibir um número ainda menor destas construções em produções espontâneas: Mithun (1984) afirma que, em línguas não indo-europeias como o Mohawk, o Gungwinggu e Kahlamet, a porcentagem de orações dependentes em textos orais não chega nem a $10 \%$.

Essa observação se reflete em nossos dados. Como mencionamos anteriormente, os textos naturalísticos disponíveis são transcrições de narrativas orais produzidas por falantes nativos. Eles possuem, portanto, características de textos orais. Isso significa que a tendência é encontrarmos muito mais sentenças curtas do que longas, o que, por sua vez, implica em uma frequência muito maior de sentenças simples do que sentenças contendo uma ou mais subordinadas. Na tabela abaixo, reproduzimos a quantidade de orações subordinadas levantada para cada um dos textos disponíveis. O leitor pode verificar que de fato há um número relativamente pequeno de sentenças subordinadas em comparação a orações matrizes: ${ }^{2}$

Tabela 2 - Número de orações subordinadas em textos naturalísticos

\begin{tabular}{lcc}
\hline \multirow{2}{*}{ TEXTO } & \multicolumn{2}{c}{ NÚMERO DE SENTENÇAS } \\
\cline { 2 - 3 } & TOTAL & COM SUBORDinADAS \\
\hline Botyj Pynhadna & 324 & 20 \\
Gokyp & 52 & 5 \\
Encontro dos Capivari e dos Karitiana & 390 & 23 \\
Ritos fúnebres & 351 & 35 \\
Osiipo & 288 & 37 \\
\hline
\end{tabular}

Além disso, outras construções possuem situações de uso tão específicas que é

2 Como observa Mithun (1984), não é uma tarefa simples isolar sentenças em textos naturalísticos. Portanto, nosso principal critério foi considerar as entradas do texto transcrito original, que em geral compreendem "idea units"comparáveis a um enunciado. Como a língua não possui conjunções subordinadoras (STORTO, 1999), nos valemos de outras pistas para detectar as subordinadas em produções naturalísticas, como a posição do verbo, presença de morfologia verbal e aspectos prosódicos. 
praticamente impossível encontrá-las em um discurso espontâneo. É o caso das chamadas perguntas indiretas e perguntas de longa distância, que examinaremos nos próximos capítulos. Se orações subordinadas não são tão frequentes em textos orais, perguntas contendo orações subordinadas são ainda mais infrequentes. Mesmo em línguas com corpora bem mais estabelecidos essas construções são extremamente raras: Yang (2012) reporta uma frequência de 0,2\% de perguntas QU- de longa distância no input de uma criança adquirindo inglês. No caso de línguas menos documentadas, essa situação complica-se ainda mais. Legate (2011), por exemplo, menciona que perguntas QU- de longa distância só puderam ser coletadas através de elicitação em Warlpiri. Nos corpora disponíveis sobre essa língua, os falantes preferiram em geral empregar uma sentença envolvendo coordenação.

A varredura dos nossos textos nos mostrou apenas três exemplares de perguntas indiretas. Em relação a perguntas QU- de longa distância, não encontramos nenhum caso. Isso não significa que construções desse tipo sejam impossíveis na língua, pois, como veremos no capítulo 3, os falantes produzem e compreendem estruturas equivalentes com bastante facilidade. A questão é que, sendo o texto naturalístico um fragmento da língua, ele não contém todas as suas estruturas possíveis. Dessa forma, é provável que a situação comunicativa que propicia o uso de construções como perguntas com orações subordinadas simplesmente não emergiu. Na realidade, mesmo perguntas simples são difíceis de encontrar no material disponível. Os textos disponíveis até então são narrativas contadas por anciãos da comunidade Karitiana. Eles constituem, portanto, monólogos, nos quais outras pessoas não interagem com o falante ou o fazem minimamente. ${ }^{3}$ Por conta disso, é difícil encontrar perguntas direcionadas ao interlocutor - mesmo perguntas simples, sem encaixamento. Na realidade, encontramos mais frequentemente nesses textos perguntas como 2 abaixo, que constituem exemplos de discurso direto.

(2) Discurso direto

A-pytim'adn-a iri-'a-j i-sooj.

2s-trabalhar-IMP CIT-fazer-IRR 3-esposa

"Vai trabalhar, disse a esposa dele."

["Botyj̃ Pynhadna"]

Além disso, existe outra limitação do uso exclusivo de textos naturalísticos. Por serem um fragmento de discurso real, eles não contêm as "impossibilidades"da língua os chamados dados negativos (MATTHEWSON, 2004). No capítulo 6, veremos que a interação entre o morfema ti-, que aparece em orações relativas de objeto, e a negação - ki revela propriedades bastante importantes sobre a interpretação de sintagmas nominais nestes ambientes. Nesse ponto, veremos que será crucial examinar quais interpretações essa sentença não pode ter. Aqui, existem duas dificuldades: primeiro, a coocorrência desses dois morfemas é bastante rara e casos suficientemente claros só puderam ser coletados

3 A única exceção é o início do texto "Ritos funerários", no qual o neto da narradora, presente no momento da narrativa, dirige a ela algumas perguntas curtas incitando-a a falar sobre os costumes funerários tradicionais. 
através de dados manipulados. Isso ressoa no problema já exposto acima, da não ocorrência de certas construções nos corpora por serem restritas a situações comunicativas muito específicas. Porém, ainda que encontremos uma construção deste tipo, jamais teríamos a informação do que ela não pode significar. Na realidade, para termos certeza, teríamos que perguntar explicitamente a um falante, o que já constitui uma forma de elicitação.

Assim, nos valemos também de dados coletados através de elicitação direta, ou seja, dados controlados pelo pesquisador para um determinado objetivo e imersos em um contexto igualmente controlado (THORNTON, 1996). Esses dados foram checados com diversos falantes nativos para garantir que representasse de fato a língua tal como utilizada coletivamente. Esse método foi sempre utilizado em um segundo momento, quando o exame dos dados naturalísticos não se mostrara frutífero para encontrarmos as construções em estudo.

Acreditamos que a diversificação das fontes de dados enriquece a discussão aqui exposta. Seguindo Crowley (1993), pensamos que um dos objetivos do trabalho com línguas pouco conhecidas é criar um corpora que possa ser acessado e usado por diversas gerações de linguistas, muitas vezes trabalhando sob perspectivas teóricas distintas: "As abordagens mais legíveis - e certamente mais valiosas - parecem ser aquelas que são relativamente abertas ao ecleticismo teórico". Assim, embora muitas construções discutidas aqui tenham sido escolhidas por serem pontos de interesse de uma linguística de linha mais formal, o esforço por incluir diversos tipos de dados reflete nosso desejo de que os fragmentos de língua coletados sejam úteis para pesquisadores com interesses diversos.

\subsection{Localização e classificação}

A língua Karitiana é falada por uma etnia de mesmo nome, os Karitiana. Quase todos os falantes se concentram no estado de Rondônia e a maioria habita o parque indígena TI Karitiana, criada pelo decreto $\mathrm{n}^{\mathrm{O}} 93.068$ de 1986 e que se estende por 90 mil hectares (BRASIL, s.d.; ISA, s.d.). ${ }^{4}$

No censo mais recente realizado por Storto e Rocha (2018), foi contabilizado um total de 396 pessoas pertencentes à etnia. Nem todas, contudo, têm o Karitiana como primeira língua: os autores relatam que toda a população que vive na aldeia fala o Karitiana como primeira língua; em contrapartida, dentre os Karitiana que vivem na região urbana de Porto Velho, apenas 29 de uma população total de 96 pessoas o tem como primeira língua. Em outras palavras, a proximidade e a mobilidade de falantes para a região urbana parece ser um fator de risco importante para a perda linguística, o que torna os esforços de descrição e revitalização ainda mais urgentes.

4 Dentro da TI Karitiana, a população divide-se em cinco aldeias: Aldeia central, Candeias, Joari, Igarapé Preto e Caracol. Delas, Candeias e Joari estão fora do perímetro da reserva, em áreas tradicionalmente ocupadas pelo grupo. 
O Karitiana foi classificado como uma língua Tupi pertencente à família Arikém (RODRIGUES, 1986). Esta família seria composta por duas línguas, o Karitiana e o Arikém. Desta última, restaram apenas descrições de palavras e frases isoladas, dentre elas a lista coletada por Nimuendajú (1932). Desde Rodrigues (1986), se postula que a família Arikém sofreu um processo de mudança vocálica que alterou as vogais de muitos cognatos. Assim, existe uma correspondência sistemática entre alguns sons do Karitiana e de outras línguas, como entre [o] e [y], ou [a] e [e]:

Tabela 3 - Cognatos em línguas Tupi (RODRIGUES, 1986)

\begin{tabular}{l|cccccc} 
& Tupinambá & Aweti & Munduruku & Tupari & Gavião & Karitiana \\
\hline mão & po & po & by & po & pabe & py \\
pé & py & py & i & tsito & pi & pi \\
caminho & pe, ape & me & e & ape & be & pa \\
eu & ixe & atit, ito & on & on & õot & yn \\
você & ene & en & en & en & ẽet & an \\
mãe & sy & ty & xi & tsi & ti & ti \\
pesado & posyi & potyi & poxi & potsi & patii & pyti \\
marido & men & men & itop & men & met & man \\
onça & iawar & ta'wat & wida & ameko & neko & ombaky, obaky \\
árvore & 'yb & 'yp & 'ip & kyp & 'iip & 'ep \\
cair & 'ar & 'at & 'at & kat & 'al- & 'ot \\
\hline
\end{tabular}

Storto e Baldi (1994) sistematizam essas mudanças ao postular uma grande mudança vocálica em cadeia responsável pelas seguintes correspondências entre outras línguas Tupi e a família Arikém (veja também Dietrich (2009)):

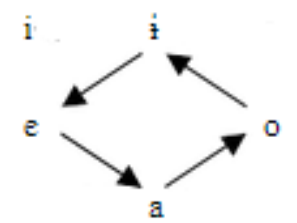

Figura 1 - Grande mudança vocálica (STORTO; BALDI, 1994)

As primeiras descrições da língua Karitiana foram feitas por David e Rachel Landin, um casal de missionários do Summer Institute of Linguistics (R. LANDIN, 1982; D. LANDIN, 1984). David Landin também foi responsável pela criação do primeiro dicionário na língua (D. LANDIN, 2005). Além disso, o Karitiana também tem sido estudada desde a década de 90 por Luciana Storto, que se debruçou sobre diversos aspectos morfossintáticos da língua em uma série de publicações (HALE; STORTO, 1997; STORTO, 1999, et seq.). Ela também foi responsável pela captação, transcrição e tradução dos cinco textos orais que serão usados no decorrer do trabalho como exemplos de produções naturalísticas. Além disso, ela orientou e colaborou com diversos pesquisadores que têm se dedicado à 
descrição e análise de vários aspectos do Karitiana, como Müller (2011), Sanchez-Mendes (2009; 2014), Coutinho-Silva (2008), Carvalho (2010), Rocha (2011; 2014; 2016), Vivanco (2014; 2017), Ferreira (2017) e Alexandre (2016). Paralelamente, o linguista Caleb Everett também se dedicou à análise de diversos aspectos do Karitiana em algumas publicações (EVERETT, 2006; 2008). Além disso, diversos membros da comunidade têm se formado no curso de Educação Intercultural da Universidade Federal de Rondônia e publicado seus trabalhos de conclusão de curso na área de educação, como João Karitiana (J. B. K. KARITIANA, 2015), Luiz Karitiana (L. C. KARITIANA, 2015), Inácio Karitiana (I. KARITIANA, 2015) e Edelaine Karitiana (E. M. O. E. KARITIANA, 2017).

\subsection{Aspectos gramaticais relevantes}

\subsubsection{Morfologia verbal}

Landin (1982) e Landin (1984) foram os primeiros a identificar alguns afixos verbais; a descrição mais abrangente, contudo, foi feito por Storto (2002). Um dos primeiros aspectos da língua a se mencionar é que o Karitiana faz uma distinção entre orações chamadas de declarativas e não declarativas. Basicamente, as últimas constituiriam enunciados imperativos, negações, perguntas e orações subordinadas, ou seja, todos os contextos em que o verbo não recebe morfemas de modo.

Em orações matrizes, o verbo em Karitiana pode receber afixos de concordância, modo, e tempo. Os morfemas de concordância exibem uma alomorfia na terceira pessoa condicionada pelo status da oração como (não) declarativo:

Tabela 4 - Prefixos de pessoa

\begin{tabular}{l|cc}
\hline \multicolumn{1}{c|}{ FLEXÃO } & DECLARATIVA & NÃO DECLARATIVA \\
\hline $1^{\mathrm{a}}$ pessoa singular & $\mathrm{y}-$ & $\mathrm{y}-$ \\
$2^{\mathrm{a}}$ pessoa singular & $\mathrm{a}-$ & $\mathrm{a}-$ \\
$1^{\mathrm{a}}$ pessoa plural inclusiva & yj- & yj- \\
$1^{\mathrm{a}}$ pessoa plural exclusiva & yta- & yta- \\
$2^{\mathrm{a}}$ pessoa plural & aj- & aj- \\
$3^{\mathrm{a}}$ pessoa & $\emptyset-$ & $\mathrm{i}-$ \\
\hline
\end{tabular}

Para nossa discussão, três prefixos de modo serão relevantes: o declarativo $n a(k a)$ $/ t a(k a)$-, o assertivo py(ry)- e o condicional $\tilde{j} y$ - (ou contra-factual - veja Ferreira (2017)). ${ }^{5}$

5 A alomorfia dos morfemas de modo declarativo é condicionada pela concordância de pessoa (STORTO, 2002). Com prefixos de $1^{\mathrm{a}}$ e $2^{\mathrm{a}}$ pessoa, o alomorfe é $t a(k a)$ - e, com o morfema zero de $3^{\mathrm{a}}$ pessoa, é na(ka)-. Essa distribuição também é capturada por Everett (2006) através dos rótulos de '(não) participante do ato de fala' (speech act participant). A presença da segunda sílaba nos alomorfes de declarativo e assertivo é condicionada por fatores prosódicos da raiz. 
Segundo Storto (2002), o Karitiana faz uma distinção entre o futuro e o não futuro. As informações temporais são expressas por alomorfes condicionados ao modo empregado na oração:

Tabela 5 - Sufixos de tempo

\begin{tabular}{|c|c|c|c|c|}
\hline \multirow{3}{*}{ MODO } & \multicolumn{4}{|c|}{ TEMPO } \\
\hline & \multicolumn{2}{|l|}{ FUTURO } & \multicolumn{2}{|c|}{ NÃO FUTURO } \\
\hline & {$\left[\begin{array}{ll}\mathrm{V} & . \mathrm{cvc}\end{array}\right]$} & {$\left[\begin{array}{ll}\mathrm{V} & . \mathrm{cv}\end{array}\right]$} & {$\left[\begin{array}{ll}\mathrm{V} & . \mathrm{cvc}\end{array}\right]$} & {$\left[\begin{array}{ll}\mathrm{V} & . \mathrm{cv}\end{array}\right]$} \\
\hline Declarativo & $-\mathrm{i}$ & $-j$ & $\emptyset$ & $-\mathrm{t}$ \\
\hline Assertivo & $-\mathrm{i}$ & $-j$ & $-n$ & $-n$ \\
\hline
\end{tabular}

Além disso, a língua possui dois evidenciais ( $t a^{\prime} a \tilde{e}$ e saryt) e uma série de morfemas aspectuais que, embora formem um núcleo complexo com o verbo, possuem acento próprio (STORTO, 1999; 2002).

\subsubsection{Caso}

Landin (1984) foi o primeiro a detectar um alinhamento ergativo no Karitiana. Para ele, o que analisamos aqui como prefixos de pessoa eram considerados pronomes. Foi Storto (1999) quem reinterpretou esses pronomes como sufixos de concordância, uma análise que adotamos aqui. Por fim, Landin também foi o primeiro a detectar um alinhamento ergativo-absolutivo na língua.

Basicamente, a concordância verbal se estabelece com o argumento absolutivo (i.e., o sujeito intransitivo e o objeto direto):

(3) Concordância com verbo transitivo

Yn a-ta-oky-j an

1s 2s-DECL-matar-FUT

"Eu vou te matar."

(STORTO, 1999)

(4) Concordância com verbo intransitivo

A-ta-opiso-t an

2s-DECL-Ouvir-NFUT

"Você ouviu."

(STORTO, 1999)

Karitiana é uma língua essencialmente head-marking, pois a maioria dos sintagmas nominais não possuem marcas de caso e as funções sintáticas são explicitadas através de afixos verbais. Assim, os casos absolutivo, ergativo e genitivo são nulos: 
(5) Caso ergativo e absolutivo

Taso $\emptyset$-na-oky-t $\quad$ ombaky.

homem.ERG 3-DECL-matar-NFUT onça.ABS

"O homem matou a onça."

(6) Caso genitivo

Ana $\emptyset$-na-aka-t i-amy-t Luciana ambi-ty

Ana 3-DECL-COP-NFUT NMZ-comprar-CON.COP Luciana.GEN casa-OBL

"A Ana comprou a casa da Luciana."

Os casos oblíquos podem ser expressos através dos sufixos -ty (oblíquo), -tyyt (comitativo) e -kyn (lativo):

(7) Sufixo oblíquo -ty

Taso $\emptyset$-na-oigng-a-t õwã boet-e-ty.

homem 3-DECL-presentar-V-TEM-NFUT criança colar-EPEN-OBL

"O homem presenteou a criança com o colar."

(ROCHA, 2011)

(8) Sufixo comitativo -tyyt

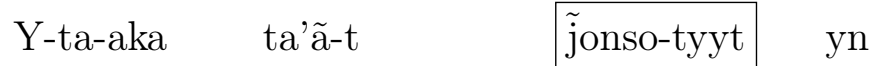

1s-DECL-COP EVID.DIR-NFUT mulher-COMIT 1s

"Eu fiquei com a esposa."

["Osiipo"]

(9) Sufixo lativo -kyn

$\emptyset$-naka-tat saryt- $\emptyset \quad$ Poren-a sooj gok-o-kyn

3-DECL-ir EVID.IND-NFUT Poren-N? esposa mandioca-EPEN-LAT

"A esposa de Poren foi para (o campo d)a mandioca." ～(R. LANDIN, 1982, adaptado)

\subsubsection{Estrutura argumental}

Em Karitiana, diversos diagnósticos podem ser utilizados para se detectar a valência verbal. O primeiro deles é a causativização através do morfema - $m$-. Segundo Rocha (2011) e Storto e Rocha (2015), este morfema só pode se afixar a verbos intransitivos: assim, ele é possível com o intransitivo 'ke'on' em 11 mas não com o transitivo ' $y$ ' em 13: 
(10) Verbo intransitivo 'ke'on'

$\emptyset$-py-ke'on-y-n ti'y

3-ASS-esfriar-EPEN-NFUT comida

"A comida esfriou."

(ROCHA, 2011)

(11) Verbo intransitivo 'ke'on' causativizado com m-

$\emptyset$-py-m-ke'on-y-n ti'y jonso

3-ASS-CAUS-esfriar-EPEN-NFUT comida

"A mulher fez a comida esfriar."

(ROCHA, 2011)

(12) Verbo transitivo ' $y$ '

$\emptyset$-pyry-'y-dn ti'y taso

3-ASS-comer-NFUT comida homem

"O homem comeu a comida."

(ROCHA, 2011)

(13) Verbo transitivo ' $y$ ' causativizado com m-

* $\emptyset$-pyry-m-'y-dn ti'y taso

3-ASS-CAUS-comer-NFUT comida homem

(ROCHA, 2011)

Segundo Rocha (2011), a passivização é outro teste de transitividade, pois o morfema de passiva $a$ - só se afixa a raízes transitivas. Desta forma, a ocorrência do morfema a- com um verbo intransitivo como 'pipop' é impossível, enquanto um verbo transitivo como ' $y$ ' pode ser passivizado:

(14) Verbo transitivo ' $y$ ' passivizado com a-

$\emptyset$-pyr-a-'y-dn ti'y

3-ASS-PASS-comer-NFUT comida

"Comeram a comida."

(ROCHA, 2011)

(15) Verbo intransitivo 'pipop' passivizado com a-

* $\emptyset$-pyr-a-pipop-y-n song

3-ASS-PASS-queimar-EPEN-NFUT lenha

"(Pretendido) Queimaram a lenha."

(ROCHA, 2011)

Por fim, outro diagnóstico de valência em Karitiana é a construção de cópula. Segundo Storto (2008; 2010), a cópula é uma construção na qual o argumento de um determinado verbo é alçado para a posição pré-verbal:

(16) Construção de cópula

$\mathrm{NP}\left(\emptyset\right.$-na-aka-t) $\quad \mathrm{i}-\mathrm{V}_{\text {INT }}$-t $/ \emptyset$

NP 3-DECL-COP-NFUT NMZ-V $\mathrm{INT}_{\text {-CON.COP. }}$

(STORTO, 2010) 
O verbo que entra na cópula tem duas restrições importantes. Primeiro, ele precisa estar nominalizado. Que só elementos nominais são aceitos na cópula pode ser visto nos exemplos abaixo. Primeiramente, essa construção também permite nomes; nestes casos, contudo, o nominalizador $i$ - está ausente:

(17) Construção de cópula com um nome

Kinda'o Ø-na-aka-t asyryty-t

fruta 3-DECL-COP-NFUT banana-CON.COP

"Banana é uma fruta."

(STORTO, 2010)

Além disso, é possível que outro nominalizador seja empregado no lugar de $i$ Especificamente, o nominalizador - $p a$, que cria nomes locativos ou instrumentais a partir de verbos e sintagmas verbais, pode ser empregado na construção de cópula:

(18) Construção de cópula com -pa

Tepa Ø-na-aka-t byrytik soko'î-pa-t

cipó 3-DECL-COP-NFUT tocha amarrar-NMZ-CON.COP

"Cipós são para amarrar tochas."

(STORTO, 2010)

A segunda restrição da cópula é a de só permitir verbos intransitivos:

(19) Construção de cópula com verbo intransitivo

Taso $\emptyset$-na-aka-t i-kat- $\emptyset$

homem 3-DECL-COP-NFUT NMZ-dormir-CON.COP

"O homem dormiu."

(STORTO, 2010)

(20) Construção de cópula com verbo transitivo

*Taso Ø-na-aka-t i-'y-t (ta-ti'y)

homem 3-DECL-COP-NFUT NMZ-comer-CON.COP 3ANAPH

"(Pretendido) O homem comeu (sua comida)."

(STORTO, 2008)

A cópula está ainda envolvida em uma outra construção chamada por Storto (2008; 2010) de clivagem. Em sentenças clivadas, o tema é alçado pra posição pré-verbal e o verbo é necessariamente prefixado pelo morfema $t i$-:

(21) Clivada

João $\emptyset$-na-aka-t yn ti-hit- $\varnothing \quad$ taj-ty

João 3-DECL-COP-NFUT 1s INV-dar-CON.COP faca-OBL

"É para o João que eu dei a faca." ～(STORTO, 2008, adaptado)

Quanto à presença do nominalizador $i$ - nestas construções, a posição de Storto $(2008 ; 2010)$ é de que a vogal de $t i$ - e $i$ - se fundem ao ponto de ser impossível distingui-las.

Esses diagnósticos nos levam a importantes conclusões. Uma delas é que verbos com argumentos oblíquos se comportam como intransitivos, pois eles (1) concordam com o sujeito, (2) permitem o causativizador $m$-, (3) proíbem a passiva $a$ - e (4) são gramaticais na construção de cópula: 
(22) Concordância com verbo intransitivo oblíquo

Y-pyry-kaj-a-n yn jonso hãraj-ty.

1-ASS-Sonhar-EPEN-NFUT 1s mulher bonita-OBL

"Eu sonhei com uma mulher bonita."

(ROCHA, 2011)

(23) Verbo intransitivo oblíquo com causativizador

Taso y-ta-m-so'oot- $\emptyset$ pikom-ty

homem 1s-DECL-CAUS-ver-NFUT macaco-OBL

"O homem me fez ver o macaco."

(ROCHA, 2011)

(24) Verbo intransitivo oblíquo passivizado com a-

* $\emptyset$-pyr-a-sondyp-y-n taso

3-ASS-PASS-saber-EPEN-NFUT homem

(ROCHA, 2011)

(25) Construção de cópula com verbo intransitivo oblíquo

Taso $\emptyset$-na-aka-t i-sondyp- $\emptyset \quad$ pikom-ty

homem 3-DECL-COP-NFUT NMZ-saber-CON.COP macaco-OBL

"O homem sabe do macaco."

(ROCHA, 2011)

Por fim, Storto e Rocha (2015) afirmam que não existe em Karitiana evidências para se postular as classes de verbos inacusativos e inergativos, pois todos os intransitivos permitem a causativização.

(26) Verbo 'som' causativizado

Taso $\emptyset$-naka-m-som- $\emptyset$ pykyp.

homem 3-DECL-CAUS-avermelhar-NFUT roupa

"O homem avermelhou a roupa."

(ROCHA, 2011)

(27) Verbo 'tarak' causativizado

Y-pyry-m-tarak-a-n taso.

1s-ASS-CAUS-andar-EPEN-NFUT homem

"O homem me fez andar."

(ROCHA, 2011)

Tradicionalmente, verbos inergativos resistem a esse tipo de operação (veja Hale e Keyser (2002)).

\subsubsection{Ordem de palavras}

Desde Landin (1982), observou-se que Karitiana possui uma ordem de constituintes relativamente flexível. Assim, diversos trabalhos se ocuparam em investigar os fatores que condicionariam o emprego de cada uma dessas ordens. Primeiramente, em sentenças transitivas matrizes, a ordem mais frequentemente encontrada é SVO. Ao examinar o texto "Osiipo" e diálogos, Storto (2014) verificou que essa é a ordem mais comum em 
sentenças não marcadas. Por conta disso, Landin (1982) considerara que SVO é a ordem básica da língua (veja também Everett (2006)). Já Storto (1999, et seq.) assumiu que a ordem SVO é um produto de movimento do verbo para a segunda posição da oração, o núcleo C. Especificamente, ela propõe que Karitiana seria uma língua V2 como o Alemão, dada a posição do verbo em orações finitas e a tendência de se preencher a posição pré-verbal:

\section{(28) V2}

Sete de semtembro-tyym a-taka-tar-i hotel-pip

sete de setembro-através 2s-DECL-ir-FUT hotel-em

"Você vai para o hotel até a (avenida) Sete de Setembro." $\quad$ (STORTO, 1999)

(29) V2

Ohy a-taka-'y-t taso

batata INV.DECL-DECL-comer-NFUT homem

"O homem comeu batatas."

(STORTO, 1999)

Objetos na posição inicial disparam os alomorfes de voz inversa $a$ - (declarativo) ou ti- (não declarativo). Estes morfemas serão alvo de uma investigação mais profunda no capítulo 6 - principalmente o último, que também aparece em ambientes subordinados.

Storto (1999) também mostrou que a posição pré-verbal abriga elementos focalizados. Primeiramente, entendemos que um constituinte é focalizado na medida em que ele constitui uma resposta a uma pergunta QU- em potencial (ROOTH, 1996; SELKIRK, 1995). Discursivamente, o foco pode também ser definido como a parte informativa da sentença, isto é, a parte que transforma o enunciado em uma asserção (LAMBRECHT, 1996). No par abaixo, por exemplo, o objeto focalizado 'ohy' tem que ser o primeiro constituinte da sentença:

(30) Foco na posição pré-verbal

a. Mora-mon taso ti-'y-t?

QU-COP.INT homem INV-comer-CON.COP

"O que o homem comeu?"

(STORTO, 1999)

b. Ohy a-taka-'y-t taso

batata INV.DECL-DECLComer-NFUT homem

"O homem comeu batatas."

(STORTO, 1999)

A posição pré-verbal também pode ser explorada para foco contrastivo. No exemplo 31b, o argumento 'gop sowõra' é contrastado com outros tipos de vespeiro e, por isso, ocupa a primeira posição da sentença:

(31) Foco contrastivo na posição pré-verbal

a. I-a-'obm-oko gop miem

3-PASS-furar-ITER vespa miem

"O vespeiro miem não é perfurado novamente" 
b. Gop sowõra (Ø-na-aka-t) i-a-'obm oko-t vespa vermelha 3-DECL-COP-NFUT NMZ-PASS-furar ITER-CON.COP

"Vespeiros vermelhos eram perfurados novamente."

["Osiipo"]

tipos sentenciais exigem necessariamente a ordem verbo-inicial. Um deles é o assertivo, no qual o verbo necessariamente ocupa a primeira posição (veja Storto (2002) e Everett (2006)):

(32) Modo assertivo

$\emptyset$-pyr-oky-dn iso taso.

3-ASS-matar-NFUT fogo homem

"O homem apagou o fogo."

(ROCHA, 2011)

Além disso, verbos intransitivos, quando não estão na construção de cópula, são tipicamente verbo-iniciais (STORTO, 2014a):

(33) Ordem com verbos intransitivos

$\emptyset$-na-yryt- $\varnothing \quad$ taso yj-akan-pip

3-DECL-chegar-NFUT homem 1p-aldeia-LOC

"Um homem chegou na aldeia."

(STORTO, 2014a)

Dentro de sintagmas nominais, possuidores precedem os elementos possuídos (D. LANDIN, 1984), em consonância com o caráter núcleo-final da língua (STORTO, 1999):

(34) Ordem possuidor-possuído em NPs

Yjxa $\emptyset$-naka-'y-j [yj-pikom pisyp]

1pl 3-DECL-comer-FUT 1pl-macaco carne

"Nós vamos comer a nossa carne de macaco. ～(D. LANDIN, 1984, adaptado)

Em adjetivos, contudo, a ordem é N-Adj (D. LANDIN, 1984):

(35) Ordem $N$-Adj em NPs

Y-ta-pyk-i ['ep horowa]

1-DECL-pegar-FUT pau longo

"Eu vou pegar um pau comprido." ～～(D. LANDIN, 1984, adaptado)

\subsubsection{Orações subordinadas}

Uma parte da literatura sobre o Karitiana concentrou-se principalmente nas diferenças entre orações matrizes e subordinadas. Storto (1999) descreve que uma das principais diferenças entre essas estruturas é a morfologia verbal. Como vimos em §1.3.1, o verbo em orações simples tem afixos de concordância, modo e tempo. Em contrapartida, o verbo aparece sem estes morfemas nas subordinadas: 
(36) Morfologia verbal na oração matriz

Taso $\emptyset$-na-oky-t boroja

homem 3-DECL-matar-NFUT cobra

"O homem matou a cobra."

(STORTO, 1999)

(37) Morfologia verbal na oração subordinada

[Taso boroja oky tykiri] $\emptyset$-naka-hyryp- $\emptyset$ õwa

homem cobra matar PERF. 3-DECL-chorar-NFUT criança

"Quando o homem matou a cobra, a criança chorou."

(STORTO, 1999)

A questão dos afixos de concordância em orações subordinadas é um pouco mais complexa do que os outros morfemas. De fato, a língua permite (e, na realidade, prefere, como veremos à frente) certas marcas de pessoa no verbo referenciando argumentos pronominais como em 39:

(38) Pronome livre em orações subordinadas

[yn opiso] a-taka-kãra-t an

[1s ouvir] 2-DECL-pensar-NFUT 2s

"Você achou que eu ouvi."

(STORTO, 1999)

(39) Cliticização em orações subordinadas

[y-opiso] a-taka-kãra-t an

[1-ouvir] 2-DECL-pensar-NFUT 2s

"Você achou que eu ouvi."

(STORTO, 1999)

Contudo, Storto (1999) demonstrou que esta marca de pessoa não é uma concordância de fato, porque ela não pode coocorrer com um pronome livre como a concordância em orações matrizes:

(40) Concordância em orações matrizes

Y-ta-opiso-t yn

1-DECL-Ouvir-NFUT 1s

"Eu ouvi"

(STORTO, 1999)

(41) Condordância em orações subordinadas

*[yn y-opiso] a-taka-kãra-t an

[1s 1-ouvir] 2-DECL-pensar-NFUT 2s

"Você achou que eu ouvi."

(STORTO, 1999)

Dessa forma, a autora conclui que essa marca de pessoa em ambientes subordinados seria uma espécie de pronome cliticizado ao verbo.

Sobre isso, é preciso dizer que, ao menos em textos naturalísticos, parece existir uma preferência pelas formas cliticizadas em vez de pronomes livres. Em outras palavras, estruturas como 39 são mais frequentemente encontradas do que aquelas como 38. Na realidade, configurações como 38 são geralmente encontradas em produções espontâneas quando existem dois pronomes: 
(42) Oração subordinada com pronome livre em produção naturalística

Yjxa i-mondet byyk otadnamyn otidnan $\emptyset$-na-m-'y okoo-t osiip

1p 3-acabar PERF. quatro lua 3-DECL-CAUS-fazer? ASP.REIT osiip

"Quando acababamos com ele, no tempo de quatro meses, a pessoa faz o osiip de novo"

["Osiipo"]

Se houver dois argumentos pronominais, o mais próximo do verbo será cliticizado (Storto, comunicação pessoal). Geralmente, este argumento será o objeto se ele não for omitido na oração. ${ }^{6}$ No capítulo 4 , discutiremos os pronomes cliticizados mais demoradamente e sugeriremos que eles sejam reinterpretados como marcadores possessivos.

Ainda sobre a morfologia verbal, os únicos elementos permitidos são os de alterações de valência verbal (ROCHA, 2016), marcadores aspectuais (STORTO, 2012) e evidenciais (VIVANCO, 2007; ALEXANDRE, 2016):

(43) Causativizador em oração subordinada

[Õwa Elivar ti-m-tat] $\emptyset$-naka-hit- $\emptyset$ ese-ty Orlando criança Elivar INV-CAUS-ir 3-DECL-dar-NFUT água-OBL Orlando

"A criança que o Elivar fez sair deu água pro Orlando."

(ROCHA, 2016)

(44) Passivização em oração subordinada

Yn $\emptyset$-na-otet- $\emptyset \quad$ ['ip a-'y]

1s 3-DECL-Cozinhar-NFUT peixe PASS-comer

"Eu cozinhei o peixe que foi comido."

(ROCHA, 2016)

(45) Marcador aspectual em oração subordinada

Y-py-so'oot-yn yn Inácio 'ep opĩ tyka-ty

1-ASS-ver-NFUT 1s Inácio árvore cortar IMPERF.MOV.-OBL

"Eu vi Inácio cortando a árvore."

(STORTO, 2012)

(46) Evidencial em oração subordinada

Pyr-y-hadn saryt-y-n José Porto Velhe-pip Maria tat

ASS-EPEN-dizer IND.EVID-EPEN-NFut José Porto Velho-em Maria ir

saryt-y-ty

IND.EVID.-EPEN-OBL

"(Diz que) José disse que (diz que) Maria vai pra Porto Velho."(VIVANCO, 2007)

Nos trabalhos de Storto (1999, et seq.), se considera que a língua também não teria complementizadores ou pronomes relativos de nenhum tipo.

(47) Ausência de subordinadores

Yn $\emptyset$-na-aka-t ingácio 'ep opĩ]-ty

1s 3-DECL-COP-NFUT NMZ-saber-CON.COP Inácio árvore cortar-OBL

"Eu sei que o Inácio corta a árvore."

(STORTO, 2012)

\footnotetext{
$\overline{6}$ Karitiana é uma língua pro-drop, na qual tanto sujeitos quanto objetos podem ser omitidos.
} 
(48) Ausência de pronomes relativos $\left[\begin{array}{lll}\tilde{J}_{\text {onso }} & \text { owwa } & \tilde{\mathrm{i}}\end{array}\right] \quad$-na-aka-t $\quad$ i-hyryp- $\emptyset$ mulher criança bater 3-DECL-COP-NFUT NMZ-saber-CON.COP "A mulher que bateu na criança chorou."

(STORTO, 2012)

Segundo Storto (1999), outro aspecto importante da subordinação é que orações matrizes e subordinadas estão em distribuição complementar com relação à posição do verbo: as primeiras são tipicamente V2, enquanto as segundas são obrigatoriamente verbofinais. Este padrão pode ser observado no par de dados em 36 e 37, no qual o verbo 'oky' ocupa diferentes posições na matriz e na encaixada.

Assim como já fora observado em orações matrizes, Karitiana permite certa variação na ordem dos argumentos em ambientes subordinados. Especificamente, Storto (1999) notou que orações encaixadas podem ter tanto a ordem SOV quanto OSV:

(49) Oração subordinada SOV

[Boroja taso oky tykiri] $\emptyset$-naka-hyryp- $\emptyset$ õwã cobra homem matar PERF 3-DECL-chorar-NFUT criança "Quando o homem matou a cobra, a criança chorou."

(STORTO, 1999)

(50) Oração subordinada $O S V$

[Taso boroja oky tykiri] $\emptyset$-naka-hyryp- $\emptyset \quad$ õwã homem cobra matar PERF 3-DECL-chorar-NFUT criança "Quando o homem matou a cobra, a criança chorou."

Existe um certo debate sobre ordem básica nestes ambientes. Storto (1999) considera que a ordem coloquial é OSV, enquanto SOV constituiria uma ordem arcaica. Contudo, trabalhos como Everett (2006) afirmam que a ordem mais frequente em subordinadas seria SOV, pois ela é frequentemente oferecida pelos falantes em traduções de sentenças sem nenhum constituinte focalizado ou topicalizado. Além disso, Vivanco (2014) aponta que parece existir uma tendência de se interpretar orações altamente ambíguas com a ordem SOV. Em 51, por exemplo, os falantes normalmente interpretam a oração encaixada com 'Karin' como sujeito e 'Ivan' como objeto. Quando a ordem dos argumentos é modificada em 52, a interpretação dos argumentos é também invertida para a maioria dos falantes. Crucialmente, a interpretação segue sempre um alinhamento SOV:

(51) Ordem de constituintes em orações subordinadas

Yn $\emptyset$-na-aka-t iso'oot [Karin Ivan mi ]-ty.

1s 3-DECL-ser-NFUT NMZ-ver-CON.COP [Karin Ivan bater]-OBL

"Eu vi a Karin bater no Ivan."

(52) Ordem de constituintes em orações subordinadas

Yn $\emptyset$-na-aka-t iso'oot [Ivan Karin mi $]$-ty.

1s 3-DECL-ser-NFUT NMZ-ver-CON.COP [Ivan Karin bater]-OBL

"Eu vi o Ivan bater na Karin." 
Por fim, pode existir também um efeito de animacidade, ao menos na interpretação de sentenças em sessões de elicitação. A animacidade tem sido apontada como uma fator relevante para a ordem de palavras em muitas línguas (veja por exemplo Hale, Jelinek e Willie (2012)). Em Karitiana, parece haver um efeito semelhante na interpretação de orações na posição de complemento: na sentença abaixo, os falantes costumam associar o sintagma nominal 'Ana' à posição de sujeito e 'ejepo' à de objeto, independente da ordem dos constituintes:

\section{Oração subordinada e animacidade}

Ivan $\emptyset$-naka-sadn- $\emptyset \quad$ 'ejepo Ana mi

Ivan 3-DECL-contar-NFUT pedra Ana bater

"Ivan contou que a Ana bateu na pedra."

(54) Oração subordinada e animacidade

Ivan $\emptyset$-naka-sadn- $\emptyset \quad$ Ana 'ejepo mi

Ivan 3-DECL-contar-NFUT Ana pedra bater

"Ivan contou que a Ana bateu na pedra."

Isso pode estar relacionada à ideia de que, em línguas naturais, frequentemente se associa a posição de sujeito a entidades agentivas (cf. por exemplo o trabalho de Kemmer (1994)). Dessa forma, essa propriedade prototípica de sujeitos é capaz de se sobrepor à tendência de interpretar sentenças como 53 como 'a pedra bateu na Ana'.

Por fim, orações relativas também parecem apresentar uma ordem relativamente variável de constituintes. As relativas do Karitiana podem ser consideradas de núcleo interno (STORTO, 1999; 2012; VIVANCO, 2014; ROCHA, 2016) e, por isso, ocupam a posição de um argumento do verbo da matriz. Por este motivo e também dada a ausência de pronomes relativos, as orações relativas são estruturalmente bastante similares a orações complemento não relativas como 55. A frontalização do núcleo da relativa é uma estratégia frequentemente usada para desambiguação, como se vê em 56 e 57a. Além disso, relativas de objeto como em geral contêm o morfema ti-, um morfema que será alvo de investigação no capítulo 6 :

Oração subordinada como complemento

Y-py-pyting-yn yn [him pisyp Inácio opĩ]-ty

1s-ASS-querer-NFU 1s caça carne Inácio cortar-OBL

"Eu quero que o Inácio corte a carne."

(STORTO, 2012)

(56) Oração relativa de sujeito

Yn (Ø-na-aka-t) i-so'oot- $\emptyset \quad$ [taso owa mi $]$-ty

I DECL-COP-NFUT NMZ-ver-CON.COP homem criança bater-OBL

"Eu vi o homem que bateu na criança."

(STORTO, 2012) 
Oração relativa de objeto

a. Yn $\emptyset$-na-aka-t i-pyting- $\emptyset$ [boet Luciana

1s 3-DECL-COP-NFUT NMZ-querer-CON.COP colar Luciana ti-m-'a]-ty

INV-CAUS-fazer-OBL

"Eu quero o colar que a Luciana fez."

b. Yn $\emptyset$-na-aka-t i-pyting- $\emptyset$ [Luciana boet

1s 3-DECL-COP-NFUT NMZ-querer-CON.COP Luciana colar ti-m-'a]-ty

INV-CAUS-fazer-OBL

"Eu quero o colar que a Luciana fez."

(VIVANCO, 2014)

Além das potenciais ambiguidades serem determinantes para a ordem de palavras em orações relativas, veremos em $\S 7.3 .3$ que, caso a ordem 57 b seja empregada, sua estrutura sintática é sinalizada através de uma prosódia mais marcada.

\subsubsection{Perguntas QU-}

Landin (1984) já identificara que, no Karitiana, a formação de perguntas envolve necessariamente a frontalização do pronome interrogativo (i.e., o elemento QU-). Em outras palavras, Karitiana é uma língua de QU- movido, o que pode ser comprovado pela impossibilidade de termos perguntas com elementos QU- não frontalizados: ${ }^{7}$

(58) Pergunta com QU- movido

Mora-mon João ti-'y-t?

QU-COP.INT João INV-comer-CON.COP

"O que o João comeu?"

(59) Pergunta sem QU- movido

*João ti-'y-t mora-mon?

João INV-comer-CON.COP QU-COP.INT

Storto (2008) afirma que a formação de perguntas QU- obedece ao alinhamento ergativo-absolutivo da língua. Especificamente, existem duas estratégias para a formação desse tipo de pergunta: uma para a extração de absolutivos (sujeito intransitivo e objeto direto) e outras para todos os elementos não absolutivos. A estratégia de extração de não absolutivos é relativamente menos complexa. Além da frontalização do pronome interrogativo para a primeira posição, o verbo é sufixado apenas com morfemas de concordância: 8

$7 \quad$ Neste aspecto, Karitiana se alinha a muitas outras línguas Tupi, nas quais o pronome interrogativo ocupa a posição inicial da sentença (RODRIGUES, 1999).

8 Descreveremos aqui apenas a estrutura de perguntas QU- no não futuro, pois as perguntas complexas investigadas nos capítulos 2 e 3 estão flexionadas neste tempo verbal. 
(60) Pergunta QU- com sujeito transitivo

Morã y-sokõ $\tilde{i}$

QU- 1-amarrar

"Quem me amarrou?"

(STORTO, 2008)

(61) Pergunta QU-com objeto oblíquo

Morã-ty aj-andyj?

QU-OBL 2p-rir

"De quem você riu?

(STORTO, 2008)

Perguntas envolvendo elementos QU- absolutivos são relativamente mais complexas e parecem envolver o processo de clivagem. Basicamente, o pronome interrogativo frontalizado é sufixado com uma cópula interrogativa -mon no não futuro, e o verbo aparece em sua forma nominalizada, característica da construção de cópula/clivagem:

(62) Pergunta QU- com sujeito intransitivo

Mora-mon i-oty-t?

QU-COP.INT NMZ-tomar.banho-CON.COP

"Quem é que tomou banho?"

(STORTO, 2008)

(63) Pergunta QU- com objeto direto

Mora-mon an ti-opi-t?

QU-COP.INT. 2s INV-cortar-CON.COP.

"O que é que você cortou?"

(STORTO, 2008)

Que -mon é uma cópula interrogativa restrita ao tempo não futuro pode ser visto em perguntas flexionadas no futuro, nas quais -mon dá lugar à cópula 'aka' (veja 16):

(64) Pergunta QU-com sujeito intransitivo no futuro

Morã i-aka-j i-oty?

QU 3-COP-FUT NMZ-tomar.banho

"Quem é que vai tomar banho?"

(STORTO, 2008)

(65) Pergunta QU-com objeto direto no futuro

Morã i-aka-j an ti-pisok

QU 3-COP-FUT 2s INV-esfaquear

"Quem é que você vai esfaquear?"

(STORTO, 2008, adaptado)

Como a formação de perguntas e sua morfologia serão cruciais para as discussões dos capítulos 2 e 3, sumarizamos na tabela abaixo as características destas construções quando flexionadas no não futuro:

Tabela 6 - Morfologia de perguntas QU-

\begin{tabular}{l|lll}
\hline \multicolumn{2}{c}{ Pronome Interrogativo } & QU & V \\
\hline \multirow{2}{*}{ Não absolutivo } & Sujeito transitivo & QU & AGR-V \\
& Objeto oblíquo & QU-ty & AGR-V \\
\hline \multirow{2}{*}{ Absolutivo } & Sujeito intransitivo & QU-mon & $i-\mathrm{V}-t /-\emptyset$ \\
& Objeto direto & QU-mon & $t i-\mathrm{V}-t /-\emptyset$ \\
\hline
\end{tabular}




\subsection{Resumo do capítulo}

Neste capítulo, apresentamos algumas informações essenciais sobre a morfossintaxe da língua, que serão pressupostas nos próximos capítulo. Naturalmente, as informações aqui apresentadas não cobriram todos os pontos de gramática já descritos para a língua - há, inclusive, outros fenômenos de ordem semântica e prosódica que serão apresentados no decorrer deste trabalho. 



\section{Perguntas indiretas}

Neste capítulo, nos debruçamos sobre a formação de perguntas indiretas em Karitiana. Em geral, perguntas indiretas podem ser descritas como perguntas que ocorrem em orações subordinadas, como 67. Este tipo de construção é frequentemente empregado em situações de discurso indireto, nas quais se reporta um enunciado proferido por algum outro falante:

\section{(66) Pergunta simples}

Quem ele viu?

(67) Pegrunta indireta

O João quer saber quem ele viu.

Ao contrário das perguntas matrizes como 66, perguntas indiretas não exigem uma resposta do interlocutor, visto que elas estão subordinadas à força ilocucional da oração matriz. Assim, como esta última é declarativa em 67, a pergunta indireta é subordinada à declaração principal. Contudo, mesmo não tendo o mesmo estatuto informacional de perguntas simples, as perguntas indiretas compartilham diversas propriedades sintáticas com suas contrapartes matrizes. A principal delas é a presença de pronomes interrogativos como 'quando', 'o que', 'como', etc., também denominados de palavras/elementos QU- na linguística formal.

Tradicionalmente, perguntas indiretas são formalizadas da mesma forma que perguntas simples - ou seja, elas contêm o movimento de um elemento QU- para a periferia esquerda da oração. Em geral, se assume que o elemento deslocado é alocado no especificador de CP, a projeção mais alta das orações e aquela responsável pela força ilocucionária das sentenças: 
(68) Movimento $Q U$ -

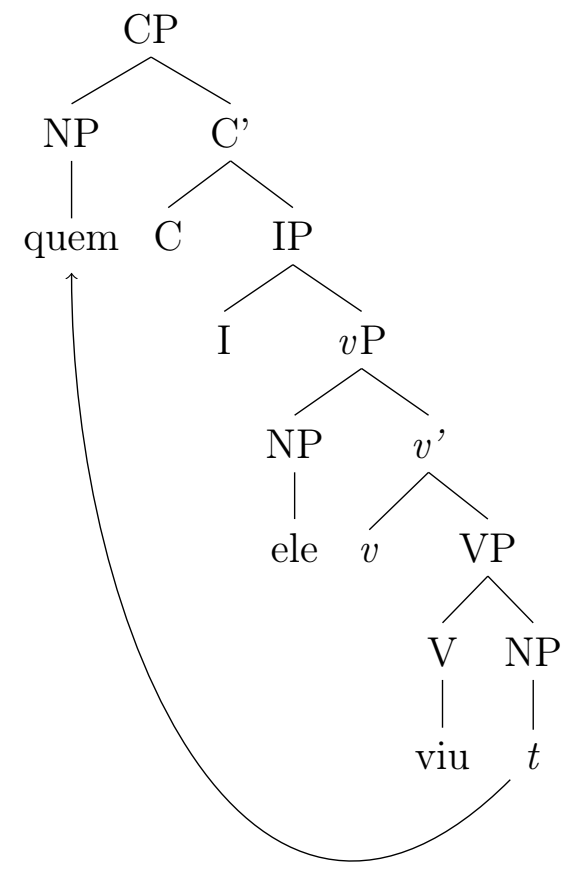

Este tipo de operação, comum a perguntas simples e indiretas e também a diversas outras construções, é denominado de movimento QU- (veja Chomsky (1977)).

Na literatura sobre o Karitiana, não temos até o momento trabalhos sobre perguntas indiretas. Como um de nossos objetivos é discutir o comportamento de subordinadas na língua, as perguntas indiretas são um dos testes ideais para proceder tal investigação: como mencionamos anteriormente, perguntas fazem referência explícita à situação comunicativa. Elas são, portanto, um indicativo de (in(dependência sintática. Dessa forma, o estudo das perguntas indiretas pode iluminar a estrutura das subordinadas, especialmente no que tange ao seu estatuto como uma oração plena.

Sendo assim, temos dois principais objetivos: (1) descrever a formação de perguntas indiretas e (2) discutir como essas perguntas lançam luz na estrutura das subordinadas. Neste capítulo, nos ocuparemos do item (1), enquanto (2) será discutido na seção §4.3.1 do capítulo 4. Neste capítulo, vamos argumentar que não há perguntas indiretas no Karitiana - isto é, não existem estruturas do tipo [MATRIz ... [SUBORDINADA QU- ...] ] como 67. Essa propriedade da língua implicará na conclusão do capítulo 4 de que as subordinadas não são orações "completas", no sentido de que elas incluem menos projeções do suas contrapartes matrizes.

Na seção §2.1, discutimos testes pertinentes à identificação de orações subordinadas nos corpora, especialmente àqueles que apartam uma simples concatenação de orações matrizes (coordenação) de estruturas de fato envolvendo subordinação. Nas seções $§ 2.2$ 
e §2.3, apresentamos os dados espontâneos e elicitados de perguntas indiretas na língua, mostrando que o Karitiana não emprega movimento QU- em contextos de perguntas indiretas. Em $§ 2.3 .1$, discutimos alguns dados marginais com elementos QU- e argumentamos que estes casos podem ser acomodados se considerarmos que o elemento QU- se comporta uma espécie de indefinido nestes ambientes. A seção §2.4 resume os dados apresentados e discute brevemente a relevância destes para a investigação da estrutura das orações subordinadas, um tópico que será mais bem explorado no capítulo 4.

\subsection{Metodologia}

Perguntas indiretas, por definição, envolvem subordinação. Desta forma, uma das questões metodológicas mais importantes é diferenciar casos de justaposição de orações independentes como 69 de estruturas com subordinação com 70:

(69) Discurso direto (pergunta simples)

"Karin quer saber: 'O que a Ana comprou?'"

(70) Discurso indireto (pergunta indireta)

"Karin quer saber o que a Ana comprou"

Em línguas como o Português, é bastente simples diferenciar os dois casos por causa do complementizador 'que'. Porém, muitas línguas não possuem complementizadores. Esse é o caso do Karitiana, que, como vimos no capítulo anterior, não possui palavras equivalentes a 'que'. Contudo, existem outras marcas de subordinação das quais podemos nos valer para identificar estas construções. Vimos na seção §1.3.5 que orações subordinadas possuem propriedades diferenciadas em relação à ordem de constituintes e à morfologia verbal. Especificamente, as subordinadas são estritamente verbo-finais e, nestas construções, o verbo aparece em uma forma mais empobrecida se comparado com a morfologia existente na matriz. Assim, usamos estes critérios para excluir de nosso corpus orações não verbo-finais como 71, que seriam casos de coordenação: ${ }^{1}$

\section{(71) Discurso direto}

[Ana $\emptyset$-na-aka-t i-sondyp-y-wak- $\emptyset] \quad$ [tihoori i-'a tyka

Ana 3-DECL-COP-NFUT NMZ-saber-EPEN-DES-CON.COP onde 3-fazer ASP Maria?]

Maria

"A Ana quer saber... Onde a Maria trabalha?"

Quanto à fonte dos dados, nossa investigação se valeu tanto de dados naturalísticos quanto de sentenças elicitadas. Esses dois conjuntos de dados serão discutidos em $\S 2.2$

1 Em alguns casos, os falantes também optam por incluir uma vírgula entre as duas orações, reforçando os outros indícios de justaposição. 
e §2.3. Veremos que, embora os dados tenham origens diferentes, os exemplos de elicitação em geral replicam o que foi observado em produções naturalísticas.

Os dados de elicitação são provenientes de dois principais métodos: um com figuras e outro com rechecagem de dados. O método com figuras envolvia um contexto de discurso indireto (ou seja, uma situação em que um personagem relata a fala de alguém) e foi baseado em testes em desenvolvimento na área de aquisição da linguagem (Elaine Grolla, comunicação pessoal). Nele, conta-se a seguinte história envolvendo três personagens: Ana, Luciana e Thiago:
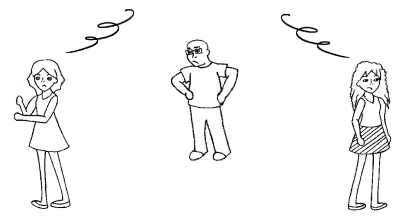

"A Luciana e a Ana estavam bravas e não estavam se falando. Sempre que uma precisava falar com a outra, elas tinham que pedir pro Thiago perguntar."

Figura 2 - Figura utilizada para elicitação

"Por exemplo, a Ana queria saber

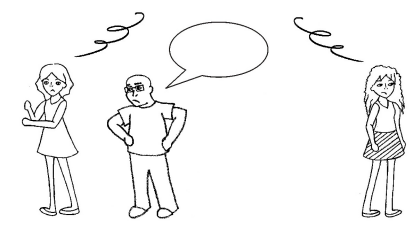

Figura 3 - Figura utilizada para elicitação quando uma outra pessoa, a Maria, ia fazer a comida, mas ela não queria perguntar ela mesma... Então ela pediu pro Thiago! Aí o Thiago disse pra Luciana: 'A Ana quer saber quando a Maria vai fazer a comida."

Após o relato da história, pedíamos ao falante para verter para o Karitiana algumas sentenças proferidas ali. Essas sentenças-alvo eram perguntas indiretas, como abaixo:

\section{Sentença do contexto 3}

A Ana quer saber quando a Maria vai fazer a comida.

Para a construção dos dados, investigamos perguntas indiretas com pronomes interrogativos nas posições de sujeito intransitivo, de sujeito transitivo, de objeto direto, de adjunto de modo, de adjunto de tempo e de adjunto de lugar. A partir destes seis contextos, testamos duas sentenças de cada tipo. Consultamos quatro falantes para as sessões de elicitação.

Além de dados de produção coletados com a metodologia acima, contamos também com sessões de elicitação nos moldes do que propusemos na seção $§ 1.1$ para verificar a aceitabilidade das sentenças produzidas por outros falantes. Estes dados, discutidos em detalhe na seção §2.3.2, nos mostram que existem estruturas para perguntas indiretas que, embora sejam gramaticais para alguns falantes, parecem ser inaceitáveis para outros. 


\subsection{Dados naturalísticos}

Como discutimos no capítulo 1, produções naturalísticas em geral contêm poucos dados de subordinação. Dessa forma, perguntas indiretas são raras nos corpora das narrativas. Abaixo, reproduzimos um dos exemplos coletados:

(73) Pergunta indireta

[Hadn hadn ta'a hit-i-t], [hadn hadn keerep

falar falar EVID.DIR. dar-EPEN-OBL falar falar antigamente

ta-ki-ty], [hadn hadn ta-iriso ta'ãt

3ANAPH-ficar-OBL falar falar 3ANAPH-companheiro EVID.DIR.

ti-sooj-o-t-o-ty], [hadn hadn ta'a hit-i-ty], [hadn

INV-casar-EPEN-OBL?-EPEN-OBL falar falar EVID.DIR. dar-EPEN-OBL falar hadn]

falar

'Tradução original: "Contou, contou o que deram pra ele, como viviam naquele tempo, contou como pegou a mulher do outro, contou o que deram pra ele, falou falou."

(Literalmente: "Falou e falou da entrega... Falou e falou sobre sua vivência... Falou e falou daquela com quem o companheiro dele casou... Falou e falou da entrega... Falou e falou...")

["Encontro dos Capivari com os Karitiana"]

Primeiramente, é preciso observar que algumas destas sentenças parecem ser, na realidade, relativas livres, como 'Eu gosto do que você gosta.' Como veremos nas próximas seções, esse é o padrão em Karitiana, pois perguntas indiretas e relativas livres têm estruturas bastante similares por não conterem elementos QU-. Outras perguntas do dado em 73 como 'hadn hadn keerep takity' são boas candidatas a perguntas indiretas, como se pode ver pelo contexto em que a frase foi proferida e pela tradução oferecida pelos falantes. Elas, contudo, são bastante similares a orações-complemento, como discutiremos à frente. Importantemente, em nenhuma destas orações o elemento QU- aparece dentro da subordinada.

Existem também dois exemplos de perguntas indiretas subordinadas a uma pergunta polar na matriz. Perceba que, nestes dados, também não há um pronome interrogativo equivalente a 'onde' ('tihoori') (veja 74): ${ }^{2}$

(74) Advérbio de lugar de pergunta simples

Tihoori i-pytim'adna Ivan?

onde 3-trabalhar Ivan

"Onde o Ivan trabalha?"

$\overline{2}$ Segundo Everett (2006), a palavra para 'onde' também pode ser ' $t i$ ' $a$ '. 
(75) Pergunta indireta com advérbio de lugar

A-so'oot-o mini an 'õrom heredni-pa-ty, y-syp'et?

2s-ver-EPEN NEG 2s macaco-preto viver-LOC-OBL 1s-tio

"Você sabe onde os macacos-pretos ficam, meu tio?"

(Literalmente: "Você não sabe sobre o lugar de morada dos macacos-preto, meu tio?")

["Encontro dos Capivari com os Karitiana]

(76) Pergunta indireta com advérbio de lugar

A-so'oot-o mini an him hereni-pa-ty, bosy?

2s-ver-INTERR NEG 2s caça viver-LOC-OBL cunhado

"Você sabe onde está a caça, meu cunhado?"

(Literalmente: "Você não sabe do lugar de morada da caça, meu cunhado?")

["Encontro dos Capivari com os Karitiana]

Perceba que, no caso de contextos locativos, o Karitiana faz uso do sufixo nominalizador - $p a$, que apresentamos brevemente no capítulo 1. Segundo Storto (1999), este sufixo converte verbos e sintagmas verbais em nomes:

(77) Nominalizador - pa com verbos

ambo-pa

subir-NMZ

"Escada"

(STORTO, 1999)

(78) Nominalizador - pa com vsintagmas verbais

Tepa $\emptyset$-na-aka-t byrytik soko' $\tilde{\mathrm{i}}$-pa-t

cipó 3-DECL-COP-NFUT tocha amarrar-NMZ-CON.COP

"Cipós são pra amarrar tochas."

(STORTO, 2008, adaptado)

Apesar de serem poucos dados, as sentenças de textos espontâneos delineiam uma tendência na formação de perguntas indiretas: a ausência do elemento QU- e o apelo a outros tipos de construções (orações-complemento e nominalizações com o morfema - $p a$ ). Veremos na próxima seção que os dados de elicitação replicam este mesmo padrão.

\subsection{Dados de elicitação}

\subsubsection{Duas estratégias para perguntas indiretas}

Os dados de produção espontânea nos mostram que a ausência do elemento QUna subordinada parece ser a principal estratégia para a formação de perguntas indiretas na língua. Paralelamente, os dados de elicitação também confirmam essa conclusão, pois os falantes produzem e aceitam amplamente construções como 79-84, sem o pronome interrogativo: 
(79) Pergunta indireta $-Q U=$ sujeito intransitivo

Ana $\emptyset$-na-aka-t i-sondyp-y-wak- $\emptyset$ i-pop

Ana 3-DECL-COP-NFUT NMZ-saber-EPEN-DES-CON.COP 3-morrer

'it-i-ty.

fazer-EPEN-OBL

"Ana quer saber quem desmaiou."

(Literalmente: "A Ana quer saber dele desmaiando.")

(80) Pergunta indireta $-Q U=$ sujeito transitivo

Ana $\emptyset$-na-aka-t i-sondyp-y-wak- $\emptyset$ ambi

Ana 3-DECL-COP-NFUT NMZ-saber-EPEN-DES-CON.COP casa

a-hãraxa-ty.

PASS-consertar-OBL

"A Ana quer saber quem vai consertar a casa."

(Literalmente: "A Ana quer saber da casa consertada.")

(81) Pergunta indireta $-Q U=$ objeto direto

Ana $\emptyset$-na-aka-t i-sondyp-y-wak- $\emptyset \quad$ Maria ti-oky-ty.

Ana 3-DECL-COP-NFUT NMZ-saber-EPEN-DES-CON.COP Maria INV-matar-OBL

"Ana quer saber o que a Maria matou."

(Literalmente: "A Ana quer saber sobre aquele que a Maria matou")

(82) Pergunta indireta - $Q U=$ advérbio 'como'

Karin $\emptyset$-na-aka-t i-sondyp-y-wak- $\emptyset$ gooj-o Ana

Karin 3-DECL-COP-NFUT NMZ-saber-EPEN-DES-CON.COP carro-O Ana

hãraxa-ty.

fix-OBL

"A Karin quer saber como a Ana consertou o carro."

(Literalmente: "Karin quer saber da Ana consertando o carro")

(83) Pergunta indireta - $Q U=$ advérbio 'quando'

Karin $\emptyset$-na-aka-t i-sondyp-y-wak- $\emptyset \quad$ 'irip Ana oky-ty.

Karin 3-DECL-COP-NFUT NMZ-saber-EPEN-DES-CON.COP anta Ana matar-OBL

"A Karin quer saber quando a Ana matou a onça."

(Literalmente: "A Karin quer saber da Ana matando a onça.")

(84) $Q U=$ advérbio 'onde'

Ana i-sondyp-y-wak- $\emptyset \quad$ Ivan pytim'adn-i-pa-ty.

Ana NMZ-saber-EPEN-DES-CON.COP Ivan trabalhar-EPEN-NMZ-OBL

"A Ana quer saber onde o Ivan trabalha."

(Literalmente: "A Ana quer saber do Ivan trabalhando.")

Aqui, há duas coisas a se mencionar. Assim como já tinha sido observado na seção anterior, algumas destas perguntas indiretas parecem estruturalmente orações relativas. Karitiana permite a omissão do núcleo de uma relativa, como se vê no dado abaixo: 
(85) Oração relativa com núcleo omitido

3-pyr-akinda otidna andyk ta'ãt opok ti-oky

3-ASS-estar.doente ASP EVID.DIR. branco INV-matar

"Aquele que o branco matou estava doente."

["Gokyp"]

Além disso, nas chamadas relativas livres o núcleo também é geralmente omitido (STORTO; VIVANCO; ROCHA, 2018):

(86) Relativa livre com núcleo omitido

Y-py-so'oot-y-n yn [Maria ti-amangã]-ty

1-ASS-ver-EPENNFUT 1s [Maria INV-plant]-OBL

"Eu vi o que a Maria matou." (STORTO; VIVANCO; ROCHA, 2018, adaptado)

Desta forma, perguntas indiretas em que o elemento QU- potencialmente ocuparia uma posição argumental (como 79, 80 e 81) poderiam ser consideradas, na realidade, orações relativas livres.

Outra opção para relativas livres é empregar um nome genérico, como 'coisa':

(87) Relativa livre com núcleo genérico

An myrỹy tykadn daki y-hot, y-'it, ta-m-'a-t.

2s diferente? ASP.IMP. ASP.REF. 1s-coisa 1s-pai DECL-CAUS-fazer-NFUT

"Você vai comer o que eu estou te dando, meu pai." ["Ritos funerários"]

Esta mesma estratégia é encontrada em perguntas indiretas que incluem um nome genérico (no exemplo abaixo, 'kinda'). Perceba também que, neste exemplo, temos o morfema $t i-$, que aparece em contextos de relativas de objeto (veja capíulo 1).

(88) Oração relativa em contexto de pergunta indireta

Ana $\emptyset$-na-aka-t i-sondyp-y-wak- $\emptyset$ kinda Maria

Ana 3-DEL-COP-NFUT NMZ-saber-EPEN-DES-CON.COP coisa Maria

ti-oky-ty.

INV-matar-CON.COP

"A Ana quer saber o que a Maria matou."

(Literalmente: "A Ana quer saber que coisa a Maria matou.")

A segunda coisa importante sobre os dados 79-84 é que, nos casos de relativas locativas como 84, é empregado o nominalizador - pa. Este mesmo padrão já tinha sido detectado nos dados naturalísticos em 75 e 76. Além disso, também há dados com o sufixo - $p$, que, como se vê no dado 90, também é um morfema locativo na língua que alterna com o - pa: 
(89) Pergunta indireta locativa com -p

Ana $\emptyset$-na-aka-t i-sondyp-y-wak- $\emptyset \quad$ Maria

Ana 3-DEL-COP-NFUT NMZ-saber-EPEN-DES-CON.COP Maria

aki-p-i-ty.

estar-LOC-EPEN-OBL

"A Ana quer saber onde a Maria estava."

(90) Pergunta indireta locativa com $-p$

João $\emptyset$-na-aka-t i-sondyp-y-wak- $\emptyset$ ombaky Karin

João 3-DEL-COP-NFUT NMZ-saber-EPEN-DES-CON.COP onça Karin

oky-p-y-ty

matar-LOC-EPENOBL

"O João quer saber o local onde a Karin matou a onça."

Por fim, é preciso mencionar também que, no caso de perguntas indiretas de QUmúltiplo, o QU- também não aparece em perguntas encaixadas. Em Karitiana, há apenas um pronome interrogativo nestas construções e a outra variável é substituída por um pronome de terceira pessoa (STORTO, 1999):

(91) Pergunta de QU múltiplo

Mora-mon i ti-oky-t?

QU-COP.INT. 3 INV-matar-CON.COP.

"Quem matou o quê?"

(Literalmente: "Quem matou 'ele(s)"?)

(STORTO, 1999)

(92) Resposta à pergunta 91

Jonso $\emptyset$-na-oky-t $\quad$ sojxa, taso $\emptyset$-na-oky-t irip

mulher 3-DECL-matar-NFUT porco homem 3-DECL-matar-NFUT anta

"A mulher matou o porco, o homem matou a anta."

(STORTO, 1999)

Nos casos em que o QU- múltiplo é uma pergunta indireta, nenhum elemento QU- emerge:

(93) QU- múltiplo

Morã i-mĩ?

QU 3-bater

"Quem bateu em quem?"

(Literalmente: "Quem bateu 'nele(s)'?")

(94) Pergunta indireta com QU- múltiplo

Ôwa ti $\emptyset$-na-aka-t i-sondyp-y-wak- $\emptyset$

Criança mãe 3-DECL-COP-NFUT NMZ-saber-EPEN-DES-CON.COP

i-a-mi-ty.

NMZ-PASS-bater-OBL

"A mãe das crianças quer saber quem bateu em quem."

(Literalmente: "A mãe das crianças quer saber sobre eles sendo agredidos.") 
Em suma, o elemento QU- não é pronunciado em contextos de perguntas indiretas e a língua parece empregar outras estruturas (orações-complemento, relativas livre, passivização, etc.) para cobrir o significado destas construções. Contudo, a ausência do pronome interrogativo parece fazer com que muitas destas sentenças sejam ambíguas: por exemplo, o dado em 82 fora de contexto poderia significar tanto 'A Karin quer saber como a Ana consertou o carro' quanto 'A Karin quer saber quando a Ana consertou o carro.' No entanto, assim como se observa para o dado naturalístico em 73, a desambiguação parece ocorrer através do contexto: como vimos em $\S 2.1$, existia um contexto que amparava a produção destas sentenças. Assim, elas não eram ambíguas em seu contexto de produção.

Tendo em vista tanto os dados naturalísticos quanto os de elicitação, podemos então afirmar que o modo paradigmático de se construir perguntas indiretas em Karitiana é sem o emprego de um elemento QU-. Nesse sentido, as perguntas indiretas diferem bastante das estruturas do Inglês ou Português, pois estas últimas seriam caracterizadas pelo movimento QU- em 68. Em última instância, isso significaria que os dados em 79-84 não parecem ser perguntas propriamente ditas e que eles se assemelhariam mais a orações relativas e a complementos sentenciais como 96 abaixo:

(95) Pergunta indireta - $Q U=$ advérbio 'como'

Karin $\emptyset$-na-aka-t i-sondyp-y-wak- $\emptyset \quad$ gooj-o Ana

Karin 3-DECL-COP-NFUT NMZ-saber-EPEN-DES-CON.COP carro-O Ana hãraxa-ty. consertar-OBL

"A Karin quer saber como a Ana consertou o carro."

(96) Complemento sentencial

Yn $\emptyset$-na-aka-t i-so'oot- $\emptyset \quad$ Maria gok amangã-ty

1s 3-DECL-COP-NFUT NMZ-ver-CON.COP Maria mandioca plantar-OBL

"Eu vi a Maria plantar mandioca."

Contudo, embora a ausência da palavra QU- seja a forma paradigmática para a construção de perguntas indiretas na língua, o estatuto de perguntas com o elemento QUnão é óbvio. A princípio, poderíamos esperar que os falantes não permitissem a introdução de pronomes interrogativos nos dados 79-84, julgando dados com esta configuração como agramaticais. Porém, como veremos na seção seguinte, este não é comportamento que observamos para todos os nossos consultores.

\subsubsection{O status marginal de perguntas indiretas com QU-}

A partir dos dados espontâneos e de elicitação, afirmamos que o modo arquetípico de se construir perguntas indiretas em Karitiana é sem o pronome interrogativo. Contudo, qual seria o estatuto de uma sentença com o pronome interrogativo como 97 ? 
Pertgunta indireta com pronome interrogativo

?Ana $\emptyset$-na-aka-t i-sondyp-y-wak- $\emptyset \quad$ morã pop

Ana 3-DECL-COP-NFUT NMZ-saber-EPEN-DES-CON.COP QU morrer

'it-i-ty.

fazer-EPEN-OBL

"A Ana quer saber quem desmaiou."

De onze falantes consultados, sete aceitam uma pergunta indireta como $97 .{ }^{3}$ Não é possível, portanto, dizer que se trata de uma idiossincrasia de um ou outro falante, visto que mais da metade dos falantes consultados permite estas construções. Porém, é de se questionar a razão pela qual dados como 97 não emergem em produções naturalísticas, já que eles seriam aceitáveis para uma parte dos falantes.

O fato da gramaticalidade de 97 não ser unânime e também sua ausência em produções naturalísticas nos leva a crer que estas construções são marginais na língua. Além disso, mesmo que consideremos construções com o QU- como 97 um produto da gramática de alguns falantes, elas também não possuem o mesmo status de perguntas indiretas com QU- em línguas como o Inglês e o Português. Em outras palavras, subordinadas como 97 também não seriam perguntas indiretas propriamente ditas. Nas próximas seções discutiremos duas propriedades da língua que nos levam a tal conclusão: o estatuto de elementos QU- como elementos indefinidos e o o recorte sociolinguístico dos julgamentos.

\subsubsection{Estatuto dos QU-}

Um aspecto que pode lançar luz às perguntas indiretas como 97 é o estatuto dos elementos QU- nestas construções. Há diversos indícios de que pronomes interrogativos em Karitiana não funcionam exatamente da mesma forma que línguas como o Inglês e Português - em especial, argumentaremos que eles não têm, por si só, força quantificacional. A implicação dessa ideia é de que as perguntas indiretas como 97 não são exatamente equivalentes a perguntas matrizes com movimento QU-, mas sim a orações-complemento contendo uma espécie de pronome indefinido.

$\mathrm{Na}$ linguística formal, uma palavra QU- como um pronome interrogativo é um quantificador, ou seja, um elemento que opera sobre conjuntos (HEIM; KRAZTER, 1998). Por exemplo, quando se enuncia algo como "Quem chegou?", estaríamos perguntando qual o ser humano relevante no contexto que pertence ao conjunto das pessoas que chegaram. Assim, o QU- executa essa operação de quantificar as entidades relevantes no contexto de enunciação.

Sintaticamente, pode-se assumir que um QU- se torna um quantificador de duas formas: (1) por localizar-se em uma posição específica na estrutura - normalmente Spec, CP - ou (2) por ter intrinsecamente uma força quantificacional (DOBROVIE-SORIN,

3 Para sinalizar o caráter misto dos julgamentos, optamos por incluir o símbolo '?' antes dos dados seguindo as diretrizes expostas no início deste trabalho. 
1990). Em Karitiana, vamos argumentar que apenas a opção (1) é instanciada - ou seja, um elemento QU- só se torna um quantificador se estiver em Spec, CP, uma posição na qual ele pode ser regido por um núcleo com traços interrogativos $\left(\mathrm{C}_{[+\mathrm{QU}]}\right)$.

Existem diversos indícios mostrando que os elementos QU- do Karitiana não têm instrinsecamente força quantificacional. Um deles são as construções chamadas de QU- $D$ linked, cuja estrutura seria algo como [QU NP] - e.g., "Qual aluno chegou?"(PESETSKY, 1987). Nestas construções, o pronome interrogativo constrói uma relação entre o grupo de alunos e as pessoas que chegaram. Em outras palavras, o que se está perguntando é "me aponte as entidades do grupo de alunos que também pertencem ao grupo das pessoas que chegaram". Curiosamente, em Karitiana, um elemento QU- não parece conseguir sozinho executar essa mesma operação entre os conjuntos. Isso porque ele sempre precisa da cópula ' $a k a$ ' para quantificar os conjuntos relevantes: ${ }^{4}$

QU-D-linked

[Morã 'ep aka]-mon hỹ?

QU pau COP-COP.INT. INTERR

"Que pauzinho é?"

["Ritos fúnerários"]

(99) QU-D-linked

[Morã kinda aka]-mon Ana ti-oky-t?

QU animal COP-COP.INT. Ana INV-matar-CONC.ABS.

"Que bicho a Ana matou?"

Embora o mecanismo que transforma morã em um quantificador nas perguntas D-linked precise ser mais bem investigado, o que estes dados parecem nos indicar é que, pelo menos para esta classe de palavras QU-, estes elementos não podem agir diretamente sobre os NPs. Assim, esses elementos QU- não parecem ser intrinsecamente quantificadores na língua. No capítulo 3, veremos casos semelhantes 98, nos quais uma oração inteira passa a se comportar como um elemento QU- por ocupar a posição de Spec, CP (um fenômeno chamado pied-piping de larga-escala).

Nos trabalhos de semântica sobre o Karitiana, frequentemente se concluiu que a língua parece não exibir nenhum tipo de quantificadores no domínio nominal (MÜLLER; STORTO; COUTINHO-SILVA, 2006; COUTINHO-SILVA, 2008; SANCHEZ-MENDES, 2009; 2014; STORTO; THOMAS, 2012). Por exemplo, Coutinho-Silva (2008) afirma que o chamado quantificador universal 'akatyym', tradicionalmente traduzido como 'todo',

4 QU- adverbiais não necessitam da cópula ' $a k a$ ':

(i) QU-adverbial

Tikat ngongonronga-t i-'a tyka Maria 'et-o?

QU verão-ADVZ 3-fazer ASP Maria filho-ENF

"Quantos anos o filho da Maria tem?" 
parece funcionar como uma oração relativa (como "os que estão aqui/lá") e não como um quantificador strictu sensu. Prova disso seria que o morfema -tyym é um auxiliar aspectual, que se combinaria com a cópula 'aka' (veja 101 e 102, respectivamente). Ou seja, estes são morfemas independentes, que, ao serem combinados, geram leituras similares à quantificação universal (veja também Storto e Thomas (2012)).

(100) Exemplo de 'akatyym'

[Taso aka-tyym] $\varnothing$-na-soko'i-t eremby man COP-ASP DECL-amarrar-NFUT rede

"Todos os homens amarraram as redes."

(COUTINHO-SILVA, 2008)

(101) Marcação aspectual 'tyym' em outro ambiente

[A-yry tyym] yjxa $\quad \varnothing$-na-oky-j

2-chegar ASP 1PL.INCL 3-DECL-matar-FUT

"Quando você chegar, nós vamos matar (a caça)" (STORTO; THOMAS, 2012)

(102) Cópula 'aka' em outro ambiente

Dibm Ø-naka-tar-i [ony taso aka]

amanhã 3-DECL-ir-FUT DEM homem COP

"Aquele homem irá amanhã."

(COUTINHO-SILVA, 2008)

Além disso, 'akatyym' pode emergir com marcas de pessoa quando deslocado, indicando que ele de fato funcionaria como uma oração subordinada (COUTINHO-SILVA, 2008; STORTO; THOMAS, 2012):

(103) Marcas de pessoa em 'akatyym'

Ta-aka-tyym $\emptyset$-na-soko $\tilde{\mathrm{i}}$-t $\quad$ eremby taso

3ANAPH-COP-ASP 3-DECL-amarrar-NFUT rede homem

"Todos os homens amarraram a rede."

(COUTINHO-SILVA, 2008)

Além disso, não existem a grosso modo equivalentes exatos a palavras como 'nada' ou 'ninguém'. Para veicular o significado de 'nada', por exemplo, frequentemente se emprega uma construção existencial:

(104) Ausência de palavra para 'nada'

I-bodn-i padni y-hoot y-hadna

3-NEG.EXIS-EPEN- NEG 1s-coisa 1s-dizer

"Eu não tenho nada pra dizer."

(Literalmente: "Não existe coisa minha que eu disse.")

Segundo Müller e Sanchez-Mendes (2007) e Storto (2014), a palavra para 'ninguém' é expressa através de uma construção com o advérbio 'si'rimat', que pode ser traduzido como 'jamais' ou 'nunca' (veja também D. Landin (2005)): 
(105) Advérbio 'si'rimat'

I-semboko padni si'rima-t eremby

3-ficar.molhado NEG nunca-ADVZ rede

"Redes nunca ficam molhadas."

(STORTO, 2014a)

(106) Advérbio 'si'rimat' para 'ninguém'

I-a-okooto padni si'rima-t y-'it

3-PASS-morder NEG nunca-ADVZ 1s-filho

"Ninguém mordeu meu filho."

(Literalmente: "Meu filho nunca foi mordido."

(STORTO, 2014a)

Estes e diversos outros fenômenos levaram Sanchez-Mendes (2009) a sugerir que a quantificação de elementos nominais tal como ocorre no Inglês e Português não existiria em Karitiana.

Por fim, outro possível indício de que um elemento QU- não tem força quantificacional é sua impossibilidade em funcionar como um pronome relativo em relativas livres. Os falantes não aceitam relativas livres com um elemento QU- dentro da subordinada como 107, independente do julgamento oferecido por eles para 97. Para veicular o significado expresso por relativas livres, o núcleo deve ser obrigatoriamente nulo (como no exemplo 86): ${ }^{5}$

(107) Relativa livre com pronome interrogativo

*Yn Ø-naka-'y-t morã João 'y.

1s 3-DECL-comer-NFUT QU João comer

"(Pretendido) Eu como o que o João come."

Se alguns falantes aceitam perguntas indiretas como 97, seria possível que também aceitassem 107. Porém, isso não ocorre. Obviamente, este teste não é o indício mais robusto de que elementos QU- não são intrinsecamente quantificadores, pois nem todas as línguas empregam elementos QU- como pronomes relativos: em Alemão, por exemplo, se utiliza a classe de determinantes para esta função. Porém, acreditamos que, junto com as outras evidências disponíveis, ele acaba reforçando a ideia de que elementos QU- não têm força quantificacional.

Se os elementos QU- não são quantificadores, o que eles seriam então? Existem algumas evidências de que os elementos QU- poderiam estar funcionando como uma espécie de indefinido e/ou um nome genérico em subordinadas como 97. Uma das razões que nos levam a crer nisso é o fato de muitos dos falantes que aceitam subordinadas com QU- na subordinada oferecerem traduções não com um QU-, mas como um pronome indefinido: ${ }^{6}$

5 Porém veja Coutinho-Silva (2008) para dados conflitantes.

6 Estamos assumindo a proposta de Heim (1982), na qual indefinidos não possuem força quantificacional. Neste caso, sua interpretação é dada ou por algum outro elemento da oração ou através da operação default de fechamento existencial. 
(108) Tradução de pergunta indireta com indefinido

?Luciana $\emptyset$-na-aka-t i-sondyp-y-wak- $\emptyset \quad$ morã Maria

Luciana 3-DECL-COP-NFUT NMZ-saber-EPEN-DES-CON.COP QU Maria oky-ty.

matar-OBL

"Luciana quer saber que a Maria matou alguém." [sic]

Além disso, vimos anteriormente que, em alguns casos, os falantes produzem perguntas indiretas nas quais o QU- é substituído por um nome genérico, como 'coisa' ('kind $\left.a^{\prime}\right)$ :

(109) Pergunta indireta com nome genérico 'coisa'

Luciana $\emptyset$-na-aka-t i-sondyp-y-wak kinda Maria

Luciana 3-DECL-COP-NFUT NMZ-saber-EPEN-DES-CON.COP coisa Maria ti-m'a-ty.

INV-fazer-OBL

"Luciana quer saber da coisa que a Maria fez."

Sobre isso, Haspelmath (1997) aponta que, translinguisticamente, existem grandes correlações entre pronomes interrogativos, nomes genéricos como 'coisa' e pronomes indefinidos. Especificamente, as palavras QU- exibem também leituras de pronomes indefinidos em diversas línguas:

(110) Pronome interrogativo

[Alemão]

Wer kommt da?

quem vem lá

"Quem está vindo?"

(HASPELMATH, 1997, adaptado)

(111) Pronome indefinido

[Alemão]

Da kommt wer.

lá vem quem

"Alguém está vindo."

(HASPELMATH, 1997, adaptado)

Segundo o autor, é também comum que línguas sem uma categoria específica para indefinidos empreguem nomes genéricos como 'coisa' no lugar destes:

(112) Nomes genéricos como indefinidos
a. (neg) jum 'algo' (literalmente, '(uma) coisa')
[Mongol Khalkha]
b. rud (eigin)
'algo' (literalmente, 'uma (certa) coisa')
[Irlandês]
c. wax 'algo' (literalmente, 'coisa')
[Somali] 
Além disso, em muitas línguas certos elementos se tornam indefinidos ou quantificadores a partir de outros elementos presentes na oração. É o que ocorre em Lakhota e Japonês, por exemplo. Nessas línguas, as palavras QU- adquirem sua força quantificacional a partir de certas partículas. No caso do Lakhota, Haspelmath aponta que o QU'táku' só pode funcionar como um pronome interrogativo quando a partícula 'he' estiver presente:

(113) Pronome indefinido

[Lakhota]

Wičháša ki táku naxiu.

homem o que ouviu

"O homem ouviu algo."

(HASPELMATH, 1997)

(114) Pronome interrogativo

[Lakhota]

Wičháša ki táku nax?u he?

homem o que ouviu Q

"O que o homem ouviu?"

(HASPELMATH, 1997)

Em Japonês, o significado do elemento QU- também advém de diversas partículas presentes na oração (KRATZER; SHIMOYAMA, 2017; SUDO, 2010). No exemplo abaixo, vemos que 'dare' pode significar 'quem', 'qualquer um' e 'ninguém' a depender das partículas a que ele está associado:

$Q U=$ pronome interrogativo

[Japonês]

John-wa dare-o sukina no?

John-TOP QU-ACC gosta Q

"De quem o John gosta?"

(SUDO, 2010)

$Q U=$ pronome indefinido não específico

[Japonês]

John-wa dare-demo sukida

John-TOP QU-Free.Choice gosta

"John gosta de qualquer um."

(SUDO, 2010)

$Q U=$ pronome indefinido negativo

[Japonês]

John-wa dare-mo sukidya-nai

John-TOP QU-CONC.NEG. gosta-NEG

"John não gosta de ninguém."

(SUDO, 2010)

Se nossa interpretação dos dados estiver correta, os elementos QU- do Karitiana seriam similares ao do Lakhota e do Japonês por não terem por si só força quantificacional. Além disso, os QU- do Karitiana também parecem herdar sua força quantificacional de outros elementos na oração. Por exemplo, a partícula interrogativa ' $h \tilde{y}$ ' pode opcionalmente estar presente em perguntas no Karitiana (D. LANDIN, 1984): 
(118) Partícula interrogativa ' $h \tilde{y}$ '

An i-oky-t sojxa hỹ?

2s 3-matar-NFUT? queixada INTERR

"Você matou a queixada?"

(D. LANDIN, 1984, adaptado)

Desta forma, existiria um outro elemento que marcaria a oração como interrogativa e do qual o elemento QU- estaria herdando sua força quantificacional em perguntas simples. A partir da discussão acima sobre a correlação entre a posição sintática e a força quantificacional, a interação do QU- com a partícula interrogativa pode ser capturada com a seguinte estrutura: para se tornar um quantificador, o elemento QU- deve se mover para uma posição em que está sob o escopo de (ou em que é regido por) uma partícula interrogativa. Esta posição será Spec, CP, na qual ele estará no domínio do núcleo $\mathrm{C}_{[+\mathrm{QU}]}$. Em perguntas simples, $\mathrm{C}_{[+\mathrm{QU}]}$ poderá realizado foneticamente ou como ' $h \tilde{y}$ ' ou como um morfema nulo:

(119) Pergunta simples com QU-

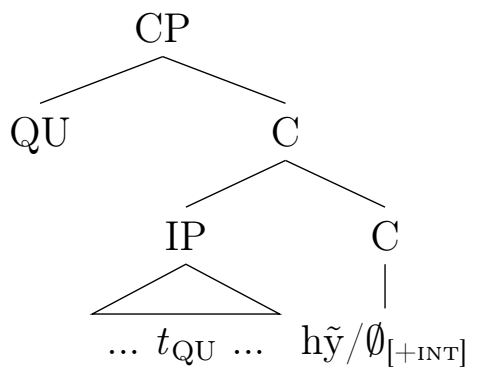

Em orações subordinadas, a partícula ' $h \tilde{y}$ ' não é atestada. Isso nos leva a crer que, nestes ambientes sintáticos, a projeção responsável por tornar este elemento um quantificador, CP, não estaria presente. Tal análise já fora proposta por Storto (1999) ao observar que a língua não possui complementizadores de nenhum tipo. No capítulo 4, desenvolvemos esta análise com maior detalhamento e argumentamos que ela de fato parece ser a mais correta para as subordinadas da língua. Por ora, assumiremos que, dada a suposta ausência da posição Spec, CP, não seria possível para um elemento QUadquirir força quantificacional em orações subordinadas. Nestes casos, ele adquire uma leitura default de indefinido, como 'alguém' em 122.

\subsubsection{Recorte sociolinguístico}

Os falantes consultados em sessões de elicitação executam diferentes funções e, portanto, têm diferentes status formas de se relacionar com sua língua. Por exemplo, alguns professores indígenas parecem ser mais conservadores, sobretudo em relação a formas marginais e/ou mais estigmatizadas (veja a discussão sobre a ortografia 'ombaky/obaky' no início deste trabalho). No que diz respeito ao julgamento de perguntas indiretas com 
QU-, parece haver uma tendência: pessoas mais velhas e/ou professores indígenas tendem a rejeitá-las, enquanto falantes mais novos são em geral mais permissivos. Vejamos um exemplo:

$Q U=$ Advérbio 'como'

?Karin $\emptyset$-na-aka-t i-sondyp-y-wak- $\emptyset$ tikat 'irip Ana

Karin 3-DECL-COP-NFUT NMZ-saber-EPEN-DES-CON.COP ADV anta Ana

oky-ty.

matar-OBL

"Karin quer saber como a Ana matou a anta."7

A sentença 120 foi julgada como gramatical por seis falantes e rejeitada por outros quatro. Destes últimos, dois são professores. Isso pode indicar que estes falantes, por trabalharem na área de educação, talvez tenham mais sensibilidade para questões linguísticas e reconheçam dados como 120 como marginais em sua língua.

Falantes mais velhos também tendem a rejeitar perguntas indiretas com pronomes interrogativos. Um de nossos consultores mais velhos, com cerca de 40 anos, rejeitou sistematicamente todas as estruturas abaixo:

$Q U=$ sujeito intransitivo

?Ana $\emptyset$-na-aka-t i-sondyp-y-wak- $\emptyset$ morã pop

Ana 3-DECL-COP-NFUT NMZ-saber-EPEN-DES-CON.COP QU morrer

'it-i-ty

fazer-EPEN-OBL

"Ana quer saber quem desmaiou."

(122) $Q U=$ objeto direto

?Luciana $\emptyset$-na-aka-t i-sondyp-y-wak- $\emptyset$ morã Maria

Luciana 3-DECL-COP-NFUT NMZ-saber-EPEN-DES-CON.COP QU Maria oky-ty.

matar-OBL

"Luciana quer saber o que a Maria matou."

(123) $Q U=$ advérbio de modo

?Karin $\emptyset$-na-aka-t i-sondyp-y-wak- $\emptyset$ tikat gooj Ana

Karin 3-DECL-COP-NFUT NMZ-saber-EPEN-DES-CON.COP como canoa Ana

hãrajxa-ty.

consertar-OBL

"Karin quer saber como a Ana consertou a canoa."

(124) $Q U=$ sintagma oblíquo

?Karin $\emptyset$-na-aka-t i-sondyp-y-wak- $\emptyset$ morã-pip 'irip Ana

Karin 3-DECL-COP-NFUT NMZ-saber-EPEN-DES-CON.COP QU-em anta Ana

oky-ty.

matar-OBL

"Karin quer saber com o que a Ana matou a anta."

7 Essa sentença também pode ser interpretada como 'Karin quer saber quantas antas a Ana matou.' 
$Q U=$ advérbio

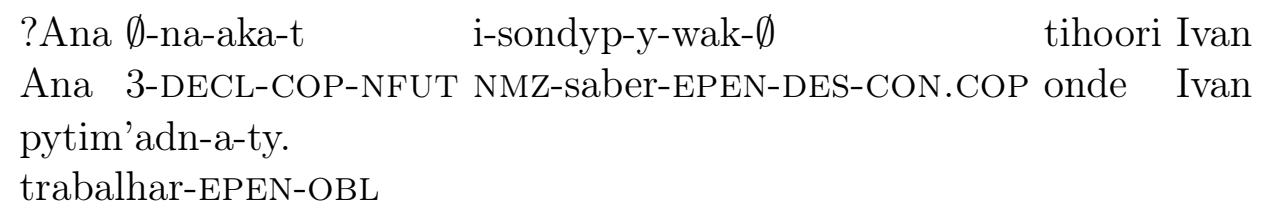

"A Ana quer saber onde o Ivan trabalha."

O recorte social destes julgamentos nos leva a crer que, quanto mais conservador o falante, mais ele tende a rejeitar subordinadas com o elemento QU-. Paralelamente, é interessante relembrar que estas sentenças não aparecem nos textos naturalísticos, cujos narradores são pessoas de grande estima dentro da comunidade (são, em geral, as lideranças indígenas). Assim, é possível que as sentenças em 121-125 sejam formas inovadoras e, portanto, tendem a ser percebidas pelos falantes mais conservadores como uma espécie de 'deturpação' da língua original.

Outra possibilidade é de que 121-125 sejam impossíveis na língua, mas que, por um interesse colaborativo, foram acomodadas pelos falantes que as aceitaram. Neste caso, se forçaria uma leitura do QU- como um pronome indefinido. É preciso mencionar ainda que a configuração das formas inovadoras em 121-125 é similar às perguntas indiretas no Português, o que talvez sinalize uma possível transferência na hora de julgar os dados em sessões de elicitação. Todos os falantes consultados eram bilíngues em Karitiana e Português e falantes mais jovens tendem a ser mais proficientes em Português do que os mais velhos.

O que é crucial aqui é que, de um jeito ou de outro, o emprego de elementos QU- em contextos de perguntas indiretas parece ser uma inovação na língua, pois ela é característica de falantes mais jovens e/ou menos conservadores. Em outras palavras, esse significado indefinido dos elementos QU- dentro de subordinadas parece ser uma função adicional destes elementos. Translinguisticamente, esse é o padrão que se observa: Haspelmath (1997) afirma que, se um mesmo elemento funciona concomitantemente como um pronome interrogativo e indefinido, a segunda função é sempre derivada da primeira:

"[...] Uma coisa nós sabemos com certeza: a função interrogativa é sem-
pre primária, e a função indefinida é sempre secundária. Um pronome
interrogativo pode perder sua função indefinida (e.g., o 'quis/quem,
do Latim, que sobreviveu nas línguas românicas modernas, mas não
pode ser mais usado como indefinido; similarmente, o 'tís', 'quem', do
grego clássico não pode mais ser usado como indefinido no grego mo-
derno)."(HASPELMATH, 1997, tradução nossa)

No fragmento acima, Haspelmath argumenta a favor da primazia da função interrogativa como primária a partir de elementos que perderam a sua função adicional como um pronome indefinido. Curiosamente, ele menciona que uma outra evidência adviria de pronomes interrogativos que adquiriram a função indefinida com o passar do tempo: 
"Infelizmente, eu desconheço um caso robusto no qual um pronome interrogativo que não tem o sentido indefinido o adquire em algum estágio posterior. Tais casos poderiam nos dar pistas para explicar o mecanismo de emergência de indefinidos a partir de interrogativos."(HASPELMATH, 1997, tradução nossa)

O comportamento dos elementos QU- em perguntas indiretas marginais como 97 seria uma evidência-chave para a proposta de Haspelmath, uma vez que o significado indefinido parece estar sendo progressivamente atribuído a pronomes interrogativos em posições não canônicas.

\subsection{Resumo do capítulo}

Vimos neste capítulo que, ao contrário do que ocorre em línguas como o Inglês e o Português, as perguntas indiretas do Karitiana não são estruturalmente equivalentes a perguntas matrizes, pois tradicionalmente não se emprega elementos QU- para construílas. Na realidade, elas parecem ser estruturalmente muito mais similares a orações relativas ou complementos sentenciais do que a perguntas propriamente ditas.

Além disso, argumentamos que, mesmo nos casos em que os falantes permitem um QU- na subordinada, essa estrutura ainda não é exatamente equivalente à de perguntas matrizes: como estes elementos não teriam força quantificacional e não existiria em subordinadas a projeção $\mathrm{CP}$, eles seriam na realidade uma espécie de pronome indefinido nestes ambientes.

Em última instância, nossa discussão implica que, strictu sensu, não existem perguntas indiretas em Karitiana. Esta conclusão, por sua vez, resulta em certas propriedades acerca da estrutura das orações subordinadas na língua: especificamente, argumentaremos, seguindo Storto (1999) e Rocha (2016), que elas são domínios "menores"e "mais dependentes"do que orações matrizes. A exata formalização destas construções será apresentada no capítulo 4. 


\section{Perguntas QU- de longa distância}

\subsection{Introdução}

Como mencionamos no capítulo anterior, a formação de perguntas é um possível teste para investigarmos o status das orações subordinadas no Karitiana, pois elas constituem um diagnóstico de independência sintática. Neste capítulo, vamos investigar um outro tipo de pergunta que ocorre em sentenças bi-oracionais: as chamadas perguntas QU- de longa distância. Ao contrário das perguntas indiretas, as perguntas de longa distância são perguntas de fato, na medida em que exigem uma resposta do interlocutor. Porém, elas ainda diferem das perguntas simples por serem necessariamente bi-oracionais e por o pronome interrogativo ser um constituinte da oração subordinada:

(126) Pergunta simples

Quemi $_{\mathrm{i}}$ o João viu $t_{\mathrm{i}}$ ?

(127) Pergunta QU- de longa distância

Quem $_{\mathrm{i}}$ a Maria acha [que o João viu $t_{\mathrm{i}}$ ]

Este tipo de pergunta também envolve movimento QU- para Spec, CP. No entanto, se assume que o movimento do pronome interrogativo para essa posição se dá em etapas, através dos Spec, CP intermediários (CHOMSKY, 1986a; 2001): 
(128) Movimento QU- cíclico sucessivo

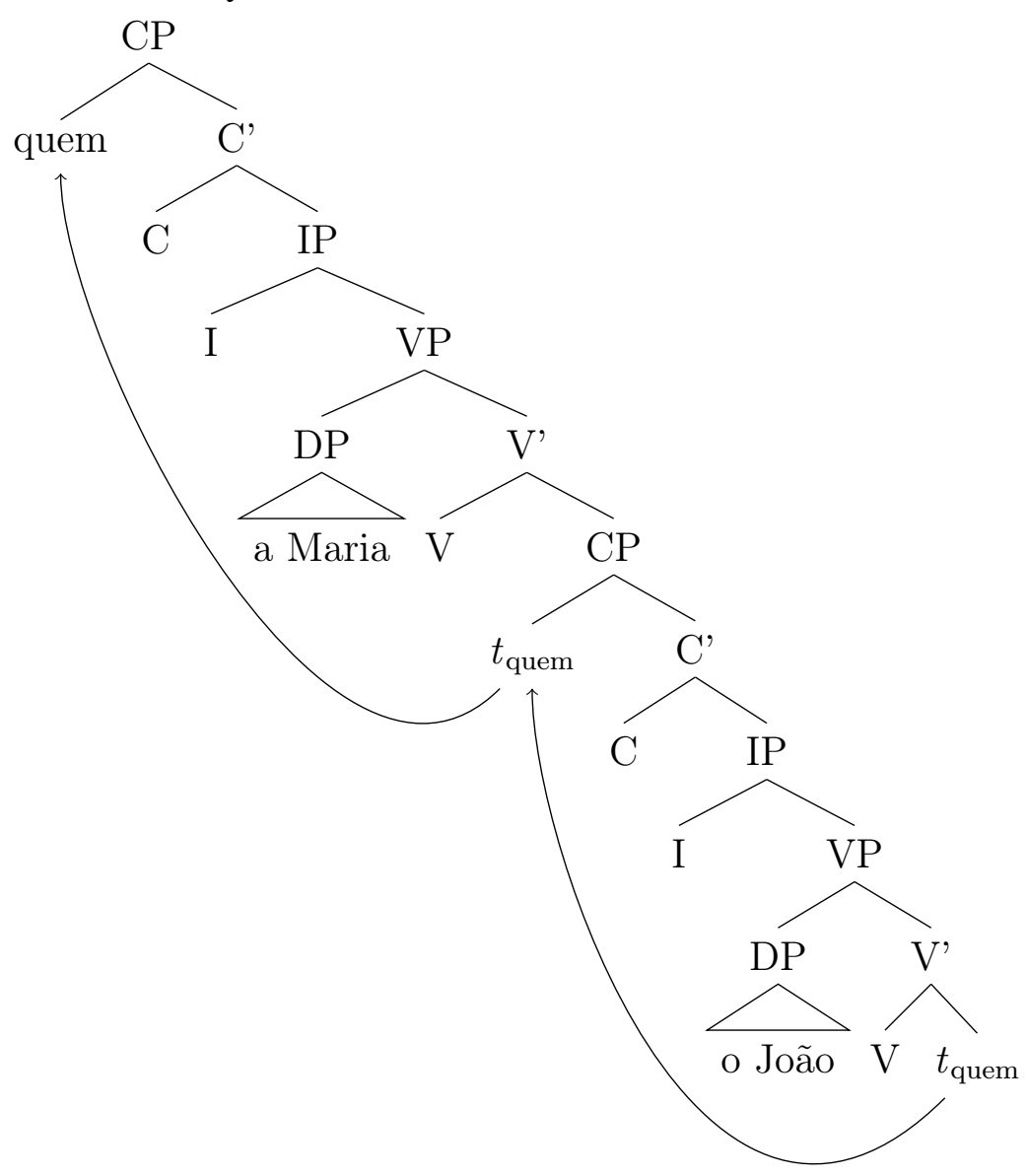

A formação de perguntas simples em Karitiana foi investigada por Landin (1984), Storto (1999; 2008; 2010) e Everett (2006). Contudo, dados de perguntas QU- de longa distância não foram reportados na literatura sobre a língua. Desta forma, nosso primeiro objetivo é descrever a formação de perguntas QU- de longa distância em Karitiana. Especificamente, mostraremos que, nessas construções, toda a oração subordinada contendo o elemento QU- parece ser deslocada para a periferia esquerda da oração - um fenômeno tradicionalmente conhecido como pied-piping de larga-escala. No capítulo 4, argumentaremos que o emprego de tal estratégia revela propriedades importantes sobre a estrutura das subordinadas.

\subsection{Metodologia}

Por serem sentenças bi-oracionais, as perguntas de longa distância colocam o mesmo problema que as perguntas indiretas: ao nos depararmos com uma determinada sentença, como podemos saber se ela de fato envolve subordinação ou se seria um caso de coordenação? Assim como foi discutido na seção §2.1, usaremos os mesmos critérios para 
identificar casos de subordinação, a saber, a ordem de palavras, a morfologia verbal e a entonação.

É importante mencionar que, diferentemente de perguntas indiretas, não há nenhum caso de pergunta QU- de longa distância nos dados espontâneos. Como vimos em $\S 1.1$, perguntas QU- de longa distância são construções extremamente raras - em Inglês, por exemplo, mencionamos o trabalho de Yang (2012), que reporta uma frequência de 0,2\% no input de uma criança adquirindo a língua. Desta forma, investigações sobre este tipo de construção geralmente demandam elicitação direta.

Os dados reportados aqui também consistiram de duas tarefas de tradução com figuras e sessões de elicitação com testes de gramaticalidade. A primeira tarefa de tradução envolvia a seguinte sequência de figuras:

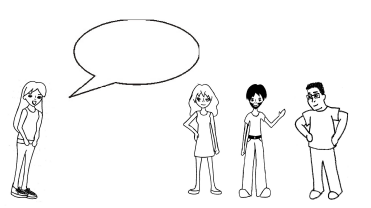

"A Karin estava contando umas fofocas por aí... Por exemplo, ela contou que o Ivan tinha desmaiado na sala de aula."

Figura 4 - Figura utilizada para elicitação

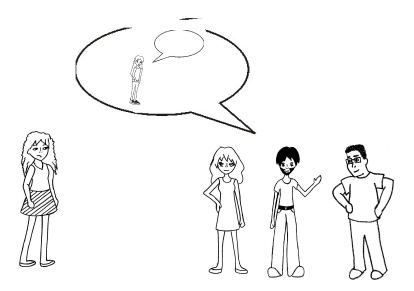

"Mas o pessoal foi contar pra Ana, que é a professora dela, que ela estava contando mentiras por aí... Ela ficou muito brava, porque não era o Ivan que tinha desmaiado na aula, mas sim uma outra

Figura 5 - Figura utilizada para pessoa...' elicitação
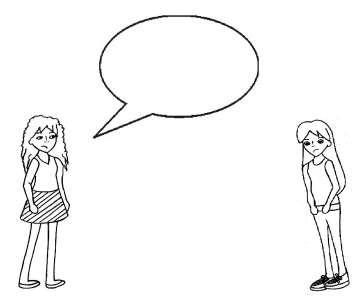

"A Ana foi então tirar satisfação com a Karin sobre as fofocas. 'Quem você acha que desmaiou?', ela perguntou."

Figura 6 - Figura utilizada para elicitação

Depois, pedíamos aos falantes para traduzirem algumas sentenças da história. Em especial, queríamos que eles vertessem a seguinte pergunta para o Karitiana:

\section{Pergunta QU- de longa distância}

Quem você acha que desmaiou?

A segunda elicitação também envolveu figuras, mas o contexto de tradução das sentenças diferia ligeiramente. Em especial, o contexto envolvia duas pessoas reais: a linguista Luciana Storto, que morou na comunidade Karitiana na década de 90, e Nelson 
Karitiana, seu principal colaborador na época. Primeiramente, instruíamos os colaboradores de que gostaríamos de fazer algumas perguntas para o Nelson Karitiana, pra ver se ele de fato conhecia a Luciana Storto depois de tanto tempo convivendo com ela. Nós dizíamos, porém, que gostaríamos de fazer essas perguntas em Karitiana e, por isso, precisávamos da ajuda do colaborador para traduzir as sentenças. Tendo esse cenário como pano de fundo, contávamos algumas histórias, como:

"A Luciana e o Thiago estavam indo pra aldeia Candeias, e a Luciana pediu pro Thiago comprar algumas coisas que eles poderiam precisar lá. O Thiago comprou um caderno para eles trabalharem, mas ele também achou que eles poderiam
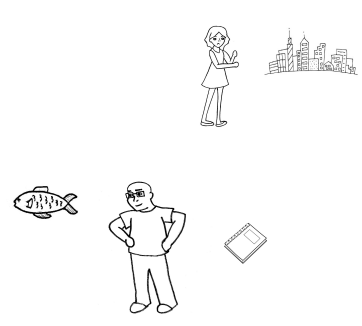

Figura 7 - Figura utilizada para elicitação
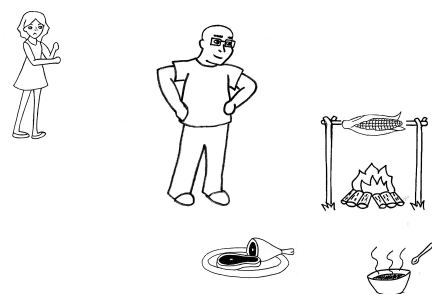

Figura 8 - Figura utilizada para elicitação ficar com fome e comprou peixe pra levar. A Luciana ficou bem brava com isso, porque ela sabe que o Candeias tem muito peixe e que eles não iam precisar disso lá! Ela ficou tão, tão brava com o Thiago, que decidiu não fazer mais nada com ele e foi embora pra São Paulo!"

'A Luciana e o Thiago estavam na aldeia e o Thiago foi fazer o almoço. Ele tinha várias comidas pra preparar, como carne assada, mingau ou milho. Ele fez a carne e o mingau, e depois escolheu fazer também o milho. Só que a Luciana ficou muito brava com ele no final: ela gosta de carne e mingau, mas ela odeia milho. 'Pô, Thiago, já não te disse que eu não como milho?', ela falou."

A partir das histórias acima, pedíamos ao colaboradores para traduzir algumas perguntas, que seriam posteriormente endereçadas a Nelson Karitiana. Para os contextos acima, elas seriam:

Pergunta QU- de longa distância

A Luciana foi pra São Paulo depois que o Thiago comprou o quê?

Pergunta QU-de longa distância

A Luciana ficou brava depois que o Thiago cozinhou o quê?

Além dessas duas tarefas, também fizemos uma elicitação controlada envolvendo julgamentos de gramaticalidade. Assim como no caso das perguntas indiretas, oferecíamos ao falante uma sentença em Karitiana que poderia ou ter sido produzida por outro falante 
ou construída pelo próprio pesquisador, e pedíamos que ele as julgasse como possível ou impossível em sua língua.

Quanto ao template dos dados, investigamos perguntas de longa distância a partir de quatro tipos de orações subordinadas: nas posições de complemento direto (veja 132) e de argumento oblíquo (133), como orações relativas (134) e como orações adverbiais (135):

(132) Subordinada como objeto direto

Ivan $\emptyset$-naka-sadn- $\emptyset$ [Ana ombaky oky]

Ivan 3-DECL-contar-NFUT Ana onça matar

"O Ivan contou que a Ana matou uma onça."

(133) Subordinada como argumento obliquo

Karin $\emptyset$-na-aka-t i-koro'op kãra-t [Ana médico

Karin 3-DECL-COP-NFUT NMZ-dentro suspeitar-CON.COP. Ana médico

mi

bater-OBL

"A Karin acha que a Ana bateu num médico."

(134) Subordinada como oração relativa

Yn Ø-naka-'y-t [kinda'o taso ti-amangã tyja].

1s 3-DECL-comer-NFUT fruta home INV-plantar IMPERF.MOV

"Eu comi (algumas d)as frutas que o homem plantou."

(ROCHA, 2016)

(135) Subordinada como oração adverbial

[ambi-sok jonso otam byyk- $\emptyset$ $] \quad \emptyset$-na-oky-t him taso

casa-em mulher chegar PERF.ASP.-ADVZ 3-DECL-matar-NFUT caça homem

"Depois que a mulher tinha chegado em casa, o homem matou a caça."(ROCHA, 2016)

Elaboramos duas sentenças para cada template acima, totalizando oito contextos. No total, cinco falantes foram consultados.

\subsection{Perguntas QU- de longa distância e pied-piping de larga escala}

A partir de subordinadas como 132-135, coletamos as perguntas de longa-distância equivalentes:

(136) Pergunta de longa distância com complemento direto

[Morã Karin ti-ko]-mon João ti-sadnan- $\emptyset$ ?

QU Karin INV-quebrar-COP.INT João INV-contar-CON.COP

"O que o João contou que a Karin quebrou?" 
(137) Pergunta de longa distância com argumento oblíquo

[Morã pop 'it]-i-ty i-kãra Karin?

QU morrer fazer-EPEN-OBL 3-suspeitar Karin

"Quem a Karin acha que desmaiou?"

(138) Pergunta de longa distância com oração relativa

[Morã ti-m-'a]-mon syke Luciana ti-'y-t?

QU INV-CAUS-fazer-COP.INT mingau Luciana INV-eat-CON.COP.

"A Luciana comeu o mingau que quem fez?"

(Literalmente: "[O mingau que quem fez] a Luciana comeu?")

(139) Pergunta de longa distância com oração adverbial

[Morã Thiago by-hip byyk] i-pa'ira Luciana?

QU Thiago CAUS-cozinhar PERF.ASP. 3-ficar.brava Luciana

"Luciana ficou brava depois que o Thiago cozinhou o quê?"

(Literalmente: "[Depois que o Thiago cozinhou o quê] a Luciana ficou brava?")

Nos dados acima, a oração subordinada inteira parece estar deslocada para a periferia esquerda da sentença. Existem dois argumentos que provam que esta de fato parece ser a interpretação correta destes dados. Primeiramente, sentenças em que somente o pronome interrogativo é deslocado são julgadas ou como agramaticais ou ou como marginais:

(140) Pergunta de longa distância com movimento do pronome interrogativo

*Morã i-kãra Karin [Ana mĩ]-ty?

QU 3-suspeitar Karin Ana bater-OBL

"(Pretendido) O que a Karin acha que a Ana matou?"

(141) Pergunta de longa distância com movimento do pronome interrogativ

*Morã João ti-sadnan- $\emptyset$ [Karin ti-ko]-mon?

QU João INV-contar-CON.COP. Karin INV-quebrar-COP.INT.

"(Pretendido) O que o João contou que a Karin quebrou?"1

Os morfemas que emergem em 132-135 constituem outro argumento a favor da ideia de que a oração subordinada inteira foi frontalizada. Vimos na seção §1.3.6 que a morfologia interrogativa é sensível à função sintática do elemento QU-: se ele for um elemento não absolutivo, o verbo é marcado com um prefixo de concordância; se ele for um argumento absolutivo, a pergunta necessariamente envolverá uma clivagem com os morfemas -mon, $i$ - $/ t i$ - e - $t / \emptyset$. Curiosamente, os morfemas que emergem em perguntas de longa distância fazem sempre referência à função sintática da oração subordinada, e não à do pronome interrogativo. Vejamos abaixo alguns exemplos deste padrão.

Na sentença 142, o morfema de oblíquo - ty aparece como sufixo da oração subordinada e o verbo é prefixado pela concordância de $3^{\text {a }}$ pessoa $i$-. Como se vê na comparação com o dado em 143, estes mesmos morfemas emergem quando o pronome interrogativo é um argumento oblíquo de um verbo como 'andyj' ('rir'):

1 Alguns falantes que aceitam esta sentença a interpretam como duas orações simples coordenadas, como "O que o João contou e a Karin quebrou?". 
(142) Subordinada como argumento oblíquo

[Morã Ana oky]- ty i-kãra Karin?

QU Ana matar-OBL 3-suspeitar Karin

"O que a Karin acha que a Ana matou?"

(143) Pergunta simples com argumento oblíquo

Morã-ty aj-andyj?

QU-OBL 2p-rir

"De quem você riu?"

(STORTO, 2008)

Crucialmente, a oração subordinada de 142 é o argumento oblíquo do verbo '(koro'op) kãra' ('suspeitar'). Já o pronome interrogativo é objeto direto do verbo transitivo 'oky' ('matar'). No entanto, não há nesta sentença nenhuma morfologia referente à extração de argumentos absolutivos, como -mon, ti- ou -t. Como vimos na seção §1.3.6, estes morfemas estão obrigatoriamente presentes quando o elemento QU- é um sujeito intransitivo ou um objeto direto. Na realidade, os morfemas em 142 nos indica que o que está sendo deslocado é um argumento oblíquo - ou seja, a própria oração na posição de objeto oblíquo contendo o elemento QU-.

Uma situação similar ocorre quando a subordinada é uma oração relativa, como no exemplo abaixo. Como mencionamos no capítulo 1, as orações relativas em Karitiana são estruturas de núcleo interno (STORTO, 1999; 2012; VIVANCO, 2014; 2015) - assim, a oração inteira ocupa a posição de um argumento. No exemplo em 144, a relativa toda seria um objeto direto do verbo da matriz ' $y$ ' ('comer'). Crucialmente, a morfologia QUque emerge no verbo ' $y$ ' (os morfemas -mon, $t i$ - e $-t$ ) é semelhante a casos em que se extrai um objeto direto como 145. Importantemente, o elemento QU- em 144 é um sujeito transitivo, cuja extração não dispara este tipo de morfologia (veja §1.3.6):

(144) Pergunta de longa distância com oração relativa

[Morã ti-m-'a]-mon syke Luciana ti-'y-t]?

QU INV-CAUS-fazer-COP.INT. mingau Luciana INV-comer-CON.COP.

"Luciana comeu o mingau que quem fez?"

(Literalmente: "[Mingau que quem fez] a Luciana comeu?")

(145) Pergunta simples com objeto direto

Mora-mon an ti-opi- $\mathrm{t}$ ?

QU-COP 2s INV-cortar-CON.COP.

"O que você cortou?"

(STORTO, 2008)

Finalmente, o mesmo ocorre em casos de orações adverbiais. No dado 146, o único morfema afixado ao verbo matriz 'pa'ira' é um prefixo de concordância. Na pergunta simples em 147, vemos que esta situação é idêntica a casos de perguntas simples com elementos QU- adverbiais (ou seja, a extração de um elemento não absolutivo). Além disso, o pronome interrogativo em 146 tem caso absolutivo, mas a morfologia característica de extração de absolutivos (-mon, $t i$ - e $-t$ ) também não emerge nesta sentença: 
(146) Pergunta de longa distância com oração adverbial

[Morã Thiago by-hip byyk] i-pa'ira Luciana?

QU Thiago CAUS-cozinhar PERF.ASP. 3-ficar.brava Luciana

"A Luciana ficou brava depois que o Thiago cozinhou o quê?"

(Literalmente: "[Depois do Thiago cozinhar o que] a Luciana ficou brava?"

(147) Pergunta simples com advérbio

Tikat i-harãxa aka gooj-o Ana?

Como 3-consertar COP carro-ENF Ana?

"Como que a Ana consertou o carro?"

Em suma, o que a língua parece transparecer a partir de sua morfologia é que, de alguma forma, é a subordinada que passa a funcionar como o elemento QU- em casos de perguntas de longa distância. Em outras palavras, é ela e não o pronome interrogativo que sofre o movimento QU- para Spec, CP. Na próxima seção, veremos que este padrão é característico de um fenômeno chamado de pied-piping de larga-escala, no qual a oração subordinada contendo o pronome interrogativo passa a se comportar como o elemento QU-.

\subsubsection{Pied-piping de larga-escala}

Na seção anterior, vimos duas propriedades de perguntas QU- de longa distância no Karitiana: (1) a oração subordinada inteira é deslocada para a periferia esquerda da sentença; e (2) a oração subordinada passa a "funcionar"como o elemento QU-, disparando a morfologia interrogativa de acordo com sua função sintática. Esse fenômeno já fora descrito para outras línguas sob o nome de pied-piping de larga-escala ou pied-piping oracional (COLE, 1982; URBINA, 1993; URBINA; ETXEPARE, 2003; HECK, 2008; CABLE, 2010; RICHARDS, 2008; HORVATH, 2006). Línguas que fazem uso do pied-piping de larga-escala são o Quechua de Imbabura (COLE, 1982), o Basco (URBINA, 1993; URBINA; ETXEPARE, 2003; ARREGI, 2003), o Latim (HECK, 2008), o Tlingit (CABLE, 2010) e o Bangla (SIMPSON; BHATTACHARYA, 2000). Nestas línguas, perguntas QUde longa distância envolvem a frontalização da oração subordinada contendo o elemento QU-. Abaixo, ilustramos o fenômeno com um dado do Tlingit, no qual toda a oração subordinada relativa '[um peixe que é quão grande]' é frontalizada:

(148) Pied-piping de larga-escala

[Tlingit]

[NP[CP Wáa kwligeyi ] xáat ] sá i tuwáa sigóo?

como é.grande.REL peixe Q seu espírito.em alegra-se

"Você quer um peixe que seja de que tamanho?"

(Literalmente: "[Um peixe que é quão grande] você quer?")

(CABLE, 2010) 
O pied-piping de larga-escala é um subtipo de pied-piping, um fenômeno inicialmente descrito por Ross (1967). Em linhas gerais, o pied-piping pode ser definido como "o fenômeno através do qual uma determinada operação de movimento T, designada para deslocar um elemento A, acaba deslocando elementos adicionais em conjunto com A."(HORVATH, 2006). Os exemplos prototípicos de pied-piping geralmente envolvem preposições em perguntas simples. Em línguas como o Inglês, NPs na posição de complemento de uma preposição podem se mover sozinhos para Spec, CP (veja 149), em uma operação conhecida como preposition-stranding (ou P-stranding). Já em línguas como o Português, tal configuração é impossível: nestes mesmos ambientes, o PP inteiro precisa ser deslocado para a periferia esquerda da oração. Neste último caso, temos uma instância de pied-piping:

(149) P-stranding

What $t_{\mathrm{i}}$ is he talking [about $t_{\mathrm{i}}$ ??

(150) Pied-piping

[Do que $]_{i}$ ele está falando $t_{\mathrm{i}}$ ?

Nos casos de pied-piping em larga-escala, os "elementos adicionais"deslocados conjuntamente com a palavra QU- são a oração subordinada inteira que a contém. Desta forma, a estrutura de uma pergunta QU- de longa distância em Karitiana seria como abaixo, na qual a oração inteira (indicada provisoriamente como um XP) ocupa o Spec,CP da matriz:

\section{Pergunta de longa distância com pied-piping de larga-escala}

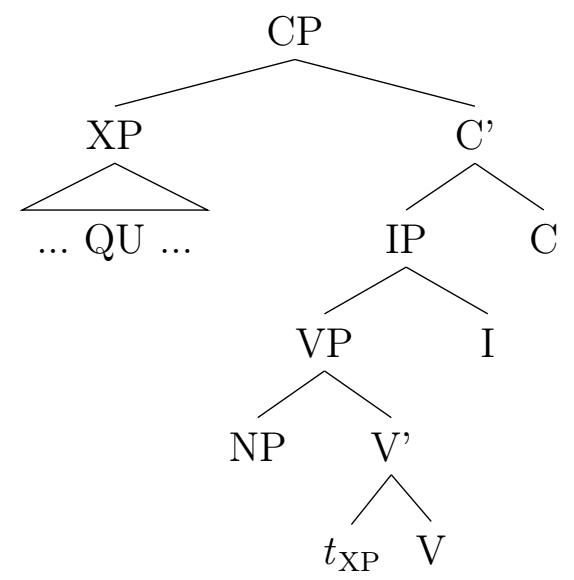

No próximo capítulo, discutiremos mais a fundo a estrutura 151, mostrando especificamente como a arquitetura interna de uma subordinada poderia explicar a existência do pied-piping de larga-escala em Karitiana. 


\subsubsection{Focalização}

Em línguas como o Basco e o Bangla, observou-se também que construções de foco podem disparar pied-piping de larga-escala (URBINA, 1993; SIMPSON; BHATTACHARYA, 2000). Na sentença 153, a oração subordinada inteira é deslocada quando seu constituinte 'Jon' é focalizado:

(152) Foco em sentenças simples

[Basco]

JONEK irakurri du liburua

Jon lido tem livro

"Jon leu o livro."

(URBINA, 1993)

(153) Foco e pied-piping de larga-escala

[Basco]

[JON etorri den] galdetu du

Jon vindo tem-COMP perguntado tem

"Eu perguntei se foi o Jon que veio."

(URBINA, 1993)

Em Karitiana, temos uma situação similar, pois um elemento focalizado dentro de uma oração subordinada induz a frontalização da subordinada inteira. Como vimos no capítulo 1, um elemento focalizado necessariamente ocupa a posição pré-verbal em orações matrizes (STORTO, 1999). Assim, o NP 'ohy' em 154b ocupa a posição pré-verbal em resposta a uma pergunta QU- simples de objeto:

Elementos focalizados em posição pré-verbal

a. Mora-mon taso ti-'y-t QU-COP.INT homem INV-comer-CON.COP.

"O que o homem comeu?"

(STORTO, 1999)

b. OHY a-taka-'y-t taso

batata INV(DECL)-DECL-Comer-CON.COP. homem

"Batatas, o homem comeu."

(STORTO, 1999)

Crucialmente, uma resposta à uma pergunta QU- de longa distância também envolve frontalização de toda oração subordinada, e não apenas do elemento focalizado. No contexto em 155, somente o objeto é focalizado, pois o material restante da subordinada está pressuposto no momento da enunciação. No entanto, a oração inteira ocupa a posição pré-verbal em 155b, indicando a ocorrência de pied-piping.

Pied-piping de larga-escala com foco

a. [Morã Ana oky]-ty i-kãra Karin? QU Ana matar-OBL 3-suspeitar Karin

"O que a Karin acha que a Ana matou?"

b. [OMBAKY Ana oky]-ty $\emptyset$-naka-kãra-t Karin. onça Ana matar-OBL 3-DECL-suspeitar-NFUT Karin

"É um jaguar que a Ana acha que a Karin matou." 
Em resumo, Karitiana se comportaria como outras línguas com pied-piping de larga-escala nas quais o foco tem um comportamento análogo à formação de perguntas de longa distância. Junto com os casos de formação de perguntas, o comportamento da focalização em sentenças bi-oracionais nos mostra que os constituintes de uma oração subordinada parecem estar de alguma forma inacessíveis para operações fora dela. No capítulo 4, veremos como a opacidade destes domínios podem estar correlacionados com sua estrutura sintática.

\subsubsection{Topicalização}

Segundo Horvath (2006), a existência de pied-piping envolvendo CPs é controversa e, em algumas línguas, este fenômeno pode ser reinterpretado de alguma outra forma (HECK, 2008; HORVATH, 2006). ${ }^{2}$ Por exemplo, línguas como o Inglês permitem construções como 156, nas quais a oração inteira sofre um processo de deslocamento à esquerda chamado de topicalização (veja Chomsky (1977)):

\section{(156) Possivel caso de pied-piping de larga-escala}

[Where did he go], do you think?

(HORVATH, 2006)

Desta forma, alguém poderia argumentar que os casos de perguntas QU- de longa distância envolveriam na realidade um processo de frontalização simples como a topicalização. Se for este o caso, a formação de perguntas de longa distância não seria exatamente análoga à de perguntas simples, pois elas envolveriam processos ligeiramente distintos. Para casos paradigmáticos de pied-piping de CPs, como o Basco, a análise como movimento QU- tem sido questionada ao ponto de Horvath (2006) afirmar que existem evidências não controversa a favor da existência de pied-piping com orações. Dentro deste cenário, queremos demonstrar que os casos de pied-piping de larga-escala em Karitiana constituem de fato um movimento da oração subordinada para Spec, CP e que não podem ser interpretados de outra forma.

À semelhança da topicalização em outras línguas, Karitiana possui uma outra construção que move elementos para a posição inicial da oração: a chamada topicalização (D. LANDIN, 1984; EVERETT, 2006) ou construção de foco (STORTO, 1999). Esta construção envolve a frontalização de um argumento para a posição pré-verbal. Se o morfema declarativo estiver presente, o verbo aparecerá prefixado com o morfema $a$-;

2 É preciso mencionar que, a partir de Chomsky (1977), se assumiu que tanto topicalização quanto a formação de perguntas envolvem movimento QU-, ou seja, um deslocamento para Spec, CP. É somente a partir de Rizzi (1997) que se propõe que a projeção CP possa ser expandida em posições mais especializadas. A questão que está em jogo aqui é se as línguas que deslocam a oração inteira contendo o QU- o fazem da mesma similar a perguntas simples ou a topicalizações. Se o último caso for verdadeiro, isso nos leva a perguntar por que línguas como o Português, que fazem uso de diversos mecanismos de topicalização, não os empregam massivamente para construir perguntas QU- de longa distância. 
se a oração for não declarativa, ele será prefixado com ti- (veja o capítulo 6 para mais informações sobre estes morfemas):

Construção de foco declarativa

Tem Tema a-taka-m-tat- $\emptyset \quad$ Botỹj.

Tem Tema InV.DECL-DECL-CAUS-ir-NFut Botỹj

"Tem Tema, Botỹj levou."

(STORTO, 1999)

(158) Construção de foco declarativa

ambi-ty a-ta-so'oot- $\emptyset$

casa-OBL INV.DECL-DECL-ver-DECL

"A casa, eles viram."

(STORTO, 1999, adaptado)

(159) Construção de foco não declarativa

Sepa y-ti-m-'a tyja-t

cesto 1s-INV-CAUS-FAZER IMPERF.SENTADO-NFUT

"Um cesto, estou tecendo."

(STORTO, 1999)

Desta forma, poderíamos argumentar que os supostos casos de pied-piping de orações como 136-139 poderiam ser na realidade construções de foco sendo usadas em perguntas. Neste caso, não teríamos um pied-piping de larga-escala propriamente dito, mas sim uma pergunta simples com uma oração subordinada inteira focalizada na primeira posição da sentença.

Contudo, a morfologia verbal em perguntas de longa-distância mostra que essa não pode ser a análise mais correta. Vimos que as orações subordinadas recebem todos os morfemas que normalmente se afixam a pronomes interrogativos em perguntas, como mon e -ty. Além disso, vimos também que a morfologia do verbo da matriz reflete a função sintática da oração subordinada. Assim, no exemplo em 160 abaixo, o verbo aparece em sua forma clivada, pois ela é exigida quando argumentos absolutivos sofrem movimento QU-, como 161:

(160) Pergunta de longa distância

[Morã Karin ti-ko]-mon João ti-sadnan- $\emptyset$ ?

QU Karin INV-quebrar-COP.INT João INV-contar-CON.COP

"O que o João contou que a Karin quebrou?"

(161) Pergunta simples

Mora-mon taso ti-'y- t?

QU-COP.INT homem INV-comer-CON.COP

"O que o homem comeu?"

(STORTO, 1999)

Crucialmente, as construções de foco como 157-159 não exigem toda essa morfologia especial. Apenas ti- está presente em ambos os casos, mas, como veremos em 6, este morfema emerge em diversos ambientes, não estando portanto restrito a construções de foco. Assim, nossa conclusão é de que as orações subordinadas em construções como 160 sofrem de fato movimento QU- e que, portanto, as perguntas de longa distância em Karitiana constituem de fato casos de pied-piping de orações. 


\subsubsection{Movimento interno do QU-}

Nos dados de pied-piping de larga-escala, o elemento QU- sempre se posiciona na borda da oração deslocada. Esse padrão pode ser visto no dado abaixo: dado que SOV parece ser a ordem-base em subordinadas (veja capítulo 1), a ordem original parece ser modificada em 162 através da frontalização interna de 'morã':

(162) Movimento secundário do elemento QU-

[Morã $\tilde{\mathrm{i}}_{\mathrm{i}}$ Thiago $t_{\mathrm{i}}$ by-hip byyk i-pa'ira Luciana?

QU Thiago CAUS-cozinhar PERF.ASP. 3-ficar.brava Luciana

"Luciana ficou brava depois que o Thiago cozinhou o quê?"

Esse movimento interno à subordinada parece ser obrigatório, pois elementos QUem posições não iniciais degradam ligeiramente a sentença. Em 164, vemos que colocar o objeto 'gok' à frente do elemento QU- diminui a aceitabilidade da sentença:

(163) Movimento secundário

Morã ti-m-'a-mon gok Luciana ti-'y-t?

QU INV-CAUS-fazerCOP.INT mandioca Luciana INV-comer-CON.COP

"A Luciana comeu a mandioca que quem fez?"

(164) Ausência de movimento secundário

?Gok morã ti-m-'a-mon Ivan ti-'y-t?

mandioca QU INV-CAUS-fazer-COP.INT Ivan INV-comer-CON.COP

É preciso lembrar que OSV é uma ordem lícita para orações subordinadas, como discutimos na seção §1.3.5. Assim, o problema de 164 não é a ordem de constituintes OSV em si, mas a posição não inicial do pronome interrogativo 'morã'.

Esse mesmo padrão tem sido detectado em outras línguas com pied-pipig de largaescala. No dado de Quechua abaixo, se percebe que o QU- se posiciona na periferia da oração deslocada: ${ }^{3}$

3 É preciso mencionar que, dada a possibilidade de algumas línguas topicalizarem elementos através de movimento para posição inicial, existem casos de pied-piping de larga-escala em que um elemento (geralmente o sujeito) precede a oração deslocada. Isso aparentemente ocorre em Basco (URBINA, 1993) e em Bangla (SIMPSON; BHATTACHARYA, 2000):

(ii) [Mikeli [zer esan ondoren]] joan zen etxetik?

Mikel-D o.que dizer depois ir Aux casa-de

"Ele foi embora de casa depois de dizer o que pro Mikel?"

(URBINA, 1993)

(iii) jOn [meri kon boi-Ta poRe-che] bollo?

John [Mary qual livro-CLA ler-tem.3] disse

"Que livro o John disse que a Mary leu?"

(SIMPSON; BHATTACHARYA, 2000) 
(165) Movimento secundário com pied-piping de larga-escala [Quechua de Imbabura] $\left[_{\mathrm{CP}} \operatorname{Imata}_{2} \text { wawa } \mathrm{t}_{2} \text { mikuchun }\right]_{3}$-taj Maria $\mathrm{t}_{3}$ munan? o.que.ACC criança.NOM comer.SUJ-Q Maria querer.PR3

"O que a Maria quer que a criança coma?" (Hermon (1985) apud Heck (2008))

No entanto, Heck $(2008 ; 2009)$ pontua que esta operação ocorre na realidade em diversos casos de pied-piping. Um exemplo é a extração com NPs, como se vê nos exemplos abaixo de Tzotzil. Segundo Aissen (1996), a ordem usual em sintagmas nominais de Tzotzil é possuído-possuidor, como em 166a. Qualquer tentativa de inversão desta ordem resulta em agramaticalidade, como se observa em 166b. Porém, quando pied-piping acontece, em 167, as possibilidades de ordem de constituintes dentro do NP se invertem, e apenas a ordem possuidor-possuído é permitida:

(166) Ordem de constituintes em NPs

[Tzotzil]
a. S-p'in li Maruch-e
A3-panela o Maruch-ENC
"A panela de Maruch."
b. *(li) Maruch s-p'in (..-e)
o Maruch A3-panela ENC

(AISSEN, 1996)

(167) Ordem de constituintes em NPs com pied-piping

[Tzotzil]
a. [Buch'u x-ch'amal $]_{\mathrm{i}}$ i-cham $t_{\mathrm{i}}$ ? quem A3-criança CP-morreu
'O filho de quem morreu?"
b. *[X-ch'amal buch'u $]_{\mathrm{i}}$ i-cham $t_{\mathrm{i}}$ ? A3-criança quem CP-morreu

(AISSEN, 1996)

O mesmo ocorre com o pied-piping de sintagmas nominais no Zapotec de San Dionicio (BROADWELL, 2001) e em Chol (COON, 2009).

É possível que, em Karitiana, este movimento também não esteja restrito a casos de pied-piping de larga-escala. Devido ao padrão de ordem de constituintes em NPs, não é possível detectar o mesmo fenômeno em muitos ambientes nominais. Com possuidores, o genitivo precede o possuído, e essa ordem permanece inalterada nos casos de pied-piping:

(168) Ordem de constituintes em NPs

[Nelson 'it-i carro] $\emptyset$-na-aka-t i-pop- $\emptyset$.

Nelson filho-EPEN carro 3-DECL-COP-NFUT NMZ-morrer-CON.COP

"O carro do filho do Nelson quebrou." 
(169) Ordem de constituintes em NPs com pied-piping

[Morã 'it-i carro]-mon i-pop- $\emptyset$ ?

QU filho-EPEN carroCOP.INT NMZ-morrer-CON.COP

"O carro do filho de quem quebrou?"

No entanto, talvez seja possível detectar um fenômeno semelhante ao deslocamento interno do QU- em perguntas com adjetivos. Como vimos no capítulo 1, a ordem usual em sintagmas nominais é NP-Adj. Quando o adjetivo é questionado, uma partícula comparativa, 'horot' ('como'), também emerge. Contudo, o importante aqui é que, em casos de pied-piping, o elemento QU- junto com a partícula 'horot' parece se inverter em relação ao sintagma nominal. Assim, a ordem em 170 é alterada em 171, pois sintagma adjetival [morã horot] ('como o quê') passa a preceder o nome 'taso':

\section{Ordem de constituintes em NPs com adjetivos}

Maria $\emptyset$-na-aka-t i-mana-t taso se'a-ty

Maria 3-DECL-COP-NFUT NMZ-casar-CON.COP homem bonito-OBL

"Maria casou com um homem bonito."

(171) Ordem de constituintes em NPs com adjetivos e pied-piping

[[Morã horot] taso aka]-ty i-mana Maria?

QU como homem COP-OBL 3-casar Maria

"A Maria casou com um homem como o quê?"

A inversão da ordem nome-adjetivo em 171 poderia indicar talvez que esse movimento do QU- em perguntas de longa-distância como 162 é na realidade uma propriedade mais geral de constituintes que sofrem pied-piping em Karitiana.

Sobre isso, Heck (2008; 2009) denomina esse movimento do elemento QU- dentro do constituinte que sofre o pied-piping como movimento secundário. Por o movimento secundário ocorrer em diversos casos de pied-piping, Heck (2008; 2009) postulou a seguinte generalização:

\section{(172) Generalização de borda}

Se $\alpha$ dispara pied-piping de $\beta$, então $\alpha$ tem que estar na borda de $\beta$. $\quad$ (HECK, 2009)

Uma propriedade importante deste movimento secundário no pied-piping de largaescala em Karitiana é que ele não é um movimento QU-. Isso pode ser demonstrado através da ausência da morfologia que encontramos dentro da subordinada nestes casos. ${ }^{4}$ Por exemplo, vimos na seção §1.3.6 que a extração de um absolutivo como o objeto direto em 173 dispara um processo de clivagem detectado pelos morfemas - mon, $i$ - e - $t$ (ou seu

$4 \quad$ Isso não significa que, em todas as línguas com pied-piping de larga-escala, o movimento secundário não pode ser considerado uma espécie de movimento QU-. Em Basco, por exemplo, Ortiz de Urbina (1993) afirma que o movimento secundário é um movimento QU-, pois ele dispara o V2 característico de deslocamentos para Spec, CP em orações matrizes. 
alomorfe $-\emptyset)$. Contudo, o movimento interno de 'morã' não força a clivagem do verbo encaixado 'pop 'it' em 174:

(173) Extração de sujeito intransitivo

Mora-mon i-oty- $\underline{\mathrm{t}}$ ?

QU-COP.INT NMZ-tomar.banho-CON.COP

"Quem é que tomou banho?"

(STORTO, 2008)

(174) Movimento secundário em pergunta de longa distância

[Morã pop 'it]-i-ty i-kãra Karin?

QU morrer fazer-EPEN-OBL 3-suspeitar Karin

"Quem a Karin acha que desmaiou?"

Na realidade, a clivagem, quando necessária, é apenas observada na matriz e depende da função sintática da oração subordinada e não do QU- em si. Esse padrão, discutido na seção §3.3.1, pode também ser visto no dado abaixo. Em 175, a clivada no verbo da matriz emerge por causa da função sintática da oração subordinada como um objeto direto:

(175) Verbo em sua forma clivada na oração matriz

[Morã ti-m-'a]-mon gok Luciana ti-'y-t?

QU INV-CAUS-fazer- COP.INT mandioca Luciana INV-comer- CON.COP

"Quem fez essa mandioca que a Luciana comeu?"

Além disso, outra evidência mostrando que o movimento secundário não é um movimento QU- é o comportamento da partícula ' $h \tilde{y}$ ' nestes ambientes. Como discutimos na seção §2.3.2.1, a partícula interrogativa ' $h \tilde{y}$ ' emerge em perguntas simples, sendo portanto uma realização fonológica de um núcleo C com traços [QU]. Se o movimento interno do pronome interrogativo fosse de fato um movimento QU-, esperaríamos que a partícula interrogativa emergisse nestes ambientes também. ${ }^{5}$ Contudo, este não é caso, pois ' $h \tilde{y}$ ' é proibido na oração subordinada (independente se a partícula ' $h \tilde{y}^{\prime}$ co-ocorrer na matriz):

5 Esse padrão é encontrado em algumas línguas que exibem o pied-piping de larga-escala e partículas interrogativas, como o Tlingit:

(iv) Particula interrogativa

[Tlingit]

[[Wáa kwligeyi CP] xáat NP] sá i tuwáa sigóo?

quão é.grande.REL peixe Q seu espírito.em alegra.se

'Você quer um peixe que é quão grande?"

(CABLE, 2010)

É importante mencionar que Cable (2010) não analisa essa partícula interrogativa 'sá' como um núcleo $\mathrm{C}_{[\mathrm{QU}]}$, mas sim como uma espécie de elemento "satélite ao QU-". Para mais informações, veja também o trabalho de Kishimoto (2005) sobre as partículas interrogativas do Sinhala. 
(176) Partícula 'hỹy' em pergunta de longa-distância

[Morã pop 'it]-i-ty a-kãra an-o hỹ?

QU morrer fazer-EPEN-OBL 2s-pensar 2s-ENF INTERR

"Quem você acha que morreu?"

(177) Particula 'hỹy' em pergunta de longa-distância

*[Morã Ivan oky]-ty hỹ a-kãra ano (hỹ)?

QU Ivan matar-OBL INTERR 2s-pensar 2s-ENF INTERR

Em suma, o movimento secundário de pronomes interrogativos não pode ser interpretado como uma espécie de movimento QU-. Essa conclusão está em consonância com o que vimos no caso das perguntas indiretas no capítulo 2, que não incluem pronomes interrogativos. No próximo capítulo, argumentamos que todas essas propriedades podem ser acomodadas se assumirmos que subordinadas não têm a projeção $\mathrm{CP}$, a posição para qual os pronomes interrogativos devem se mover na formação de perguntas. Além disso, essa proposta explicaria a impossibilidade de ' $h \tilde{y}$ ' ocorrer nestes ambientes também. Por fim, como a projeção CP estaria ausente em ambientes subordinados, o movimento de 'morã' em 174 seria para o especificador da projeção mais alta das subordinadas. Como veremos em $\S 4.3 .2$, essa posição seria Spec, $n \mathrm{P}$.

Uma outra pergunta muito mais complexa de ser respondida é a motivação por trás deste movimento. Em outras palavras, se a oração subordinada inteira passa a funcionar como o QU- e se desloca para Spec, CP, porque o elemento QU- precisa sofrer este deslocamento interno também? Em §4.3.2, vamos oferecer uma possível explicação para o movimento secundário, na qual a borda de domínios sintaticamente opacos tem grande importância.

\subsection{Resumo do capítulo}

Neste capítulo, apresentamos dados de perguntas QU- de longa distância em Karitiana. Vimos que a língua obrigatoriamente frontaliza toda a oração subordinada nestas construções em um processo chamado de pied-piping de larga-escala. Além disso, vimos que o Karitiana também recorre ao pied-piping quando um constituinte da subordinada é focalizado e também que essa operação não pode ser reinterpretada como uma mera frontalização, como em casos de construções de foco. Na próxima seção, discutiremos com maior profundidade a estrutura das subordinadas, argumentando que sua estrutura interna pode explicar a prevalência do pied-piping de larga-escala. 



\section{Estrutura das orações subordinadas}

Nos capítulos anteriores, nos dedicamos a examinar a formação de perguntas em sentenças bi-oracionais e vimos que o Karitiana emprega estratégias diferenciadas para construir perguntas indiretas e perguntas QU- de longa distância. Neste capítulo, argumentaremos que estas estratégias estariam diretamente relacionadas à estrutura das subordinadas na língua. Especificamente, proporemos uma modificação na estrutura das subordinadas de Storto (1999), incluindo nela um núcleo $n$ de natureza nominal. Veremos que esta característica seria responsável por grande parte do seu comportamento diferenciado, pois, em certa medida, as orações subordinadas se comportariam sintaticamente como sintagmas nominais complexos.

Na seção §4.1, revisamos as propriedades de subordinadas discutidas na literatura, dando ênfase nas características oracionais destas construções. Em §4.2, propomos uma estrutura nominalizada para estas construções e explicamos como ela daria conta dos dados de perguntas bi-oracionais em $\S 4.3$. Oferecemos ainda argumentos independentes para a estrutura com nominalização, como as tough-constructions (seção §4.4.1), a extração com verbos-factivos (§4.4.2), o fenômeno da cliticização (§4.4.3), e a existência de relativas de núcleo interno (§4.4.4). Por fim, discutimos como essa proposta pode lançar luz em certas propriedades do efeito V2 em $§ 4.5$.

\subsection{Propriedades das orações subordinadas}

No capítulo 1, apresentamos algumas propriedades de orações subordinadas em Karitiana. Dentre elas, vimos que elas não possuem pronomes relativos ou complementizadores, que o verbo aparece sem morfologia de concordância, tempo e modo e que a ordem de constituintes é obrigatoriamente verbo-final. O conjunto dessas propriedades, quando comparadas com orações matrizes, as faz parecer uma espécie de construção "defectiva".

Na literatura sobre a língua, autores como Storto (1999; 2011; 2012; 2013) e Rocha (2016) se debruçaram mais demoradamente sobre estas construções. Uma pergunta que eles buscam responder é se as propriedades "defectivas" poderiam ser um indicativo de nominalização, visto que subordinadas não contêm propriedades tipicamente oracionais como tempo e modo. Essa investigação tem como pano de fundo a ideia relativamente difundida de que a nominalização é uma estratégia de subordinação bastante presente em línguas indígenas da América, sobretudo naquelas faladas em território brasileiro. Por exemplo, Gijn, Haude e Muysken (2011) afirmam que a nominalização é a estratégia de subordinação mais comum nas línguas da América do Sul. Além disso, Dixon e Aikhenvald (1999) dizem que a nominalização em ambientes encaixados é um traço característico das 
línguas amazônicas. Sobre as línguas Tupi especificamente, Rodrigues e Cabral (2012) afirmam que a nominalização de subordinadas é uma estratégia frequentemente encontrada nas línguas desta família. Em contrapartida, Gijn, Galúcio e Nogueira (2015) afirmam que as línguas Tupi empregam estratégias bastante diversificadas de subordinação, sendo a nominalização uma delas. Contudo, eles também observam que a nominalização é bastante recorrente em casos de orações relativas, uma característica também observada por Gijn, Haude e Muysken (2011) para as línguas sul-americanas (sob o rótulo de "nominalização de participante').

Em Karitiana, o que nos leva a questionar se as orações subordinadas são ou não nominalizadas é seu comportamento ambíguo: por um lado, essas construções exibem uma série de propriedades oracionais; por outro, elas também têm comportamentos típicos de sintagmas nominais. Nas próximas seções, discutimos cada uma dessas propriedades mais demoradamente e apresentaremos também as propostas de Storto e Rocha para estas construções.

Mesmo não exibindo morfemas de tempo, aspecto e concordância, as subordinadas possuem diversas outras propriedades que as aproximam de orações matrizes. Segundo Storto (2012), diversos morfemas aspectuais que são encontrados em orações matrizes são igualmente possíveis em orações encaixadas: em 179, por exemplo, vemos que o aspectual 'tyka' é gramatical em um ambiente encaixado:

Marcador aspectual na oração matriz

I $\emptyset$-na-aka-t i-pon tyka-t

3s 3-DECL-COP-NFUT NMZ-atirar IMPF.MOV-CON.COP

"Ele está caçando."

(STORTO, 2012)

(179) Marcador aspectual em oração subordinada

Y-py-so'oot-yn yn [Inácio 'ep opi tyka]-ty

1-ASS-ver-NFUT 1s Inácio árvore cortar IMPERF.MOV-OBL

"Eu vi Inácio cortando a árvore."

(STORTO, 2012)

Rocha (2016) demonstra ainda que, salvo algumas combinações que geram problemas de interpretação, as orações subordinadas permitem quase todos os morfemas aspectuais. Assim, o paradigma em 178 e 179 não é um caso isolado, mas sim uma possibilidade em qualquer caso de subordinação.

Além disso, evidenciais também parecem ser permitidos em orações matrizes e subordinadas (VIVANCO, 2007; ALEXANDRE, 2016):

(180) Marcador evidencial na oração matriz

Tem Tema a-taka-m-tat- $\emptyset \quad$ saryt Botỹj

Tem Tema InV.DECL-DECL-CAUs-ir-NFut EVID Botỹj

"Tem Tema, Botỹj levou."

(STORTO, 1999) 
(181) Marcador evidencial na oração subordinada

$\emptyset$-pyry-hadna-n José [carro-ty Pedro amy saryt]-y-ty

3-ASS-dizer-NFUT José carro-OBL Pedro comprar IND.EVID-EPEN-OBL

"José disse que (diz que) Pedro comprou um carro."

(VIVANCO, 2007)

Rocha (2016) também aponta que, embora esteja em uma forma não finita em subordinadas, o verbo ainda retém certas propriedades tipicamente verbais, como mudanças de valência. Especificamente, é possível empregar em subordinadas tanto o causativizador -m- quanto o morfema de passiva - $a$-:

(182) Causativizador na matriz

$\emptyset$-py- $\underline{m-k e}$ on-y-n ti'y jonso

3-ASS-CAUS-esfriar-EPEN-NFUT comida mulher

"A mulher fez a comida esfriar."

(ROCHA, 2011)

(183) Causativizador na subordinada

Yn Ø-na-oky-t [pikom õwa ti-m-pykyn-a]

1s 3-DECL-matar-NFUT macaco criança INV-CAUS-correr-V.TEM

"Eu matei o macaco que a criança fez correr."

(ROCHA, 2016)

(184) Passiva na matriz

$\emptyset$-pyr-a - -tak- $y-n \quad$ gijo

3-ASS-PASS-pilar-EPEN-NFUT milho

"Pilaram o milho."

(ROCHA, 2011)

(185) Passiva na subordinada

Yn $\emptyset$-naka-'y-t ['ip a-otet byyk]

1s 3-DECL-comer-NFUT peixe PASS-cozinhar ASP.PFV

"Eu comi o peixe depois que ele foi cozido."

(ROCHA, 2016)

$\mathrm{Na}$ realidade, é possível inclusive que ambos apareçam concomitantemente em subordinadas, à semelhança do que ocorre na matriz:

(186) Causativizador e passiva em oração matriz

$\emptyset$-na-a-m-se'y-t jonso

3-DECL-PASS-CAUS-beber-NFUT mulher

"Fizeram a mulher beber."

(ROCHA, 2011)

(187) Causativizador e passiva em oração subordinada

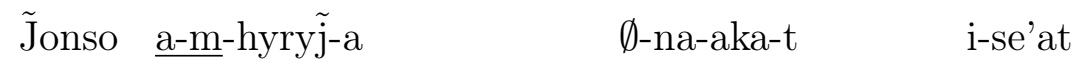
mulher PASS-CAUS-cantar-V.TEM $\emptyset$-DECL-COP-NFUT NMZ-bonito-CON.COP.

"A mulher que fizeram cantar é bonita."

(ROCHA, 2016) 
Por causa das propriedades verbais listadas acima, Storto (1999; 2011; 2012; 2013) e Rocha (2016) assumem que subordinadas são de fato orações, e não nomes. Elas, no entanto, seriam estruturas "menores"do que orações matrizes, na medida que incluiriam menos projeções sintáticas do que suas contrapartes matrizes. Especificamente, elas não conteriam os núcleos funcionais C, T, Agr, Mood e suas respectivas projeções. Na proposta original de Storto (1999), subordinadas seriam projeções de um núcleo Asp. Como marcadores evidenciais também são permitidos nestas construções, podemos reformular essa proposta assumindo que as subordinadas são projeções de um sistema flexional defectivo contendo apenas as projeções Evid e Asp:

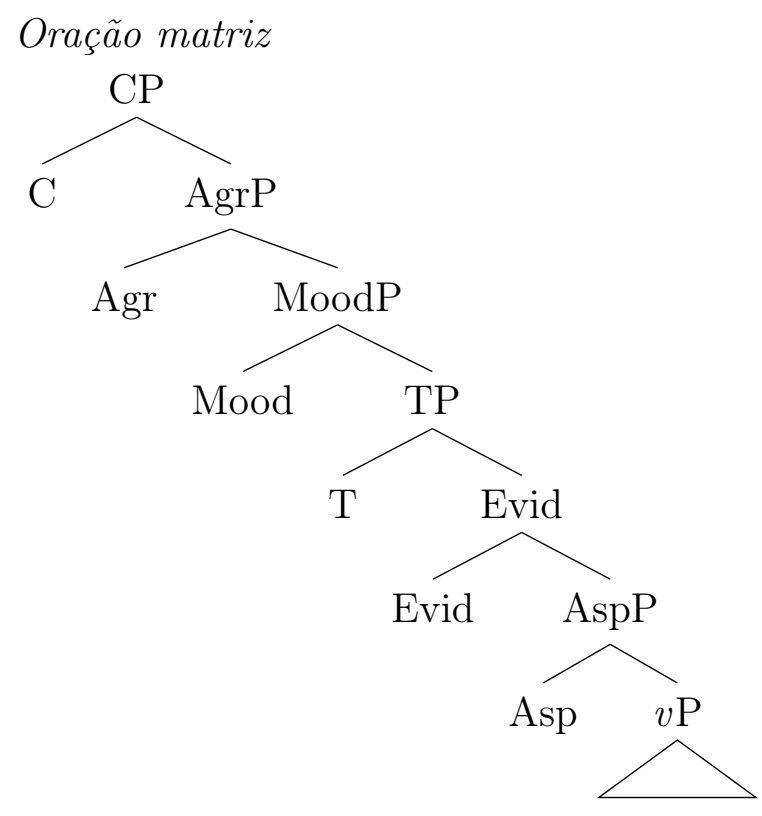

(189)

Oração subordinada

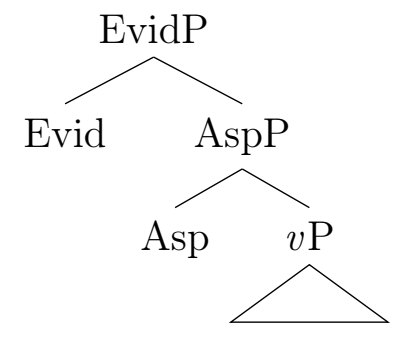

A vantagem da estrutura em 189 é de que ela é capaz de explicar duas propriedades de orações subordinadas. Primeiramente, seu caráter infinitivo explicaria a ausência dos núcleos referentes a concordância, modo e tempo na estrutura sintática. Além disso, 189 explica ainda porque as subordinadas retêm diversas propriedades verbais como alternâncias de valência: a estrutura do $v \mathrm{P}$ abaixo do AspP permanece inalterada e, tradicionalmente, é nesta parte da estrutura que mudanças de valência teriam lugar (veja por exemplo Hale e Keyser (2002)). 
Embora a estrutura em 189 acomode muitos comportamentos das subordinadas, ela não consegue capturar todas as suas propriedades. Especificamente, as subordinadas exibem também diversos comportamentos nominais que as distanciam de orações matrizes. O primeiro deles é a presença de nominalizadores em certos tipos de orações encaixadas. Como vimos anteriormente, Karitiana possui o sufixo nominalizador - $p a$, que converte verbos ou sintagmas verbais em nomes instrumentais ou locativos (STORTO, 1999; EVERETT, 2006):

\section{$\{-p a\}$ como nominalizador}

$$
\begin{aligned}
& \text { ambo -pa } \rightarrow \text { ambopa } \\
& \text { subir NMZ ("escada") }
\end{aligned}
$$

Vimos ainda que este morfema pode ser usado em orações subordinadas que trazem uma informação locativa, como uma pergunta indireta locativa. Além disso, ele também pode aparecer em uma oração relativa locativa:

\section{(191) Pergunta indireta locativa}

Ana i-sondyp-y-wak- $\emptyset$ [Ivan pytim'adn]-i-pa-ty.

Ana NMZ-saber-EPEN-DES-CON.COP Ivan trabalhar-EPEN-NMZ-OBL

"A Ana quer saber onde o Ivan trabalha."

(Literalmente: "A Ana quer saber do Ivan trabalhando.")

(192) Oração relativa locativa

Y-pyr-amynt-yn [cama taso kat-a-pa]-ty

1-ASS-comprar-NFUT [cama homem dormir-EPEN-NMZ]-OBL

"Eu comprei a cama onde o homem dormiu."

Outra propriedade nominal das subordinadas é de que estas construções são sufixadas por morfemas de caso como qualquer outro sintagma nominal da língua. Como se vê no exemplo 193, o verbo 'pyting' exige que seu argumento seja marcado com o morfema oblíquo -ty. Crucialmente, esse mesmo sufixo marca uma subordinada na posição de objeto de 'pyting' como em 194:

(193) Morfema oblíquo em sintagmas nominais

$\emptyset$-py-pyting-yn jonso opi-ty

3-ASS-querer-NFUT mulher brinco-OBL

"A mulher quer o brinco"

(ROCHA, 2011) 
(194) Morfema oblíquo em orações subordinadas

Yn $\emptyset$-na-aka-t i-pyting- $\emptyset \quad$ [gijo Luciana ti-tak]-a-ty.

1s 3-DECL-Cop-NFUT NMZ-querer-CON.COP. milho Luciana INV-pilar-EPEN-OBL

'Eu quero o milho que a Luciana pilou."

Não é óbvio se CPs recebem caso nas línguas do mundo (embora possivelmente eles tenham papéis temáticos como qualquer outro NP). Observemos primeiro o chamado caso estrutural, i.e., um tipo de caso que é atribuído em uma determinada posição sintática para que sintagmas nominais sejam licenciados (veja Pesetsky e Torrego (2011), entre outros). O paradigma em 195 mostra que um sintagma nominal - no caso, 'the book' precisa estar em uma posição em que ele receba caso estrutural, como a posição de sujeito em 195a. Tradicionalmente, se considera que a voz passiva absorve o caso atribuído aos objetos (BURZIO, 1986); dessa forma, um NP que não se move para a posição de sujeito não receberá caso. O resultado dessa derivação é então agramatical, como em 195b:

(195) NPs precisam de caso estrutural

a. [The book $]_{\mathrm{i}}$ was put $t_{\mathrm{i}}$ under the table.

b. *It was put [the book] under the table. (PESETSKY; TORREGO, 2011)

Crucialmente, o mesmo padrão observado para NPs em 195 não se repete com CPs, pois, ao contrário de NPs, eles não precisam se mover para a posição de sujeito para serem licenciadas em passivas:

CPs não precisam de caso estrutural

a. [That the world is round $]_{\mathrm{i}}$ was believed $t_{\mathrm{i}}$ by the ancient Greeks.

b. It was believed by the ancient Greeks [that the world is round]. (PESETSKY; TORREGO, 2011)

Além da posição de sujeito, sintagmas nominais também podem ser licenciados através de diversos marcadores, tal como preposições e marcadores oblíquos como o -ty do Karitiana. Sobre isso, Ross (2004) demonstrou que, quanto maior o grau "oracional" de uma construção, mais ela resistirá à marcação de caso através de uma preposição. Isso pode ser observado através das orações em 197, que, segundo um autor, formam um continuum de nominalização do "mais oracional" em 197a para o "mais nominal" em 197c. Como se vê no comportamento da preposição 'at' em cada caso, as orações menos nominalizadas 197a e 197b resistem à preposição, enquanto aquela mais nominalizada em 197c na realidade a exige: 
(197) Grau nominal das orações subordinadas e preposições

a. I was surprised (*at) that you had hives.

b. I was surprised (*at) to find myself underwater.

c. I was surprised *(at) Jim's retching.

(ROSS, 2004)

Dessa forma, o fato do morfema oblíquo - ty estar presente em subordinadas do Karitiana como 194 aproximaria estas construções de orações nominalizadas em outras línguas, como 197c.

Por fim, um exemplo de uma propriedade não oracional de subordinadas é o comportamento da negação nestes ambientes. Em orações matrizes, a negação sentencial é feita através do 'padni', cuja presença geralmente dispara uma epêntese (veja 7):

(198) Negação sentencial com 'padni'

Yn i-atik-i padni gopisop

1s 3-jogar-EPEN NEG lixo

"Eu não joguei o lixo."

(STORTO, 2017)

No entanto, a negação em orações subordinadas não é feita através do emprego de 'padni', mas sim através do sufixo - ki (D. LANDIN, 1984; STORTO, 2017):

(199) Negação -ki em oração subordinada

[Projeto Açaí pip a-tat-a-ki]-t $\quad$ y-ta-so'oot- $\emptyset \quad$ yn an-ty

projeto Açaí em 2s-ir-EPEN-NEG-ADVZ 1s-DECL-ver-NFUT 1s 2s-OBL

"Quando você ainda não tinha ido pro Projeto Açaí, eu te encontrei." (STORTO, 2017)

Como Landin (1984) já havia observado, a negação com -ki é bastante restrita e nunca é usada para construir enunciados negativos. ${ }^{1}$ Em muitos casos, o morfema $-k i$ pode ser considerado uma espécie de sufixo privativo que significaria algo como 'sem $x$ ' (STORTO, 2017).

(200) Negação -ki como privativo

Kyry-dna-ki

fígado-ADJZ-NEG

"Sem fígado"

(STORTO, 2017)

Em 201, 'sojoty hipiki' significaria 'sojoty sem cozinhar (=cru)' e 'taso osiiki' em 202 poderia ser 'homens sem osiipo (o ritual de iniciação)':

1 Segundo Storto (1999), a negação -ki também estaria presente em perguntas. 
(201) Negação-ki como privativo

An i-m-' $\tilde{y}-j \quad h \tilde{y}, \quad$ sojoty hip-i-ki hỹ?"

2s 3-CAUS-comer?-FUT INTERR sojoty cozinhar-EPEN-NEG INTERR

"Você vai aplicar o sojoty cru?"

["Osiipo"]

(202) Negação -ki como privativo

Taso osii-ki i-oky padni keerep him

homem osiip-NEG 3-matar NEG antigamente caça

"Os homens sem o osiip não matavam caça antigamente'

["Osiipo"]

Em resumo, o comportamento da negação distancia orações subordinadas de orações matrizes. Vale lembrar que essa situação é semelhante ao que ocorre em construções nominalizadas como os action nominals, um tipo de nominalização lexical como 'O João vendeu o carro' $\rightarrow$ 'A venda do carro pelo João'. ${ }^{2}$ Segundo Koptjevskaja-Tamm (2002) e Comrie e Thompson (2007), algumas línguas não preservam a negação sentencial nestes tipos de nominalização. Em Inglês, por exemplo, a negação sentencial é 'not', enquanto a negação nominal é o prefixo non-. Como se vê no exemplo abaixo, action nominals fazem uso da negação nominal (COMRIE; THOMPSON, 2007):

(203) Negação em orações e sintagmas nominais

a. Harry is not my brother.

b. This is a non-party.

(COMRIE; THOMPSON, 2007)

(204) Negação em action nominals

a. Gloria's non-participation in the meeting surprised me.

b. *Gloria's not participation in the meeting surprised me.

(COMRIE; THOMPSON, 2007)

Assim, ainda que a estrutura em 189 consiga capturar o caráter não finito das orações subordinadas, algo ainda precisa ser dito para que o comportamento não oracional e/ou nominal destas construções seja igualmente contemplado.

Além de não conseguir capturar todos os comportamentos nominais das orações subordinadas, a estrutura em 189 também não consegue explicar um fenômeno de perguntas complexas: o pied-piping de larga-escala. Vimos em 1 que, para construir perguntas QU-, Karitiana move o pronome interrogativo para a primeira posição. Nos casos de perguntas de longa distância, contudo, esse movimento deve necessariamente incluir a oração

2 De forma geral, empregamos diversos exemplos action nominals como exemplos prototípicos de nominalização. Contudo, é preciso pontuar que alguns autores fazem a distinção entre action nominals e nominalização oracional (clausal nominalization). Grosso modo, a diferença entre elas é que, no último caso, "não há evidência a favor de se ver o núcleo daquele sintagma como um nome lexical" (COMRIE; THOMPSON, 2007, tradução nossa). Porém, como observa Koptjevskaja-Tamm (2002), muitas línguas não parecem distinguir as duas construções. 
inteira contendo o pronome interrogativo, como discutimos no capítulo 3. Nossa conclusão foi então que a oração subordinada constituiria uma espécie de domínio opaco (no sentido de Chomsky (1986a)) para o movimento do pronome interrogativo; nesse cenário, veremos em $\S 4.3 .2$ que a única forma lícita de se construir perguntas de longa distância seria através do movimento do domínio todo (i.e., pied-piping de larga escala).

O problema da estrutura 189 é que, tradicionalmente, orações não finitas tendem a ser mais "porosas" do que construções finitas - ou seja, elas na realidade têm constituintes mais acessíveis do que suas contrapartes flexionadas (veja por exemplo Boskovic (2015)). No caso de construções de raising, como 205, o movimento do NP para a posição de sujeito da matriz é lícito quando a oração é não finita, mas proibido quando ela é um CP (cf. 206):

(205) Raising com infinitivo

$\mathrm{He}_{\mathrm{i}}$ seems [ $t_{\mathrm{i}}$ to have left early]

(BOSKOVIC, 2015)

(206) Raising com CP

* $\mathrm{He}_{\mathrm{i}}$ seems [that $t_{\mathrm{i}}$ left early]

Se a estrutura 189 tal como foi inicialmente formulada estivesse correta, seria esperado então que as subordinadas facilitassem o movimento de seus constituintes, não o impedissem como vemos nos casos de perguntas de longa-distância. Dessa forma, a estrutura em 189 não é suficiente para explicar o comportamento das subordinadas em sua totalidade. Por conta disso, a reformulamos ligeiramente na próxima seção para contemplar os novos dados aqui descritos.

\subsection{Proposta}

Nesta seção, apresentamos uma modificação da estrutura em 189 que capturaria os comportamentos nominais das orações subordinadas e também as perguntas bioracionais descritas nas seções anteriores. Primeiramente, é preciso explicitar o arcabouço teórico que embasa nossa discussão. Assumiremos que, no domínio das orações, não existem categorias discretas, mas sim um continuum de nominalização (BORSLEY, 2000; KOPTJEVSKAJA-TAMM, 2002; ROSS, 2004; COMRIE; THOMPSON, 2007; BAKER, 2011). Nas palavras de Baker:

"A teoria gerativa das categorias é prototipicamente discreta. Uma coisa ou é um nome, ou não é. [...] Essa propriedade discreta parece bem justificada para categorias morfológicas simples e básicas. [...] Contudo, na área de nominalização/complementação, pode-se observar uma continuidade, aparentemente. Algumas orações subordinadas parecem ter muitas propriedades nominais e poucas propriedades oracionais; outras têm poucas propriedades nominais e mais propriedades oracionais."(BAKER, 2011, tradução nossa) 
Esse comportamento misto descrito por Baker é frequentemente encontrado nas línguas quando examinamos constituintes maiores do que palavras. Em Coreano, por exemplo, um action nominal retêm grande parte de suas propriedades oracionais, como o tempo e a marcação de caso:

(207) Tempo e caso em oração nominalizada

[Coreano]

[kŭnyə ka motŭn ton ŭl kacy-əs'-ki] t'æmun e kŭ nŭn kunyə ka ela NOM todo dinheiro ACC ter-PAST-AN razão em ele NOM ela ACC pilyoh-æs'-ta.

precisar-PAST-FIN

"Ele precisava dela porque ela tinha todo dinheiro." (KOPTJEVSKAJA-TAMM, 2002)

Em Polonês, os action nominals preservam distinções aspectuais, como entre perfectivo/imperfectivo.

(208) Distinção imperfectivo/perfectivo em construção nominalizada

[Polonês]

a. Czytanie tej książki dało dużo radości

"O [processo de] ler aquele livro me deu muito prazer."

b. Przeczytanie tej książki dało dużo radości

"[A totalidade do ato de] ler aquele livro me deu muito prazer." (COMRIE; THOMPSON, 2007)

Além disso, é possível que construções nominalizadas exibam ainda alternâncias de valência. Em Turco, por exemplo, um action nominal pode ser ativo como 209a ou

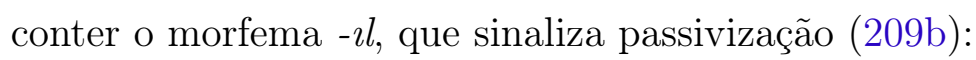

(209) Distinção ativo/passivo em construção nominalizada

[Turco]

a. Hasan-in mektub-u yaz-ma-s1

Hasan-GEN carta-ACC escrever-VN-dele

"A escrita de Hasan da carta"

b. Mektub-un (Hasan tarafindan) yaz-1l-ma-s1

carta-GEN Hasan por escrever-PASS-VN-dele

"A carta sendo escrita (por Hasan)'

(COMRIE; THOMPSON, 2007)

Em Polonês, há ainda a possibilidade de marcar uma alternância causativaincoativa em action nominals:

(210) Alternância causativa-incoativa em construção nominalizada

[Polonês]

a. Otwieranie drzwi

"a abertura da porta (por alguém)"

b. Otwieranie siędrzwi

"a abertura da porta (possivelmente espontânea)" (COMRIE; THOMPSON, 2007) 
Em suma, estes dados mostram que certas construções podem exibir uma mistura de propriedades oracionais e nominais. Nesse sentido, uma oração nominalizada pode ser então definida como um tipo de construção que retêm tanto propriedades oracionais quanto nominais e que pode, a depender da língua, estar mais ou menos próximo de orações finitas ou de sintagmas nominais. Como as orações do Karitiana também exibem um comportamento misto, com propriedades oracionais (como marcadores aspectuais e evidenciais, os processos de mudança de valência) e nominais (nominalizadores, marcação de caso, ausência da negação sentencial), nossa definição implicaria que as orações subordinadas do Karitiana seriam de fato construções nominalizadas.

Dito isso, como podemos capturar os diversos graus de nominalização estruturalmente? Na linguística formal, há duas principais propostas: a de Ross (2004) e a de Borsley e Kornfilt (2000)/Baker (2011). No primeiro caso, o autor propõe atribuir às construções em um continuum nominal um valor de 1.0 (+oracional, -nominal) a 0.0 (oracional, +nominal). As construções intermediárias seriam ordenadas linearmente entre estes dois polos e receberiam valores entre 1.0 e 0.0. Um dos problemas dessa proposta é de que talvez seja complicado para algumas línguas definir em que ponto exato do continuum certas construções se localizam. Se consideramos por exemplo "O João ler o livro" ou "O João lendo o livro", como definir qual destas construções estaria mais próxima do polo [+oracional]?

Outro problema é que as diversas restrições sintáticas têm que ser flexibilizadas para conter os valores das construções a que se aplicam. Por exemplo, determinadas regras sintáticas só se aplicariam a construções com um determinado valor $x$, sendo que $x$ pode ainda ser "maior ou menor que $y$ ". Essa proposta faz parte então de uma gramática muito mais complexa - e, portanto, muito mais difícil de ser adquirida por uma criança. Em outras palavras, teríamos um problema de adequação explicativa, nos termos de Chomsky (1986).

Na proposta de Borsley e Kornfilt (2000) e Baker (2011), as propriedades mistas destas construções nominalizadas podem ser explicadas pela associação da estrutura oracional com certos núcleos de natureza nominal. Em outras palavras, as diferentes composições e arranjos de núcleos funcionais de natureza verbal e nominal espelhariam o comportamento misto destas construções.

A partir dessa proposta, modificaremos ligeiramente a estrutura em 189 para conter uma projeção de um núcleo $n$, de natureza nominal e foneticamente nulo na maioria dos casos: ${ }^{3}$

3 Optamos pela minúscula $n$ para enfatizar que este núcleo pode apenas ser foneticamente realizado como uma forma presa, como os sufixos - pa e - a (veja a discussão no capítulo 5). Além disso, $n$ parece traduzir melhor a função morfossintática deste núcleo, que é a de derivar sintagmas nominais complexos a partir de outros tipos de projeções. 
(211) Estrutura nominalizada das orações subordinadas

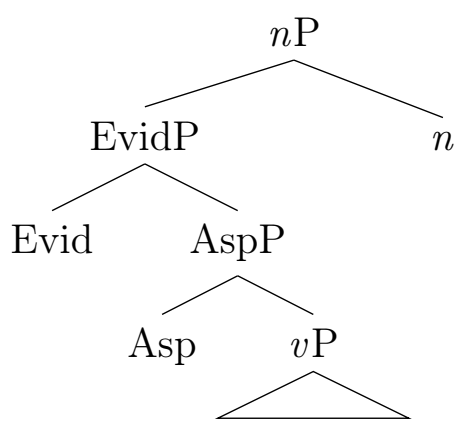

Bem como a estrutura sem o nominalizador em 189, 211 também explica a ausência de complementizadores, tempo, modo e concordância através da ausência das projeções responsáveis por essas marcações. Além disso, alternâncias de valência continuam sendo possíveis, pois a estrutura abaixo do $v \mathrm{P}$ permanece inalterada. Contudo, diferentemente de 189, 211 é capaz de capturar diversos comportamento nominais destas construções. Primeiramente, por serem em última instância um sintagma nominal e não um $\mathrm{CP}$, as orações subordinadas precisam de caso como qualquer outro sintagma nominal na língua, o que explicaria a emergência do sufixo - ty nestes ambientes. Além disso, por mais que o núcleo $n$ seja nulo em muitos casos, existem dois casos em que ele possivelmente teria conteúdo fonológico: o caso das subordinadas locativas com -pa (veja 191 e 192) e possivelmente algumas subordinadas marcadas com o sufixo - $a$, que serão mais bem discutidas no capítulo 5. Dessa forma, a própria existência destes nominalizadores abertos justifica a proposição de um núcleo nominal na estrutura em 211.

Nas próximas seções, discutimos como 211 explicaria os dados de perguntas bioracionais vistos nos capítulos 2 e 3 . Além disso, argumentamos ainda que a estrutura em 211 é capaz de iluminar diversos fatos à primeira vista não relacionados, como a ausência de tough-constructions (seção §4.4.1), a formação de perguntas com verbos factivos (seção $\S 4.4 .2$ ), o fenômeno da cliticização em orações subordinadas (§4.4.3) e a existência de relativas de núcleo interno (§4.4.4). Além disso, discutiremos algumas implicações desta proposta que eliminam certas complicações sobre o efeito V2 em $\S 4.5$.

\subsection{A estrutura das subordinadas e perguntas bi-oracionais}

Nesta seção, discutiremos como a estrutura proposta em 211 explicaria os dados de perguntas bi-oracionais expostos nos capítulos 2 e 3. No caso das perguntas indiretas, veremos que tanto a estrutura sem o núcleo nominal quanto àquela com o núcleo nominal conseguem em geral capturar o padrão observado nestas construções, pois o relevante aqui é que a projeção CP esteja ausente. Contudo, veremos em $\S 4.3 .2$ que o pied-piping em 
perguntas de longa-distância é mais bem explicado se assumirmos 211 e que, portanto, a existência deste fenômeno constitui uma evidência a seu favor.

\subsubsection{Perguntas indiretas}

Vimos no capítulo 2 que a forma prototípica de se construir uma pergunta indireta em Karitiana é sem a palavra QU-:

\section{(212) Pergunta indireta}

Karin $\emptyset$-na-aka-t i-sondyp-y-wak- $\emptyset$ gooj-o Ana

Karin 3-DECL-COP-NFUT NMZ-saber-EPEN-DES-CON.COP carro-O Ana

hãraxa-ty.

consertar-OBL

"A Karin quer saber como a Ana consertou o carro."

(Literalmente: "Karin quer saber da Ana consertando o carro")

\section{(213) Pergunta indireta locativa}

Ana i-sondyp-y-wak- $\emptyset \quad$ Ivan pytim'adn-i-pa-ty.

Ana NMZ-saber-EPEN-DES-CON.COP Ivan trabalhar-EPEN-NMZ-OBL

"A Ana quer saber onde o Ivan trabalha."

(Literalmente: "A Ana quer saber do Ivan trabalhando.")

Se assumirmos uma estrutura para as orações subordinadas que não contém o núcleo $\mathrm{C}$ e a projeção máxima correspondente, o padrão em 212 se explica. Tradicionalmente, pronomes interrogativos ocupam a posição de Spec,CP (CHOMSKY, 1986b); como as subordinadas do Karitiana não incluiriam esta projeção, não há como haver perguntas indiretas como as do Inglês ou do Português, nas quais o pronome interrogativo se localizaria em Spec, CP.

Aqui, é justo pontuar que tanto a estrutura sem o núcleo nominal em 189 quanto 211 são capazes de explicar o comportamento de construções como 212. Contudo, a estrutura em 211 tem a vantagem adicional de capturar uniformemente todas as perguntas indiretas, incluindo aquelas incluindo o morfema nominalizador - $p a$. Como vimos anteriormente, as subordinadas com o - $p a$ são as únicas orações encaixadas que têm um nominalizador foneticamente pronunciado (mas veja o capítulo 5). Crucialmente, vimos também que - $p a$ está presente em perguntas indiretas locativas:

\section{(214) Pergunta indireta locativa}

Ana i-sondyp-y-wak- $\emptyset$

Ivan pytim'adn-i-pa-ty.

Ana NMZ-saber-EPEN-DES-CON.COP Ivan trabalhar-EPEN-NMZ-OBL

"A Ana quer saber onde o Ivan trabalha."

(Literalmente: "A Ana quer saber do Ivan trabalhando.") 
Embora a estrutura em 189 seja capaz de explicar a ausência da palavra para 'onde' no dado acima, algo precisa ser dito para capturarmos a presença de -pa. Se assumirmos a estrutura com o núcleo $n$ em 211, essas duas propriedades podem ser igualmente capturadas.

Em suma, a estrutura em 211 é capaz de elucidar a inexistência de perguntas indiretas na língua, oferecendo ainda uma explicação única para todas as construções deste tipo.

\subsubsection{QU- de longa distância}

Na última seção, discutimos como a estrutura em 211 explicaria o comportamento das perguntas indiretas. Nesta seção, examinamos o segundo tipo de pergunta em ambiente bi-oracional discutido nos capítulos anteriores: as perguntas QU- de longa distância.

Ao contrário das perguntas indiretas (que, strictu sensu, não existem em Karitiana) a língua de fato possui perguntas de longa distência. No entanto, vimos que ela faz uso de uma estratégia particular nestes ambientes: o pied-piping de larga escala. Para capturar este fenômeno em sua totalidade, precisamos antes discutir a natureza do pied-piping para então elucidarmos como exatamente 211 estaria relacionada ao comportamento destas construções.

Nas línguas do mundo, parece haver uma implicação: sempre que o movimento para fora de um determinado domínio sintático é permitido, pied-piping é bloqueado (HECK, 2008; 2009). ${ }^{4}$ No exemplo 215, observamos que o movimento do sintagma nominal para fora do PP é permitido em dinamarquês; desta forma, pied-piping do PP é bloqueado em 216:

(215) Movimento para fora de PP

[Dinamarquês]

Jeg gad vide hvemi du har snakket [PP med $t_{\mathrm{i}}$.

eu gostaria saber quem você tem falado com

"Eu gostaria de saber com quem você falou."

(HECK, 2008)

(216) Impossibilidade de pied-piping

[Dinamarquês]

*Jeg gad vide [PP med hvem $]_{\mathrm{i}}$ du har snakket $t_{\mathrm{i}}$

Eu gostaria saber com quem você tem falado

"(Pretendido) Eu gostaria de saber com quem você falou."

(HECK, 2008)

Alternativamente, quando o movimento pra fora de um determinado domínio é proibido, pied-piping pode salvar a derivação em algumas línguas. Em Tzotzil, por exemplo, o movimento de um sintagma nominal para fora de um sujeito é proibido (veja 217), e pied-piping é a estratégia de reparo para evitar agramaticalidade (AISSEN, 1996):

4 Há casos problemáticos em que o pied-piping parece ser opcional, como ocorre no Inglês. No entanto, alguns falantes somente aceitam o pied-piping quando esta operação for forçada - por exemplo, dentro de adjuntos. Além disso, argumenta-se que, mesmo para aqueles que aceitam o pied-piping opcionalmente, estas construções pertencem a um registro diferente. Para mais informações sobre a opcionalidade do pied-piping, veja Heck (2008; 2009). 
(217) Movimento com NP em posição de sujeito

[Tzotzil]

*Buch'u $u_{\mathrm{i}}$ y-elk'an chij [ $t_{\mathrm{i}} \mathrm{x}$-ch'amal $]$ ?

quem A3-roubar ovelha A3-criança

'(Pretendido) "A criança de quem roubou ovelhas?"

(AISSEN, 1996)

(218) Pied-piping com NP na posição de sujeito

[Tzotzil]

[Buch'u x-ch'amal $]_{\mathrm{i}}$ y-elk'an chij $t_{\mathrm{i}}$ ?

quem A3-criança A3-roubar ovelhas?

"A criança de quem roubou ovelhas?"

(AISSEN, 1996, adaptado)

Dessa forma, pied-piping parece ser uma estratégia de último recurso, empregada quando o movimento para fora de um determinado domínio é proibido (HECK, 2008; 2009). Crucialmente, o pied-piping de larga-escala é uma estratégia empregada para evitar violações de ilhas sintáticas em línguas que possuem essa opção (COLE, 1982; URBINA, 1993; CABLE, 2010). Uma ilha sintática é um termo cunhado por Ross (1967) para designar um determinado domínio sintático do qual não é possível extrair nenhum constituinte. Certas orações subordinadas, como orações relativas, orações adverbiais e perguntas indiretas, são exemplos clássicos de ilhas sintáticas.

Nas perguntas de longa distância do Quechua de Imbabura, a oração subordinada inteira deve ser frontalizada se ela for uma relativa (COLE, 1982):

(219) Pied-piping de larga-escala com ilhas (oração relativa) [Quechua de Imbabura]

a. *Ima-ta-taj $\mathrm{j}_{\mathrm{i}}$ riku-rka-ngui [ $t_{\mathrm{i}}$ randi-shka runa-ta]? o.que-ACC-INT ver-PAST-2 comprar-NMLZ homem-ACC

'O que você viu [o homem que comprou]?"

b. [Ima-ta randi-shka runa-ta-taj] riku-rka-ngui? o.que-ACC comprar-NMLZ homem-ACC-INT ver-PAST-2

'(Literalmente) [O homem que comprou o quê] você viu?" （COLE, 1982, adaptado)

Por conta dessa propriedade, o pied-piping de larga-escala tem inclusive sido estendido para casos menos óbvios de violações de ilhas. Em algumas línguas, um pronome interrogativo pode ocorrer dentro de uma ilha se ele não se mover. É o caso do japonês:

(220) Pronome interrogativo in situ dentro de ilha

[Japonês]

Taroo-ga [nani-o te-ni iretakoto]-o sonnani okotteru no?

Taro-NOM o.que-ACC obteve fato-ACC tão muito estar bravo Q

"Você está muito bravo pelo fato do Taro ter obtido o quê?"

(CHOE, 1987)

Assumindo que mesmo em línguas com QU- in situ o pronome interrogativo deve se mover cobertamente, algo precisaria ser dito para que uma violação de ilha seja evitada em 220. Assim, se propôs que línguas com a configuração em 220 lançariam mão do piedpiping de larga-escala em LF, ou seja, a frontalização da oração subordinada ocorreria sem nenhum reflexo fonológico (CHOE, 1987; PESETSKY, 1987). 
Considerando então a natureza do pied-piping e o fato do pied-piping de largaescala ser obrigatório com todos os nossos tipos de perguntas de longa distância (veja 136139), podemos então concluir que as subordinadas em Karitiana são domínios opacos para movimento - em outras palavras, elas seriam ilhas sintáticas. Nesse sentido, o movimento da palavra QU- em perguntas simples é gramatical, pois não há a intervenção de nenhuma barreira; por outro lado, como as orações subordinadas seriam ilhas, o movimento do pronome interrogativo é proibido e o pied-piping de larga-escala é a estratégia empregada para se evitar agramaticalidade.

Por mais que todas ilhas sintáticas tenham em comum a propriedade de barrar movimento, cada uma delas tem propriedades distintas. Assim, a conclusão acima nos leva então a questionar que tipo de ilha as subordinadas do Karitiana seriam. Neste ponto, a estrutura nominalizada em 211 pode esclarecer a questão. Em Karitiana, sintagmas nominais parecem ser ilhas para extração, como se nota ao tentar extrair o possuidor em 221. Dessa forma, o pied-piping é a estratégia empregada para evitar agramaticalidade em $222:^{5}$

(221) Extração de dentro de NPs sem pied-piping

*Morã $\tilde{\mathrm{i}}^{-\mathrm{mon}}$ Ivan ti-'y-t [t $\quad$, gok]?

QU-COP.INT. Ivan INV-comer-CON.COP. mandioca

(222) Extração com NPs com pied-piping

[Morã gok $]_{i}$-O-mon Ivan ti-'y-t?

QU mandioca-EPEN-COP.INT. Ivan INV-comer-CON.COP.

"A mandioca de quem o Ivan comeu?"

Assim, as subordinadas se comportariam como qualquer outro sintagma nominal na língua na medida em que não permitiriam extração de nenhum de seus constituintes.

Essa restrição de movimento com subordinadas pode estar relacionada à chamada Complex NP Constraint, que foi originalmente proposta por Ross (1967) para explicar a impossibilidade de se extrair elementos para fora de sintagmas nominais complexos como

$\overline{5}$ Adjetivos parecem ser uma exceção, na medida em que eles não disparam pied-piping obrigatoriamente:

(v) Maria $\emptyset$-na-aka-t i-mana-t taso hãraj-ty.

Maria 3-DECL-COP-NFUT NMZ-casar-NFUT homem bonito-OBL

"A Maria casou com um homem bonito."

(vi) a. [Morã horot] i-amy pykyp-y-ty Karin? QU COMP 3-comprar roupa-EPEN-OBL Karin

"A Karin comprou uma roupa como?"

b. [Morã horot pykyp aka]-ty i-amy Maria? QU COMP roupa COP-OBL 3-comprar Maria

'A Maria comprou uma roupa como?"

Esse tipo de extração será mais bem discutida no capítulo 7, no qual examinamos as relações entre fenômenos prosódicos como a epêntese e o movimento sintático. 
subordinadas nucleadas por 'fact'/'claim' ou de orações relativas (mas veja Boskovic (2015) para uma aplicação mais ampla desta regra).

(223) Complex NP Constraint

Nenhum elemento contido em uma sentença dominado por um sintagma nominal com um núcleo nominal lexical pode se mover para fora deste sintagma nominal por uma transformação.

(ROSS, 1967, tradução nossa)

(224) CNPC operativo

$*$ The hat $_{\mathrm{i}}$ which I believed [the claim that Otto was wearing $t_{\mathrm{i}}$ ] is red. (ROSS, 1967)

Em resumo, a estrutura em 211 é capaz de explicar a existência do pied-piping de larga-escala em Karitiana ao considerarmos que as orações subordinadas são construções nominalizadas. Assim, o movimento de qualquer um de seus constituintes seria uma violação da CNPC em 223.

Além disso, nossa proposta de que as orações subordinadas seriam uma espécie de sintagma nominal complexo pode ainda explicar o movimento secundário em perguntas de longa-distância, tal como discutido na seção §3.3.4. Basicamente, observamos que, em casos de pied-piping de larga-escala, o pronome interrogativo deve adicionalmente se mover para a borda da oração subordinada:

Movimento secundário em pied-piping

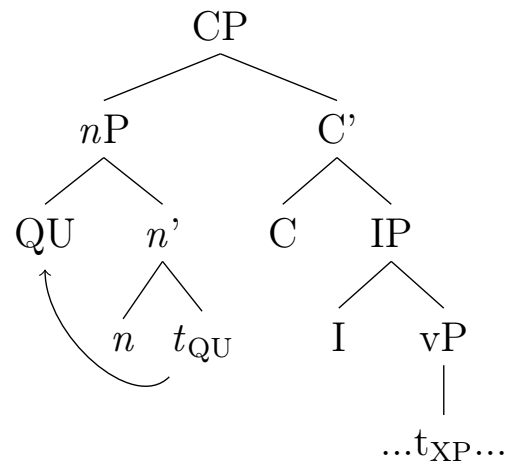

Talvez este movimento secundário possa ser capturado se assumirmos que Spec, $n \mathrm{P}$ é uma posição privilegiada dentro da subordinada, pois seria a única passível de ser acessada por elementos fora desse domínio. Dentro da teoria sintática sobre movimento, os domínios sintáticos CP e $v \mathrm{P}$ seriam fases, ou seja, domínios sintáticos inacessíveis para operações fora dele (CHOMSKY, 2001). Este princípio é formalizado na seguinte restrição, tradicionalmente conhecida como a condição de impenetrabilidade de fases:

(226) Condição de impenetrabilidade de fases

[Para uma fase forte HP com o núcleo H,] o domínio de H não é acessível a operações fora de $\mathrm{H}$; somente $\mathrm{H}$ e sua borda são acessíveis para tais operações.

(borda da fase: posições de adjunto e especificador)

(CHOMSKY, 2001) 
A consequência de 226 é que se um determinado elemento tiver que estabelecer alguma relação sintática com um elemento dentro da fase, este último deve se mover para a borda da fase para ser acessível a tais operações. Em última instância, essa restrição implementa o movimento cíclico sucessivo em 128.

Se assumirmos que sintagmas nominais também são fases, então sua posições de especificadores também podem ser incluídas na definição de borda da fase acima (nas linhas de Longobardi (1991)). Assim, a posição de Spec, de $n$ P, para a qual o elemento QU- se move, é uma posição privilegiada: por um lado, ela permite que o pronome interrogativo estabeleça relações com elementos fora da subordinada, como o $\mathrm{C}_{[\mathrm{QU}]}$; por outro, o elemento QU- não pode se mover além, pois a oração nominalizada é uma ilha sintática. Em outras palavras, o movimento para a borda do sintagma nominal é uma forma de o pronome interrogativo interagir com elementos da matriz sem violar as restrições de ilha.

\subsubsection{Orações subordinadas adverbiais}

Nossa proposta é de que as orações subordinadas do Karitiana seriam construções nominalizadas em um certo grau, o que, por sua vez, seria responsável por disparar o piedpiping de larga-escala. Desta forma, nossa discussão parece sugerir uma implicação: se uma determinada pergunta de longa-distância envolve pied-piping de larga-escala, então a subordinada nela presente é necessariamente uma construção nominalizada. Nessa linha de raciocínio, uma oração adverbial como 227 abaixo seria também classificada como uma construção nominalizada:

$$
\begin{aligned}
& \text { Pied-piping de larga-escala com oração subordinada adverbial } \\
& \text { [ambi-sok jonso otam byyk- } \emptyset] \quad \text { }] \text {-na-oky-t him taso } \\
& \text { casa-em mulher chegar PERF.ASP.-ADVZ } 3 \text {-DECL-matar-NFUT caça homem } \\
& \text { "Depois que a mulher tinha chegado em casa, o homem matou a caça." }
\end{aligned}
$$

(ROCHA, 2016)

Contudo, parecem existir diferenças importantes entre as diversas orações subordinadas examinadas neste trabalho. Vejamos os exemplos em Português abaixo:

\section{Oração subordinada completiva}

"O João acha [que Maria foi pra praia.]

Oração subordinada relativa

"O João comeu [o bolo que a Maria fez.]

(230) Oração subordinada adverbial

"A Maria lavou a louça [depois que o João cozinhou.]

Nos dados acima, vemos que todas as orações em parênteses não podem ocorrer de forma autônoma, estando sempre condicionadas à existência de uma oração matriz. 
Contudo, existem diferenças sintáticas importantes entre as orações 228-229 e aquela em 230. No caso das completivas e relativas, a oração é um argumento do verbo principal, ou seja, ela é uma parte essencial da oração matriz. Já as orações adverbiais são acessórias, na medida em que elas não são essenciais para saturar o predicado da oração matriz.

Em Karitiana, as orações adverbiais se assemelham a completivas e relativas por não conterem uma série de propriedades oracionais, como concordância, modo e tempo. Porém, é de se questionar se, nestes casos, há de fato uma nominalização: se uma nominalização implicaria na criação de um sintagma nominal - que, por definição, é um elemento saturado, que atua prototipicamente como argumento de um predicado -, um advérbio/adjunto não deveria poder atuar como um sintagma nominal e vice-versa.

Para solucionar esta questão, há duas possibilidades. Primeiramente, podemos assumir que as adverbiais são de fato construções nominalizadas, mas que sofreriam ainda um outro processo derivacional que as transformaria em adjuntos. Como veremos à frente, uma proposta nessa linha de raciocínio foi desenvolvida para explicar a construção de cópula em Karitiana. Em segundo lugar, podemos advogar por um tratamento à parte das orações adverbiais, propondo que, em contraposição às completivas e relativas, elas de fato não seriam construções nominalizadas. Discutiremos cada uma dessas propostas detalhadamente abaixo.

Na primeira proposta, as orações adverbiais seriam nominalizadas como qualquer outra subordinada na língua. ${ }^{6}$ Para ocupar posições tipicamente adverbiais, as orações nominalizadas devem sofrer um processo derivacional que transforme nomes em adjuntos. Um processo similar foi reportado em línguas família Karib - porém, de forma inversa. Segundo Meira (no prelo), existe na língua Tiriyó uma classe de adjetivos/advérbios nominalizados:

\section{(231) Nominalização de advérbio}

[Tiriyó]

pena-to

tempos.atrás-NZR

"um antigo'

(MEIRA, no prelo)

Se as línguas Karib instanciam casos em que nomes são derivados a partir de advérbios, é possível talvez haver derivações de advérbios a partir de nomes. Esta operação seria então instanciada pelas orações adverbiais do Karitiana, que se tornariam

6 Sobre isso, é importante relembrar que estas construções de fato exibem comportamento que classificamos como tipicamente nominais, como o uso de marcas de pessoas presas (que reanalisaremos com possessivos em 4.4.3):

(vii) Marcas de pessoa em orações adverbiais [Yj-kikin byyk], Ø-na-pyn-hot- $\emptyset$ y-'et-e-'et 'ej-e-kyn. 1pl-chorar PERF. 3-DECL-DEON-ir-NFUT 1s-filho-EPEN-filho túmulo-EPEN-LAT "Depois de chorarmos, tem que ir pro túmulo, meu neto." 
adjuntos a partir da sufixação da morfologia característica, como o sufixo adverbializador - $t$ (STORTO, 1999; SANCHEZ-MENDES, 2014; ROCHA, 2016) e os marcadores aspectuais (tal como 'byk' em 227).

$\mathrm{Na}$ própria língua Karitiana, existem casos em que isso supostamente ocorre. Como mencionamos na seção §1.3.3, verbos intransitivos podem ser empregados na construção de cópula se forem nominalizados através do prefixo $i$ - e sufixados pelos morfemas - $t$ ou $\emptyset$ :

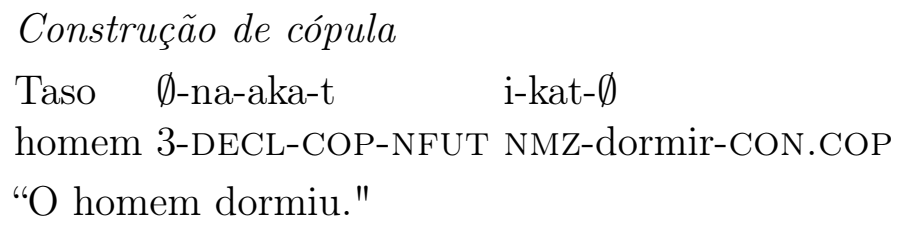

Rocha (2016) analisa os alomorfes - $t$ e - $\emptyset$ da construção de cópula como adverbializadores, já que eles seriam homófonos ao morfema adverbializador na língua. Além disso, ele cita em respaldo à sua análise o exemplo abaixo de Tiriyó, no qual o complemento da cópula possuiria concomitantemente um morfema adverbializador e um particípio:

Construção de cópula

[Tiriyó]

$$
\text { apë=n-ai } \quad \text { t-[ee-pahka-e] }
$$

$3 \mathrm{ASS}=3 \mathrm{~S}_{\mathrm{A}}$-COP ADVZR.PART-S $\mathrm{A}_{\mathrm{A}}$-INTRZR-quebrar-PART

"Seu assento está quebrado."

(MEIRA, 1999 apud ROCHA, 2016)

Dessa forma, o processo morfológico de derivação de um advérbio a partir de um nome pode ser encontrado tanto em outras línguas como em outras construções da própria língua Karitiana, o que abre a possibilidade de este tipo de operação ocorrer com orações adverbiais também.

Uma outra alternativa é não considerar as orações adverbiais como construções nominalizadas. Nesse caso, o pied-piping de larga-escala poderia ser explicado se assumirmos que estas construções ainda seriam ilhas sintáticas, embora não do tipo nominal complexo. Como mencionamos acima, orações na posição de adjunto também se comportam como ilhas sintáticas em muitas línguas, como é o caso do Português:

(234) Oração adverbial como ilha sintática

a. A Maria ficou brava [quando o João cumprimentou a ex-namorada].

b. ${ }^{*}$ Quem $_{\mathrm{i}}$ a Maria ficou brava [quando o João cumprimentou $t_{\mathrm{i}}$ ]

Dessa forma, a ocorrência de pied-piping de larga-escala com orações adverbiais poderia não estar relacionado a um suposto um estatuto nominal da oração, mas sim à propriedade de ilha destas construções. Neste caso, as orações subordinadas adverbiais 
receberiam um tratamento diferenciado de outras subordinadas que ocupam posições argumentais, ainda que a essência do pied-piping se mantivesse para todas as subordinadas.

Em resumo, existem duas possibilidades de análise para as orações subordinadas adverbiais . Primeiramente, podemos considerá-las de fato construções nominalizadas que posteriormente sofreriam um processo derivacional. Em contrapartida, podemos assumir que as orações adverbiais não são construções nominalizadas. Neste caso, elas seriam tratadas de uma forma diferenciada com relação aos fenômenos apresentados: a ocorrência de pied-piping de larga-escala, por exemplo, estaria relacionada ao seu estatuto como uma ilha sintática, não a uma propriedade [+nominal] destas construções. Neste ponto da pesquisa, não temos evidências suficientes para nos decidir por uma ou outra análise; assim, esperamos que investigações futuras sejam capazes de elucidar esta questão.

\subsection{Argumentos independentes}

Além das perguntas bi-oracionais, existem outros argumentos que reforçam a análise das subordinadas tal como proposta em 211. Eles são de duas naturezas. Primeiro, temos aqueles relacionados à ausência da camada CP nestas construções. Estes podem ser explicados tanto pela estrutura em 189 quanto 211. Um deles é a ausência de toughconstructions na língua, que será discutida em §4.4.1. Porém, existem outras particularidades que só podem ser explicadas se postularmos um núcleo nominal em subordinadas. Estes serão discutidos na seção $§ 4.4 .2$ em diante.

\subsubsection{Ausência de 'tough-constructions'}

Tough-constructions são construções com uma configuração como 235, que incluem um adjetivo como 'difícil' ou 'fácil' selecionando uma oração infinitiva contendo um argumento correferente a um NP da matriz:

\section{Tough-construction}

John is tough [to please].

" João é difícil de agradar."

Tradicionalmente, tough-constructions involvem um operador nulo, i.e., um operador sem conteúdo fonológico que sofre um movimento QU- (veja Chomsky (1986a)). Este operador se moveria para Spec, CP assim como os pronomes interrogativos:

(236) Estrutura de tough-construction com operador nulo

John is tough $\left[\varnothing_{\mathrm{i}}\right.$ to please $\left.t_{\mathrm{i}}\right]$

Operadores nulos foram originalmente propostos para explicar a correferência entre elementos da matriz e da subordinada sem postular que eles fariam parte de uma 
mesma cadeia de movimento. Segundo Sorin (1990), operadores nulos não têm intrinsecamente força quantificacional e só podem se tornar quantificadores a partir de uma posição sintática específica. Crucialmente, se Spec, CP estiver indisponível em orações subordinadas como estamos assumindo aqui, isso implicaria a impossibilidade de haver operadores nulos nestas construções. Em última instância, isso prevê que, se as subordinadas do Karitiana não contiverem de fato a projeção CP, a língua não terá tough-constructions como 235. Essa previsão se confirma, pois, para expressar o significado de tough-constructions em Português, os falantes de Karitiana usam estratégias bastante diferentes e distantes de 236 :

Equivalentes a tough-constructions

A-b-osedn-i-paap pitat João.

NEG-CAUS-ficar.feliz-EPEN-para muito João

"O João não dá pra ficar feliz."

(Pretendido: "O João é difícil de agradar.")

(238) Equivalentes a tough-constructions

I-osedna padni padni João.

3-ficar.feliz NEG NEG João

"João não é feliz (de jeito nenhum)."

(Pretendido: "O João é difícil de agradar.")

Assim, a ausência de tough-constructions em Karitiana reforça a análise de que as subordinadas não seriam CPs como no Inglês e Português.

\subsubsection{Extração com verbos factivos}

Segundo Kiparsky e Kiparsky (1971), verbos como 'arrepender-se' ou 'esquecer' podem ser classificados como factivos, pois seus complementos oracionais podem ser parafraseados como "o fato de...". Uma característica peculiar desta classe de verbos é a de que eles não permitem a extração de constituintes de seus complementos oracionais. Assim, não é possível mover 'who' quando o verbo da matriz for 'regret' ou 'forget', mas essa mesma operação é permitida com o verbo não factivo 'believe':

Verbo factivo

*Who ${ }_{\mathrm{i}}$ do you regret/forget [ $t_{\mathrm{i}}$ likes this book] ?

(ADAMS, 1985)

Verbo não factivo

$\mathrm{Who}_{\mathrm{i}}$ do you believe [ $t_{\mathrm{i}}$ likes this book]?

(ADAMS, 1985)

Tradicionalmente, essa impossibilidade tem sido explicada ao assumir que o complemento de um verbo factivo tem um caráter nominal - possivelmente, sua estrutura conteria um NP nulo como 'fato'. Tal análise encontra respaldo em diversos comportamentos nominais dessas orações, tais como a presença de determinantes (241) e a possibilidade de gerúndios (242) em algumas línguas: 
(241) Determinante no complemento oracional de um verbo factivo

Lamentamos el que Pedro no haya pasado el exámen.

"Nós lamentamos que Pedro não tenha passado no exame." (ZUBIZARRETA, 1982)

(242) Verbos factivos permitem gerúndio

a. Sally regrets having agreed to the proposal.

b. *Sally believes having agreed to the proposal.

(ADAMS, 1985)

Como o complemento oracional seria um sintagma nominal complexo, a extração de constituintes com verbos factivos é impossível, pois ela caracterizaria uma violação da CNPC em 223.

No Karitiana, existe a possibilidade do paradigma em 239-240 não se replicar. Como o pied-piping de larga-escala já é uma possibilidade para evitar violações de CNPC na língua, então é possível que a língua construa perguntas de longa-distância com verbos factivos através da frontalização de toda a subordinada. De fato, isso se verifica, já que construções equivalentes a 239 são possíveis e envolvem pied-piping de larga-escala:

Pied-piping de larga-escala com verbo factivo 'koro'op oky'

[Morã harahara ko]-ty i-koro'op oky Pedro?

QU espelho quebrar-OBL 3-dentro machucar Pedro

"O Pedro lamentou que quem quebrou o espelho?"

(Literalmente: "[Quem quebrou o espelho] lamentou Pedro?"

(244) Pied-piping de larga-escala com verbo factivo 'diwyt'

[Morã bykypa oky]-ty i-diwyt João?

QU barata matar-OBL 3-esquecer João

'(Literalmente) "[Quem matou a barata] o João lamentou?"

Em suma, a agramaticalide de perguntas de longa distância com verbos factivos em muitas línguas deve-se ao fato de elas não terem uma estratégia para evitar uma violação de CNPC. O pied-piping de larga-escala cria a possibilidade de construir tais perguntas ao mover a oração inteira, o que faz com que, em Karitiana, a extração de complementos de verbos factivos seja possível. ${ }^{7}$

\subsubsection{Cliticização em subordinadas}

Como vimos no capítulo 1, a cliticização de argumentos pronominais é um fenômeno característico de orações subordinadas. Em orações matrizes, tanto o pronome livre

$7 \quad$ Isso não implica, no entanto, que todas as línguas que possuem pied-piping de larga-escala o empregarão com verbos factivos. Em Basco, por exemplo, perguntas de longa-distância com verbos factivos soam marginais com o pied-piping (URBINA; ETXEPARE, 2003). 
quanto a concordância são possíveis (veja 245), mas essa mesma configuração não é possível em orações subordinadas: nelas, só é permitido o uso do pronome livre como em 247 ou de um pronome cliticizado como 248:

(245) Concordância em orações matrizes

Y-ta-opiso-t yn

1-DECL-Ouvir-NFUT 1s

"Eu ouvi"

(STORTO, 1999)

(246) Condordância em orações subordinadas

*[yn y-opiso] a-taka-kãra-t an

[1s 1-ouvir] 2-DECL-pensar-NFUT 2s

"Você achou que eu ouvi."

(STORTO, 1999)

(247) Pronome livre em orações subordinadas

[yn opiso] a-taka-kãra-t an

[1s ouvir] 2-DECL-pensar-NFUT 2s

"Você achou que eu ouvi."

(STORTO, 1999)

(248) Cliticização em orações subordinadas

[y-opiso] a-taka-kãra-t an

[1-ouvir] 2-DECL-pensar-NFUT 2s

"Você achou que eu ouvi."

(STORTO, 1999)

(249) Cliticização em orações subordinadas

[Yj-sooj pasagama-ki tykiri], Ø-na-monde-t osiip myjym otidna-t

1s-esposa obter?-NEG ASP 3-DECL-acabar-NFUT osiip cinco lua-ADVZ

"Se não obtemos esposas, o Osiip termina depois de três meses" ["Osiipo"]

Como mencionamos em $\S 1.3 .5$, a cliticização parece ser a regra em ambientes subordinados, sendo os pronomes livres característicos de casos em que dois pronomes ocorrem. Além disso, é importante mencionar que a classe de pronomes cliticizados é idêntica à de pronomes possessivos. Por exemplo, $y$ - e $y j$ - são tanto os pronomes de primeira pessoa do singular e plural cliticizados quanto marcadores de posse:

(250) Possessivo y-

Y-haj

1-irmão.mais.novo

"Meu irmão mais novo (ego masculino)"

(STORTO, 1999)

(251) Possessivo yj-

Ting i-a-m-'y-t yj-asoo-p

timbó NMZ-PASS-CAUS-pôr-CON.COP 1p-rosto-LOC

"O timbó precisa ser aplicado no nosso rosto'

["Osiipo"] 
Dessa forma, os sintagmas nominais que aparecem em subordinadas poderiam não ter o mesmo estatuto que orações matrizes. Especificamente, eles poderiam ser genitivos, o que também explicaria o fato de cliticização ser tão frequente e quase obrigatória, como vimos em §1.3.5. Isso se estenderia não só para os pronomes, mas para NPs referenciais também, que poderiam ser igualmente genitivizados. Sobre isso, é importante relembrar que a marcação de genitivo é nula na lingua (veja o capítulo 1).

A tendência pela cliticização e a semelhança dos pronomes cliticizados com possessivos aproxima ainda mais as nossas orações subordinadas de sintagmas nominais complexos. Crucialmente, muitas línguas marcam seus argumentos com o caso genitivo quando uma determinada construção é nominalizada, como o dado de Turco abaixo exemplifica:

Genitivo no sujeito

Hasan [uşă̆-in oda-yi temizle-diğ-in-i] söyle-di.

Hasan servo-GEN cômodo-ACC limpar-FACT-3SG-ACC dizer-PAST

"Hasan disse que o servo limpou o cômodo." ～(COMRIE; THOMPSON, 2007)

Em suma, o comportamento dos supostos clíticos seria mais um argumento a favor da estrutura em 211, pois ela consegue concomitantemente capturar as propriedades nominais destas construções como o uso de possessivos como marcas de pessoa.

\subsubsection{Relativas de núcleo interno}

Nossa análise das orações subordinadas como construções nominalizadas lança luz ainda sobre outros aspectos da língua. Como mencionamos em 1, as relativas do Karitiana são de núcleo interno. Translinguisticamente, construções deste tipo estão restritas a línguas que fazem uso da nominalização (CULY, 1990):

(253) Condição de independência para orações relativas de núcleo interno

Uma língua terá orações relativas de núcleo interno somente se ela também tiver outras construções nominalizadas com propriedades de independência. (CULY, 1990, tradução nossa)

Segundo o autor, os tipos de orações com estas "propriedades de independência" seriam complementos de discurso indireto (e.g. perguntas indiretas, complementos de verbos dicendi, etc.) e complementos factivos (e.g. 'o fato de que...', 'a ideia que...', etc.). Uma intuição por trás dessa generalização é de que a língua só pode ter relativas de núcleo interno se já for possível que orações com propriedades de independência funcionem como sintagmas nominais e ocupem posições típicas destes elementos.

Com a nossa estrutura nominalizada em 211, todas as orações subordinadas da língua seriam nominalizadas - incluindo as perguntas indiretas, complementos de verbo dicendi e factivos. Dessa forma, Karitiana se enquadraria na generalização em 253 e constituiria um argumento a mais a favor dela, pois a língua de fato exibe relativas de núcleo interno. 


\subsection{Efeito V2}

Ao propormos uma estrutura ligeiramente diferente para as orações subordinadas, também permitimos que fatos já bastante conhecidos da gramática do Karitiana ganhem novas interpretações. Um destes fatos é a ordem de constituintes em orações matrizes e subordinadas - mais especificamente, sua distribuição complementar. Como visto no capítulo 1, orações matrizes exibem uma espécie de efeito V2, enquanto orações subordinadas são obrigatoriamente verbo-finais. Tal comportamento levou Storto (STORTO, 1999) a classificar Karitiana como uma língua V2, uma classificação característica de línguas germânicas como o Alemão.

No entanto, Holmberg (2015) apontou que Karitiana exibe construções desviantes do V2 prototípico, como a possibilidade de ter mais de um XP no slot pré-verbal e a possibilidade de orações verbo-iniciais:

Ordem V3

Mynda taso $\emptyset$-na-m-potpora-j ese

lentamente homem 3-DECL-CAUS-ferver-FUT water

"O homem ferveu a água lentamente."

(STORTO, 1999)

(255) Ordem verbo-inicial

$\emptyset$-na-aky-t ejepo.

3-DECL-estourar-NFUT pedra

"A pedra estourou."

(ROCHA, 2011)

Outra diferença em relação ao V2 germânico diz respeito a orações encaixadas. Nas subordinadas do Karitiana, a ordem verbo-final é explicada por Storto pela ausência da camada CP: como o verbo se moveria para esta posição para adquirir a morfologia flexional, a ausência desta projeção em subordinadas faria com que o verbo permanecesse dentro do $v \mathrm{P}$ dentro destes ambientes (veja Storto (1999)). A questão é que, em outras línguas V2, a mesma distribuição complementar entre orações matrizes e subordinadas existe mesmo com a existência de CPs encaixados:

(256) Subordinadas em linguas V2

[Alemão]

Maria glaubt [dass Peter nach Hause geht.]

Maria acha que Peter para casa vai

"Maria acha que Pedro vai pra casa."

(HOLMBERG, 2015)

Em outras palavras, embora exista uma certa semelhança com o V2 germânico, existem ainda algumas outras características que distanciam o Karitiana de línguas V2 prototípicas.

Contudo, podemos pensar que uma intuição por trás da proposta original de Storto é de que, embora gere paradigmas similares ao V2 germânico, o V2 do Karitiana seria de uma natureza ligeiramente diferente. Basicamente, o status das subordinadas 
como uma espécie de oração truncada faria com que todos os argumentos permanecessem dentro do sintagma verbal, o que geraria sua propriedade verbo-final.

Nesse sentido, nossa proposta de que as orações subordinadas são construções nominalizadas dá mais corpo à ideia de que a propriedade verbo-final do Karitiana é diferente daquela de línguas como o Alemão. Especificamente, muitas línguas exibem uma alteração de ordem em construções nominalizadas em relação às suas contrapartes oracionais (KOPTJEVSKAJA-TAMM, 2002). Em Russo, por exemplo, orações são tipicamente SVO, mas construções nominalizadas exibem a ordem VOS. Como o leitor pode verificar nas traduções, esse mesmo padrão se verifica em Português:

(257) Ordem SVO em sentenças

[Russo]
a. Petrov oskorbil Ivanov-a.
Petrov:NOM insultou Ivanov-ACC
"Petrov insultou Ivanov."
b. Ivanov uvažal Petrov-a. Ivanov:NOM respeitou Petrov-ACC "Ivanov respeitava Petrov."

(KOPTJEVSKAJA-TAMM, 2002)

(258) Ordem VOS em action nominals

[Russo]
a. oskorbl-enie Ivanov-a Petrov-ym insultar-AN Ivanov-GEN Petrov-INSTR "O insulto de Petrov por Ivanov."
b. uvaž-enie Petrov-a k Ivanov-u respeitar-AN Petrov-GEN para Ivanov-INSTR

"O respeito de Petrov por Ivanov."

(KOPTJEVSKAJA-TAMM, 2002)

Em outras palavras, a alteração de ordem em subordinadas do Karitiana estaria muito mais próxima daquela observada com nominalizações como 257-258 do que a subordinada em Alemão em 256. Nesse sentido, desvios do V2 germânico seriam até esperados, pois, no fundo, a distribuição complementar entre orações matrizes e subordinadas teria uma natureza distinta em Karitiana.

\subsection{Resumo do capítulo}

Neste capítulo, propusemos uma modificação na estrutura das subordinadas em 189 ao inclur um núcleo nominal $n$. Em outras palavras, as subordinadas do Karitiana seriam construções nominalizadas, mas ainda reteriam parte de sua arquitetura oracional. Tal proposta é possível se adotarmos a ideia de que a nominalização envolve não categorias discretas, mas um continuum de construções com arranjos diferentes de núcleos tipicamente oracionais e nominais.

Argumentamos também que esta seria a análise mais adequada para estas construções, pois ela explica o comportamento de todas as perguntas com sentenças bi-oracionais 
dos capítulos 2 e 3 . Além disso, defendemos que a estrutura nominalizada em 211 também é capaz de elucidar uma série de outros fenômenos, como a ausência de tough-constructions, a extração com verbos factivos, a cliticização e a presença de relativas de núcleo interno. Por fim, discutimos ainda a questão da ordem de palavras e o efeito V2, que foi originalmente proposto para o Karitiana por Storto (1999). Na próxima seção, veremos que essa proposta também pode ser capaz de explicar a distribuição de um sufixo -a, que, até o momento, não foi discutido em detalhe na literatura. Além disso, veremos como nossa proposta pode interagir com certos fenômenos prosódicos no capítulo 7. 


\section{Sufixo -a}

\section{$5.1 \quad$ Vogal -a}

No capítulo 4, propusemos que as subordinadas do Karitiana seriam projeções de um núcleo de natureza nominal $n$ como em 259:

Estrutura das orações subordinadas

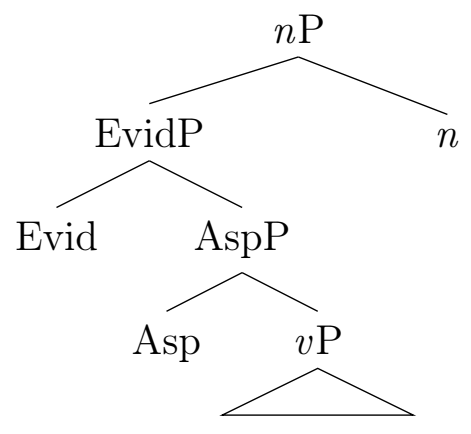

Dado que a realização deste núcleo seria um morfema nulo na maioria dos casos, isso poderia nos levar a questionar sua existência. Contudo, existe na língua um possível candidato à contraparte aberta deste núcleo de natureza nominal. Este seria o sufixo - $a$, um morfema que tem sido detectado em algumas subordinadas:

(260) Vogal - a em oração subordinada

Yn $\emptyset$-na-oky-t [pikom pykyn-a]

1s 3-DECL-matar-NFUT macaco correr-NMZ

"Eu matei o macaco que correu."

(ROCHA, 2016)

(261) Vogal - a em oração subordinada

[J̃onso hỹryj-a] $\emptyset$-na-aka-t i-se'a-t

mulher cantar-NMZ 3-DECL-COP-NFUT NMZ-bonito-CON.COP

"A mulher que cantou é bonita."

(ROCHA, 2016)

O comportamento aparentemente errático deste sufixo fez com que ele recebesse pouca atenção em trabalhos anteriores: Storto (1999, et seq.) o denominou como vogal temática, enquanto autores como Everett (2006) e Rocha (2016) o glosam como parte da raiz verbal.

Nossa proposta é de que o - $a$, em conjunto com um morfema zero e o nominalizador - $p a$, seria uma realização fonética do núcleo $n$. Como veremos à frente, essa análise se ampara no fato de que o - a emerge em diversos ambientes nominais na língua, nos quais um determinado sintagma sofreu um processo derivacional e se tornou um sintagma nominal complexo. Veremos também que essa análise se ampara em dados de outras línguas 
Tupi, cujos cognatos de - a se comportam de maneira similar ao Karitiana. Dessa forma, nossa estrutura para as subordinadas em 259 terá a vantagem adicional de explicar a distribuição de um morfema cujo comportamento misterioso não fora examinado em detalhe antes.

\subsection{Outras análises de -a}

Antes de argumentarmos que - a é um núcleo de natureza nominal, apresentamos evidências de que, ao menos no estágio atual da língua, este morfema não pode ser considerado uma epêntese ou parte da raiz.

O fenômeno da epêntese será mais bem discutido no capítulo 7. Por ora, vamos apenas apresentar algumas de suas principais características. Segundo Storto (1999), o processo de epêntese em Karitiana é empregado para evitar um encontro consonantal que viola as restrições fonotáticas da língua. Em geral, a vogal inserida repete a qualidade do segmento vocálico da sílaba anterior, mas é frequente também a inserção da vogal central alta -y em certos ambientes, como a negação (veja a discussão no capítulo 7):

(262) Epêntese repetindo vogal anterior

$\begin{array}{ll}\text { kookot }- \text { pa } \rightarrow & \text { kookotopa } \\ \text { passar NMZ } & \text { "ponte" }\end{array}$

(STORTO, 1999)

(263) Epêntese com -y

Yn i-kyndop-y padni kãramatom

1s 3-abrir-EPEN NEG porta

"Eu não vou abrir a porta."

(EVERETT, 2006, adaptado)

Embora esteja restrita a uma classe de verbos específicos como 'pykyn', 'hỹryj' e 'esym', a vogal - a não faz parte de suas raízes. Isso pode ser detectado de duas formas. Primeiramente, o sufixo - $a$ não emerge em todos os contextos. No dado abaixo, vemos que o verbo 'cantar' flexionado pode não ser sufixado por - $a$ :

(264) Verbo 'cantar' flexionado

Gokyp $\emptyset$-naka-hỹryj- $\emptyset \quad$ omenda

sol 3-DECL-cantar-NFUT meio-dia

"O sol cantou ao meio-dia."

(STORTO, 1999)

(265) Verbo 'cantar' flexionado

$\emptyset$-naka-hỹryj ta'ã-t y-'it gop-o 'obm tyso'oot

3-DECL-cantar EVID.DIR-FUT 1s-pai vespa-EPEN furar ASP

"Meu pai cantava enquanto perfurava o vespeiro."

["Osiipo"] 
Outra evidência de que a vogal - $a$ não faz parte da raiz destes verbos são os casos de reduplicação. A reduplicação da raiz verbal é uma estratégia em Karitiana para sinalizar a pluracionalidade de eventos, isto é, para indicar que o evento designado ocorreu necessariamente mais de uma vez (MULLER; SANCHEZ-MENDES, 2007; STORTO, 2014b):

Reduplicação da raiz verbal

Pikom-kyn $\emptyset$-na-pon-pon- $\emptyset \quad$ õwa monkey-POS 3-DECL-atirar-RED-NFUT criança

"A criança atirou várias vezes nos macacos" (MULLER; SANCHEZ-MENDES, 2007, adaptado)

Crucialmente, a vogal - $a$ não emerge no primeiro elemento em casos de reduplicação, mostrando que ela não faz parte da raiz destes verbos: ${ }^{1}$

Pluracionalidade e vogal - a

João i-hỹryj-hỹryj-a-t musica-ty.

João NMZ-RED-cantar-N-NFUT música-OBL

“João cantou mais de uma música.'

[Sanchez-Mendes, manuscrito]

(268) Pluracionalidade e vogal - a

João i-pykyn-pykyn-a-t

João NMZ-RED-correr-N-NFUT

"O João correu várias vezes.'

[Sanchez-Mendes, manuscrito]

Desta forma, essas duas evidências nos mostrariam que a vogal - $a$ não pode ser tratada como uma epêntese ou como parte da raiz, o que reforça seu status como um sufixo à parte.

$\overline{1}$ Nos dados de Storto (2014), existem também alguns outros exemplos que podem conter o sufixo - $a$ :

(viii) $\emptyset$-naka-yt- $\emptyset$

3-DECL-cavar-DECL

'(Alguém) cavou (algo)."

(STORTO, 2014b, adaptado)

(ix) $\emptyset$-naka-yt-yd-na-t

3-DECL-RED-cavar-DECL

'(Alguém) cavou (algo)."(vários eventos de cavar)

(STORTO, 2014b, adaptado)

Possivelmente, este dado segue o mesmo padrão de 267 e 268, mas incluindo uma possível sonorização e nasalização do segmento [t] do verbo 'yt'. Ele, contudo, não é tão claro quanto 267 e 268, pois Karitiana também exibe um sufixo adjetivizador -na. Embora este não seja o contexto de uso prototípico de -na, a presença de mudanças fonológicas mais invasivas na raiz nos faz questionar a análise deste dado como exemplo do sufixo $-a$. 


\section{3 -a em sintagmas nominais complexos}

Vamos iniciar nossa argumentação mostrando três dos principais ambientes em que o sufixo - a é encontrado. O primeiro deles é com orações subordinadas (relativas) com determinados verbos, como já vimos anteriormente:

(269) Vogal - a em oração subordinada

Yn $\emptyset$-na-oky-t [pikom pykyn-a]

1s 3-DECL-matar-NFUT macaco correr-NMZ

"Eu matei o macaco que correu."

(ROCHA, 2016)

(270) Vogal - a em oração subordinada

[J̃onso hỹryj-a] ฤ-na-aka-t i-se'a-t

mulher cantar-NMZ 3-DECL-COP-NFUT NMZ-bonito-CON.COP

"A mulher que cantou é bonita."

(ROCHA, 2016)

Outro ambiente em que - $a$ emerge é com esta mesma classe de verbos dentro da construção de cópula:

(271) Vogal a-com 'pykyn'

Jonso $\emptyset$-na-aka-t i-pykyn-a-t

mulher 3-DECL-COP-NFUT NMZ-correr-V.TEM-CON.COP

"A mulher correu."

(272) Vogal a- com 'hỹryj'

Jonso $\emptyset$-na-aka-t i-hỹryj-a-t

mulher 3-DECL-COP-NFUT NMZ-cantou-V.TEM-CON.COP

"A mulher cantou."

Por fim, o - $a$ também aparece em certos compostos com a estrutura [N Adj]: ${ }^{2}$

(273) Sintagma nominal com morfema - a-

a. Ombaky

"Onça"

b. Ombaky in-a

onça pequeno-NMZ

"Gato"

(274) Sintagma nominal com morfema - a-

a. Sojxa

"Porco'

b. Sojxa in-a

porco pequeno-NMZ

"Caititu."

(VELDEN, 2010)

2 Landin (2005) grafa a palavra para 'gato' como 'ombaky 'in'. 
Crucialmente, existe um par mínimo mostrando que - $a$ de fato emerge em ambientes para sinalizar a ocorrência de um processo derivacional como a composição: nos exemplos 275 e 276, vemos que a presença de - $a$ ocorre no último caso, em que o sintagma em questão se tornou um NP complexo (um composto): ${ }^{3}$

(275) Sentença simples

Ombaky 'eem

onça sujo/preto

"A onça está suja"ou "A onça é preta."

(EVERETT, 2006, adaptado)

(276) Sintagma nominal com morfema - a-

Ombaky 'eem-a

onça preto/sujo-NMZ

"Irara"

(D. LANDIN, 2005, adaptado)

Todos os exemplos acima têm em comum o fato de termos um determinado elemento ou sintagma que passou por algum tipo de processo derivacional e se transformou ou em um nome simples (no caso da cópula em 271-272) ou em um nome complexo (os compostos em 273-276 e as orações subordinadas relativas em 269 e 270). No caso das cópulas em 271 e 272, vimos no capítulo 1 que um verbo nestes ambientes precisa estar nominalizado. Isso pode ser demonstrado pelos exemplos repetidos abaixo, nos quais se verifica que as cópulas também permitem nomes:

Construção de cópula com nome

Kinda'o $\emptyset$-na-aka-t asyryty-t

fruta 3-DECL-COP-NFUT banana-CON.COP

"Banana é uma fruta."

(STORTO, 2010)

(278) Construção de cópula com verbo intransitivo

Taso $\emptyset$-na-aka-t i-kat- $\emptyset$

homem 3-DECL-COP-NFUT NMZ-dormir-CON.COP

"O homem dormiu."

(STORTO, 2010)

Dessa forma, um verbo intransitivo também sofre um processo derivacional para ser usado na construção de cópula, operação esta sinalizada através - $a$.

O processo de formação de nomes compostos em 273-276 também é derivacional, pois um sintagma com a forma [NP NP Adj] é transformado em um único NP complexo. Por fim, a situação destes compostos seria similar ao de subordinadas como 269 e 270. Se considerarmos que as orações subordinadas também sofrem um processo derivacional e se tornam um NP com uma estrutura interna complexa, temos uma explicação uniforme para a distribuição de - a nestes ambientes. Em última instância, a diferença entre um composto e uma subordinada nominalizada é que, no primeiro caso, o elemento se comporta como

\footnotetext{
3 Como veremos mais à frente, a palavra para 'irara' em Arikém também continha o sufixo $a$-.
} 
uma palavra e é lexicalizado, enquanto o mesmo processo com orações subordinadas é produtivo e cria NPs não dicionarizáveis.

Em suma, ao propor em 259 um núcleo de natureza nominal $n$ em orações subordinadas, somos capazes de explicar a presença do sufixo - $a$ em diversos ambientes de natureza nominal.

\section{4 -a com verbos flexionados}

Um contra-argumento para nossa análise de - a como um núcleo de caráter nominal é o fato de - $a$ emergir em alguns contextos prototipicamente não nominais, como com certos verbos flexionados:

(279) Verbo conjugado com - a

Y-pyr-y-hỹryj-a-n yn

1s-ASS-EPEN-cantar-NMZ-NFUT 1s

"Eu cantei."

(ROCHA, 2011)

(280) Verbo conjugado com - a

$\emptyset$-pyr-y-pykyn-a-n jonso.

3-ASS-EPEN-Correr-N-NFUT mulher

"A mulher correu."

Para acomodar estes dados em nossa proposta, é preciso primeiro pontuar que o morfema - a parece estar em um processo de mudança linguística. Como vimos nos dados acima, o sufixo - a geralmente está restrito a uma classe de verbos como 'hỹryj', 'pykyn', 'esym', etc. Além disso, ele aparece congelado em alguns compostos, sobretudo em nomes de animais. Ele não é, portanto, um morfema produtivo, mas sim um elemento que parece ter sido fossilizado em certas combinações com algumas raízes específicas.

Por enquanto, - $a$ não parece ser parte da raiz, como vimos nos dados em §5.2. Porém, ele pode estar sendo reinterpretado por alguns falantes como parte dela. Uma evidência disso seria a possível variação que temos no uso de - $a$ com verbos finitos: como vimos nos dados 264 e 265 repetidos abaixo, não é sempre que - $a$ emerge com estes verbos flexionados:

(281) Verbo 'cantar' flexionado

Gokyp $\emptyset$-naka-hỹryj- $\emptyset \quad$ omenda

sol 3-DECL-cantar-NFUT meio-dia

"O sol cantou ao meio-dia."

(STORTO, 1999)

(282) Verbo 'cantar' flexionado

$\emptyset$-naka-hỹryj ta'ã-t y-'it gop-o 'obm tyso'oot

3-DECL-cantar EVID.DIR-FUT 1s-pai vespa-EPEN furar ASP

"Meu pai cantava enquanto perfurava o vespeiro." 
$\mathrm{Na}$ realidade, mesmo os falantes que aceitam 279 e 280 aceitam essas mesmas construções sem a vogal - $a$ - neste caso, a vogal epentética - $y$ - é inserida para evitar o encontro vocálico:

Equivalente a 279 com -y $\emptyset$-pyry-hỹryj-y-n $\quad$ jonso.

3-ASS-cantar-EPEN-NFUT mulher

"A mulher cantou."

(284) Equivalente a 280 com -y $\emptyset$-pyry-pykyn-y-n $\quad$ jonso.

3-ASS-correr-EPEN-NFUT mulher

"A mulher correu."

Assim, propomos que - $a$ está em um processo de mudança de um elemento funcional para um elemento inerte, fossilizado ao final de certas raízes. Na próxima seção, discutiremos um possível cognato do sufixo - $a$ em outras línguas Tupi, cujo comportamento em algumas línguas Tupi-Guarani é bastante similar aos casos de - $a$ com verbos flexionados no Karitiana.

\section{5 -a e seus cognatos em outras línguas}

A distribuição de - $a$ em Karitiana remete a um outro sufixo - $a$ presente em outras línguas Tupi - especialmente na família Tupi-Guarani. Em algumas dessas línguas, sintagmas nominais em diversas posições são sufixadas por - $a$ : no exemplo do Tupinambá abaixo, vemos este morfema (glosado como 'caso argumentativo') tanto no sujeito 'os contrários' quanto no objeto 'meu pai':

(285) Sufixo - a

Sjé r-ú $\beta$-a t-oßajár-a ja- $\emptyset$ -

[Tupinambá]

eu CONT-pai-ARG HUM-adversário-ARG 3SUJ-3OBJ-comer

"Os contrários comeram o meu pai." (Anchieta (1595) apud Rodrigues (2013))

Embora este sufixo inicialmente tenha sido correlacionado com algum tipo de caso (veja Rodrigues (1999)), o fato de ele marcar elementos em posições sintáticas diversas nos mostra que - $a$ aparentemente não está relacionado à função sintática do elemento que o carrega.

Na literatura sobe línguas Tupi-Guarani, o sufixo - a tem sido alvo de um grande escrutínio, pois ele ainda exibe relativa produtividade em muitas línguas dessa família. De forma geral, a intuição de grande parte dos autores é de que ele se afixa a um predicado para tranformá-lo em um argumento (mas veja a discussão em Queixalós (2006)). Nos dados de Tapirapé abaixo, podemos postular que 'men' seria um predicado como 'ser casado(a)' e a afixação de - $a$ o transforma em um sintagma nominal como 'meu cônjuge'. O mesmo pode ser observado com ' $h \tilde{y} n$ ' em 287 : 
(286) Sufixo - a

[Tapirapé]

a. xe-men

1s-marido

"Eu sou casada/Tenho marido."

b. xe-men-a

1s-marido- $\mathrm{N}$

"Meu marido"

(LEITE, 1990, adaptado)

(287) Sufixo - a

[Tapirapé]

a. xe-hỹn

1s-dente

"Eu tenho dente."

b. xe-hỹj-a

1s-dente-N

"Meu dente"

(LEITE, 1990, adaptado)

Por esta razão, esse morfema parece agir como uma espécie de nominalizador - muito embora, como veremos à frente, ele pareça estar perdendo sua função em muitas línguas Tupi. ${ }^{4}$

A distribuição de - $a$ nas línguas Tupi-Guarani ressoa no comportamento de - $a$ em Karitiana, sobretudo o fato de existirem pares mínimos como 286-287. Estes dados seriam bastante similares ao que encontramos com Karitiana em 275 e 276, em que a presença do - a sinaliza um processo derivacional de composição. Além disso, em algumas línguas o - a emerge nas chamadas orações equativas, como se vê nos dados do Asuriní do Tocantins abaixo. Estas seriam equivalentes às construções de cópula em Karitiana, nas quais o - a também emerge (veja 267-268):

(288) - a em orações equativas

[Asuriní do Tocantins]

Apetyráw-a txé r-ér-a

Apetyráwa-N 1 CONTIGUIDADE-nome-N

"Apetyráwa é meu nome."

(QUEIXALÓS, 2006, adaptado)

Crucialmente, esse morfema também emerge em algumas orações subordinadas, em construções que por vezes são denominadas de gerúndio pelos autores que a descreveram:

$\overline{4}$ Alguns autores preferem não se referir ao sufixo - $a$ como um nominalizador pelo fato de ele co-ocorrer com outros nominalizadores em algumas línguas (veja Queixalós (2006) e Praça, Magalhães e Cruz (2017)). No Karitiana, teríamos uma situação similar na construção de cópula em 267 e 268, em que o - a co-ocorreria com o nominalizador $i$ - 
- a como gerúndio

iukae'ym-a

não.matar.N

"Não matando."

(290) - a como gerúndio

1SG-N não=3.I-ver-NEG 2SG.II=R-REF-escorregar-NMZ-N

"Eu não vi a sua escorregação."

(PRAÇA; MAGALHÃES; CRUZ, 2017, adaptado)

Possivelmente, a denominação de gerúndio pretende capturar o comportamento nominal destas construções. Dessa forma, este sufixo seria bastante semelhante ao que vimos em Karitiana, com o morfema - $a$ emergindo em subordinadas que, segundo a estrutura em 259, seriam também construções nominalizadas.

Mesmo em seu percurso histórico o sufixo - a das língua Tupi-Guarani ecoa no comportamento do morfema - $a$ em Karitiana. Segundo Queixalós (2006), as línguas Tupiguarani variam no grau de produtividade e distribuição deste morfema. Algumas línguas, como o Kamaiurá, parecem permiti-lo em diversas posições, enquanto outras o restringiram a algumas posições e/ou apenas algumas raízes. Curiosamente, em línguas nas quais o sufixo - a está em processo de dissolução, se verifica comportamentos similares ao do - $a$ em Karitiana. Vimos na seção anterior que o sufixo - a parece começar a se estender para verbos flexionados, ou seja, ele parece estar sendo reinterpretado como parte da raiz e estar sendo reaproveitado como um tipo de epêntese, evitando choques consonantais que violariam as restrições fonotáticas da língua. Segundo Queixalós (2006), esse mesmo cenário pode ser observado na língua Tupi-Guarani Emerillon, na qual o sufixo - a se tornou opaco e "não é nada mais do que uma relíquia sem nenhum status gramatical, que só tem sido preservado onde previne a ocorrência de sequências fonêmicas não permitidas" (tradução nossa).

Além de Emerillon, o comportamento do morfema - $a$ em Suruí é também bastante similar ao sufixo - $a$ do Karitiana. Nesta língua, o - a sofreu um processo de alçamento e tornou-se um schwa [ə]. À semelhança do Karitiana, esse morfema também parece estar se estendendo para verbos finitos, como se observa na seguinte passagem de Ruth Monserrat citada por Queixalós (2006):

\footnotetext{
"Monserrat observa que, na fala dos Suruí mais jovens, o [ə] final estendeuse para formas que não eram nunca associadas com o sufixo $-a$, como verbos finitos. Em outras palavras, este sufixo, que já é gramaticalmente opaco, está se tornando um simples fonema de final de palavra."(QUEIXALÓS, 2006, tradução e grifo nosso)
}

Certas línguas Tupi-Guarani como o Guarani Paraguaio, a Língua Geral Amazônica e o Kokama/Omagua tiveram um histórico de intenso contato e/ou períodos de aqui- 
sição como L2. Para elas, Queixalós (2006) observa que essa tendência já se concretizou, pois o - $a$ se fossilizara como parte da raiz:

$$
\begin{aligned}
& \text {-a como parte da raiz } \\
& \text { [Guarani Paraguaio] } \\
& \text { a. mána } \\
& \text { b. óga } \\
& \text { "casa" }
\end{aligned}
$$

Além disso, Cabral ((2001) apud Queixalós (2006)) reconhece diversos cognatos em outras famílias Tupi nas quais o morfema - $a$ ou já se tornou parte da raiz completamente ou funciona como uma espécie de nominalizador com certos verbos. Este era o caso de Xipaya, uma língua atualmente extinta da família Juruna. Nesta língua, o - a congelou-se em certas raízes, enquanto ainda funciona como um nominalizador com certas classes de verbos:

a. - a como parte da raiz

[Xipaya]

aká

"casa"

b. - a como nominalizador de certas raízes verbais

[Xipaya]

i. etúk

"comer"

ii. etúka

"comida"

(QUEIXALÓS, 2006)

Crucialmente, o comportamento dúbio do - a de Xipaya é exatamente o que se verifica em Karitiana: por vezes, o - a parece atuar como uma espécie de núcleo nominalizador, como nos casos de compostos e orações subordinadas; em outros contextos, porém, ele parece estar sendo reinterpretado como parte da raiz (como nos verbos flexionados), tornando-se um segmento opaco. Dessa forma, quando considerado em um cenário mais amplo, a distribuição de - a em Karitiana passa a ser um exemplo em tempo real da dissolução do morfema - $a$, uma tendência bastante forte dentro do tronco Tupi.

\subsubsection{Grande mudança vocálica e o enfático -o}

Propomos neste trabalho que o sufixo - $a$ em Karitiana seria uma possível realização do núcleo $n$ na estrutura em 259 e que ele seria cognato ao morfema - $a$ de outras línguas Tupi. Contudo, a possível relação diacrônica entre o - $a$ do Karitiana e de outras línguas Tupi pode ser questionada, pois a língua sofreu uma mudança vocálica em cadeia que tornou seu sistema vocálico diferente de suas outras línguas-irmãs. Como vimos no capítulo 1, a família Arikém sofreu as mudanças descritas abaixo: 


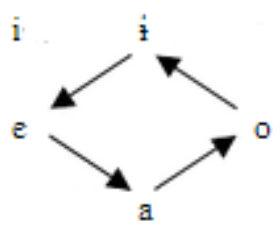

Figura 9 - Grande mudança vocálica (STORTO; BALDI, 1994)

Seguindo esse padrão de correspondências, a vogal [a] de outras línguas Tupi corresponderia à vogal [o] em Karitiana. Na realidade, Storto e Baldi (1994) de fato atestam um sufixo que ocorre em elementos nominais e que possivelmente corresponderia ao sufixo - a de outras línguas Tupi: o enfático -o. Este morfema foi chamado de enfático por Storto (1999) por causa de sua distribuição prototípica. Especificamente, Storto afirma que ele aparece em enunciados isolados como 'Osiip' em 293 e no final de enunciados como 294:

(293) Enfático com enunciado isolado

a. Osiip-o ritual.de.iniciação-ENF

"Ritual de iniciação."

b. Yn-ty y-'it-i hadna tyym yn Ø-naka-m-'a-t ta'ã-t 1s-OBL 1s-pai-EPEN fala também 1s 3-DECL-CAUS-fazer-NFUT EVID.DIR osiip osiip "(Com) a palavra do meu pai (direcionada) a mim, eu fiz o osiip" ["Osiipo"]

(294) Enfático -o no final de enunciado

I-hadna sogng myrỹ'in y-taka-tat- $\emptyset$ tysyp y-taka-'a ta'ã-t 3-dizer desde somente 1s-DECL-ir-NFUT IMPERF 1s-DECL-fazer EVID.DIR-NFUT yn-o

1s-EMPH

"Visto que ele falou comigo, eu vou lá, eu disse." (STORTO, 1999, adaptado)

Além disso, é possível também encontrar o enfático em itens de lista:

(295) Enfático em item de lista

$\emptyset$-naka-m-'a-t pom-o, pom eem-o, bisỹ, syyj-o, pã'yy $\tilde{j}$-o, 3-DECL-CAUS-fazer-NFUT tuna-ENF, tuna preto-ENF mutum jacamim, jacu-ENF tyym kinda papy-dna

também coisa pena-ADJz

"Fez tuna, tuna preta, mutum, jacamim, jacu e os bichos de pena."

["Botyj Pynhadna"]

Como se vê nos exemplos acima, o sufixo -o emerge em elementos nominais como nomes e pronomes. Assim, talvez seria complicado fazer uma conexão entre o sufixo $a$ do Karitiana e o morfema - a de outras línguas Tupi, pois já existiria em Karitiana 
um cognato deste morfema cuja forma é consistente com a mudança vocálica. Contudo, vamos aqui argumentar a favor da análise de que o morfema - a da proto-língua gerou dois sufixos distintos em Karitiana: um - $a$, que se fixou na forma pré-mudança vocálica e cuja distribuição é bastante restrita, e um -o, que é produtivamente empregado na língua com uma função distinta de seu ancestral.

O primeiro passo de nossa argumentação é mostrar que, embora a mudança vocálica na família Arikém tenha sido bastante pervasiva, ela não afetou todos os elementos do Karitiana. Em outras palavras, existem exceções à regra de mudança em cadeia. A título de exemplo, vejamos o caso da palavra 'penereg' em Karitiana. Dietrich (2009) aponta as seguintes correspondências entre essa palavra e seus cognatos em línguas Tupi-Guarani:

Tabela 7 - Cognatos de 'penereg' em Tupi (DIETRICH, 2009)

\begin{tabular}{lcc}
\hline \multirow{2}{*}{ LínguA } & & VocÁBUlO \\
\cline { 2 - 3 } & ORTOGRAFIA & SignificAdo \\
\hline Karitiana & penereg & 'sapatear, saltar' \\
Guarani Paraguaio & perereg & 'batir las asas el ave..' \\
Guarani Moderno & perere & 'sacudir-se, bater as asas' \\
Tenetehára-Tembé & pererek & \\
Parintintin & piririg & 'separar-se (a pele do corpo, a remela dos olhos)' \\
Asuriní do Tocantins & pereperek & 'peidar muito' \\
Wayãmpi & pelele & 'bater as asas, estremecer, tremer' \\
Ka'apór & piririk & 'piscar' \\
Garayó & piríri & 'faiscar' \\
\hline
\end{tabular}

Neste caso especificamente, o vocábulo 'penereg' em Karitiana não parece ter passado pela mudança vocálica, pois formas com a vogal [e] de fato se verificam em outras línguas Tupi. Sobre isso, Dietrich pontua que, se assumíssemos que a mudança vocálica do Arikém se aplicara neste caso, teríamos que postular a forma **piririk em ProtoTupi. Esta conclusão seria bastante inverossímil, visto que esta forma não teria nenhum reflexo nas outras línguas-filhas. Assim, é mais plausível considerar que este vocábulo especificamente não passou pela mudança vocálica em cadeia. Dito isso, a ideia de que sufixo - a também não tenha sofrido a mudança vocálica se torna mais plausível.

Contudo, as maiores evidências de que o sufixo - $a$ e o enfático -o estariam relacionados vêm da própria família Arikém. Se estes dois morfemas estiverem relacionados e forem cognatos ao - $a$ de outras línguas Tupi, é esperado que encontremos um no lugar do outro, ou seja, que - $a$ seja atestado em ambientes em que -o tipicamente emerge e vice-versa.

A primeira evidência de que isso de fato ocorre vem do Arikém, a língua-irmã do Karitiana. O Arikém é uma língua considerada extinta, mas alguns registros de vocábulos 
e pequenas frases sobreviveram. Aqui, nos valemos da lista de palavras coletadas por Curt Nimuendajú (NIMUENDAJÚ, 1932).

Arikém já possuía uma espécie de -o enfático, como apontam Storto e Baldi (1994): muitas palavras transcritas por Nimuendajú contêm o símbolo a, que, segundo o autor, representaria um som "entre $a$ e $o$ ". A prova de que este símbolo é usado para a vogal [o] (ou algo próximo dela) pode ser observado no cognato para a palavra 'lua', que seria [o’ti] em Karitiana (veja também Storto e Baldi (1994)):

Tabela 8 - Vogal [o] na lista de Nimuendajú

\begin{tabular}{cccc}
\hline \multicolumn{2}{c}{ LiSTA DE NimUEndAJÚ } & \multirow{2}{*}{ Karitiana } & \multirow{2}{*}{ TRAduÇão } \\
\cline { 1 - 2 } Transcrição original & Possível transcrição fonética & & \\
\hline aotí & {$[$ o.'ti] } & [o.'ti] & 'lua' \\
\hline
\end{tabular}

Na tabela abaixo, vemos essa vogal a aparecendo nos mesmo contextos em que o enfático - o seria usado em Karitiana, como na palavra isolada para 'mandioca':

Tabela 9 - Enfático -o na lista de Nimuendajú

\begin{tabular}{|c|c|c|c|}
\hline \multicolumn{2}{|c|}{ LISTA DE NIMUENDAJÚ } & \multirow{2}{*}{ KARITIANA } & \multirow{2}{*}{ TRADUÇÃO } \\
\hline Transcrição original & Possível transcri & & \\
\hline ṅgákă & ['ngoko] & ['ngoko] & mandioca \\
\hline
\end{tabular}

Crucialmente, alguns vocábulos na lista de Nimuendajú têm o - $a$ ao final, mostrando que Arikém, assim como Karitiana, também provavelmente exibia tando o sufixo - a quanto o -o (este último transcrito como $a$ ). O exemplo abaixo mostra a palavra em Arikém para 'irara' e, como o leitor pode verificar, ela é idêntica ao composto 'ombaky 'eem-a' ([õmba'kì 'ê:ma]) do Karitiana:

Tabela 10 - Sufixo - a na lista de Nimuendajú

\begin{tabular}{cccc}
\hline \multicolumn{2}{c}{ LiSTA DE NimUENDAJÚ } & \multirow{2}{*}{ KARITIANA } & \multirow{2}{*}{ TRADUÇÃo } \\
\cline { 1 - 2 } Transcrição original & Possível transcrição fonética & & \\
\cline { 1 - 2 } amaku-éma & [oma'kì 'ẽ:ma] & [õmba 'ki 'ẽ:ma] & irara \\
\hline
\end{tabular}

O mais importante da lista de Nimuendajú é que, em um determinado contexto, existe uma interpolação entre $-a$ e $-o$ ao final de palavras muito similares. As cores em Arikém são diretamente cognatas ao Karitiana, como se pode ver nos dados abaixo. Curiosamente, as palavras para azul e preto contêm o sufixo -o, mas a palavra para vermelho contêm o morfema $-a$ : 
Tabela 11 - Variação entre - o e - $a$ na lista de Nimuendajú

\begin{tabular}{|c|c|c|c|}
\hline \multicolumn{2}{|c|}{ LISTA DE NIMUENDAJÚ } & \multirow{2}{*}{ KARITIANA } & \multirow{2}{*}{ TRADUÇÃO } \\
\hline Transcrição original & Possível transcrição fonética & & \\
\hline i-paka & [i 'poko] & 'pok'] & branco \\
\hline i-ëmå & [i'ê:mo] ${ }^{5}$ & ễ:m] & preto \\
\hline i-kera & [i'kero] & ['ket] ${ }^{6}$ & azul \\
\hline isåma & [i'sõma] & ['sõm] & vermelho \\
\hline
\end{tabular}

Esta interpolação entre - $a$ e -o se verifica em diversos outras entradas da lista de Nimuendajú, nas quais o - a é empregado em enunciados isolados em que se esperaria um -o: primeiro, vemos uma alternância nos vocábulos para 'filho' e 'filha', que em Karitiana corresponderiam a 'y'it' (falante masculino) e 'y'et' (falante feminino). Vemos que, nos cognatos do Arikém, o primeiro é sufixado por - $a$, enquanto o segundo teria o morfema -o. Além disso, a palavra para pena em Arikém na lista também tem um - a ao final, um ambiente em que esperaríamos o enfático -o:

Tabela 12 - Variação entre - o e - $a$ na lista de Nimuendajú

\begin{tabular}{|c|c|c|c|}
\hline \multicolumn{2}{|c|}{ LISTA DE NIMUENDAJÚ } & \multirow{2}{*}{ KARITIANA } & \multirow{2}{*}{ TRADUÇÃO } \\
\hline Transcrição original & Possível transcrição & & \\
\hline u-sëră & [i'sera] & y-'it & meu filho (ego masculino) \\
\hline u-ëră & [i'sero] & y-'et & meu filho/minha filha (ego feminino) \\
\hline i-sábăbă & [i'soba] & sop & pena $^{7}$ \\
\hline
\end{tabular}

Assim, temos aqui um indicativo de que - $a$ e - o de fato estariam relacionados, pois temos o sufixo - $a$ sub-repticiamente emergindo em contextos nos quais prototipicamente teríamos o - o - ao final de enunciados isolados.

Também temos evidências de - a sendo usado no lugar de -o no próprio Karitiana. Estes dados envolvem o sufixo comitativo -tyyt, que discutimos no capítulo 1 e exemplificamos em 296. Crucialmente, temos o morfema - a sendo sufixado em -tyyt nos dados em 297 e 298. Como vimos anteriormente, o final de enunciados é um dos ambientes prototípicos do enfático -o:

(296) Comitativo -tyyt

Ta-haj-a-tyyt $\quad \emptyset$-naka-'agngi-t õwa

3ANAF-irmão-EPEN-COMIT 3-DECL-COP-NFUT criança

"A criança está com o irmão mais velho."

["Botỹj Pynhadna"]

(297) Sufixo - a em final de enunciado

A-ty a-taka-haadna-j yta-tyyt-a.

isso-OBL DECL.INV-DECL-falar-FUT 1pl-COMIT-NMZ

"É sobre isso que você vai falar com a gente."

["Ritos fúnebres"] 
(298) Sufixo - a em final de enunciado

Aj-tyyt-a.

2pl-COMIT-NMZ

"Com vocês."

["Ritos fúnebres"]

Outro exemplo em que - $a$ é usado no lugar de -o vem de um dado de Rodrigues (1986), que lista a palavra para 'marido' contendo o sufixo - $a$.

(299) Sufixo - a em final de enunciado

Man-a

marido- $\mathrm{N}$

"Marido"

(RODRIGUES, 1986)

No dicionário de Landin (2005) e em nossos trabalhos de campo, sempre nos deparamos com o vocábulo 'man' para designar 'marido'. Como possivelmente a palavra descrita por Rodrigues constituiria um enunciado isolado, este seria outro exemplo do sufixo - a sendo usado no lugar do enfático -o.

Em suma, os dados acima ilustram casos em que o morfema - $a$ emerge em contexto prototípicos de -o. Exemplos em que o inverso ocorre - ou seja, casos em que -o é empregado no lugar de - a - são bastante raros, no entanto. Em nossa investigação, encontramos apenas um possível exemplo. Vimos na seção §5.3 que um dos ambientes característicos do sufixo - $a$ é em compostos com a estrutura-base [NP NP Adj]. No exemplo abaixo, temos um composto formado pelas palavras 'ese' ('rio, igarapé') e ''eem' ('preto/sujo'), que denomina uma das aldeias Karitiana, a aldeia Joari ou Igarapé Preto. Trata-se, portanto, de um contexto de derivação morfológica, no qual frequentemente se encontra o sufixo - $a$. Aqui, no entanto, temos o morfema $-o .^{8}$

(300) Sufixo -o em composto

Ese 'eem-o

rio sujo/preto-O

"(Aldeia) Igarapé Preto."

(ARAÚJO, 2014, adaptado)

Em resumo, existe uma certa interpolação nos contextos de ocorrência dos morfemas - $a$ e -o, o que nos leva a postular uma possível conexão diacrônica entre eles. Provavelmente, a família Arikém primeiro estendeu o sufixo - a para os usos como enfático, pois vemos o - a em finais de enunciado tanto em Arikém quanto em Karitiana. Sendo produtivamente usado nessa posição, o - $a$ passa pela mudança vocálica em cadeia nestes contextos. Nos contextos em que ele não é mais empregado produtivamente, ele se torna opaco e se congela como a forma pré-mudança - $a$. Isso explicaria também porque

8 Obviamente, poderíamos contra-argumentar que o exemplo em 300 contêm o -o por possivelmente ter sido proferido em um enunciado isolado, sendo portanto um enfático - o. Neste caso, o principal teste seria inserir o composto em 300 em uma sentença e verificar se o -o se mantém em uma posição não final. Infelizmente, não dispomos deste dado até o momento. 
existem poucos casos de - o sendo utilizado no lugar de - $a$ : como o - $a$ tende cada vez mais a se tornar um elemento inerte que faz parte da raiz, ele resiste muito mais à mudança vocálica atestada para a família Arikém.

\subsection{Resumo do capítulo}

Neste capítulo, oferecemos mais uma evidência para a estrutura nominalizada das subordinadas em 259 ao apresentarmos uma provável realização fonológica do núcleo $n$, o sufixo - a. Argumentamos que este morfema seria junto com o enfático -o um cognato do sufixo - $a$ em outras línguas Tupi, que tipicamente emerge em nomes e construções nominalizadas. No capítulo 7, parte dessa discussão será retomada, pois discutiremos ainda uma vogal misteriosa que marca nomes dentro de orações subordinadas e que guarda grande semelhança com os sufixos $-o /-a$. 


\section{Parte II}

\section{Outros fenômenos}





\section{Morfema de voz inversa ti-}

Na parte I deste trabalho, apresentamos perguntas QU- complexas e discutimos também a estrutura de orações subordinadas. Neste capítulo, examinamos um outro fenômeno relacionado ao movimento QU- e a orações subordinadas: o morfema ti-. Por exibir diversas propriedades aparentemente não relacionadas e ocorrer em ambientes muito distintos, a investigação deste morfema retoma muitos pontos que já foram tratados nos capítulos anteriores. Porém, dada sua complexidade, ele demanda uma investigação à parte.

O morfema ti- emerge tipicamente em três tipos de construções: perguntas QUem que o pronome interrogativo é o objeto (veja 301), construções de focalização do objeto (302) e orações relativas cujo núcleo é o objeto direto (303) (D. LANDIN, 1984; STORTO, 1999; EVERETT, 2006):

(301) Pergunta QU- de objeto

Morã-mon taso ti-oky-t?

QU-COP.INT homem INV-matar-CON.COP

"O que o homem matou?"

(STORTO, 1999)

(302) Construção de foco do objeto

'Ep i-ti-pasagng-ã-t João.

árvore 3-INV-contar-N-NFUT João

"Árvores, o João está contando"

(STORTO, 1999)

(303) Oração relativa de objeto

Yn $\varnothing$-na-aka-t i-pyting- $\emptyset$ [gijo Luciana

1s 3-DECL-COP-NFUT NMZ-querer-CON.COP. [milho Luciana

ti-tak]-a-ty.

INV-pilar]-EPEN-OBL

"Eu quero o milho que a Luciana pilou."

(VIVANCO, 2014)

Os autores que descreveram a distribuição de ti- também notaram que ele altera o padrão de concordância da língua. Como vimos no capítulo 1, verbos transitivos concordam com o argumento absolutivo como em 304. No entanto, quanto ti- está presente (veja 305), o verbo passa a concordar com o NP ergativo:

Concordância normal

SUBJ $\mathrm{V}_{\mathrm{TR}}$ OBJ

(305) Concordância excêntrica

OBJ SUBJ ti-V


(306) Concordância normal

Yn a-ta-oky-j an

1s 2s-DECL-machucar-FUT 2s

"Eu vou te machucar."

(STORTO, 1999)

(307) Concordância excêntrica com ti-

'Ep aj-ti-pasagng-a-t ajxa

árvores 2pl-INV-contar-N-NFUT 2pl

"Árvores, vocês estão contando."

(STORTO, 1999)

Por conta disso, Storto (2005) afirma que ti- cria um ambiente de ergatividade cindida na língua.

O morfema ti- já foi classificado como um topicalizador (R. LANDIN, 1982; D. LANDIN, 1984; EVERETT, 2006), um marcador de foco do objeto (STORTO, 1999) e um morfema de voz inversa (STORTO, 2005). Tal profusão terminológica provavelmente deriva de sua complexidade estrutural, pois ele exibe diversas propriedades aparentemente não relacionadas. Neste trabalho, optamos por adotar a terminologia proposta por Storto (2005) de inversa por ter uma maior neutralidade, sobretudo no que diz respeito à estrutura da informação.

Neste capítulo, oferecemos uma nova análise do morfema ti- como um clítico pronominal. Assim, as sentenças em que ti- ocorre seriam configurações de redobro de clítico, nas quais o elemento pronominal cliticizado ao verbo é referente a um outro NP expresso na oração. Defendemos que essa análise é capaz de capturar tanto as propriedades que foram observadas até então para ti- como também outras que ainda não tinham sido discutidas até o momento, como a leitura pressuposicional do tema.

Na seção §6.1, apresentamos algumas outras propriedades do morfema ti- que já foram observadas na literatura, como sua relação com a valência dos verbos e traços de pessoa. Em $§ 6.2$, discutimos algumas análises alternativas que já foram propostas para este morfema e argumentamos que nenhuma delas é capaz de capturar o fenômeno em sua totalidade. Nossa proposta de redobro de clítico será apresentada em §6.3. Também discutimos como essa análise explicaria a presença de $t i$ - nas três construções elencadas acima, bem como outros fenômenos, como a concordância excêntrica, a impossibilidade de passivização e a leitura especial do tema nestas construções. Por fim, discutimos alguns possíveis problemas da análise de redobro de clítico em $\S 6.5$ e como acomodá-los em nossa proposta.

\subsection{Propriedades}

Como mencionamos acima, uma das razões para a profusão terminológica de $t i$ é de que se trata de um fenômeno com propriedades distintas. Primeiramente, vimos que 
ele ocorre em três tipos de construções que envolvem o objeto - as perguntas QU- de objeto, as construções de foco de objeto e as orações relativas de objeto -, e também que ele aciona um padrão de concordância diferenciado. Além destas propriedades, titambém parece interagir com a valência verbal. Especificamente, ti- só se afixa a verbos transitivos e também parece intransitivizá-los. Revisaremos essas duas propriedades mais demoradamente nas seções $§ 6.1 .1$ e $§ 6.1 .2$. Além disso, este morfema parece estar restrito a objetos de $3^{\text {a }}$ pessoa, uma propriedade que será discutida na seção §6.1.3.

\subsection{1 ti- só prefixa verbos transitivos}

$T i$ - parece ter uma restrição com relação à valência do verbo a que ele se prefixa. Primeiramente, ele nunca emerge com verbos intransitivos: ${ }^{1}$

(308) Ausência de ti-

Yn $\emptyset$-na-amang- $\emptyset \quad$ [se-pip erery 'ot]

1s 3-DECL-plantar-NFUT [rio-em algodão cair]

"Eu plantei o algodão que caiu no rio." (Elicitação de Luciana Storto, 2013)

(309) Ausência de ti-

Y-py-so'oot-yn yn [taso pykyn-a]-ty

1s-ASS-ver-NFUT 1s homem correr-N-OBL

"Eu vi o homem que correu."

Landin (1984) foi o primeiro a notar que ti- só interage com objetos diretos. ${ }^{2}$ Assim, ele só prefixa verbos transitivos, sejam eles intrinsecamente transitivos ou derivados através do causativizador $-m$-:

(310) ti- com verbo transitivo causativizado

Sepa i-ti-m-'a tỹja

cesto 3-INV-CAUS-fazer PROG

"É um cesto que estou tecendo."

(HALE; STORTO, 1997)

(311) ti-com verbo transitivo causativizado

[Õwa Elivar ti-m-tat] $\emptyset$-naka-hit- $\emptyset \quad$ ese-ty Orlando

criança Elivar INV-CAUS-ir 3-DECL-dar-NFUT água-OBL Orlando

"A criança que o Elivar fez sair deu água para o Orlando."

(ROCHA, 2016)

Se o argumento interno for um NP marcado com um oblíquo como em 313, tinão emerge:

1 Como vimos no capítulo 1, Storto e Rocha (2015) propõem que a distinção entre verbos inacusativos e inergativos inexiste em Karitiana e que todos os verbos monoargumentais são, na realidade, inacusativos. Dessa forma, o tipo de verbo intransitivo é indiferente para a presença de $t i$-.

2 A primeira menção é, na realidade, de Landin (1982). Ela, contudo, não diz explicitamente que ti- só ocorre com objetos diretos. 
(312) ti- com objeto direto

Yn $\emptyset$-na-amang- $\emptyset \quad$ [erery Maria ti-mong]

1s 3-DECL-plantar-NFUT algodão Maria INV-cultivar

"Eu plantei o algodão que Maria cultivou." (Elicitação de Luciana Storto, 2013)

(313) Ausência de ti-com objeto oblíquo

Yn $\emptyset$-na-amang- $\emptyset \quad$ [erery-ty Maria ta-'et-e

1s 3-DECL-plantar-NFUT algodão-OBL Maria 3ANAF-filha-EPEN

hit-i-p]

dar-EPEN-LOC/INF

"Eu plantei o algodão que a Maria deu pra filha dela." (Elicitação de Luciana

Storto, 2013)

\subsection{2 ti- $\mathrm{V}$ é intransitivo}

A ideia de que ti-de alguma forma intransitiviza o verbo já foi aventada por Hale and Storto (1997), Storto (1999), e Everett (2006), com diferentes conclusões. ${ }^{3}$ Everett (2006) assume que um verbo marcado com $t i$ - é de fato intransitivo por causa da concordância com o sujeito transitivo. Por outro lado, Hale e Storto (1997) e Storto (1999) assumem que o verbo em uma construção com ti- se mantém transitivo e que outros mecanismos gerariam a concordância excêntrica. Especificamente, eles tratam o $t i$ - como uma espécie de antipassiva espúria - uma análise que discutiremos em detalhe na seção §6.2.3. Aqui, oferecemos alguns argumentos mostrando que $t i$ - de fato intransitiviza o verbo. As evidências vêm de dois diagnósticos: as construções de cópula e a distribuição complementar com a passiva.

Como vimos no capítulo 1, a construção de cópula é um teste para se detectar intransitividade na língua, pois ela só admite verbos intransitivos. Essa proibição se mantêm independentente do argumento frontalizado: se o agente (como em 314) ou o tema (315):

(314) Construção de cópula com verbo transitivo

*Taso $\emptyset$-na-aka-t i-'y-t (ta-ti'y)

homem 3-DECL-COP-NFUT NMZ-comer-CON.COP (3ANAPH-comida)

(STORTO, 2010)

(315) Construção de cópula com verbo transitivo

*Ti'y $\emptyset$-na-aka-t taso i-'y-t

comida 3-DECL-COP-NFUT homem NMZ-comer-CON.COP.

3 Landin (1984) não menciona intransitividade especificamente, mas aponta o padrão de concordância excêntrica (que, na proposta do autor, era entendida a partir de pronomes livres) e discute uma possível caracterízação desse morfema como uma voz passiva. 
Crucialmente, se um verbo transitivo estiver prefixado por $t i$-, ele é permitido na construção de cópula. Como vimos no capítulo 1, esse tipo de construção tem sido denominado de 'clivada' por Storto (STORTO, 2010).

(316) Construção de cópula com ti- - clivada

Erery ( $\emptyset$-na-aka-t) keerep jonso ti-amang-ã-t

algodão 3-DECL-COP-NFUT antigamente mulher INV-plantar-N-CON.COP

"Foi algodão que as mulheres plantavam antigamente."

(STORTO, 2010)

(317) Construção de cópula com ti- - clivada

Ti'y Ø-na-aka-t taso ti-'y-t

comida 3-DECL-COP-NFUT homem INV-comer-con.cop.

"Foi comida que o homem comeu."

Assim, ti- parece intransitivizar o verbo, pois, ao ser sufixado por este morfema, um verbo transitivo passa pelos testes que tipicamente diagnosticam intransitividade na língua.

Como vimos em 1, a passiva é outro diagnóstico de intransitividade, visto que o prefixo $a$ - só se afixa a verbos transitivos (ROCHA, 2011; STORTO; ROCHA, 2015). Ela, portanto, é permitida com um verbo transitivo como ' $y$ ', mas não com o intransitivo 'se' $y$ ':

(318) Passiva com transitivo

$\emptyset$-pyr-y-a-'y-dn ti'y

3-ASS-EPEN-PASS-COmer-NFUT comida

"A comida foi comida."

(ROCHA, 2011)

4 Somente o tema pode ser frontalizado neste caso:

(x) Extração do agente em clivada

*Taso $\emptyset$-na-aka-t ti'y ti-'y-t.

homem 3-DECL-COP-NFUT comida INV-comer-CON.COP.

Neste sentido, a clivada mimetiza o que já foi observado por Storto (2008) nas construções QU-, nais quais o sujeito intransitivo e o objeto formam uma classe natural.

5 Que estes verbos são respectivamente transitivos e intransitivos pode ser demonstrado pela (im)possibilidade da construção de cópula:

(xi) "y"gramatical com a cópula

*Taso $\emptyset$-na-aka-t i-'y-t

homem 3-DECL-COP-NFUT NMZ-comer-CON.COP.

(ROCHA, 2011)

(xii) "Se'y"gramatical com a cópula

Jonso $\emptyset$-na-aka-t i-se'y-t

mulher 3-DECL-COP-NFUT NMZ-beber-CON.COP.

"A mulher bebeu."

(ROCHA, 2011) 
(319) Passiva com intransitivo

* $\emptyset$-pyr-y-a-se'y-dn kytopo

3-ASS-EPEN-PASS-beber-NFUT chicha

"(Pretendido) A chicha foi bebida.")

(ROCHA, 2011)

Crucialmente, $t i$ - e $a$ - estão em distribuição complementar, pois um mesmo verbo não pode ser concomitantemente marcado por estes dois morfemas (independente da ordem entre eles):

\section{Inversa em oração subordinada}

Yn $\emptyset$-na-otet- $\emptyset \quad$ 'ip taso ti-'y

1s 3-DECL-cozinhar-NFUT peixe homem INV-comer

"Eu cozinhei o peixe que o homem comeu."

(ROCHA, 2016)

(321) Passiva em oração subordinada

Yn $\emptyset$-na-otet- $\emptyset \quad$ 'ip a-'y

1s 3-DECL-cozinhar-NFUT peixe PASS-comer

"Eu cozinhei o peixe que foi comido."

(ROCHA, 2016)

(322) Inversa e passiva em oração subordinada

*Yn $\emptyset$-na-otet- $\emptyset \quad$ 'ip ti-a-'y

1s 3-DECL-cozinhar-NFUT peixe INV-PASS-comer

(ROCHA, 2016)

(323) Passiva e inversa em oração subordinada

*Yn $\emptyset$-na-otet- $\emptyset \quad$ 'ip a-ti-'y

1s 3-DECL-cozinhar-nfut peixe PASS-INV-comer

Além das orações relativas, ti- e $a$ - também estão em distribuição complementar em perguntas QU-:

(324) Passiva em pergunta QU-de objeto

Morã-mon i-a-oky-t?

QU-COP.INT. NMZ-PASS-matar-CON.COP.

"Quem foi morto?"

(325) Inversa e passiva em pergunta $Q U$ - de objeto

*Morã-mon ti-a-oky-t?

QU-COP.INT. INV-PASS-matar-CON.COP.

"(Pretendido) Quem foi morto?"

O morfema ti- exibe também uma alomorfia que mencionamos brevemente em capítulos anteriores e que pode ser ilustrativa. Basicamente, os contextos discutidos em 301-303 são todos não declarativos segundo a terminologia proposta por Storto (1999) e exposta no capítulo 1. Contudo, em contextos declarativos, o alomorfe usado para a voz inversa não é $t i-$, mas sim um morfema $a$ - homófono à passiva: 
(326) Voz inversa declarativa

'Ep a-ta-pasagng- $\emptyset$

árvore INV.DECL-DECL-contar-NFUT

"As árvores, eles contaram."

(STORTO, 1999)

A questão é então se a passiva e a inversa podem estar de alguma forma interrelacionados ou se até seriam o mesmo marcador. Essa discussão será feita na seção §6.4.3, na qual discutiremos como a nossa análise é capaz de capturar a distribuição complementar entre $t i$ - e $a$-.

\subsection{3 ti- tem traços de $3^{\mathbf{a}}$ pessoa}

Existem evidências mostrando que a contraparte declarativa de $t i$-, o morfema $a$-, teria traços de terceira pessoa. Especificamente, ele é agramatical com objetos de $1^{\mathrm{a}} \mathrm{e}$ $2^{\mathrm{a}}$ pessoa em construções de foco do objeto (STORTO, 1999):

(327) Inversa declarativa com objeto em $3^{\underline{a}}$ pessoa

I a-ta-oky-t

3s INV.DECL-DECL-matar-NFUT

"Ele, eles mataram."

(STORTO, 1999)

(328) Inversa declarativa com objeto em $1^{\underline{a}}$ pessoa

*Yn a-ta-oky-t

1s INV.DECL-DECL-matar-NFUT

"(Pretendido) Eu, eles mataram."

(STORTO, 1999)

(329) Inversa declarativa com objeto em $2^{a}$ pessoa

*An a-ta-oky-t

2s INV.DECL-DECL-matar-NFUT

"(Pretendido) Eu, eles mataram."

(STORTO, 1999)

Infelizmente, os dados não puderam ser replicados com o morfema $t i-$, pois grande parte dos falantes tende a recusar sentenças matrizes não declarativas em sessões de elicitação.

\subsection{Outras análises possíveis}

Na literatura sobre o $t i$-, algumas análises já foram aventadas, como a possibilidade de ti- ser um marcador de frontalização ou uma passiva espúria. Além disso, a semelhança de $t i$ - com construções análogas em outras línguas sugerem outras análises, como a possibilidade de um tipo especial de (anti)concordância. Nas próximas seções, agrupamos as principais contra-propostas para este morfema e argumentamos que elas não são capazes de explicar o fenômeno em sua totalidade. 


\subsection{1 ti- marca frontalização}

Uma das análises mais intuitivas sobre o ti- é de que ele marcaria a frontalização do tema (D. LANDIN, 1984). Essa análise encontra respaldo no fato de que, em seus contextos típicos de ocorrência como 301-303, o objeto aparece sempre deslocado na periferia esquerda da sentença. O principal problema com tal proposta é que, em sua formulação mais simples, ela não é inteiramente correta, pois não é verdade que o tema ocupa a periferia esquerda da oração em todas as sentenças com $t i$-. Vejamos alguns exemplos.

Como vimos acima, um dos contextos em que $t i$ - prototipicamente emerge é uma oração relativa de objeto. Embora o objeto tipicamente se encontre deslocado à esquerda nessas orações, vimos no capítulo 1 que existe uma variação de ordem que permite que ele apareça em posições não frontalizadas (VIVANCO, 2014; 2015)

Objeto não frontalizado com ti-

Yn $\emptyset$-na-aka-t i-pyting- $\emptyset$ [Ana pykyp

1s 3-DECL-COP-NFUT NMZ-querer-CON.COP [Ana roupa

ti-pipãram]-a-ty

INV-costurar]-EPEN-OBL

"Eu quero as roupas que a Ana costurou."

Além disso, adjuntos e argumentos tipicamente ocupam a primeira posição em orações subordinadas (mas veja Storto (1999) para outras posições possíveis em relativas). Isso implica que, quando um destes elementos estiver presente, o tema ocupará uma posição não periférica:

(331) Advérbio na periferia da oração subordinada com ti-

Karin $\emptyset$-na-aka-t i-engy-t [koot syke Ivan

Karin 3-dDECL-COP-NFUT NMZ-vomitar-NFUT ontem mingau Ivan

ti-m-'a]-ty.

INV-CAUS-fazer-OBL

"Karin vomitou o mingau que o Ivan fez ontem."

Em alguns casos de perguntas QU- de longa distância com relativas de objeto, o núcleo da relativa não só não se localiza na periferia da oração, como também estaria bastante longe dessa posição:

\footnotetext{
Pergunta de longa distância com oração relativa

[[Morã ti-m-'a]-mon syke] Luciana ti-'y-t?

QU INV-CAUS-fazer-COP.INT mingau Luciana INV-comer-CON.COP.
}

"A Luciana comeu o mingau que quem fez?"

Estes dados nos mostram que o objeto não aparece na periferia esquerda em todas as construções com ti- . Tal conclusão lança dúvida na análise da frontalização, pois, se ela de fato ocorre, provavelmente não é uma operação tão simples como se supunha para 
os casos em 301-303. Para contornar esse problema, propomos na seção §6.3 que uma espécie de frontalização de fato ocorre, mas que ela seria um movimento bem mais curto de que foi proposto originalmente.

\subsection{2 ti- marca movimento QU-}

Como vimos no início deste capítulo, ti- emerge em contextos em que o objeto se move para Spec, CP como perguntas QU-. Por conta disso, poderíamos então propor que este morfema seria um marcador de movimento QU-. Essa ideia ganharia ainda mais força se as outras duas construções em que ti- emerge - a construção de foco de objeto e a relativa de objeto - também envolverem movimento para Spec, CP.

Sobre isso, é importante pontuar que Storto (1999) afirma que o slot pré-verbal em orações matrizes é o próprio Spec, CP. Assim, a derivação de uma pergunta QU- e de uma construção de foco de objeto como 302, que tem o tema na posição pré-verbal, seriam bastante similares. Sobre as orações relativas, desde Chomsky (1977) se assume que estas construções conteriam movimento de um elemento (um pronome interrogativo ou um operador nulo) para Spec, CP. Se isso se estender para as relativas do Karitiana, seria possível analisar o ti- como um marcador de movimento QU- em todos os contextos.

Para desenvolver esta análise com mais cautela, poderíamos supor que esse morfema possa ser de um dos dois tipos de marcadores que fazem referência ao movimento QU-: uma concordância QU- ou uma anticoncordância. O primeiro caso refere-se a uma classe de marcadores que emerge como reflexo da ocupação ou da passagem de um elemento por Spec, CP. Um dos exemplos mais prototípicos deste tipo de fenômeno são os alomorfes do núcleo $\mathrm{C}$ em irlandês, no qual o complementizador ' $a L$ ' emerge como reflexo de um movimento QU- em orações relativas e perguntas QU- (MCCLOSKEY, 2001). A título de comparação, veja que esta mesma partícula não emerge em casos em que não há movimento QU-, como 335:

(333) Oração relativa

[Irlandês]

An lá a bhí muid i Machaire Rabhartaigh $t$

o dia aL estar[PASs] nós em Machaire Rabhartaigh

"O dia que nós estávamos em Machaire Rabhartaigh' (MCCLOSKEY, 2001)

(334) Pergunta QU- [Irlandês]

Cá fhad a bhí siad fá Bhaile Âtha Cliath t?

QU extensão aL estar[PASS] eles perto Dublin

"Por quanto tempo eles estiveram em Dublin?'

(MCCLOSKEY, 2001)

(335) Sentença bi-oracional declarativa [irlandês]

Deir siad gur ghoid na síogaí í.

dizer eles C[PASS] roubou as fadas ela

"Eles dizem que as fadas a roubaram.".

(MCCLOSKEY, 2001) 
À semelhança do complementizador ' $a L$ ' em irlandês, o morfema $t i$ - poderia ser então o reflexo morfológico do preenchimento de Spec, CP. Existem, contudo, dois problemas aqui. O primeiro deles é a presença de $t i$ - em relativas de objeto como 303. Se quiséssemos estender a análise de que ti- é o reflexo morfológico de um Spec, CP preenchido, isso implicaria em assumir que algum elemento nas orações relativas (possivelmente o próprio núcleo) ocuparia a posição de Spec, CP. Como mencionamos acima, essa é geralmente a análise tradicional de relativas desde Chomsky (1977), e também frequentemente se assume que mesmo relativas de núcleo interno envolvem de movimento QU- do núcleo para Spec, CP (cf. Cole (1987) e Vries (2002), inter alia). O problema dessa proposta é que, como vimos em nos capítulos 2 e 4, as subordinadas do Karitiana não parecem incluir uma projeção CP. Dessa forma, não seria possível afirmar que ti- emerge em orações relativas de objeto por causa do preenchimento de Spec, CP nestes casos, pois essa projeção simplesmente inexistiria nessas construções.

O outro tipo de marcador que ti- poderia ser é um outro morfema característico de perguntas QU-, a anticoncordância. A diferença entre a anticoncordância para uma concordância QU- simples é de que a primeira é um morfema que suplanta os afixos de concordância na presença de movimento QU-. Intuitivamente, sua principal função parece ser a de evitar a concordância usual com um determinado argumento (normalmente o sujeito) sempre que um movimento QU- ocorre - daí a terminologia de anticoncordância (OUHALLA, 1993; BAIER, 2016). Em Berbere, por exemplo, a concordância normal não é permitida em casos de movimento QU-, como perguntas com pronomes interrogativos. Neste caso, é preciso usar uma forma especial do verbo, uma espécie de particípio:

(336) Concordância simples

[Berbere]

T-zra tamghart Mohand

3sg.f-ver mulher Mohand

"A mulher viu Mohand?"

(BAIER, 2016)

(337) Anticoncordância em pergunta

[Berbere]

Man tamghart ay yzrin Mohand?

qual mulher COMP ver-(PART) Mohand

"Qual mulher viu Mohand?"

(OUHALLA, 1993)

(338) Concordância simples em pergunta

*man tamghart ay t-zra Mohand?

qual mulher COMP 3sg.f-ver Mohand

(OUHALLA, 1993)

Embora tradicionalmente a anticoncordância emerja com sujeitos e em contextos em que há movimento QU-, podemos supor que ela talvez apareça em qualquer grupo de construções no qual a concordância com determinado argumento é evitada por algum 
motivo. Assim, o emprego de $t i$ - em perguntas seria uma estratégia para se "evitar" a concordância com o elemento absolutivo. Tal proposta consistiria em um grande desvio dos casos prototípicos de anticoncordância, que envolvem movimento QU-. Ela, contudo, capturaria a distribuição dos fatos em Karitiana, pois, em casos em que ti- aparece, a concordância usual com o argumento absolutivo ou é suprimida (perguntas QU-) ou é substituída pela concordância excêntrica (construções de foco de objeto).

O principal problema dessa proposta é que uma anticoncordância tradicionalmente suplanta uma concordância que é virtualmente possível naquele ambiente, ou seja, sua função é substituir uma concordância que de outra forma existiria em determinada construção. A questão é que, no caso das orações subordinadas, não existe concordância, apenas NPs livres ou pronomes cliticizados (que re-analizamos como possessivos em §4.4.3). Assim, não haveria como ti- substituir a concordância normal em orações subordinadas simplesmente pelo fato de a própria concordância normal ser impossível nesses ambientes.

Em resumo, qualquer análise (seja de concordância QU- ou de anticoncordância) que vincule a presença do ti- com movimento QU- terá problemas a enfrentar. Por outro lado, considerar que ti- é totalmente desvinculado do movimento QU- é igualmente problemático, pois dois dos seus ambientes prototípicos de fato envolvem movimento QU-. Como veremos na seção §6.4.1, evitaremos este problema ao assumir que a operação executada por ti- é um pré-requisito para que o movimento QU- ocorra em perguntas QUe construções de foco. Assim, por não ser o movimento QU- em si mas apenas por fazer parte dele, nossa análise não incorre nos problemas elencados acima.

\subsection{3 ti- como uma antipassiva espúria}

O comportamento de $t i$ - encontra ecos em construções similares de outras línguas, como a antipassiva espúria de Chukchi (BOBALIJK; BRANIGAN, 2006). Como se vê nos exemplos em 339 e 340, Chukchi é uma língua de alinhamento ergativo-absolutivo que antipassiviza orações através do prefixo -ine-. Na construção antipassiva em 340, o sujeito transitivo 'homens jovens' é promovido a absolutivo e o objeto 'carga' se torna um instrumental. A construção em 341, no entanto, é difícil de classificar: se, por um lado, o morfema de antipassiva -ine- está presente, por outro a marcação de caso dos elementos parece indicar que a oração retêm um caráter ativo:

(339) Voz ativa

[Chukchi]

Paaček-a kimit?-ən ne-nł?etet-ən

juventude-ERG carga-ABS 3PL.SUBJ-carregar-3SG.OBJ

"(Os) homens jovens levaram a carga." (Kozinsky et al. (1988) apud Bobalijk e Branigan (2006)) 
(340) Antipassiva

[Chukchi]

Paaček-ət ine-nł?etet-y?et kimit?-e

juventude-PL(ABS) AP-carregar-3PL.SUBJ carga-INST

"(Os) homens jovens levaram uma carga." (Kozinsky et al., (1988) apud Bobalijk

e Branigan (2006))

(341) Antipassiva espúria

[Chukchi]

ə-nan yəm $\emptyset$-ine-\$?u-y?i

ele-ERG eu(ABS) 3SG.SUBJ-AP-ver-3SG.SUBJ

"Ele me viu." ～(Skorik (1977) apud (BOBALIJK; BRANIGAN, 2006))

Assim, a antipassiva em 341 é denominada de 'espúria' por não ter o mesmo comportamento intransitivizador da antipassiva "real"em 340.

A similaridade de antipassivas espúrias com $t i$ - foi principalmente explorada para o Karitiana por Hale and Storto (1997). No caso de antipassivas espúrias, a construção parece ser transitiva mesmo com o morfema de antipassiva, pois os argumentos retêm a mesma marcação de caso da voz ativa (veja Bobalijk e Branigan (2006)). Além disso, a antipassiva espúria altera o padrão de concordância da ativa e o verbo passa a não concordar mais com o objeto (perceba a ausência do sufixo do objeto em 341). Neste aspecto, ela teria um efeito muito semelhante à anticoncordância.

No caso do ti-, Hale e Storto observam que nenhum argumento parece estar demovido, o que seria de se esperar em uma (anti)passiva típica. Em outras palavras, os argumentos parecem reter o mesmo caso que uma oração sem ti-. Também a concordância segue um padrão similar ao da antipassiva espúria, pois a concordância com o objeto em construções de foco é suplantada pela concordância com o sujeito transitivo assim como 341.

Contudo, mostramos na seção §6.1.2 que as construções com ti- passam em testes de intransitividade na língua como a construção de cópula e a passivização. Assim, podemos afirmar que, ao contrário do dado de Chukchi em 341, essas construções são de fato intransitivas. Além disso, mesmo que um oblíquo não emerja nos argumentos das construções com $t i$-, isso não implica que os NPs retêm os mesmos casos de orações sem este morfema. No caso de Chukchi, existem morfemas de caso com conteúdo fonológico, o que torna bem mais simples a tarefa de identificar o estatuto dos argumentos. Em Karitiana, a marcação de absolutivo, ergativo e genitivo são todas feitas através de morfemas nulos (veja o capítulo 1); assim, é muito difícil saber exatamente com qual caso os sintagmas nominais são marcados.

Outra questão relevante é que, como vimos em $\S 4.4 .3$, a cliticização quase obrigatória de pronomes nos faz crer que ao menos um dos argumentos carrega caso genitivo em orações subordinadas. Se for este o caso, os argumentos não reteriam o mesmo caso em construções com e sem ti-, o que distanciaria as primeiras de antipassivas espúrias como 341. 
Além disso, não é ainda totalmente correto dizer que (anti)passivas necessariamente envolveriam um dos argumentos marcados com um morfema oblíquo. Em Basco, por exemplo, os sintagmas nominais carregam exatamente o mesmo caso que sua contraparte ativa, pois os agentes da passiva são marcados com caso ergativo nessa língua (PERLMUTTER; POSTAL, 1977). Nesse caso, a ocorrência de passivização é sinalizada apenas através do verbo e de seu auxiliar:

(342) Voz ativa

[Basco]

Piarresk egin du etchea.

Peter/ERG fez tem casa/ABS

"Peter fez a casa."

(PERLMUTTER; POSTAL, 1977)

(343) Voz passiva

[Basco]

Piarresk egina da etchea.

Peter/ERG feita é casa/ABS

"A casa foi feita por Peter."

(PERLMUTTER; POSTAL, 1977)

Em suma, não é possível por enquanto afirmar com certeza se os argumentos mantêm ou não o mesmo estatuto em orações sem $t i$-, pois isso demandaria o desenvolvimento de diagnósticos mais sofisticados para detectar o caso dos argumentos. Por ora, podemos afirmar que existem diversas evidências de que as construções com $t i$ - são intransitivas, ao contrário das antipassivas espúrias. Sendo assim, concluímos que, apesar da aparente similaridade, as construções com ti- não podem ser consideradas antipassivas espúrias. Por fim, a impressão de que os argumentos têm em construções com $t i$ - a mesma configuração de orações transitivas - o que, por sua vez, levou à análise de antipassiva espúria - pode ser uma ilusão criada pelo fato da língua marcar vários casos diferentes através de morfema nulos.

\subsection{4 ti- como passiva}

A discussão sobre antipassivas espúrias levanta uma outra hipótese: se um verbo com ti- é intransitivizado e o objeto direto é de alguma forma promovido para uma posição mais alta, essa construção não poderia ser então considerada uma forma de passiva? Na realidade, essa hipótese já fora aventada por Landin (1982) em um dos primeiros trabalhos sobre o $t i$ - Ela também encontraria respaldo no fato de que $t i$ - e a passiva $a$ - estariam em distribuição complementar, além de capturar a homofonia entre o alomorfe de voz inversa declarativa $a$ - e a própria passiva.

Tradicionalmente, a diferença entre uma passiva e uma inversa reside no grau de transitividade entre essas construções: enquanto passivas intransitivizariam o verbo, nas inversas o agente e o tema estariam ambos expressos (embora com um grau de topicalidade inverso em relação às orações equivalentes ativas). Assim, um fator que ampara a conclusão 
de que $t i$ - é uma espécie de passiva é seu comportamento intransitivo, como vimos na seção $\S 6.1 .2$.

Contudo, embora ti- intransitivize o verbo de certa forma e pelo menos um de seus argumentos tenha possivelmente sido genitivizado, a construção ainda exibe certas propriedades transitivas. Especificamente, o agente/causa e o tema ainda retêm algumas de suas propriedades sintáticas de sujeito e o objeto. Isso pode ser demonstrado através de um teste com o 'akatayym'. Como mencionamos em $§ 2.3 .2 .1$, essa palavra é usada para veicular o significado de 'todo' na língua:

Quantificador 'akatyym'

[Taso aka-tyym] $\emptyset$-na-soko', $\tilde{\mathrm{i}}$-t $\quad$ eremby

homem COP-ASP 3-DECL-amarrar-NFUT rede

"[Todos os homens] amarraram a rede."

(COUTINHO-SILVA, 2008)

Como mencionamos antes, Coutinho-Silva (2008) e Storto e Thomas (2012) ofereceram diversas evidências de que 'akatyym' tem diversas propriedades oracionais, sendo uma delas a presença de marcas de pessoa. O que é mais relevante aqui é que, quando deslocado para a posição inicial, os prefixos de pessoa em 'akatyym' fazem distinção entre sujeitos e objetos: basicamente, 'taakatyym' é sempre correferente ao sujeito e 'iakatyym', ao objeto:

(345) TA-akatyym relacionado ao sujeito

Ta-aka-tyym $\emptyset$-na-soko' $\tilde{\mathrm{i}}$-t $\quad$ eremby taso

3ANAF-COP-ASP 3-DECL-amarrar-NFUT rede homem

"Todos os homens amarraram a rede"

(COUTINHO-SILVA, 2008)

(346) I-akatyym relacionado ao objeto

I-aka-tyym $\emptyset$-na-soko $\tilde{\mathrm{i}}$-t $\quad$ eremby taso

3-COP-ASP 3-DECL-amarrar-NFUT rede homem

"O homem amarrou todas as redes."

(COUTINHO-SILVA, 2008)

'Akatyym' é atestado em orações subordinadas. No dado abaixo, mostramos que ele pode ocorrer em conjunto com o núcleo de uma oração relativa de objeto:

(347) Akatyym em orações subordinadas

João $\emptyset$-na-soko $\tilde{\mathrm{i}}$-t $\quad$ eremby aka-tyym Ivan ti-m'a

João 3-DECL-amarrar-NFUT rede COP-ASP Ivan INV-fazer

"João amarrou todas as redes que o Ivan fez."

Crucialmente, quando 'akatyym' é frontalizado, o prefixo de pessoa utilizado é $i$-, não $t a-$ : 
(348) I-akatyym relacionado ao tema

João $\emptyset$-na-soko' $\tilde{\text { i-t }}$ i-aka-tyym eremby jonso ti-m'a

João 3-DECL-amarrar-NFUT 3-COP-ASP rede mulher INV-fazer

"João amarrou todas as redes que o Ivan fez."

(349) TA-akatyym relacionado ao tema

*João $\emptyset$-na-soko'î-t ta-aka-tyym eremby jonso ti-m'a

João 3-DECL-amarrar-NFUT 3ANAF-COP-ASP rede mulher INV-fazer

Este teste nos mostra que o tema em uma construção com ti- (neste caso, uma relativa de objeto) ainda retém seu estatuto como objeto, pois o prefixo de pessoa com 'akatyym' se assemelha a casos de correferência com objetos como 346. Isso, por sua vez, nos leva a concluir que $t i$ - não é exatamente uma passiva, pois passivas tradicionalmente promovem o argumento interno para a posição de sujeito. A impossibilidade de se empregar 'taakatyym' em casos como 349 nos mostra que este não é o caso, pois o tema não se comporta como um sujeito nestas construções

Embora o ti- não seja exatamente uma passiva, as interações entre essas duas construções são evidentes e precisam ser capturadas de alguma forma. Na seção §6.4.3, explicaremos as relações entre as estruturas de passiva e redobro de clítico ao assumir que, em ambos os casos, existiria um elemento de natureza argumental que é incorporado ao verbo.

\subsection{5 ti- como concordância}

Na seção §6.1.3, mostramos que o morfema de voz inversa só ocorre com objetos de $3^{\text {a }}$ pessoa. Por conta dessa restrição, é possível então pensar que $t i$ - seria uma espécie de concordância disparada em determinados ambientes. Uma análise nessa linha de raciocínio foi proposta para a voz inversa do Kadiwéu (Guaikuru): segundo Nevins e Sandalo (2011), o morfema de inversa - $d$ :- seria uma marcação de concordância empobrecida, que emergiria quando um argumento [ + participante] é frontalizado para obedecer à hierarquia de pessoa como em 351:

(350) Oração transitiva ativa

[Kadiwéu]

(naGada) y-emaa (naGada)

(ela) 3AG-amar (ela)

"Ela a ama"

(NEVINS; SANDALO, 2011)

(351) Voz inversa

[Kadiwéu]

(naGada) (ee) i-d:-emaa

(ela) (eu) 1OBJ-INV-amar

"Ela me ama"

(NEVINS; SANDALO, 2011) 
Assim como - $d$ :- em Kadiwéu, ti- poderia ser um morfema de concordância com o traço [-participante], englobando objetos em $3^{\text {a }}$ pessoa. Tal conexão é plausível, dado que um dos alomorfes de concordância de $3^{\text {a }}$ pessoa é $i$ - (STORTO, 2002, e veja também $\S 6.3 .1)$.

O problema dessa análise é que $t i$ - emerge em contextos nos quais a concordância usual não é permitida, como as orações subordinadas relativas. Esse mesmo ponto já havia sido observado na análise desse morfema como anticoncordância (veja §6.2.2), o que demonstra a dificuldade em analisar $t i$ - como qualquer espécie de concordância. Além disso, se $t i$ - fosse de fato um morfema de concordância, construções nais quais este morfema coocorre com um prefixo de pessoa como 352 abaixo teriam então uma marcação dupla de pessoa:

ti- e concordância

Yn $\emptyset$-na-otet- $\emptyset \quad$ 'ip a-ti-'y

1s 3-DECL-Cozinhar-NFUT peixe 2S-INV-comer

"Eu cozinhei o peixe que você comeu."

Contudo, a dupla marcação de pessoa não parece ser permitida na língua, como a coocorrência dos prefixos de $1^{\mathrm{a}}$ e $2^{\mathrm{a}}$ pessoa no dado em 354 nos mostra:

(353) Concordância única

An y-taka-mi-t

2s 1s-DECL-bater-NFUT

"Você me bateu."

(354) Dupla concordância

*An a-y-taka-mĩ-t

2s 2s-1s-DECL-bater-NFUT

Dessa forma, concluímos que ti- não pode ser um morfema de concordância de nenhum tipo, pois ele não exibe o comportamento e distribuição da concordância real. Na seção §6.3.1 mostraremos uma forma alternativa de capturar os traços de pessoa no morfema ti- sem recorrer à análise de concordância.

\subsubsection{Resumo da seção}

Nas últimas seções, apresentamos algumas análises alternativas para o ti- e discutimos porque elas não conseguem capturar todas as propriedades deste morfema. $\mathrm{Na}$ próxima seção, apresentamos a análise de ti- como um clítico pronominal e as construções em que ele aparece como configurações de redobro de clítico, e mostramos nas seções $\S 6.4 .1, \S, \S 6.4 .4$ e $\S 6.4 .3$ como ela é capaz de capturar sua distribuição e seu comportamento. 


\subsection{Proposta}

Nas seções anteriores, vimos que ti- exibe um conjunto bastante complexo de propriedades morfossintáticas. Primeiramente, ele emerge em construções em que movimento QU- do objeto ocorre, mas a ocorrência de movimento QU- não parece ser a condição necessária para o uso do ti-. Ele, em certo sentido, "promove" o objeto, na medida em que o tema passa a ocupar posições sintáticas mais altas quando este morfema está presente. No entanto, ele parece se diferenciar de uma passiva, pois, embora um verbo prefixado por $t i$ - se comporte como um intransitivo, seus argumentos ainda parecem reter propriedades de sujeito e objeto direto. Por fim, ele também não pode ser considerado uma (anti)-concordância por ocorrer em ambientes sintáticos nos quais a concordância não é usualmente permitida.

Para capturar todas essas propriedades, propomos que construções com ti- são uma configuração de redobro de clítico. Este fenômeno, tipicamente encontrado em línguas românicas, engloba um elemento pronominal cliticizado ao verbo e co-referente com um outro NP na oração, como é o caso de 'la' e 'a ella' no exemplo abaixo:

Redobro de clítico

[Espanhol]

La llamaron a ella.

ela 3PL-chamar ela

"(Literalmente) (Eles) a chamaram a ela."

(SUÑER, 1988)

Propomos que $t i$, à semelhança de ' $l a$ ' em 355 seria um elemento pronominal. Este morfema e o tema seriam ambos gerados como complemento de V, em uma estrutura comumente chamada de "grande NP" (URIAGEREKA, 1995; NEVINS, 2011).

(356) Estrutura de base

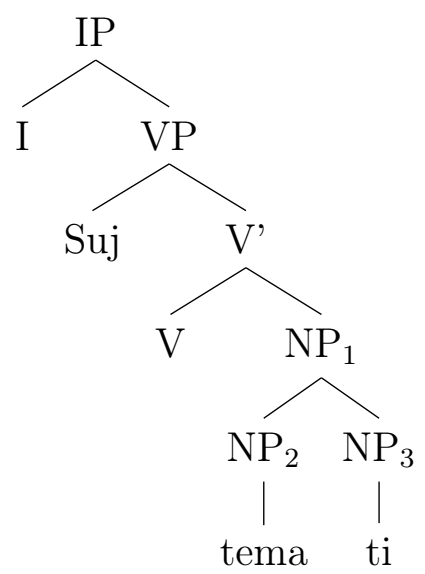

Dada a natureza afixal de $t i$-, ele se moveria para uma posição em que seja possível se sufixar em um hospedeiro. Assim, ele se move para o domínio do núcleo ao qual vai se afixar, a saber, uma posição de adjunção em $v$ P. Ao fazê-lo, ele "arrasta"o tema consigo em uma operação que remete ao pied-piping com NPs (veja §4.3.2). 


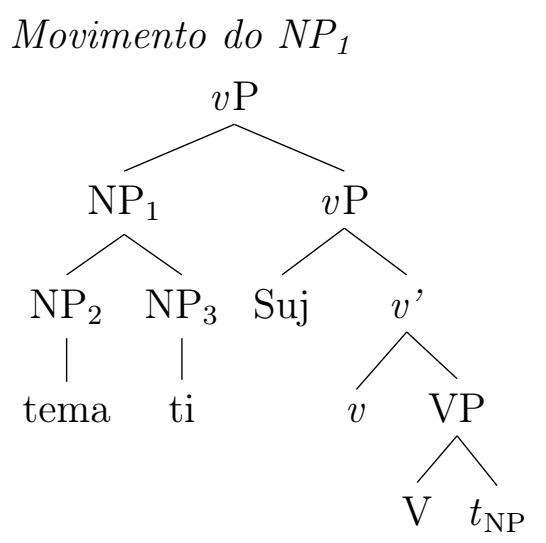

Por seu caráter argumental, a afixação de $t i$ - em $v$ altera a valência verbal, pois o ti- acabaria sendo de certa forma incorporado ao verbo. Esta operação remete à propriedade de absorver caso/papel temático que frequentemente tem sido atribuída aos clíticos das línguas românicas (mas veja Suñer (1988)).

Embora o movimento do $\mathrm{NP}_{1}$ para a borda do $v \mathrm{P}$ seja disparado por ti-, uma consequência desta operação é que o tema também é arrastado para essa posição. Crucialmente, nessa posição, ele adquire muito mais mobilidade dentro da oração - e veremos que essa também é uma característica de algumas construções de redobro de clítico (ALEXIADOU; ANAGNOSTOPOUlOU, 2000). Essa questão será explorada mais a fundo na seção §6.4.1; por ora, basta notar que esta estrutura encontra eco na estrutura de passiva proposta por Collins (2005), na qual a principal função de um morfema passivo em inglês é de "contrabandear" (smuggle, no original) o argumento interno para fora do $v \mathrm{P}$. Na nossa estrutura, ti- também acaba "contrabandeando" o $\mathrm{NP}_{1}$ para fora do sintagma verbal ao forçar o movimento do $\mathrm{NP}_{1}$ para a borda deste domínio sintático.

Na próxima seção, detalharemos essa proposta ao mostrar que ti- pode ser analisado como um pronome tanto diacronicamente quanto sincronicamente. Além disso, também apresentaremos evidências da Teoria da Ligação mostrando que o tema é de fato gerado como complemento de $\mathrm{V}$.

\subsubsection{Natureza pronominal de ti-}

O cerne de nossa proposta se encontra na natureza argumental de $t i$-. Por ter um caráter afixal e, portanto, não ter a mobilidade característica dos clíticos românicos, o estatuto de $t i$ - como um elemento pronominal pode ser questionado. Assim, discutiremos nesta seção evidências de que $t i$ - de fato se comporta como uma espécie de pronome.

Primeiramente, é importante mencionar que, embora os exemplos prototípicos de clíticos contenham elementos com certa mobilidade, eles podem ser elementos afixais em algumas línguas. É o caso do Amárico abaixo, no qual o clítico '-ìw' tem um comportamento afixal (KRAMER, 2014; BAKER; KRAMER, 2016): 
(358) Clitico afixal

[Amárico]

Almaz tämari-w-1n ayy-ät $\int t \int \underline{-i w}$

Almaz.F aluno-DEF.M-ACC ver-3FS.S-3MS.O

"Almaz viu o estudante do sexo masculino."

(KRAMER, 2014)

Considerando a própria gramática da língua, se pode dizer que Karitiana faz amplo uso da cliticização. Como vimos na seção §4.4.3, a cliticização tem sido proposta nas orações subordinadas do Karitiana para explicar as marcações de pessoa que não permitem correferência com NPs livres. Além disso, a própria concordância de pessoa parece ser derivada historicamente de pronomes livres, pois existe na língua grande semelhança entre pronomes livres e marcas afixais de pessoa (veja sistemas similares em Bhat (2004)): ${ }^{6}$

Tabela 13 - Semelhança entre pronomes livres e afixos de concordância

\begin{tabular}{l|cc}
\cline { 2 - 3 } & PRONOME LIVRE & CONCORDÂNCIA \\
\hline $1^{\text {a }}$ pessoa singular & yn & y- \\
$2^{\mathrm{a}}$ pessoa singular & an & $\mathrm{a}-$ \\
$3^{\mathrm{a}}$ pessoa & $\mathrm{i}$ & $\mathrm{i}-/ \emptyset$ \\
$1^{\mathrm{a}}$ pessoa plural inclusiva & yjxa & yj- \\
$1^{\mathrm{a}}$ pessoa plural exclusiva & yta & yta- \\
$2^{\mathrm{a}}$ pessoa singular & ajxa & aj- \\
\hline
\end{tabular}

Por conta disso, em muitas línguas é difícil detectar se uma certa marcação de traços de pessoa seria uma concordância ou um redobro de clítico. Para distinguir estes dois casos, é preciso se valer de diversos diagnósticos (veja Baker e Kramer (2016)), como veremos no decorrer deste capítulo.

Em suma, é plausível que $t i$ - seja um clítico mesmo sendo um elemento afixal. O segundo passo então é mostrar que $t i$ - pode ter uma natureza pronominal. Sobre isso, a estrutura interna de $t i$ - revela uma possível origem pronominal, pois, como se vê na tabela acima ' $i$ ' é também o pronome de $3^{\text {a }}$ pessoa (e que possivelmente deu origem ao alomorfe de concordância não declarativo $i$-). Crucialmente, em línguas aparentadas como o Akuntsu, o Mekéns, o Tupari e o Makuráp, o morfema cognato de ti- é i- (RODRIGUES; CABRAL; SILVA, 2006; STORTO, 2005): ${ }^{7}$

(359) Cognato de ti-

[Akuntsu]

Tawt ée u-i-mí

porcão 1-NO-matar

"Porcão (é) o matado por mim."

(ARAGON (ms.) apud RODRIGUES;

CABRAL; SILVA (2006))

6 Essa semelhança inclusive levou Landin (1984) a analisar a concordância como pronomes livres.

7 Em Makuráp, na realidade o morfema cognato é a versão nasalizada $\tilde{i}$. 
(360) Cognato de ti-

[Tupari]

Apo o-ị-tóp

quem 1-NO-ver

"Quem eu vi? (pedindo confirmação do perguntado)" (RODRIGUES; CABRAL; SILVA, 2006)

Em algumas dessas línguas, o pronome de $3^{\text {a }}$ pessoa é também homófono ao morfema de voz inversa. Observe que, no exemplo de Mekéns abaixo, $i$ - é tanto a voz inversa (glosado como OD, de 'objeto direto') quanto a concordância de $3^{\mathrm{a}}$ pessoa: ${ }^{8}$

(361) Voz inversa homófona à marca de terceira pessoa

[Mekéns]

Aose [ameko i-sogo] se-er-a i-toa

homem cachorro/onça OD-morder 3c-dormir-VT 3-Aux + deitado + sim

"O homem que o cachorro mordeu estava dormindo.'

(GALUCIO, 2006)

Assim, a natureza pronominal de $t i$ - é plausível dada a possível conexão diacrônica com o pronome $i$ -

Contudo, o que dizer do fone [t] em $t i-$ ? Segundo Rodrigues, Cabral e Silva (2006), a porção consonantal de $t i$ - seria um resíduo dos chamados prefixos relacionais que existem em algumas línguas Tupi. Segundo Rodrigues (2013), esses prefixos relacionais emergem para indicar contiguidade entre dois elementos, como entre o nome e seu possuidor, um verbo intransitivo e seu sujeito e um verbo transitivo e seu objeto:

(362) Morfema relacional

[Tupinambá]

wirá- $\emptyset \quad$ r-áß-a

pássaro-ARG CONT-pena-ARG

"a pena do pássaro" (FIGUREIA (1687) apud RODRIGUES; CABRAL; SILVA $(2006))$

Em muitas línguas Tupi-Guarani que fazem amplo uso destes prefixos relacionais, o cognato de $t i-,-e m i-$, frequentemente emerge após um prefixo relacional: ${ }^{9}$

(363) Cognato de ti- com prefixo relacional

[Tupinambá]

Ajẽté kó né r-apé- $\emptyset$ a'é né r-emi-ekár-a

na-verdade este $2 \quad R_{1}$-caminho-ARG esse $2 R_{1}$-NO-procurar-ARG

"Na verdade, este é o caminho de você, a coisa procurada por você" (ANCHIETA

(1977) apud RODRIGUES; CABRAL; SILVA (2006))

(Ou: Na verdade, este é o caminho de você, a coisa que você procurou.")

8 Em Wayoro (família Tupari), o morfema cognato a ti-é um dos alomorfes de terceira pessoa (Fernanda Nogueira, comunicação pessoal).

9 Esse prefixo é denominado de Relacional 1, porque existiam duas classes de prefixos relacionais em Tupinambá (veja (RODRIGUES, 1986)). 
Sobre isso, Payne (1994) descreve que, nas línguas Tupi da família Tupi-Guarani, uma combinação do morfema relacional com prefixos de pessoa (Set 2) ocorre em construções orientadas para o argumento paciente, o que a autora também denomina como inversa. Assim, possivelmente Karitiana fazia uso de prefixos relacionais como muitas línguas Tupi e um destes prefixos acabou fossilizado no pronome cliticizado $i$-. ${ }^{10}$

Além das evidências diacrônicas de que Karitiana clitiza pronomes, uma evidência sincrônica de que $t i$ - teria um estatuto argumental é o fato de um dos alomorfes de voz inversa ter traços de $3^{\mathrm{a}}$ pessoa, como vimos em $\S 6.1 .3$. Vimos também na seção $§ 6.2 .5$ que esse morfema dificilmente pode ser tratado como uma espécie de concordância; dessa forma, o estatuto de $t i$ - como clítico pronominal acomodaria os traços de pessoa sem recorrer à análise de concordância.

Assim, acreditamos que essas evidências sejam suficientes para comprovar o estatuto pronominal de $t i$-. Finalmente, é também importante pontuar que existe um teste frequentemente usado na literatura para diagnosticar pronomes, o strong/weak crossover. Ele, contudo, ele parece ser inaplicável em Karitiana, como discutiremos mais detalhadamente em $\S 6.5 .1$.

\subsubsection{Tema é gerado como complemento de $\mathrm{V}$}

Outro ingrediente importante de nossa proposta é de que o tema é gerado como complemento do verbo, em uma projeção NP contendo também o morfema ti-. Nesta seção, apresentamos evidências demonstrando que o tema é de fato gerado nessa posição. O primeiro argumento vem da teoria da ligação, o módulo que regula a distribuição das expressões nominais nas línguas e que tem sido usado para diagnosticar a posição sintática destes elementos.

Antes de passarmos aos dados com ti-, é preciso mostrar que os princípios de ligação propostos para outras línguas são de fato operativos em Karitiana. Primeiramente, o Princípio A, que seria responsável pela distribuição de expressões anafóricas, também funciona em Karitiana, pois Storto (2007) afirma que a anáfora de $3^{\text {a }}$ pessoa ta- precisa ser c-comandada pelo seu antecedente:

Princípio $A$
a. Taso $\emptyset$-na-oky-t ta-ota homem 3-DECL-matar-NFUT 3ANAPH-amigo
'O homem matou seu próprio amigo."
b. *Ta-ota $\emptyset$-na-oky-t taso 3ANAPH-amigo 3-DECL-matar-NFUT homem

(STORTO, 2007)

\footnotetext{
10 Dietrich (2009) também observa reflexos de prefixos relacionais na família Arikém, que frequentemente se fossilizaram como um segmento [s].
} 
Ta-ota a-ta-oky-t taso

3ANAPH-amigo DECL.INV-DECL-matar-NFUT homem

'O homem matou seu próprio amigo." [mas veja Storto (2007) para dados alternativos]

Storto também afirma que pronomes não podem estar ligados dentro da mesma oração, em obediência ao Princípio B. Perceba que a anáfora ta- e o pronome possessivo i- estão em distribuição complementar em 364a e 366, o que seria a configuração clássica dos Princípios A e B.

(366) Princípio $B$

Taso $_{\mathrm{i}} \quad \emptyset$-na-oky-t $\quad \mathrm{i}_{\mathrm{j} / * \text {-ota }}$

homem 3-DECL-matar-NFUT 3-amigo

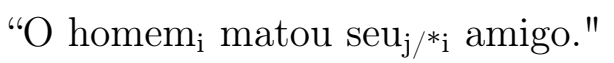

(STORTO, 2007)

Storto não chega a mencionar o Princípio C. No entanto, os dados abaixo demonstram que o Princípio C também está operativo em Karitiana:

(367) Principio $C$

$\mathrm{I}_{\mathrm{i} / *_{\mathrm{j}}} \emptyset$-naka-kot- $\emptyset \quad$ João $\mathrm{j}_{\mathrm{j}}$ taj

3 3-DECL-estilhaçar-NFUT João faca

"Ele $\mathrm{i}_{\mathrm{i} /{ }_{\mathrm{j}}}$ estilhaçou a faca do João $\mathrm{O}_{\mathrm{j}}$ "

Por levar em conta a noção estrutural de c-comando em sua formulação, os testes de ligação podem ser usados como diagnóstico da posição dos NPs em uma estrutura sintática. Assim, é possível afirmar que a posição do tema na estrutura em 356 é de fato a correta, pois é possível que uma anáfora esteja na posição de objeto em uma construção com ti-:

(368) Tema c-comandado pelo objeto

Yn $\emptyset$-naka-kot- $\emptyset \quad$ ta $\mathrm{i}_{\mathrm{i}}$-gooj João ${ }_{\mathrm{i}}$ ti-hãraxa

1s 3-DECL-estilhaçar-NFUT 3ANAPH-canoa João INV-consertar

"Eu estilhacei sua própria canoa que o João consertou."

A possibilidade da anáfora na posição no tema demonstra que, em algum ponto da derivação sintática, 'gooj' é c-comandado pelo sujeito. Dessa forma, o dado em 368 seria um argumento a favor da estrutura de $\mathrm{NP}_{1}$ em 356.

Um outro argumento de que o tema é gerado dentro do $\mathrm{NP}_{1}$ juntamente com o morfema $t i$ - é de que estes dois elementos não podem estar separados por uma ilha sintática. No capítulo 4, mostramos que todas as subordinadas da língua são domínio opacos para a extração (i.e., ilhas). Crucialmente, o tema e ti- não podem estar separados por uma subordinada: 
(369) Tema e pronome separados por ilha

Mora-mon João ti-vende-t [i-hãraxa byyk]?

QH-COP.INT João INV-vender-CON.COP 3-consertar PERF.

"O que João vendeu depois de consertar?"

(370) Tema e ti- separados por ilha

*Mora-mon João ti-vende-t [ti-hãraxa byyk]?

QH-COP.INT João INV-vender-CON.COP 3-consertar PERF.

Em outras palavras, os dados acima mostram que o tema deve ser gerado em uma posição próxima ao ti- em algum ponto da derivação, o que é facilmente capturado por nossa estrutura em 357.

\subsubsection{Resumo da proposta}

Nesta seção, apresentamos nossa proposta de que construções com ti- são configurações de redobro de clítico e motivamos dois de seus principais ingredientes: o estatuto argumental de ti- e a posição do tema abaixo do sujeito, dentro de um $\mathrm{NP}_{1}$. Na próxima seção, explicaremos como essa análise capturaria diversas outras propriedades deste morfema.

\subsection{Redobro de clítico e propriedades de ti-}

Como vimos no início deste capítulo, existem duas principais propriedades das construções com $t i$ - que nossa análise precisa capturar: (1) a emergência deste morfema em perguntas QU-, construções de foco do objeto e relativas de objeto, e (2) o padrão excêntrico da concordância. Esses tópicos serão discutidos nas seções §6.4.1 e §6.4.2. Nas seções anteriores, vimos também que $t i$ - parece ter uma conexão com a passivização; assim, argumentamos em $§ 6.4 .3$ que a estrutura de redobro de clítico é capaz de capturar as semelhanças entre as duas construções. Além disso, apresentamos na seção §6.4.4 uma peculiaridade destas construções que não havia sido descrita antes, a leitura pressuposicional do tema. Veremos que esta propriedade é um argumento para nossa estrutura em 356-357, pois, além de ser um diagnóstico da posição sintática que estamos propondo, esse efeito semântico é típico de configurações de redobro de clítico translinguisticamente.

\subsubsection{Perguntas QU-, construções de foco e relativas de objeto}

Para explicar satisfatoriamente o ti-, nossa estrutura de redobro de clítico em 357 precisa explicar a presença deste morfema em seus três ambientes mais prototípicos. Vimos anteriormente que ti- emerge em duas construções que envolvem movimento QU-: as perguntas QU- e as construções de foco do objeto. Contudo, vimos também em §6.2.2 que não é possível considerar ti- como a própria marca de um movimento QU-, pois há 
casos em que esse morfema emerge mesmo na ausência dessa operação. Esse problema pode ser evitado se assumirmos que $t i$ - de alguma forma cria a possibilidade para que o movimento QU- do objeto ocorra. Dessa forma, explicamos porque o movimento QUdepende da presença de $t i$ - sem termos que assumir o contrário, que ti-necessariamente apareceria quando o tema sofreu movimento QU-.

Como vimos anteriormente, frequentemente se assume que o movimento QU- para Spec, CP se dá ciclicamente. No que diz respeito a objetos, um dos ciclos que comporiam este movimento mais longo é um movimento anterior para uma posição na borda do sintagma verbal. Como discutimos no caso do movimento secundário das perguntas de longa distância em §4.3.2, a borda (a posição de especificador ou adjunto) de uma projeção na teoria de fases proposta por Chomsky (2001) é uma posição acessível para elementos fora dela. Como mencionamos naquela seção, movimentos para posições de borda de um sintagma são um requerimento para evitar uma violação da Condição de Impenetrabilidade de Fases, repetida aqui como 371:

Condição de impenetrabilidade de fases

[Para uma fase forte HP com o núcleo $\mathrm{H}$,] o domínio de $\mathrm{H}$ não é acessível a operações fora de $\mathrm{H}$; somente $\mathrm{H}$ e sua borda são acessíveis para tais operações.

(definição de borda: posições de adjunto ou especificador) (CHOMSKY, 2001)

Considerando que os domínios de $\mathrm{CP}$ e $v \mathrm{P}$ seriam fases, a presença de $t i$ - nos casos de movimento QU- segue naturalmente. Como um dos resultados do movimento em 357 é a posição do $\mathrm{NP}_{1}$ na borda de $v \mathrm{P}$, o tema pode em seguida se mover para Spec, CP sem violar a restrição em 371 :

Movimento QU-

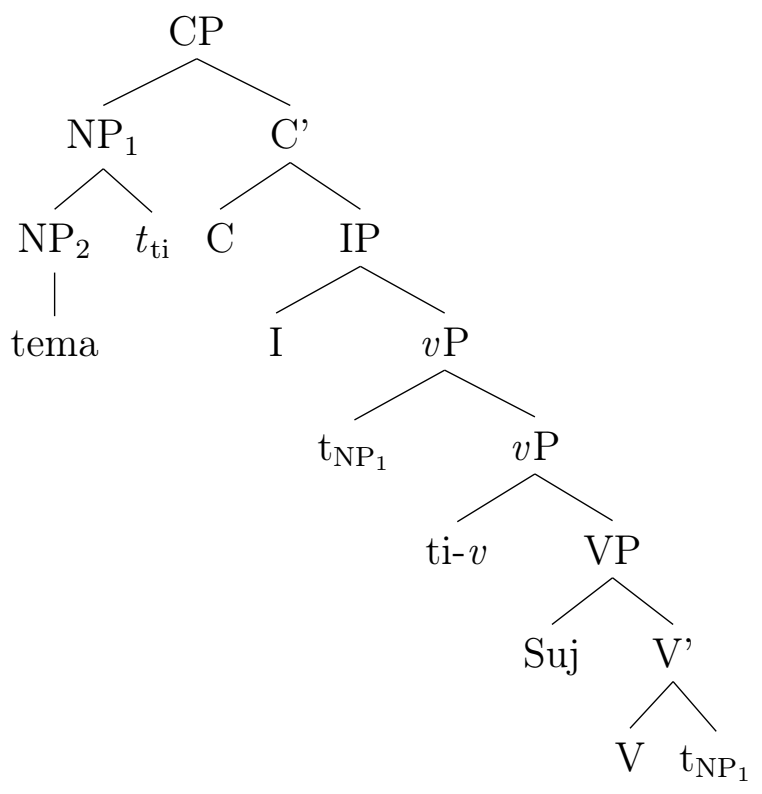


O movimento de $\mathrm{NP}_{1}$ seria então uma espécie de remnant movement, i.e., o deslocamento de uma projeção que já teve um de seus constituintes movidos. É necessário que todo o $\mathrm{NP}_{1}$ se mova para Spec, $\mathrm{CP}$ e não apenas o tema, pois sintagmas nominais seriam ilhas em Karitiana (veja §4.3.2). Em outras palavras, todo o $\mathrm{NP}_{1}$ sofre pied-piping por ser uma domínio opaco para movimento. Sobre isso, é importante relembrar que o pied-piping já é uma opção amplamente explorada em Karitiana, como vimos com as perguntas de longa distância em §4.3.2. Dessa forma, a única diferença aqui seria o caráter remnant dessa operação.

Em resumo, o movimento do $\mathrm{NP}_{1}$ para que ti- possa satisfazer seus requerimentos de afixação é também explorado pela língua para se construir o movimento QU-. Em outras palavras, $t i$ - cria condições para o tema possa se mover para além do $v \mathrm{P}$, como ocorre no movimento para Spec, CP. Nesse sentido, Karitiana se comportaria como línguas como o Tagalog (RACKOWSKI; RICHARDS, 2005), Indonésio (ALDRIDGE, 2008) e Defaka (BENNETT; AKINLABI; CONNEL, 2012), nas quais a extração para a borda do vP é uma etapa necessária para movimento QU-. ${ }^{11}$

Esse cenário nos remete ainda às construções de redobro de clítico em algumas línguas. Nelas, a presença de um clítico confere uma maior mobilidade para o argumento duplicado. Em Grego, por exemplo, o redobro de clítico é obrigatório sempre que o objeto se move acima de T (ALEXIADOU; ANAGNOSTOPOULOU, 2000):

(373) Movimento do tema com redobro de clítico

[Grego]

To vivlio o Jannis * (to) egrapse

o livro-ACC o John-NOM CL escreveu

"(?) O livro, John escreveu (ele)"(ALEXIADOU; ANAGNOSTOPOULOU, 2000)

Segundo Alexiadou e Anagnostopolou (2000), a cliticização/redobro de clítico constitui uma "porta de escape" para o movimento de sintagmas nominais, o que seria exatamente a situação da estrutura com $t i$ - em 372.

11 Crucialmente, em algumas dessas línguas a ocorrência de movimento QU- está vinculada a morfemas de alteração de valência. Em Tagalog, por exemplo, somente elementos marcados com 'ang'/'yang' podem se mover para Spec, CP. Segundo Rackowski e Richards (2005) e Aldridge (2008), elementos que contêm essa partícula se movem através da borda do $v \mathrm{P}$ (e têm necessariamente uma leitura específica, o que, como veremos em $§ 6.4$.4 é também uma propriedade de $t i$-). No exemplo abaixo, observe a interação entre movimento QU-, 'yang' e a presença do morfema transitivizador men-:

(xiii) Marcador de transitividade e movimento $Q U$ -

[Bahasa Indonesia]

Bill men-gira Tom men-harap Fred men-cintai siapa

Bill trans-pensa Tom TRAns-espera Fred trans-ama quem

"Quem o Bill pensa que o Tom espera que o Fred ame?"

(xiv) Ausência de marcador de transitividade e movimento QU-

Siapa $_{\mathrm{i}}$ yang Bill $\emptyset$-kira Tom $\emptyset$-harap Fred $\emptyset$-sintai $t_{\mathrm{i}}$ who Bill pensa Tom espera Fred ama

"Quem o Bill acha que o Tom espera que o Fred ame?

(SADDY, 1991) 
Em resumo, a análise de redobro de clítico é capaz de explicar a presença de $t i$ em construções QU- sem assumir que esse morfema é a própria marca do movimento para Spec, CP. No entanto, existe ainda a terceira construção em que este elemento tipicamente aparece: as orações relativas de objeto. Nelas, o movimento QU- não ocorreria, pois, como defendemos no capítulo 4, a projeção CP inexiste em subordinadas.

Embora não haja movimento para Spec, CP, é possível dizer que as relativas do Karitiana exploram o deslocamento do objeto para a borda do $v \mathrm{P}$ com uma outra finalidade. Como mencionamos no capítulo 1, o núcleo da relativa aparece frequentemente frontalizado em relativas de objeto. Assim como no Karitiana, a frontalização do núcleo é uma opção bastante utilizada em línguas com relativas de núcleo interno cujas subordinadas exibem um alto grau de ambiguidade (BASILICO, 1996). Esse padrão pode ser visto nos dados de Diegueño abaixo, nos quais a frontalização do núcleo em 375 desambigua a oração relativa:

(374) Relativa de núcleo interno ambígua

$\operatorname{xatkcok}(-0)$ wi:m tuc-pu-c $\mathrm{n}^{\mathrm{Y}} \mathrm{iL}^{\mathrm{Y}}$

cachorro(-OBJ) pedra.COMIT eu.bater-DEM-SUJ preto

"A pedra com a qual eu bati no cachorro é preta."

"O cachorro em que eu bati com a pedra é preto."

[Diegueño]

Movimento do núcleo para desambiguar relativa

Diegueño]

'wi ${ }^{\mathrm{y}} \quad$ 'xat $(-0) \quad \mathrm{ni}^{\mathrm{Y}} \mathrm{i}-\mathrm{m} \quad$ 'tu:-pu-c $\quad \mathrm{n}^{\mathrm{Y}} \mathrm{iL}^{\mathrm{Y}}$ cis

pedra cachorro(-OBJ) aquilo.COMIT eu.bater-DEM-SUJ preto.realmente

"A pedra com a qual eu bati no cachorro é preta."

(BASILICO, 1996)

Em Karitiana, as orações subordinadas também exibem um alto grau de ambiguidade (veja Storto (1999), Storto (2012), Vivanco (2014) e Rocha (2016)). Essa propriedade fica mais óbvia com verbos de percepção na oração matriz, como abaixo:

(376) Oração subordinada ambigua

Y-py-so'oot-o-n yn sosy mynda ajxa ti-oky-ty

1s-ASS-ver-EPEN-NFUT 1s tatu devagar 2pl INV-matar-OBL

"Eu vi vocês matarem o tatu devagar."

"Eu vi o tatu que vocês mataram devagar."

(STORTO, 1999)

Quando ti- emerge em subordinadas, a operação executada por este morfema teria então uma função diferente dos casos de movimento QU-: o movimento do $\mathrm{NP}_{1}$ para a borda do $v \mathrm{P}$ seria um mecanismo para explicitar o núcleo da relativa em um ambiente ambíguo, assim como nos casos das relativas ambíguas em Diegueño.

Em resumo, a operação executada por ti- de mover o tema para a borda do $v \mathrm{P}$ é explorada na língua para diversas funções, o que explicaria a ocorrência deste morfema 
em diversos contextos. Primeiramente, ti- conferiria uma maior mobilidade ao objeto, permitindo que ele se mova para além do $v \mathrm{P}$. Como vimos, esse procedimento é essencial nos casos em que o tema se move para Spec, CP. Além disso, esse mesmo movimento para a borda do $v \mathrm{P}$ pode ser explorado em subordinadas ambíguas para que o núcleo de uma oração relativa seja explicitado.

\subsubsection{Concordância excêntrica}

Como vimos anteriormente, quando a concordância é possível em uma construção com ti-, ela exibe um padrão desviante da concordância tipicamente encontrada em construções transitivas. Aqui, seguimos as intuições de Landin (1984), Storto (1999), Hale e Storto (1997) e Everett (2006) de que a concordância pode ser um diagnóstico de intransitividade. Se levarmos em conta que um verbo marcado por $t i$ - é intransitivizado por ele, e que ele portanto manifesta o comportando típico de intransitivos (veja §6.1.2), a concordância excêntrica se explica. Basicamente, nas construções intransitivizadas por ti-, a concordância se dá com o sujeito, assim como qualquer outro verbo intransitivo na língua.

Assumindo essa proposta, temos ainda um efeito colateral bastante bem-vindo: não será preciso postular um contexto de ergatividade cindida na língua como em Storto (2005), pois um um verbo com ti- se comportaria exatamente como qualquer outro intransitivo na língua. Assim, seja qual for o mecanismo de concordância que faz com verbos passem a concordar com seu único argumento em sentenças intransitivas, esta mesma operação seria disparada com verbos marcados com $t i-.{ }^{12}$

\subsection{3 ti- e a passivização}

Em $\S 6.1 .2$, vimos que $t i$ - e a passiva $a$-, que também possui a propriedade de intransitivizar verbos transitivos, estão em distribuição complementar. Nesta seção, discutiremos a razão desta restrição, fazendo referência à estrutura de redobro de clítico proposta em 357.

Primeiramente, é preciso relembrar que existe uma possível ligação histórica entre os dois morfemas (STORTO, 2005). Como vimos em $\S 6.1 .3$, o alomorfe declarativo de $t i$ é $a$-, que, por sua vez, é homófono ao morfema de passiva. Para demonstrar que esta conexão pode não ser acidental, veja que uma homofonia similar pode ser encontrada em Mekéns, no qual o morfema de inversa $i$ - é homófono ao de antipassiva (STORTO, 2005; GALUCIO, 2006):

12 Podemos talvez assumir que a concordância em Karitiana funcionaria de uma forma cíclica (no espírito de Béjar e Rezac (2009)): primeiramente, uma sonda (o núcleo $v$ ) tenta concordar com um NP dentro do VP; se não houver um argumento nessa posição (como aconteceria no caso de verbos intransitivos e construções com $t i$-), a sonda se volta para o argumento acima dela e estabelece a relação de concordância com ele. 
(377) Inversa $i$ - em pergunta $Q U$ -

arob $=\tilde{e}$ te te e-i-mi?

[Mekéns]

$\mathrm{qu}=$ realmente verdadeiramente foc 2 s-INVERSA-matar

"O que você matou mesmo?'

(GALUCIO, 2006)

(378) Inversa $i$ - construção de foco do objeto

[Mekéns]

irap te o-i-ko

massaco.de.mandioca foc 1s-INVERSA-ingerir

"Foi massaco de mandioca que eu comi'

(GALUCIO, 2006)

(379) Antipassiva $i$ -

[Mekéns]

ot i-mi-a-t ameko-pe

1s inv-matar-vog.tem.-passado onça-oblíquo

"Eu matei (a onça)'

(GALUCIO, 2006)

Ao comentar essa ligação aparentemente antiga entre a inversa e a (anti)passiva, Storto (2005) pontua que um dos traços em comum entre essas construções é o de "modificar a hierarquia natural do agente sobre o paciente de um verbo transitivo". Em outras palavras, tanto passivas quanto inversas invertem a proeminência dos NPs, promovendo o tema de alguma forma. A questão então é como capturar estruturalmente essa associação.

Com vimos em $\S 6.3$, nossa proposta é que ti- seria um clítico pronominal que acaba alçando o tema para a borda de $v \mathrm{P}$ ao se cliticizar e intransitivizar a raiz verbal. Assim, a ideia aqui é de que a passiva de alguma forma executaria uma operação similar, o que inibiria a coocorrência destes dois morfemas. Sobre isso, Baker, Johnson e Roberts (1989) propõem que morfemas de passiva sejam na realidade um elemento argumental, à semelhança do que discutimos aqui para clítico pronominal $t i$. Por conta disso, este morfema receberia caso do verbo como qualquer outro NP, o que explicaria a suposta propriedade de absorção de caso acusativo em construções passivas. Em algumas línguas, esse morfema poderia ser inclusive um núcleo $\mathrm{N}$, e os autores afirmam ainda que, quando o agente da passiva é expresso através de uma by-phrase, teríamos uma construção bastante semelhante às configurações de redobro de clítico.

Seguindo essa linha de raciocínio, poderíamos supor então que o morfema $a$ - no Karitiana teria uma natureza argumental também. Ele teria as mesmas propriedades de absorção observadas em outras línguas, pois sua afixação intransitivizaria um verbo biargumental (veja o capítulo 1). Essa formalização captura a associação entre $a$ - e $t i$ - e também sua distribuição complementar, pois ambos seriam elementos argumentais que se ligam a raiz, intransitivizando-a. Assim, é esperado que ambos não coocorram em uma mesma oração, visto que eles executariam a mesma operação.

\subsubsection{Efeito semântico}

Além de todas propriedades elencadas nas seções anteriores, $t i$ - exibe também uma outra característica que não foi descrita anteriormente na literatura. Trata-se de um 
determinado efeito semântico, que à primeira vista pode ser capturado através dos rótulos de definitude/especificidade e cuja natureza será detalhada no decorrer deste capítulo.

Esse efeito pode ser inicialmente observado no par de sentenças em 380 e 381 em um determinado contexto (as traduções foram omitidas propositalmente). Como se pode notar nestes exemplos, a única diferença entre essas sentenças é a presença ou ausência de $t i$-. Em 380, a oração com ti- é julgada como impossível neste contexto por todos os falantes; já sua contraparte sem $t i$ - é permitida por alguns falantes neste mesmo contexto:

Contexto 1: O Thiago queria uma canoa. O Ivan era um famoso carpinteiro da região, então o Thiago pediu a ele que construísse uma canoa. Ele pagou o Ivan para construir uma canoa, mas o Ivan não ouviu o pedido muito bem... Ele achou que o Thiago queria uma casa! Então o Ivan acabou construindo uma casa em vez de uma canoa.

(380) \#Thiago $\emptyset$-naka-pagng- $\emptyset$ gooj Ivan ti-m'a

Thiago 3-DECL-pagar-NFUT canoa Ivan INV-fazer

(Julgada como FALSA por todos os falantes)

(381) Thiago $\emptyset$-naka-pagng- $\emptyset$ gooj Ivan by-'a

Thiago 3-DECL-pagar-NFUT canoa Ivan fazer

(Julgada VERDADEIRA por alguns falantes)

Os dados acima indicam que, pelo menos para alguns falantes, sentenças com e sem o ti- têm significados diferentes. A princípio, $t i$ - não pode ser empregado em relativas de objeto se o tema não tiver uma referência, como no contexto acima. Assim, ti- não é um morfema sem nenhuma contribuição semântica - o que seria esperado, diga-se de passagem, se ele fosse uma marca de movimento QU- ou de (anti)concordância.

Há ainda um outro aspecto desse efeito semântico que estamos tentando capturar. Quando a negação - $k i$ está presente em uma relativa marcada com ti-, o objeto adquire o que a semântica formal chama de escopo amplo - grosso modo, somente a estrutura lógica $\exists \neg$ é permitida, enquanto $\neg \exists$ é impossível. ${ }^{13}$ Basicamente, este efeito se traduz na impossibilidade de, nessas orações relativas de objeto com ti-, temas não poderem nunca ser traduzidos como "nenhum". ${ }^{14}$

Antes de passarmos aos casos com ti-, mostramos que o escopo restrito com a negação (ou seja, a estrutura lógica $\neg \exists$ ) é possível quando ti- não está presente. No exemplo abaixo, o objeto está sob o escopo da negação - $k i$, adquirindo então a interpretação de "nenhum" (a estrutura lógica representa apenas a parte relevante da proposição):

13 A título de ilustração, empregamos uma formalização em que elementos pressuposicionais têm escopo amplo. Contudo, é preciso pontuar que, a partir do trabalho de Fodor e Sag (1982), o efeito de escopo amplo de certos elementos tem sido capturado de uma forma distinta. Para mais informações, veja também Diesing (1992).

14 Essa restrição não acontece em todos os casos em que o ti- está presente, como veremos mais à frente. 
Contexto 2: O Ivan comprou alguns colares dos Karitiana. Os colares eram muito bonitos e feitos com dente de macaco. Lá em São Paulo, o Ivan ficava contando vantagem pros amigos, contando que foi ELE quem tinha matado os macacos e ficado com os dentes. Agora, ele não conseguiu enganar a professora dele, a Luciana... A Luciana sabe que o Ivan não sabe caçar nada, e que ele não matou nenhum macaco!

Luciana $\emptyset$-na-aka-t $\quad$ i-sondyp- $\emptyset \quad$ Ivan pikom oky-ki-ty.

Luciana 3-DECL-COP-NFUT NMZ-saber-CON.COP Ivan macaco matar-NEG-OBL

"A Luciana sabe que o Ivan não matou nenhum macaco."

(A Luciana sabe que $\neg \exists \mathrm{x}$, tal que $\mathrm{x}$ é macaco $\wedge$ Ivan matou $\mathrm{x}$ )

Quando ti- está presente, o objeto não pode mais ser interpretado sob o escopo da negação. Por exemplo, os falantes rejeitam 383a no contexto abaixo, indicando que essa sentença não pode ser interpretada como "O Ivan (não) comeu nenhum macaco que a cobra picou" (interpretação 383c), que seria verdadeira na história apresentada. $\mathrm{Na}$ realidade, essa sentença só parece poder significar "O Ivan comeu o macaco que a cobra não picou" (forma lógica 383b), sendo essa a tradução frequentemente oferecida pelos falantes para essa sentença:

Contexto 3: O Ivan estava com muita fome e ele conseguiu pegar uns macacos no mato. Mas aí ele viu que todos macacos tinham uma picada de cobra. Ele ficou muito desconfiado, porque vai que a cobra é venenosa, né? Aí pode ser que ele morra envenenado também. Aí ele decidiu não comer nenhum dos macacos, e ficou com fome mesmo!

a. \#Ivan Ø-naka-'y-t pikom boroja ti-okoot-o-ki

Ivan 3-DECL-comer-NFUT macaco cobra INV-morder-EPEN-NEG

'O Ivan comeu o macaco que a cobra não picou."

b. $\exists \mathrm{x}$, tal que $\mathrm{x}$ é macaco $\wedge$ Ivan comeu $\mathrm{x} \wedge \neg$ a cobra picou $\mathrm{x}$

c. $* \neg \exists \mathrm{x}$, tal que $\mathrm{x}$ é macaco $\wedge$ Ivan comeu $\mathrm{x} \wedge$ a cobra picou $\mathrm{x}$

É importante frisar que o escopo amplo do objeto se mantêm mesmo que haja uma negação na matriz. Nesse caso, o objeto tem inclusive escopo sobre a negação sentencial 'padni' além da negação da subordinada $-k i$ :

Contexto 4: O Ivan queria comprar canoas. Ele sabia que o Pedro consertava algumas canoas e revendia. Chegando lá, o Ivan queria comprar só as que o Pedro JÁ TINHA consertado, mas o Pedro tentou empurrar uma outra pro Ivan que ainda não tinha sido consertada. O Ivan ficou muito bravo, porque ele não ia comprar uma canoa quebrada, né? Então ele só comprou uma que o Pedro tinha consertado. 
(384) I-amy padni Ivan gooj Pedro ti-hãrajxa-ki-ty.

3-comprar NEG Ivan canoa Pedro INV-consertar-NEG-OBL

"O Ivan não comprou a canoa que o Pedro não consertou."

( $\exists$ x, tal que $\neg$ Ivan comprou $\mathrm{x} \wedge \neg$ Pedro consertou $\mathrm{x}$ )

Como o leitor pode verificar na tradução dos exemplos 383a e 384, a diferença de escopo é codificada no Português através de determinantes definidos e indefinidos como 'o' e 'nenhum'. Desta forma, poderíamos então supor que $t i$ - geraria um efeito de definitude (ou talvez especificidade) em Karitiana. Em outras palavras, o objeto se tornaria definido/específico nessas construções.

Contudo, há dois pontos aqui. Primeiramente, é preciso discutir os resultados de Müller (2011), que investigou efeitos de definitude em orações matrizes do Karitiana. Partindo de dados como 385 e 386, nos quais os contextos ideais para a produção de um indefinido e definido são oferecidos, a autora conclui que não há na língua uma marcação formal para se expressar a definitude (veja também Müller, Storto e Coutinho-Silva (2006)):

(385) Contexto prototipico de indefindo

Yn Ø-naka-sadna-j õwã hadna hyk

I 3-DECL-tell-FUT criança história sobre

"Eu vou contar a história de uma criança."

(MÜLLER, 2011)

(386) Contexto prototípico de definido

$\emptyset$-py-pyn-a andyk-y-n õwa

ASS-saber-NMZ IMPF.PASS-EPEN-NFUT criança

"A criança era inteligente."

(MÜLLER, 2011, adaptado)

Os fatos expostos acima abrem a possibilidade de a língua codificar a definitude/indefinitude através de outros elementos da sentença que não uma marcação em sintagmas nominais - no caso, pelo morfema ti-. Essa hipótese nos remete à discussão de Lambrecht (1994) sobre o impacto da variação de ordem na interpretação de sintagmas nominais. Por exemplo, os dados do Tcheco em 387 nos levam a crer que, nessa língua, a ordem de constituintes codifica a definitude tanto quanto os artigos definidos em línguas como o Português:

(387) Ordem de palavras e definitude

[Tcheco]

a. Kniha je na stole.

"O livro está em cima da mesa."

b. Na stole je kniha.

"Em cima da mesa está um livro."

(LAMBRECHT, 1994)

Sobre isso, Lambrecht pontua: 
“(...) A diferença nas glosas (...) não deve ser tomada como evidência para a existência de um constraste gramatical entre definitude/indefinitude em Tcheco, expresso através da posição verbal ou pré-verbal do sintagma nominal. (...) A diferença entre posições pré-verbais e pós-verbais em Tcheco devem corresponder a alguma outra distinção gramatical, a qual (...) acontece de coincidir com a diferença em definitude no Inglês."(LAMBRECHT, 1994, p. 87)

Seguindo a linha de raciocínio de Lambrecht e o trabalho de Müller sobre o Karitiana, assumiremos que a distinção definido/indefinido não existe no Karitiana tal como no Inglês ou Português, pois optamos por restringir a propriedade de definitude à marcação (por meio de artigos, afixos nominais, etc.) em sintagmas nominais. Assim, ti- não seria a marcação de definitude em si, justamente por ser um afixo verbal. Além disso, essa visão seria mais condizente com a nossa proposta de que esse morfema seria, na realidade, um clítico pronominal.

Porém, qual é então a propriedade semântica de objetos em construções com $t i$ - e como uma estrutura de redobro de clítico gera estes efeitos interpretativos? Para lidar com esse problema, temos duas propostas: (1) o efeito semântico que ti- força é a pressuposição de existência e (2) essa interpretação é gerada por conta da posição sintática que o tema ocupa.

Para explicar a correspondência entre a posição sintática e certos efeitos interpretativos, vamos assumir a Hipótese de Mapeamento proposta por Diesing (1992). Segundo a autora, NPs em partes específicas da estrutura sintática são mapeados em diferentes partes da representação lógica da sentença:

Mapeamento de dominios sintáticos

- O material do sintagma verbal é mapeado no escopo nuclear de um quantificador

- O material na região de IP é mapeado na oração restritiva de um quantificador

(DIESING, 1992)

As partes de uma representação lógica nas quais os domínios sintáticos são mapeados estão exemplificadas a seguir:

(389) Representação lógica de uma sentença

Toda lhama comeu uma banana.

$\begin{array}{lll}\text { Toda }_{\mathrm{x}} & \text { [x é uma lhama }] & \exists_{\mathrm{y}} \mathrm{y} \text { é uma banana } \wedge x \text { comeu } y \\ \text { (quantificador) } & \text { (oração restritiva) } & \text { (escopo nuclear) }\end{array}$

Além disso, há um outro ingrediente importante: a operação de fechamento existencial inicialmente proposta por Heim (1982) para ligar variáveis introduzidas por sintagmas nominais indefinidos. Segundo Diesing, essa operação aconteceria no sintagma verbal 
- em nossas estruturas, isso possivelmente corresponderia ao $v \mathrm{P}$, sem sua borda. Assim, elementos na região do IP ou na borda do $v \mathrm{P}$ seriam mapeados na oração restritiva.

Um dos efeitos do algoritmo de mapeamento em 388 é o de que qualquer NP alçado para a região do IP ou para a borda do $v \mathrm{P}$ vai ser mapeado na oração restritiva. Nessa posição, ele adquire uma pressuposição de existência, ou seja, a existência da entidade referenciada pelo objeto é pressuposta na situação de enunciação, pois o conjunto sobre o qual um quantificador opera deve existir para que ele possa funcionar. $\mathrm{O}$ efeito disso é de que todos os elementos que induzem uma pressuposição de existência se localizariam na região do IP ou na borda do vP (DIESING; JELINEK, 1995). Nesse grupo, se incluem os sintagmas nominais definidos, os indefinidos específicos e também os determinantes "fortes" no sentido de Milsark (1977).

Em outras palavras, existe uma correlação direta entre a posição de sintagmas nominais na fora do $v \mathrm{P}$ (i.e., em sua borda ou na região de IP) e uma leitura pressuposicional. Assim, essa proposta explicaria porque o tema em construções com ti- é rejeitado em contextos em que o objeto não existe, como 380: como a pressuposição de existência não é satisfeita neste contexto, a sentença é rejeitada pelos falantes. Além disso, ela também elucidaria o porquê de, nos contextos com ti-, as traduções para o Português incluírem um artigo definido. Como os definidos são elementos pressuposicionais, os falantes escolhem codificar a operação executada por ti- através desses elementos em suas traduções.

Essa propriedade também explicaria o escopo amplo obrigatório do objeto em construções com ti- e - $k i$ : sendo pressuposicional, o objeto "escapa"do escopo de uma negação que se localiza no escopo nuclear de uma sentença. Essa característica das pressuposições de se manterem mesmo sob negação (chamada de propriedade de projeção) pode ser exemplificada pelo par de sentenças abaixo, na qual a pressuposição de que João fuma se mantêm mesmo se a sentença em questão for negada:

(390) João parou de fumar.

(Pressuposição: João fumava antes.)

(391) João não parou de fumar.

(Pressuposição: João fumava antes.)

Os dados de Karitiana se comportam exatamente como outras línguas em que o sintagma nominal se move para a região do IP. Em Alemão, por exemplo, sintagmas nominais podem se mover para fora do sintagma verbal, operação esta denominada de scrambling e diagnosticada pela posição da negação. Curiosamente, esse movimento condiciona a interpretação do objeto: quando ele está na região do IP em 393, ele adquire uma leitura pressuposicional. Perceba que o significado do objeto movido em 393 é semelhante à interpretação que temos em 383a, na qual o objeto necessariamente tem escopo amplo em relação à negação: 
(392) Objeto dentro do vP

[Alemão]

...weil ich nicht [vp [eine eizige Katze] gestreichelt] habe

porque eu não um único gato acariciado tenho

"... porque eu não acariciei nenhum gato (não há gatos acariciados)."

$(\neg \exists \mathrm{x}$, tal que $\mathrm{x}$ é gato $\wedge$ eu acariciei $\mathrm{x})$

(DIESING; JELINEK, 1995)

(393) Objeto fora do vP - scrambling

[Alemão]

...weil ich [eine eizige Katze] nicht [vP gestreichelt] habe

porque eu um único gato não acariciado tenho

"... porque tem um único gato que eu não acariciei."

$(\exists \mathrm{x}$, tal que $\mathrm{x}$ é gato $\wedge \neg$ eu acariciei $\mathrm{x})$

(DIESING; JELINEK, 1995)

Além de ser um argumento a favor da posição do tema em 357, esse efeito de interpretação também é um argumento a favor da nossa análise de redobro de clítico. Translinguisticamente, o clítico parece dobrar apenas sintagmas nominais definidos/específicos, que são elementos pressuposicionais (SUÑER, 1988; DOBROVIE-SORIN, 1990; KRAMER, 2014; BAKER; KRAMER, 2016, dentre outros):

(394) Redobro de clítico com objetos não específicos

[Espanhol]

No $\left({ }^{*}\right.$ lo $)$ oyeron a ningún ladrón.

não o 3PL-ouviu a nenhum ladrão

"Eles não ouviram nenhum ladrão."

(SUÑER, 1988)

Na realidade, Baker e Kramer (2016) postulam que a impossibilidade de ocorrer com NPs não referenciais como indefinidos não específicos e quantificadores é um dos testes para se identificar estruturas de redobro de clítico. Como se vê nos exemplos abaixo, o clítico '- $\ddot{a} w$ ' em Amárico não pode dobrar estes elementos:

(395) Redobro de clítico com indefinidos não específicos

[Amárico]

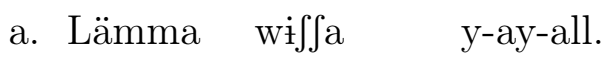

Lemma.M cachorro.M 3MS.S-ver.IMPF-AUX.3MS.S

'Lemma vê um cachorro."

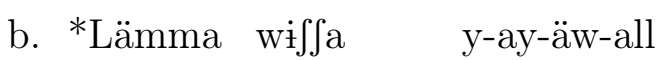

Lemma.M cachorro.M 3MS.S-ver.3MS-O-AUX.3MS.S

(BAKER; KRAMER, 2016)

(396) Redobro de clítico com elemento quantificacional

[Amárico]

a. Lämma hullu-n-imm säw ayy-ä.

Lemma.M todo-ACC-FOC pessoa ver.PF-3MS.S

'Lemma viu todos."

b. *Lämma hullu-n-imm säw ayy-äw

Lemma.M todo-ACC-FOC pessoa ver.PF(3MS.S)-3MS 
Essa é a situação que encontramos nas subordinadas com ti-. Vimos em 383a que um objeto com ti- não pode ter o significado de 'nenhum'. Além disso, em textos naturalísticos, $t i$ - não emerge em subordinadas quando o tema é não específico, como o NP 'mulheres' no exemplo abaixo:

(397) Tema com leitura não referencial

Yj-sooj pasagama-ki tykiri, Ø-na-monde-t osiip myjym otidna-t

1s-esposa obter?-NEG ASP 3-DECL-acabar-NFUT osiip cinco lua-ADVZ

"Ou se não obtemos esposas, o Osiip termina depois de três meses" ["Osiipo"]

Nossa análise de $t i$ - pode ainda iluminar uma restrição inicialmente apontada por Rocha (2016) sobre a impossibilidade desse morfema com certos marcadores aspectuais. Especificamente, o morfema ti- não pode ocorrer com 'tykiri', que, segundo Storto (2002), seria um marcador de aspecto perfectivo:

(398) Impossibilidade de ti- e 'tykiri'

*Yn $\emptyset$-naka-'y-t [kinda'o taso ti-amangã tykiri]

1s- 3-DECL-comer-NFUT fruta homem INV-plantar PERF

(ROCHA, 2016)

O autor discute que essa restrição talvez esteja relacionada à impossibilidade de $t i$ - ocorrer com o adverbializador $-t$, como pode ser visto nos dados abaixo:

(399) Oração relativa de objeto

[Taso Elivar ti-mb-otam pasagng-ã] $\emptyset$-na-oky-t myndo homem Elivar INV-CAUS-chegar-NMZ IMPERF.POST. 3-DECL-matar-NFUT cotia

"O homem que o Elivar vai fazer chegar matou a cotia."

(ROCHA, 2016)

(400) Impossibilidade de ti- $e-t$

[*Taso Elivar ti-mb-otam pasagng-ã]-t

homem Elivar INV-CAUS-chegar-EPEN IMPERF.POST.-ADVZ

Ø-na-oky-t myndo

3-DECL-matar-NFUT cotia

(ROCHA, 2016)

Rocha propõe então que a palavra 'tykiri' pode ser decomposta como [tyki-t-i] (PERF-ADV-FUT), na qual o [t] intervocálico sofre um processo de lenição e transforma-se no tepe [r] (veja Storto (1999)). No entanto, existe uma outra restrição de coocorrência entre $t i$ - e um outro morfema em que não se pode recorrer ao adverbializador - $t$. É o morfema - $p$, frequentemente chamado de infinitivo (ROCHA, 2016; STORTO; VIVANCO; ROCHA, 2018). Segundo Ferreira (2017), - $p$ frequentemente emerge na oração condicional (chamada de prótase) de uma sentença contra-factual: 
(401) Contra-factual com - $p$

Yy-'it [a-taktagngi-i-p a-pypydn-i-p,] [y-jy-pyhit se-pip

1-filho 2-nadar-EPEN-LOC/INF 2-saber-EPEN-LOC/INF 1-COND-deixar rio-em

a-pomã]-ty

2-brincar-OBL

"Meu filho, se você soubesse nadar, eu deixava você brincar no rio" (FERREIRA, 2017)

Como vimos nos capítulos anteriores, esse morfema - $p$ também pode ter uma interpretação locativa:

(402) Impossibilidade de ti- $e-p$

João $\emptyset$-na-aka-t i-sondyp-y-wak ombaky Karin

João 3-DECL-matar-NFUT NMZ-saber-EPEN-DES onça Karin

oky-p-y-ty

matar-LOC-EPEN-OBL

"O João quer saber onde a Karin matou a onça."

O dado acima pode então nos levar a parafrasear a contra-factual em 401 como 'em ocorrendo $p$, então $q$ '. ${ }^{15}$

Curiosamente, a coocorrência entre $t i$ - e - $p$ também é proibida:

(403) Impossibilidade de ti- $e-p$

Yn jy-soko'î-t eremby Maria ti-m-'a

1s COND-amarrar-NFUT rede Maria INV-CAUS-fazer

"Eu ia amarrar a rede que a Maria fez/tinha feito."

(404) *Yn jy-soko' $\tilde{\mathrm{i}}$-t $\quad$ eremby Maria ti-m-'a-p

1s COND-amarrar-NFUT rede Maria INV-CAUS-fazer-LOC/INF

Perceba ainda que, comparando com a contra-factual em 401, a sentença em 404 deveria ser gramatical com o significado de "Eu amarraria a/qualquer rede que você fizesse". Ela, no entanto, é impossível.

A ideia aqui é que a restrição entre ti- e tykiri pode não ser exatamente por causa de um morfema - $t$, e que sua causa provavelmente estaria ligada à restrição similar entre $t i$ - e - $p$. Contudo, como a nossa análise explicaria a restrição entre ti- e tykiri/ - $p$ ? Basicamente, ela poderia estar relacionada à interpretação pressuposicional que $t i$ - força

$\overline{15}$ Essa restrição não está relacionada a uma possível impossibilidade de $-p$ e 'tykiri' ocorrerem em orações em posições argumentais. Como se vê em 402 e na sentença abaixo, esses morfemas são possíveis dentro de orações relativas:

(xv) 'Tykiri' em oração relativa

Ana $\emptyset$-na-aka-j i-amy-t mynhodno ambi Ivan by'a tykiri.

Ana 3-DECL-COP-NFUT NMZ-comprar-CON.COP diferente casa Ivan fazer PERF..

"A Ana vai comprar a casa que o Ivan fizer diferente." 
no tema em orações subordinadas. Haspelmath (1997) cita que, em muitas línguas, a prótase condicional permite apenas indefinidos não específicos, proibindo sua contrapartes específicas (pressuposicionais):

(405) DPs (não) específicos na prótase condicional

[Kannada]

a. Yaar-aadaruu bandare heelutteene.

quem-INDEF vir:COND contar:FUT:1SG

'Eu vou te contar se alguém [não específico] vier."

b. *Yaar-oo bandare heelutteene.

quem-INDEF vir:COND contar:FUT:1SG

"(Pretendido) Eu vou te contar se alguém [específico] vier.") (BHAT (1981) apud HASPELMATH (1997))

Embora a natureza exata dessa restrição ainda precise de uma investigação mais profunda, é preciso mencionar que ela pode ser usada como um argumento para nossa análise da construção com ti-. Como vimos anteriormente, indefinidos específicos se comportam como elementos pressuposicionais. Assim, a impossibilidade de termos ti- na prótase de uma condicional poderia estar relacionado à interpretação que ele força nestes ambientes: em construções com ti-, o tema deve ser pressuposicional; assim, $t i$ - não pode ser usado na prótase, pois esse ambiente não admitiria elementos pressuposicionais.

Em resumo, nossa estrutura de redobro de clítico é capaz de capturar o efeito semântico que o tema adquire em construções com $t i$ - ao assumir que ele se encontraria na borda do $v \mathrm{P}$ nessas construções. Nessa posição, ele adquire uma leitura pressuposicional, o que explicaria também o escopo amplo quando a negação está presente. Por fim, é importante pontuar também que esse comportamento aproxima mais ainda o tide construções com redobro de clítico, nas quais o mesmo efeito semântico também se verifica.

\subsection{Problemas com a proposta de redobro de clítico}

\subsubsection{Redobro de clítico e weak crossover}

Na seção §6.3, apresentamos a proposta de que as construções com ti- seriam configurações de redobro de clítico. Existe, contudo, um diferença entre essas construções e as orações com ti- que nossa análise precisa capturar. Vimos ainda que um dos contextos prototípicos de $t i$ - são as perguntas QU- de objeto como no exemplo abaixo:

(406) Pergunta QU- de objeto

Morã-mon taso ti-oky-t?

QU-COP.INT homem INV-matar-CON.COP

"O que o homem matou?"

(STORTO, 1999) 
Em muitas línguas com esse fenômeno, o clítico não é permitido quando o argumento dobrado é um pronome interrogativo (BAKER; KRAMER, 2016). Em Amárico, por exemplo, o redobro através do clítico '-i $w$ ' não é possível se o argumento referenciado for um elemento QU- (veja 407b). O mesmo se verifica no dado de Romeno em 408b, no qual o clítico acusativo é impossível em perguntas QU-:

(407) Redobro de clítico com pronome interrogativo

[Amárico]

a. Mann-in ayy-if?

quem.M-ACC ver.PF-2FS.S

'O que você (feminino) viu?"

b. *Mann-in ayy-îf-iw? quem.M-ACC ver.PF-2FS.S-3MS.O

(BAKER; KRAMER, 2016)

(408) Redobro de clítico com pronome interrogativo

[Romeno]

a. Pe cine ai vazut?

PE quem tem (você) visto

'Quem você viu?"

b. *Pe cine l-ai vazut?

PE quem ele-ter(você) visto

(DOBROVIE-SORIN, 1990)

Uma intuição por trás dessa proibição é de que, por ter uma natureza pronominal, um clítico não é permitido em contextos em que pronomes são agramaticais. Especificamente, pronomes são banidos de perguntas QU- com uma configuração chamada de weak crossover, na qual o pronome interrogativo é concomitantemente ligado por um vestígio e por um pronome possessivo na posição de sujeito:

(409) Weak crossover

* $\mathrm{Who}_{\mathrm{i}}$ did his $\mathrm{i}_{\mathrm{i}}$ mother see $t_{\mathrm{i}}$ ?

(Para qual x, a mãe de x viu x?)

Uma explicação para a agramaticalidade de configurações de weak crossover é o Princípio Bijetivo (Bijection Principle), que afirma que um operador (neste caso, o pronome interrogativo) deve ligar uma e apenas uma variável (KOOPMAN; SPORTICHE, 1982). Como os clíticos teriam um estatuto pronominal, eles gerariam configurações de weak crossover em perguntas QU- assim como o pronome em 409. Por conta disso, Baker e Kramer (2016) propõem que a impossibilidade de dobrar um pronome interrogativo seja um diagnóstico para se detectar o status pronominal de um elemento. 
Nossa análise de ti- incorre então em um problema, pois aparentemente ser um clítico e dobrar um pronome interrogativo são duas propriedades excludentes. Para resolver essa questão, argumentaremos que, embora o redobro com pronomes interrogativos seja amplamente usado para se detectar o status pronominal, o teste de weak crossover não é aplicável em todas as línguas. Isso porque, em algumas delas, configurações de weak crossover não são agramaticais. Warlpiri é um exemplo, pois a língua não exibe violações de weak crossover em todos os contextos:

(410) Ausência de weak crossover

[Warlpiri]

Ngana ka nyanungu-nyangu maliki-rli wajili-pi-nyi?

quem PRES.IMPF ele-POSS cachorro-ERG perseguir-NPAST

'Quem ${ }_{\mathrm{i}}$ o cachorro dele $\mathrm{i}_{\mathrm{i}}$ está perseguindo? (HALE; LAUGHREN; SIMPSON (1995) apud LEGATE (2011)

Assim, se a língua permitir configurações de weak crossover em perguntas simples com pronomes, é esperado que construções de redobro de clítico também possam ocorrer com elementos QU-. Este poderia ser o caso em Karitiana, pois existem indícios de que a língua não proíbe weak crossover em perguntas simples. Por exemplo, no contexto abaixo, os falantes oferecem respostas indicando que a pergunta em 411a têm as variáveis relevantes ligadas:

CONTEXTO: Temos aqui a história de três pessoas: o Antonio José, o Nelson e o Walter. O Antonio José e o Nelson têm cada um seu próprio macaco. Um dia, os macacos deles ficaram meio doidos e começaram a morder as pessoas. O macaco do Antonio José mordeu o próprio dono, o Antonio José! Já o macaco do Nelson mordeu o Walter. Bom, nessa história tinha o Antonio José, né? [Faz a pergunta em 411a]

(411) a. Ausência de weak crossover

Mora-mon i-pikom ti-okoo-t?

QU-COP.INT 3-macaco INV-morder-CON.COP

'Quem o macaco dele mordeu?"

b. Respostas possíveis

i. Antonio José (2 falantes)

ii. Antonio José by'et naokoot i, Nelson by'et naokoot Walter.

"O bicho do Antonio José mordeu ele, o bicho do Nelson mordeu o Walter."

Como $i$ - é o pronome possessivo de terceira pessoa singular e plural, duas interpretações são possíveis para a pergunta 411a. Primeiramente, a resposta em 411b-i, 'Antonio José', foi dada por dois falantes. Em outras palavras, a pergunta 411a foi interpretada como 412, uma configuração clássica de weak crossover: 
(412) Quem o macaco dele $_{\mathrm{i}}$ mordeu $\mathrm{t}_{\mathrm{i}}$ ?

Além disso, a resposta de lista em 411b-ii nos indica que $i$ - também pode ser interpretado no plural, como na tradução abaixo:

(413) Estrutura da resposta em 411b-ii

Quem $_{i}$ os macacos deles morderam $_{i}$ ?

Essa configuração parece indicar que a pergunta em 411a pode talvez ser interpretada como um tipo de pergunta de QU- múltiplo, que, como vimos no capítulo 2, ocorre com o pronome $i$. Sobre isso, apenas queremos enfatizar que um dos itens da lista, 'Antonio José', constituiria uma configuração de weak crossover.

Em resumo, a ocorrência do redobro de clítico com pronomes interrogativos pode ser acomodada se assumirmos que a língua permite violações de weak crossover. Dessa forma, o teste de Baker e Kramer (2016) para se diagnosticar clíticos não é aplicável a todas as línguas, mas sim apenas àquelas que banem esse tipo de configuração.

\subsubsection{Redobro de clítico e sintagmas nominais não referencias}

Existe ainda um outro aspecto da proposta de Baker e Kramer (2016) que é problemático para nossa análise. Segundo os autores, a impossibilidade de termos redobro de clítico com pronomes interrogativos estaria na realidade relacionada a uma restrição ainda maior: a de clíticos não redobrarem sintagmas não referenciais como mencionamos na seção $§ 6.4 .4$ para os dados com um sintagma com 'nenhum $x$ ', indefinidos não específicos e quantificadores (395 e 396). ${ }^{16}$ Dessa forma, é preciso então fazer a seguinte reflexão: um dos problemas com a coocorrência de $t i$ - com elementos QU- seria, na essência, o de um clítico redobrar um elemento não referencial, o que translinguisticamente parece ser uma restrição imposta a estes elementos.

Antes de apresentarmos nossa solução para esse problema, é preciso apontar que uma restrição de $t i$ - com elementos não referenciais de fato se verifica em alguns ambientes. São os dados de orações relativas de objeto que vimos em §6.4.4: neles, o tema jamais pode ter o significado de 'nenhum' (veja 383a e 384), o que, como já vimos, estaria em consonância com o comportamento de clíticos em outras línguas. Assim, pelo

16 Além disso, os autores também propõem que eles não seriam possíveis com anáforas, pois estes elementos também não seriam referenciais:

(xvi) Redobro de clítico com anáforas

a. Lämma ras-u-n gäddäl-ä.

Lemma.M mesmo-dele-ACC matar-3MS.S

'Lemma se matou.'

b. *Lämma ras-u-n gäddälä-w

Lemma.M mesmo-dele-ACC matar(MS.S)-3MS.O

(BAKER; KRAMER, 2016) 
menos nestes ambientes, $t i$ - se comporta exatamente como esperaríamos se ele fosse um clítico pronominal. Contudo, o que dizer das outras construções em que ele aparece, especialmente as perguntas QU- de objeto? Aqui, obviamente, essa mesma restrição não se verifica, pois o $t i$ - dobra um elemento não referencial - o pronome interrogativo.

Nossa explicação reside no fato de que, em relativas de objeto e perguntas QUde objeto, a posição final do tema não é a mesma: em relativas, ele se move para a borda de $v \mathrm{P}$ como 414, enquanto em perguntas ele se moveria além, para Spec, CP:

(414) Relativa de objeto com ti-

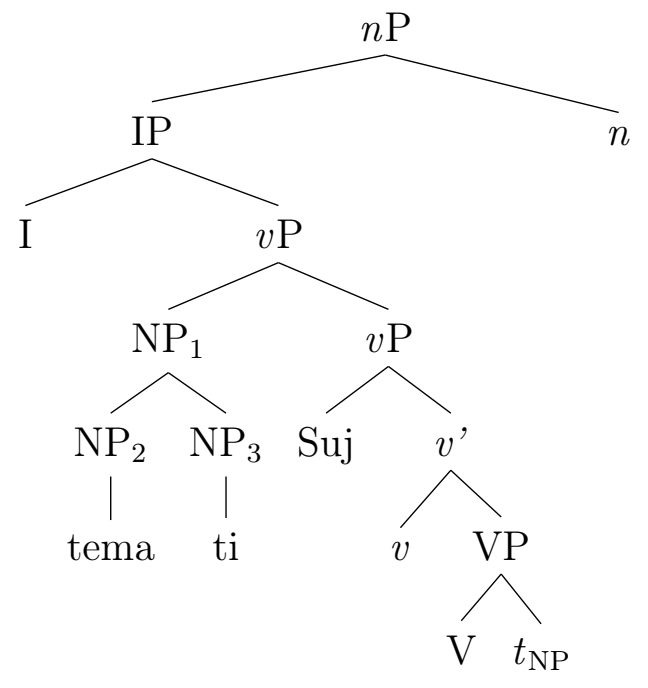

$(415)$

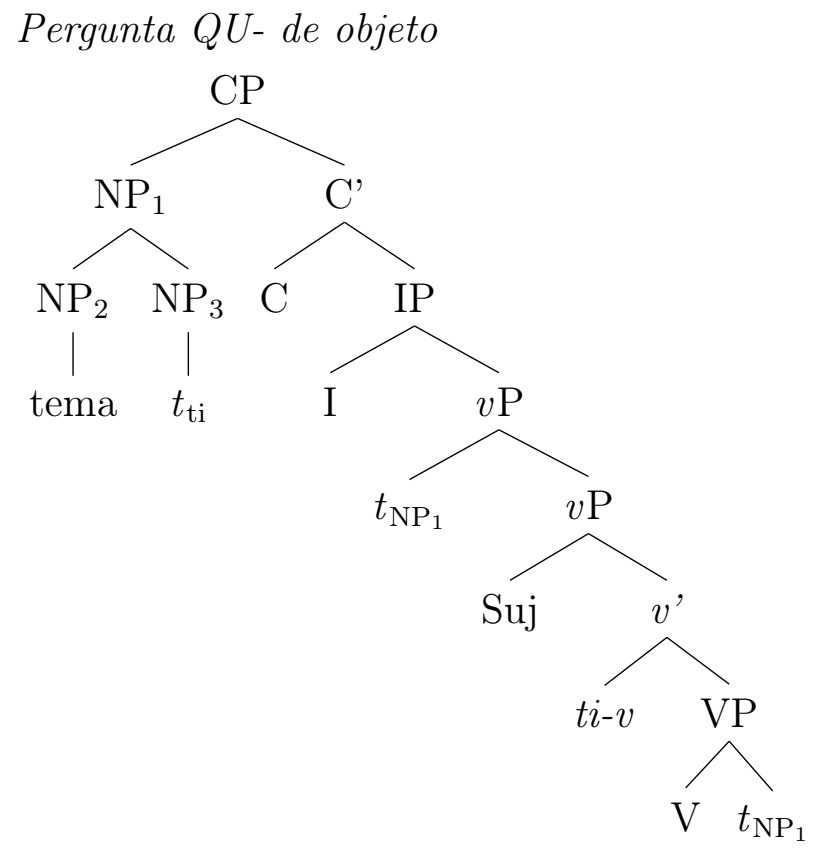

Como vimos em $\S 6.4 .1$, o movimento longo para Spec, CP pressupõe o deslocamento para a borda do $v \mathrm{P}$. O que gostaríamos de sugerir então é que essa posição na borda do $v \mathrm{P}$ seria na realidade a responsável pela restrição de não referencialidade, e não o redobro de clítico em si. Assim, nos casos em que o tema para nessa posição, como nas 
relativas de objeto, a restrição se verifica; nos casos em que ele move além, $t i$ - pode acabar dobrando sintagmas nominais não referenciais.

As evidências para essa proposta vem de duas frentes. Primeiro, vamos mostrar que elementos na posição da borda do $v \mathrm{P}$ têm essa restrição mesmo em casos que não envolvem redobro de clítico. Como mencionamos nos casos dos dados em Alemão em 392 e 393, este fenômeno é conhecido como scrambling. Nos exemplos de scrambling em Persa abaixo, os objetos que se movem para fora do $v \mathrm{P}$, permanecendo ou em sua borda ou na região de IP, adquirem a leitura pressuposicional:

(416) Scrambling e referencialidade

[Persa]

a. Kimea aghlab [ [v barâ mâ ye she'r az Hafez mi-xun-e $]$ Kimea frequentemente para nós um poema de Hafez HAB-ler-3SG "Frequentemente é o caso que Kimea lê um poema de Hafez para nós."

b. Kimea aghlab ye she'r az Hafez-ro [ [vP barâ mâ mi-xun-e] Kimea frequentemente um poema de Hafez-RÂ para nós HAB-ler-3SG

"Frequentemente é o caso que Kimea lê um poema (específico) de Hafez para nós."

(KARIMI, 2003)

Crucialmente, esses fenômenos também exibem as mesmas restrições que o redobro de clítico: somente elementos referenciais (DPs definidos, especfícos, etc.) podem em geral sofrer essa operação (DIESING, 1992; DIESING; JELINEK, 1995; KARIMI, 2003). Assim, esses dados seriam um indicativo de que é a posição do tema, não o clítico, que gera a restrição de referencialidade observada em muitas línguas.

A segunda evidência para nossa proposta é que ela prevê que a restrição de referencialidade desapareça se o tema se mover para posições além das posições de scrambling. Em muitas línguas, existe uma espécie de construção em que elementos são deslocados para a periferia esquerda (tradicionalmente, Spec, CP) e redobrados por um clítico pronominal. Esta construção é frequentemente chamada de Clitic Left-Dislocation. Vimos no dado em 373 um exemplo dessa construção no Grego. Crucialmente, elementos nessa posição podem ser não referenciais. Nos exemplos abaixo, o clítico 'ton' se refere ao indefinido não específico "um trabalhador que não sabe inglês"em 417 e ao item de polaridade negativa 'kanénan' ('ninguém') em 418:

\section{Clitic Left-Dislocation com NP não específico}

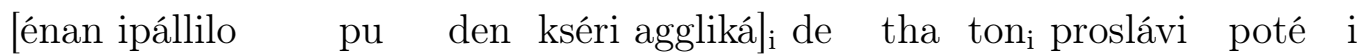
um trabalhador quem NEG sabe inglês NEG FUT CL empregar nunca a etería mas companhia nossa

"Nossa companhia nunca empregaria um trabalhador que não sabe inglês." (Literalmente: "Um trabalhador que não sabe inglês, nossa companhia nunca o empregaria.)

(KUPULA, 2014) 
(418) Clitic Left-Dislocation com item de polaridade negativa [kanénan] $]_{i}$ den ton $_{\mathrm{i}}$ simféri na íne ánergos aftin tin epohí ninguém NEG CL beneficiar SBJ estar desempregado esta a temporada "Ninguém se beneficia de estar desempregado hoje em dia"

(Literalmente: "Ninguém, ele se beneficia de estar desempregado hoje em dia.") (KUPULA, 2014)

O exemplo 418 ainda é crucial por mostrar que o item deslocado se move para a posição de Spec, CP e que ele não é gerado na base como se propõe para muitos casos de Clitic Left-Dislocation (CINQUE, 1977): tradicionalmente, itens de polaridade negativa têm que ser c-comandados pela negação. Assim, este caso mostra que o elemento 'kanénan' foi de fato gerado abaixo da negação 'den'.

Em resumo, o redobro de clítico pode ocorrer com elementos não referenciais se estes se localizarem em posições acima da posição de scrambling. Crucialmente, em Karitiana, a restrição de $t i$ - com objetos não referenciais também desaparece quando o tema se move para Spec, CP. Este fenômeno pode ser visto nos dados naturalísticos abaixo, nos quais ti- e - $k i$ co-ocorrem em uma oração matriz. Eles estão reproduzidos em 419b e 419c e vêm da narrativa "Osiipo", que relata um ritual de iniciação masculino. Nele, um rapaz que pretende se iniciar deve perfurar um vespeiro. Em um dado momento, o narrador discorre sobre vários tipos de vespas:

Leitura não referencial do tema com ti-

a. Gop sõwo-ra, gop miem-o, gop miem-o sypom, gop vespa vermelho-ADVZ vespa miem-ENF vespa miem-ENF dois vespa sõwo-ra sypom tyym miem-ENF dois também "As vespas vermelhas, a vespa miemo, a vespa miemo duas vezes, as vespas vermelhas duas vezes também" ["Osiipo"]

b. Gop bisõwora yn ti-m-'y-ki-t vespa bisõwora 1s INV-CAUS-pegar-NEG-CON.COP "A vespa bisõwora, eu não peguei."

c. Gop bikiip yn ti-m-'y-ki-t vespa bikiip 1s INV-CAUS-pegar-NEG-CON.COP "A vespa bikiip, eu não peguei."

Nas construções clivadas 419b e 419c, uma análise possível é de que os NPs 'gop bisõwora' e 'gop bikiip' têm escopo restrito com relação à negação. Em outras palavras, elas teriam as formas lógicas em 420b e 421b: 
a. Gop bisõwora yn ti-m-'y-ki-t vespa bisõwora 1s INV-CAUS-pegar-NEG-CON.COP

Literalmente: "Eu não peguei nenhuma vespa bisõwora."

b. $\neg \exists \mathrm{x}$, tal que $\mathrm{x}$ é vespa bisõwora $\wedge$ eu peguei $\mathrm{x}$

a. Gop bikiip yn ti-m-'y-ki-t

vespa bikiip 1s INV-CAUS-pegar-NEG-CON.COP

Literalmente: "Eu não peguei nenhuma vespa bikiip."

b. $\neg \exists \mathrm{x}$, tal que $\mathrm{x}$ é vespa bikiip $\wedge$ eu peguei $\mathrm{x}$

Assim, a interpretação proibida nos casos de relativas de objeto passa a ser permitida se o tema se mover além da borda do $v$ P. Dessa forma, concluímos que a restrição de interpretação não advêm do redobro de clítico em si, mas da posição ocupada pelo NP redobrado. Em última instância, isso implica que o teste com NPs não referenciais não pode ser utilizado como o principal diagnóstico de redobro de clítico, pois é preciso levar em conta qual a posição que o NP redobrado ocupa nestas construções. ${ }^{17}$

\subsubsection{Resumo da seção}

Dado o que vimos nas últimas duas seções, podemos então delinear duas possibilidades para a interpretação do tema em construções com $t i$. Primeiramente, o $t i$ - força o movimento do tema para a borda do sintagma verbal. Esta é a posição que o tema ocupa em relativas de objeto e, nestas construções, o tema deve ter uma interpretação referencial por ser mapeado na oração restritiva. Porém, a partir dessa posição, o tema pode ainda se mover para Spec, CP sem violar a Condição de Impenetrabilidade de Fases, um passo que estaria envolvido nas perguntas QU-, construções de foco do objeto e possivelmente também em clivadas. Nessa posição, a restrição de interpretação não referencial não existe mais e o tema pode ter tanto uma leitura referencial quanto não referencial.

Assim, propomos que as restrições de interpretações observadas por Baker e Kramer (2016) não estão intrinsecamente ligadas ao clítico em si, mas sim às diversas posições que os clíticos podem ocupar nestas estruturas. Se a língua permitir que o NP dobrado ocupe posições diferentes na estrutura sintática, o clítico permitirá interpretações compatíveis com essas posições também.

\subsection{Resumo do capítulo}

Neste capítulo oferecemos uma análise para as construções com o morfema $t i$ como uma estrutura de redobro de clítico. Argumentamos que essa proposta é capaz de

17 É preciso mencionar que, para alguns autores, construções de redobro de clítico e de Clitic LeftDislocation não são derivacionalmente relacionados. Para maiores informações, veja Iatridou (1995). 
explicar a distribuição deste morfema em perguntas QU-, construções de foco do objeto e relativas de objeto, além de capturar o padrão de concordância excêntrico sem assumir contextos de ergatividade cindida na língua. Além disso, discutimos as relações deste morfema com a passiva $a$ - e defendemos que nossa proposta explica ainda a leitura pressuposicional do tema nas construções com $t i$ - ao vincular essa interpretação a uma determinada posição sintática. No próximo capítulo, veremos ainda como a posição sintática dos argumentos em construções com ti-pode elucidar alguns contornos prosódicos encontrados nessas posições. 



\section{Fenômenos prosódicos}

Nos capítulos anteriores, investigamos diversas propriedades das orações subordinadas e construções de voz inversa. Neste capítulo, veremos alguns padrões prosódicos que podem oferecer argumentos independentes para as análises desenvolvidas neste trabalho. Especificamente, nos debruçaremos sobre dois fenômenos fonológicos: um sufixo -o que emerge em argumentos dentro de orações encaixadas e um padrão prosódico especial nas orações relativas com ti-. Como ambos ocorrem dentro de ambientes subordinados, será preciso mobilizar uma série de discussões apresentadas anteriormente.

Na seção §7.1, apresentamos a teoria da hierarquia prosódica, que embasará nossa discussão as seções subsequentes. Em §7.2, apresentamos uma vogal [o], que emerge em sintagmas nominais dentro de orações subordinadas e cujo status como vogal epentética ou morfema será problematizado em $\S 7.2 .1$ e $§ 7.2 .2$. Especificamente, discutimos também como essa vogal poderia ser um argumento adicional para nossa proposta de nominalização das subordinadas desenvolvida em 4. Finalmente, apresentamos um fenômeno intonacional em relativas de objeto com ti- na seção §7.3.3, discutindo possíveis conexões entre os fenômenos prosódicos de fraseamento e intonação e a estrutura proposta para subordinadas com ti- no capítulo 6.

\subsection{Hierarquia prosódica}

Como trabalharemos na interface entre fonologia e (morfos)sintaxe, é preciso primeiro explicitar qual a teoria fonológica que embasará nossa discussão dos dados, a hierarquia prosódica proposta por Nespor e Vogel (2007). Sua principal assunção é de que a cadeia fônica é organizada em constituintes prosódicos, que, por sua vez, estabelecem uma relação hierárquica entre si. Segundo Nespor e Vogel (2007), os constituintes da hierarquia prosódica seriam os seguintes: 


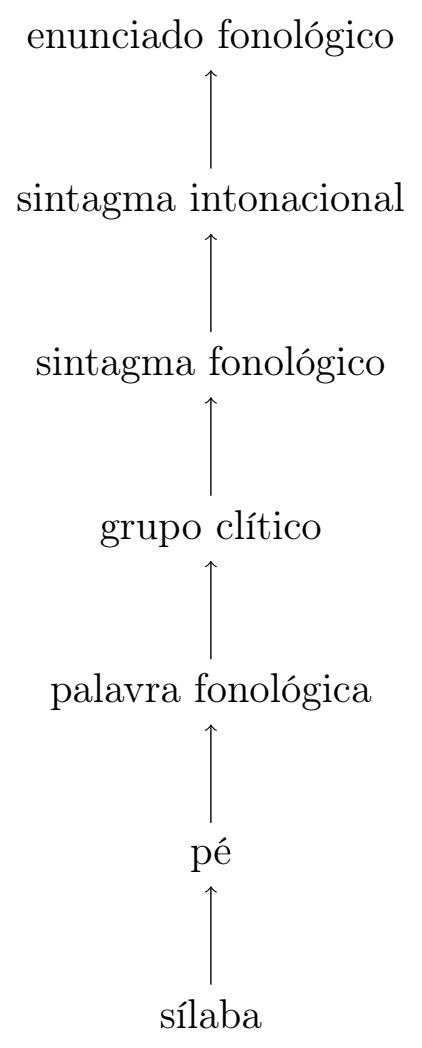

(NESPOR; VOGEL, 2007)

Os constituintes prosódicos são criados através de regras de mapeamento específicas que levam em conta os domínios morfossintáticos sobre os quais operam. Por exemplo, a constituição de um sintagma fonológico faz referência a noções sintáticas como núcleocomplemento em sua formulação e pode, portanto, ser um reflexo desse constituinte sintático. Contudo, as autoras pontuam que existem regras fonológicas específicas que alteram os constituintes prosódicos de tal forma que o isomorfismo entre os constituintes prosódicos e sintáticos não é completo. Na seção §7.3.1, veremos um dos processos que alteram o isomorfismo, a reestruturação de sintagmas intonacionais. Assim, é preciso certa cautela ao discutir evidências prosódicas para constituintes morfossintáticos, pois, embora eles possam revelar pistas sobre a estrutura sintática, a relação entre esses dois domínios não é necessariamente isomórfica em todos os casos.

Para nossa discussão, os níveis prosódicos que serão relevantes são aqueles que fazem referência a constituintes sintáticos em sua formulação, a saber: o sintagma fonológico e o sintagma intonacional. Em Karitiana, o sintagma fonológico é um dos domínios no qual a regra de epêntese, que será discutida na seção §7.2.1, opera. Já o sintagma intonacional é o locus da entonação, que será particularmente relevante para os casos de relativas de objeto com $t i$ - em $§ 7.3 .3$. 


\subsection{Sufixo -o em orações subordinadas}

Em algumas sentenças bi-oracionais, uma vogal -o emerge marcando alguns NPs dentro de orações subordinadas. Por exemplo, ela ocorre em um sujeito intransitivo dentro de uma subordinada e entre o objeto direto e um verbo transitivo:

-o entre sujeito intransitivo e verbo

Yj-so'oot hoop, y-taka-'a-t ta'ãt yta, [opok-o

1pl-ver lá 1s-DECL-fazer-NFUT EVID.DIR-NFUT 1pl inimigo-O

kat-a-pa]-ty.

dormir-EPEN-NMZ-OBL

"Vamos lá, eu disse, no local onde o inimigo dormiu." ["Encontro dos Capivari e dos Karitiana"]

(424) -o entre objeto e verbo

$\emptyset$-naka-hyryj ta'ã-t y-'it [gop-o 'obm tyso'oot]

3-DECL-cantar EVID.DIR 1s-pai/filho vespa-O furar ASP

"O meu pai cantava enquanto perfurava o vespeiro"

["Osiipo"]

(425) -o entre objeto e verbo

$\emptyset$-pyry-kiid-n [taso gop-o 'obm-on tyym]

3-ASS-existir-NFUT.ASS homem vespa-O furar-EPEN também

"Há os que perfuram vespas de verdade."

["Osiipo"]

(426) -o entre objeto e verbo

[Kytop-o pyk byyk], morãsong Ø-na-monde-t 'ej chicha-O acabar PERF. então 3-DECL-terminar-NFUT túmulo

"Quando acaba a chicha, a gente termina o túmulo." ["Ritos fúnebres"]

(427) -o entre objeto e verbo

$\emptyset$-naka-'atyn jonso, [kytop-o tak]-a-ty, [kytop pipamboj]-o-ty.

3-DECL-? mulher chicha-O pilar-EPEN-OBL chicha peneirar?-EPEN-OBL

"As mulheres pilam e peneiram a chicha." ["Ritos fúnebres"]

Neste ponto, existem duas opções de análise para essa vogal -o. Primeiramente, poderíamos considerá-la como um tipo de epêntese, um fenômeno fonológico já operante em diversos domínios morfossintáticos da língua. A segunda opção é relacionar o morfema -o com o enfático -o, que também é cognato ao sufixo nominalizador das línguas TupiGuarani (veja capítulo 5). Essas duas propostas serão apresentadas e discutidas nas seções $\S 7.2 .1$ e $\S 7.2 .2$, respectivamente. Contudo, nossa posição é que, seja qual for a análise mais adequada para este elemento, ele pode oferecer uma evidência independente para a análise desenvolvida no capítulo 4 de que orações subordinadas seriam construções nominalizadas. 


\subsubsection{Vogal -o como epêntese}

A regra de epêntese foi mencionada brevemente no capítulo 5; aqui, no entanto, ela pode ter um papel fundamental. Uma das primeiras menções a ela vem do trabalho de Landin (1984). Segundo o autor, existiria na língua uma regra fonológica inserindo a vogal central [i] em raízes verbais terminadas em consoante nas sentenças negativas:

Epêntese em orações negativas

Yn i-m-hok-y yn tomtom

1s 3-CAUS-tocar-EPEN Is violão

"Eu não vou fazer o violão tocar."

(D. LANDIN, 1984, adaptado)

Uma das principais razões para considerarmos a vogal central como epêntese neste caso é que, em Karitiana, as orações negativas parecem opcionalmente omitir a negação 'padni':

(429) Negação com 'padni'

Yn i-kyndop-y padni (karama tom)

1s 3-abrir-EPEN NEG porta

"Eu não vou abrir (a porta)."

(EVERETT, 2006, adaptado)

Assim, em casos como 428, a vogal epentética seria inserida antes do apagamento da negação (veja Storto (1999, ftn.28)).

Storto (1999) discute o processo de epêntese mais profundamente, mostrando os diversos ambientes em que ela ocorre. Basicamente, uma vogal é inserida entre duas consoantes para evitar o choque consonantal dentro de certos constituintes prosódicos. Em geral, a vogal inserida terá a mesma qualidade da vogal do núcleo da sílaba anterior, mas, em alguns casos, a vogal central [i] pode também ser empregada.

(430) Regra de epêntese

$\emptyset \rightarrow \mathrm{V} /$.C_C

(baseado em STORTO, 1999)

Segundo Storto, a epêntese é encontrada em diversos domínios prosódicos. Primeiramente, ela ocorre com nomes derivados:

(431) Epêntese em nomes derivados

bik $\quad$-pa $\rightarrow$ bikipa

sentar NMZ "banco"

(STORTO, 1999)

(432) Epêntese em nomes derivados

$\begin{array}{llll}\text { so'oot } & - \text { pa } & \rightarrow & \text { so'ootopa } \\ \text { ver } & \text { NMZ } & \text { "microscópio" }\end{array}$

(STORTO, 1999) 
De acordo com a autora, a epêntese também ocorre dentro de outros constituintes identificados por ela como sintagmas fonológicos, como dentro de compostos, entre o verbo e a negação, entre possuidor e possuído e entre NPs e posposições. Nestes contextos, existe ainda o requerimento adicional de que haja um choque de acento, o que faz com que a epêntese seja bastante comum entre compostos com palavras monomorfêmicas:

Epêntese em compostos
a. 'ip byj $\rightarrow$ 'ipibyj
peixe chefe "Surubim"
b. 'eet se $\rightarrow$ 'eetese
abelha líquides "Mel"

(STORTO, 1999)

(434) Epêntese entre verbo e negação

i-so'oot padni $\rightarrow$ iso'ooto padni

3-ver NEG "Não viu"

(STORTO, 1999)

(435) Epêntese entre possuidor e possuído

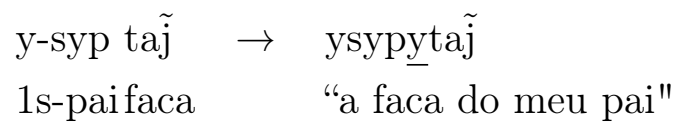

(STORTO, 1999)

(436) Epêntese em sintagmas posposicionais

y-'it sok $\rightarrow$ y'itísok

1s-filho POSP "com meu filho"

(STORTO, 1999)

Como Karitiana já faria amplo uso de uma regra de epêntese, é plausível que o segmento -o que emerge nos exemplos 423-427 seja uma epêntese que copia a qualidade da vogal da última sílaba dos argumentos 'opok', 'kytop' e 'gop'.

Até onde pudemos investigar, exemplos com essa vogal - o são encontrados apenas em orações subordinadas. Assim, nossa intuição aqui é que existe algo na estrutura das subordinadas que favorece a aplicação da epêntese em um domínio sintático maior do que os elencados em 433-436. Uma das possibilidades é de que a aplicação da epêntese nestes ambientes indicaria uma relação bem mais local entre o verbo subordinado e seus argumentos. Neste sentido, ele é um argumento adicional para a estrutura inicialmente proposta por Storto (1999), na qual os argumentos em orações subordinadas permaneceriam in situ dentro do sintagma verbal: 
(437) Estrutura da oração subordinada sem nominalizador

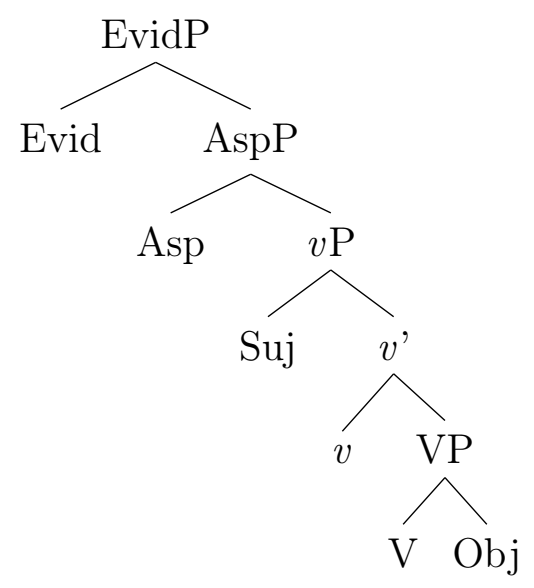

(STORTO, 1999, adaptado)

Esse argumento pode também ser estendido à nossa estrutura nominalizada em 438, na qual os argumentos encontram-se igualmente dentro do sintagma verbal:

Estrutura da oração subordinada com nominalizador

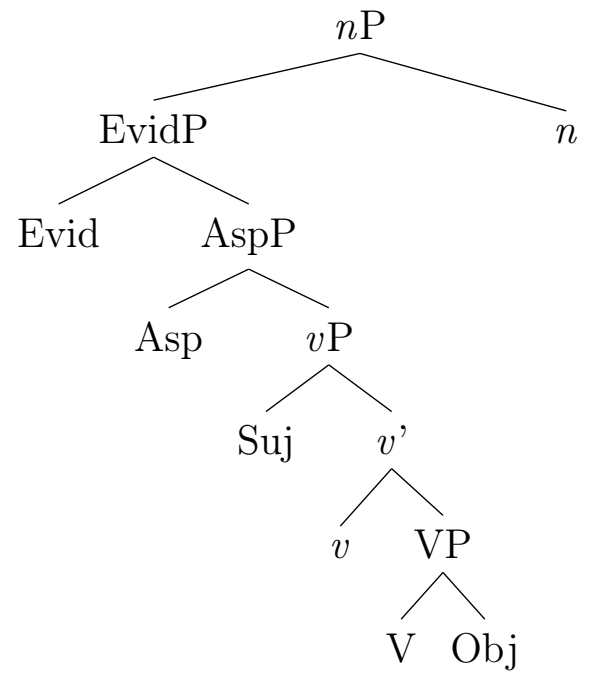

Tanto na estrutura em 437 quanto na estrutura em 438, o verbo e seus argumentos se encontrariam em uma posição bastante local. Assim, na interface sintaxe-fonologia, possivelmente o sujeito intransitivo e o objeto direto são mapeados em um único constituinte prosódico (possivelmente, um sintagma fonológico), que constituiria um domínio de aplicação da epêntese.

Existe, também, um outro aspecto desse fenômeno que pode ainda revelar conexões importantes entre orações subordinadas e sintagmas nominais, o que, por sua vez, constituiria mais uma evidência a favor da estrutura com o nominalizador em 438. Como vimos em 435, a epêntese ocorre em sintagmas nominais possessivos. Dessa forma, pode ser ainda que a epêntese ocorra nos dados de subordinadas em 423- 427 não somente 
porque o verbo e seus argumentos estão em uma relação bastante local, mas sim porque argumentos dentro de subordinadas seriam equivalentes a possuidores em sintagmas nominais. Em outras palavras, como a epêntese em sintagmas nominais possessivos aparece no elemento genitivo, sua ocorrência estariam genitivizados nestes ambientes.

Essa interpretação dos fatos é plausível por dois motivos. Primeiro, oferecemos na seção $\$ 4.4 .3$ algumas evidências de que sintagmas nominais dentro de orações subordinadas podem ser sim genitivos. Basicamente, argumentamos que o fenômeno da cliticização de pronomes em subordinadas poderia ser reinterpretado como uma genitivização dos argumentos em orações encaixadas. Em outras palavras, os pronomes cliticizados ao verbo seriam, na realidade, possuidores. Sobre isso, é importante pontuar uma conexão importante aqui: o pronome "cliticizado" pode ser tanto o sujeito intransitivo ou um objeto direto.

Cliticização com sujeito intransitivo

[Yj-kĩkin byyk], Ø-na-pyn-hot- $\emptyset \quad$ y-'et-e-'et $\quad$ 'ej-e-kyn.

1pl-chorar PERF. 3-DECL-DEON-ir-NFUT 1s-filho-EPEN-filho túmulo-EPEN-LAT

"Depois de chorarmos, tem que ir pro túmulo, meu neto." ["Ritos fúnebres"]

(440) Cliticização com objeto direto

[A-ty an yta-m-pypyyt-y]-ty yta-pyting yta, y-timo $\tilde{j}$

isso-OBL 2s 1pl-CAUS-saber-EPEN-OBL 1pl-querer 1pl 1s-tia.avó

"Nós queremos que você explique isso pra nós, tia avó." ["Ritos fúnebres"]

Crucialmente, estes são os mesmos tipos de argumentos que disparam a epêntese nos dados 423-427. Assim, é plausível que sujeitos intransitivos e objetos diretos sejam elementos genitivos em orações subordinadas, porque sua expressão pode de fato ser feita através de formas possessivas. Neste caso, a epêntese -o seria uma outra evidência para a genitivização desses elementos, o que, por sua vez, constituiria um argumento adicional para a nominalização das subordinadas tal como proposto em 438.

Outro argumento para a análise de que os NPs dentro de orações subordinadas seriam equivalentes a possessivos é a correlação entre extração e epêntese. Como mencionamos anteriormente, possuidores disparam a epêntese:

Epêntese entre possuidor-possuído

'Ep $\quad$ 'о $\rightarrow$ 'epe'o

árvore fruta "fruto da árvore"

Crucialmente, a epêntese não ocorre entre um nome e um adjetivo, mesmo que o choque consonantal ocorra e que o NP resultante seja um composto (veja Storto (1999) e Everett (2006)): 
(442) Ausência de epêntese entre nome e adjetivo

byyp som $\rightarrow$ byyp som

tartaruga vermelha (espécie de tartaruga)

(443) Ausência de epêntese entre nome e adjetivo

'ip pok $\rightarrow$ 'ip pok

peixe branco (espécie de peixe)

Crucialmente, existe uma correlação entre a epêntese e a possibilidade de extração: elementos que disparam a epêntese não podem ser extraídos e vice-versa. Assim, possuidores não podem ser extraídos do NP e disparam pied-piping, como vemos em 444 e 445; já adjetivos não permitem a epêntese e podem opcionalmente se mover, como se vê em 447a:

(444) Extração de possuidor sem pied-piping

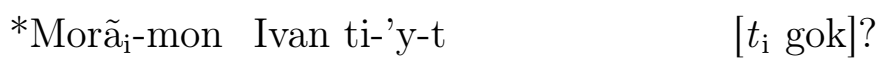

QU-COP.INT. Ivan INV-comer-CON.COP. mandioca

(445) Extração de possuidor com pied-piping

[Morã gok $]_{i-O-m o n} \quad$ Ivan ti-'y-t?

QU mandioca-EPEN-COP.INT. Ivan INV-comer-CON.COP.

"A mandioca de quem o Ivan comeu?"

(446) Sentença com $N$-Adj

Maria Ø-na-aka-t i-mana-t taso hãraj-ty.

Maria 3-DECL-COP-NFUT NMZ-casar-NFUT homem bonito-OBL

"A Maria casou com um homem bonito."

(447) Extração de adjetivo não exige pied-piping

a. [Morã horot] i-amy pykyp-y-ty Karin?

QU COMP 3-comprar roupa-EPEN-OBL Karin

"A Karin comprou uma roupa como?"

b. [Morã horot pykyp aka]-ty i-amy Maria?

QU COMP roupa COP-OBL 3-comprar Maria

"A Maria comprou uma roupa como?"

Assim, existe uma correlação direta entre disparar epêntese e estar imóvel em um determinado domínio. Por sua vez, este seria outro argumento de que, dentro de subordinadas, os argumentos de um verbo funcionariam como possuidores, pois ambos se comportariam de forma equivalente por (1) não poder se mover e disparar pied-piping (no caso de argumentos dentro da subordinada, teríamos um pied-piping de larga-escala como 448) e (2) ser um domínio de aplicação para a epêntese: 
(448) Pied-piping de larga-escala

[Morã Karin ti-ko]-mon João ti-sadnan- $\emptyset$ ?

QU Karin INV-quebrar-COP.INT João INV-contar-CON.COP

"O que o João contou que a Karin quebrou?"

Resumindo, uma possível análise para o sufixo -o nos NPs dentro de orações subordinadas seria como uma vogal epentética. Se ela estiver correta, ele seria mais uma evidência de que os argumentos dentro de orações subordinadas seriam equivalentes a elementos genitivos, o que, por sua vez, seria uma argumento adicional para a nossa proposta de nominalização com subordinadas. No entanto, embora essa sugestão de análise possa criar uma conexão entre vários fenômenos distintos, é preciso reconhecer que ela demanda uma investigação mais profunda. Além disso, o próprio estatuto do -o como uma vogal epentética pode ser questionado, como veremos na seção seguinte.

\subsubsection{Vogal -o como enfático}

Uma segunda possibilidade de análise da vogal -o nos exemplos 423-427 é a de relacioná-lo com o enfático - $o$. Sobre isso, a primeira coisa a se mencionar é que a vogal -o em subordinadas não tem a distribuição típica do enfático. Como vimos em 5 , o enfático - o aparece prototipicamente em palavras isoladas, no final de enunciados e em itens de uma lista:

Enfático com a palavra 'Osiip'

a. Osiip-o ritual.de.iniciação-ENF

'Ritual de iniciação."

b. Yn-ty y-'it-i hadna tyym yn Ø-naka-m-'a-t ta'ã-t 1s-OBL 1s-pai-EPEN fala também 1s 3-DECL-CAUS-fazer-NFUT EVID.DIR osiip osiip

'(Com) a palavra do meu pai (direcionada) a mim, eu fiz o osiip" ["Osiipo"]

(450) Enfático em final de enunciado

I-m-'a siit-o 3-CAUS-fazer pamonha-EMPH

"Faça pamonhas." (STORTO, 1999)

(451) Enfático em item de lista

$\emptyset$-naka-m-'a-t pom-o, pom eem-o, bisỹ, syyj-o, pã'yyj-o, 3-DECL-CAUS-fazer-NFUT tuna-ENF, tuna preto-ENF mutum jacamim jacu-ENF tyym kinda papy-dna

também coisa pena-ADJZ

"Fez tuna, tuna preta, mutum, jacamim, jacu e os bichos de pena." 
Dados como 449 e 450 levaram Storto (1999) a postular que esse sufixo poderia estar relacionado a um tom baixo que tipicamente emerge no final de enunciados declarativos (veja $\S 7.3 .2$ ).

Contudo, existem alguns outros casos em que o sintagma nominal sufixado por -o não está exatamente no final do enunciado. Eles, no entanto, podem ser tratados de uma forma similar e unificada, pois o elemento que os segue parece constituir um sintagma intonacional à parte. O primeiro destes exemplos são perguntas, nas quais a partícula interrogativa ' $h \tilde{y}$ ' pode estar opcionalmente presente (1984):

Partícula interrogativa ' $h \tilde{y}$ '

An i-oky-t sojxa hỹ?

2s 3-matar-NFUT porco INTERR

"Você matou o porco?"

(D. LANDIN, 1984, adaptado)

(453) Enfático com partícula interrogativa ' $h \tilde{y}$ '

Morã-pip an i-m-hip him-o (hỹ)?

QU-em 2s 3-CAUS-cozinhar carne-ENF INTERR

"Quando você vai cozinhar a carne?"

(EVERETT, 2006, adaptado)

Como o enfático nesses casos sempre é possível com ' $h \tilde{y}$ ', podemos dizer então que, de alguma forma, a ocorrência do primeiro estaria de alguma forma condicionando a presença do segundo.

Outro exemplo em que o enfático se afixa a um constituinte não final é a sentença abaixo, na qual o pronome na posição de sujeito é repetido no final da sentença:

Enfático em NP não final

Yjxa i-oky 'irip-o yjxa.

1pl 3-matar anta-ENF 1pl

"Quanto a nós, vamos matar anta." ["Encontro dos Capivari e dos Karitiana"]

Construções com repetição de sujeito foram descritas por Storto (2014) como "shifted topic", ou seja, uma estratégia para sinalizar a mudança de topicalidade dos referentes de um discurso. Por conta disso, ele possivelmente teria um estatuto de tópico suspenso (hanging topic), como o constituinte 'quanto a nós' indica na tradução. Assim, esse tópico suspenso possivelmente constituiria um sintagma intonacional separado assim como no Português - e uma diferença seria que ele apareceria no final da sentença, não no início.

Os casos com o ' $h \tilde{y}$ ' e pronomes repetidos talvez podem ser unificados ao assumirmos que o constituinte a que -o se afixa é o último elemento do sintagma intonacional, embora não seja o último constituinte do enunciado fonológico. Assim, a regra do enfático faria menção a sintagmas intonacionais em sua formulação - o que, diga-se de passagem, é plausível dada a observação de Storto de que -o poderia estar relacionado à presença de um tom baixo. 
Como discutimos no capítulo 5, existe uma conexão histórica entre o enfático -o e o morfema nominalizador - $a$ das línguas Tupi-guarani, do qual o -o possivelmente deriva através da aplicação da mudança vocálica em cadeia (STORTO; BALDI, 1994). Vimos também que o sufixo - a das línguas Tupi-guarani emerge em diversos tipos de sintagmas nominais ocupando diversas funções sintáticas:

Caso argumental

[Tupinambá]

Tapi?ír-a o-só ók-a $\emptyset$-kot‘i

vaca-ARG 3suj-ir casa-ARG CONT-para.o-lado.de

"As vacas foram para as bandas das casas."

(RODRIGUES, 1999)

Se compararmos o exemplo acima com os dados em 423-427, veremos que a vogal - o e - $a$ parecem ter um aspecto em comum: sua presença em NPs. Em outras palavras, ambos sufixos emergem afixados a certos sintagmas nominais. Sobre isso, é preciso mencionar ainda que o sufixo - $a$ emerge em possuidores em algumas línguas Tupi-Guarani (ou argumentos adnominais na terminologia de Queixalós (2006)):

(456) Sufixo - a em possuidor

[Asuriní do Tocantins]

sahý-a r-uwý-a utururú hehé

lua-N CONTIGUIDADE-sangue-N EleCai Nele

"O sangue da lua caiu nele." ～(CABRAL (1998) apud QUEIXALÓS (2006))

Dessa forma, o fato de o sufixo - o aparecer nestes ambientes poderia ser um outro indicativo da genitivização de argumentos dentro das orações subordinadas, que, como discutimos na seção anterior, é uma das propostas do capítulo 4. Assim, mesmo se o sufixo -o nos NPs de 423-427 for um enfático - o, ele ainda pode ser uma evidência adicional para nossa análise de subordinadas dada a conexão deste elemento com o sufixo - $a$ das línguas Tupi-Guarani - em especial, a presença destes sufixos em possuidores dentro de um sintagma nominal.

\subsubsection{Resumo da seção}

Examinamos nessa seção duas opções para tratarmos a vogal -o nos dados 423427: essa vogal poderia ou ser uma vogal epentética ou um sufixo enfático, que é cognato do sufixo nominalizador - $a$ em outras línguas Tupi. Até o momento, não encontramos evidências contundentes para nos decidir por nenhuma delas; dessa forma, as duas propostas se colocam como igualmente possíveis por enquanto.

No entanto, embora o estudo dessa vogal -o demande ainda uma investigação mais profunda, achamos que o grande mérito dessa discussão é o de estabelecer conexões com fenômenos que aparentemente parecem desconexos, como a estrutura da subordinadas, os sufixos - $a /-o$ e os morfemas cognatos de outras línguas da mesma família. Em especial, as evidências apresentadas nas últimas seções reforçariam a ideia de que os NPs dentro de 
subordinadas funcionariam como possuidores, o que, por sua vez, constitui um argumento adicional para nossa proposta de nominalização desenvolvida no capítulo 4 .

\subsection{Entonação das subordinadas com ti-}

Nesta seção, apresentamos o padrão prosódico das orações subordinadas com $t i$ - as orações relativas de objeto -, enfatizando uma de suas ordens mais marcadas, a SOV. Veremos que relativas de objeto com essa ordem possuem obrigatoriamente uma entonação particular devido a um fraseamento prosódico específico, o que, por sua vez, pode nos dar algumas pistas sobre a estrutura sintática destas construções.

Antes de passar aos dados em si, apresentamos na seção §7.3.1 o arcabouço teórico que embasa a nossa discussão. As propriedades da gramática intonacional do Karitiana serão apresentadas na seção §7.3.2. Ali, descrevemos todos os padrões tonais que já foram atestados na literatura e argumentamos a favor da inclusão de um contorno tonal relevante para as sentenças bi-oracionais, que denominaremos como contorno ascendente de continuação (continuation rise), em §7.3.2.1. Por fim, os dados de orações relativas são apresentados em §7.3.3. Mostraremos que, em relativas de objeto com a ordem SOV, o sujeito parece ser obrigatoriamente reestruturado em um único sintagma intonacional, como se vê pela presença obrigatória do contorno de continuação neste ambiente. Isso, por sua vez, nos dará um argumento adicional para sustentar a estrutura das construções com $t i$ - proposta no capítulo 6 , pois o sujeito aqui exibiria a mesma configuração sintáticoprosódica que elementos em posições altas nas subordinadas, como adjuntos.

\subsubsection{Fonologia Intonacional Autossegmental-Métrica}

Uma das propriedades do som mais relevantes para o estudo da intonação é a altura (ou pitch), pois a melodia de uma sentença se manifesta através dela (LADEFOGED, 2003). Segundo Ladefoged (2003), a altura pode ser definida da seguinte forma:

\footnotetext{
"Estritamente falando, a altura é uma propriedade auditiva - algo que você ouve. Não é uma propriedade acústica - um aspecto da onda sonora que se pode medir. De um ponto de vista prático ao discutir a altura da voz, podemos considerá-la como a frequência na qual os pulsos das cordas vocais recorrem, e portanto a frequência fundamental da onda sonora."(LADEFOGED, 2003, tradução nossa)
}

Por ser uma propriedade perceptual, não é possível medir a altura diretamente. No entanto, como Ladefoged pontua no fragmento acima, é possível acessá-la através de seu correlato acústico: a frequência fundamental (F0), medida em Hertz (Hz). As análises 
intonacionais se debruçam então sobre esta última propriedade, que é frequentemente representada através de uma curva por diversos programas de computador.

Embora também possam fazer referência a outros constituintes prosódicos, o domínio da intonação por excelência é o sintagma intonacional (NESPOR; VOGEL, 2007; LADD, 2008). Tradicionalmente, as línguas empregam diversas pistas para se delimitar e reconhecer sintagmas entoacionais, como pausas, alongamento das sílabas finais e também, como veremos à frente, os tons de fronteira (sobre a definição de sintagmas entoacionais, veja Cruttenden (1997)). Em muitos casos, um sintagma intonacional pode ser equivalente a uma sentença, pois a formação desse domínio prosódico leva informações sintáticas em sua formulação (NESPOR; VOGEL, 2007). Porém, isso não é necessariamente o caso, como podemos ver no exemplo abaixo, no qual o segmento 'as you know' constitui um próprio sintagma intonacional que divide o enunciado:

\section{Sintagmas intonacionais compondo um enunciado}

(That's the tortoise that) (as you know) (inhabits the Galapagos island) (NESPOR; VOGEL, 2007)

Além disso, os sintagmas intonacionais podem sofrer um processo chamado de reestruturação, no qual esse constituinte prosódico é subdividido em sintagmas entoacionais menores (NESPOR; VOGEL, 2007). Segundo Nespor e Vogel, fatores diversos podem estar envolvidos na reestruturação de sintagmas intonacionais, tais como a velocidade de fala, formalidade, etc. Nos dados discutidos aqui, o tamanho do constituinte será um fator relevante. Se o material dominado por uma sentença for longo, o sintagma intonacional resultante do mapeamento sintaxe-fonologia será automaticamente longo também. Nesses casos, a reestruturação frequentemente ocorre para gerar sintagmas intonacionais relativamente mais curtos, talvez por razões fisiológicas relacionadas à capacidade de respiração ou de processamento sintático (veja Nespor e Vogel (2007)). Assim, uma sentença longa como 458 a abaixo tem grandes chances de ser reestruturada como nos itens 458b ou 458c:

\section{Reestruturação de sintagmas intonacionais}

a. (My friend's baby hamster always looks for food in the corner of its cage)

b. (My friend's baby hamster) (always looks for food in the corner of its cage)

c. (My friend's baby hamster) (always looks for food) (in the corner of its cage)

Sentenças bi-oracionais tendem a ser mais longas do que sentenças simples com apenas uma oração (veja a discussão em O’Donnell (1974)). Assim, é comum encontrarmos casos de reestruturação envolvendo orações subordinadas. Isso é particularmente importante para a nossa discussão, pois os dados aqui analisados contêm em grande parte sentenças bi-oracionais.

A teoria de intonação que embasa nossa análise é a Teoria AutossegmentalMétrica da Fonologia Intonacional, tal como proposta por Pierrehumbert (1980; 2010) 
e Ladd (2008). Um de seus princípios mais importantes é de que a melodia de uma determinada cadeia fônica é produto de uma sequência de tons-alvo subjacentes. Em outras palavras, não é exatamente a formato da curva entoacional em si o mais importante, mas sim determinados eventos tonais alinhados a pontos específicos da cadeia fônica.

Em seu trabalho seminal, Pierrehumbert (1980) propõe que essa sequência de tons subjacentes pode ser descrita com um inventário de apenas dois alvos tonais: um baixo (L) e outro alto $(\mathrm{H})$. Importantemente, a natureza destes tons é estreitamente relacional: um tom é classificado como alto ou baixo sempre em relação aos tons precedentes, e não porque é produzido em determinada faixa de frequência. Pierrehumbert propõe ainda dois tipos de eventos tonais que serão relevantes para a análise do Karitiana: os acentos tonais (pitch accent) e os tons de fronteira (boundary tones). Os acentos tonais são movimentações melódicas que se alinham às sílabas tônicas das palavras dentro de um enunciado. No sistema de notação proposto pela autora, estes acentos tonais são indicados através de um asterisco, como $\mathrm{H}^{*}$ ou L*. Quando essas movimentações tonais se tornam ligeiramente mais complexas, como um movimento descendente seguido por um incremento de F0, estes acentos tonais podem ser representados por uma sequência de dois alvos $\left(e . g ., \mathrm{L}^{*}+\mathrm{H}\right.$ or $\left.\mathrm{L}+\mathrm{H}^{*}\right)$. Nesses casos, o asterisco indica o alinhamento relativo de cada um dos alvos em relação à sílaba tônica.

Existe ainda um outro tipo de evento tonal que está restrito à borda dos sintagmas intonacionais: os tons de fronteira. Em outras palavras, os tons de fronteira são melodias que emergem nas fronteiras dos sintagmas entoacionais, e não em sílabas tônicas de um enunciado. Crucialmente, existe uma relação bi-lateral entre os tons de fronteira e os sintagmas intonacionais: os sintagmas intonacionais devem ter necessariamente um tom de fronteira, e tons de fronteira necessariamente sinalizam as fronteiras dos sintagmas intonacionais. Estes tons também são descritos através dos alvos H e L, e são sinalizados pelo símbolo \%. Tradicionalmente, o último acento tonal de um sintagma intonacional parece ter um estatuto especial em muitas línguas (veja Cruttenden (1997)); por isso, esse acento tonal é tradicionalmente denominado de acento nuclear e a sequência formada por este e o tom de fronteira é conhecida como contorno nuclear.

Para descrever os eventos tonais, adotamos as convenções ToBI (BECKMAN; HIRSCHBERG, 1994), segundo as quais as fronteiras de sintagma intonacionais são indicadas pelo número 4. No Karitiana, um sistema de notação nas linhas do ToBI foi utilizado por Storto (1999) e Storto e Demolin (2005). Nas próximas seções, apresentamos o inventário de tons na literatura e também as notações utilizadas para cada um deles. 


\subsubsection{Gramática entoacional do Karitiana}

Na literatura sobre o Karitiana, os trabalhos que se ocuparam de discutir o sistema intonacional da língua mais profundamente foram Storto (1999), Storto e Demolin (2005) e Everett (2008). Destes, o sistema mais detalhado (e, portanto, mais completo) é aquele descrito em Storto (1999).

Antes de passarmos à descrição da intonação, é preciso mencionar que, em Karitiana, o acento se localiza na última sílaba da raiz a menos que uma sílaba longa esteja presente (STORTO, 1999). Uma exceção a este padrão são algumas palavras emprestadas do Português, como nomes próprios que possuem acento na penúltima sílaba, como 'Luciana'. Existe uma certa discussão sobre os principais correlatos do acento na língua: Everett (2008), por exemplo, aponta que a intensidade (i.e., o volume do som) parece ser o principal fator. Essa discussão não é particularmente relevante aqui; contudo, é preciso apontar que, desde de Storto (1999), se assume que a altura de fato parece ser um dos indicativos da tonicidade de uma sílaba.

Assumindo os princípios da Fonologia Intonacional, Storto (1999) e Storto e Demolin (2005) se debruçam sobre a sequência de tons-alvo que geram os contornos intonacionais. Segundo Storto (1999), em Karitiana "os tons são assinalados no mesmo plano métrico em que o acento é computado". Em outras palavras, a autora afirma que os tons são previsíveis a partir dos padrões de acento das palavras de um enunciado. ${ }^{1}$ Especificamente, ela reconhece a existência de um acento tonal $\mathrm{H}^{*}$ e propõe a seguinte regra para explicar sua distribuição:

\section{Atribuição de $H^{*}$}

Atribua $\mathrm{H}$ à sílaba acentuada de uma palavra.

(STORTO, 1999, adaptado do exemplo 26a)

O resultado da regra em 459 em uma sentença como 460a gera a sequência de tons em 460b:

a. Exemplo de atribuição de $H^{*}$

$$
\begin{aligned}
& \emptyset \text {-na-ambo saryt- } \emptyset \quad \text { Gokyp } \\
& \text { 3-DECL-subir EVID.IND-NFUT sol } \\
& \text { "O sol subiu." }
\end{aligned}
$$

b. Na-ambo sa-ryt go-kyp

$$
\mathrm{H}^{*} \quad \mathrm{H}^{*} \quad \mathrm{H}^{*}
$$

1 Storto (1999) e Storto e Demolin (2005) denominam o sistema do Karitiana como pitch accent. No entanto, não se deve confundi-lo com outros denominados também de pitch accent como o do Japonês, nos quais as palavras são marcadas como (não) acentuadas no léxico, gerando padrões prosódicos específicos na superfície (veja Beckman e Pierrehumbert (1986)). 
Esses autores também identificaram uma movimentação tonal que se alinha na fronteira direita dos sintagmas intonacionais, à semelhança dos tons de fronteira em muitas línguas. Assim, Karitiana também faz uso de movimentações tonais para delimitar sintagmas entoacionais. Descritivamente, em orações declarativas simples a altura se eleva ligeiramente na posição pré-tônica da palavra final, para depois descender até o final do enunciado. Esse padrão pode ser visto na palavra 'Gokyp' do exemplo abaixo:

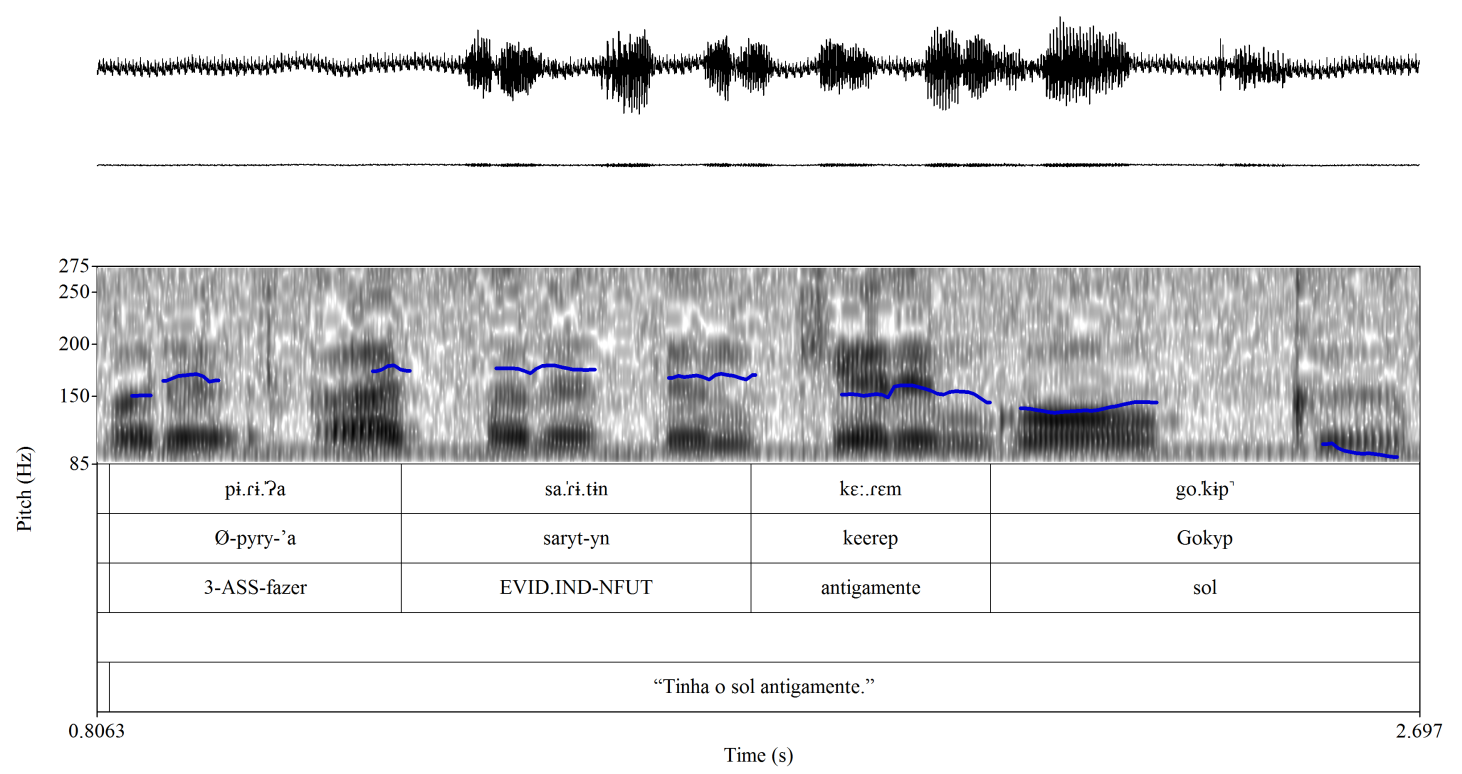

Figura 10 - Curva intonacional para "Pyry'a sarytyn keerep Gokyp"("Gokyp")

Storto afirma que esse mesmo padrão de contorno nuclear emerge em declarativas, perguntas e imperativos negativos.

Para capturar essas movimentações no final destes sintagmas intonacionais, Storto (1999) propõe uma regra de inserção de L na qual o tom H seria deslocado para a sílaba imediatamente anterior. Assim, na Figura 10, o acento H em 'gokyp' seria deslocado da sílaba tônica [kip?] para a pré-tônica [go]. Nesse ponto, acreditamos que a proposta de Storto pode ser simplificada se assumirmos uma notação diferente para este contorno nuclear. Especificamente, o último acento tonal (o acento nuclear em 10) poderia ser descrito como um $\mathrm{H}+\mathrm{L}^{*}$, que capturaria o alinhamento tardio do tom $\mathrm{L}$ em relação à sílaba tônica. Além disso, propomos ainda um tom de fronteira L\%. Nesse sentido, prescindiríamos de uma regra de inserção de L e deslocamento do H, pois um acento nuclear bitonal já conseguiria capturar a complexidade deste contorno. Além disso, estaríamos aproximando o Karitiana de outras línguas intonacionais, como o Inglês e o Português.

Storto e Demolin (2005) identificam também dois tons no contorno nuclear de imperativos: além do $\mathrm{H}^{*}$ característico de sílabas tônicas, existiria um tom de fronteira $\mathrm{H} \%$ responsável pelo aumento de F0 no final do enunciado. Assim, sumarizando os trabalhos anteriores, os tons identificados para o Karitiana podem ser resumidos na tabela abaixo: 


\begin{tabular}{|c|c|c|}
\hline \multicolumn{2}{|c|}{ CONTORNO NUCLEAR } & \multirow{2}{*}{ USO PROTOTÍPICO } \\
\hline ACENTO NUCLEAR & TOM DE FRONTEIRA & \\
\hline $\mathrm{H}+\mathrm{L}^{*}$ & $\mathrm{~L} \%$ & Declarativas, perguntas e imperativos negativos \\
\hline $\mathrm{H}^{*}$ & $\mathrm{H} \%$ & Imperativos \\
\hline
\end{tabular}

Os trabalhos citados apresentam apenas exemplos enunciados curtos, nos quais possivelmente cada sentença corresponde a um único sintagma intonacional. Contudo, como vimos em \$7.3.1, enunciados grandes tendem a ser sub-divididos em sintagmas intonacionais menores. Dessa forma, sentenças com mais de uma oração tendem a conter mais de um sintagma intonacional e, por conseguinte, mais de um tom de fronteira. No Karitiana especificamente, o acento nuclear que emerge nesse contexto parece ser diferente dos padrões descritos acima. Na próxima seção, vamos propor então a adoção de um outro acento tonal na gramática da língua, um tom L*.

\subsubsection{Contorno ascendente de continuação}

Como vimos anteriormente, a operação de reestruturação tende a se aplicar em enunciados longos. No exemplo abaixo, temos uma sentença complexa contendo duas orações. Nele, o enunciado foi reestruturado em dois sintagmas intonacionais menores, como se nota através da pausa entre a oração matriz e a subordinada.

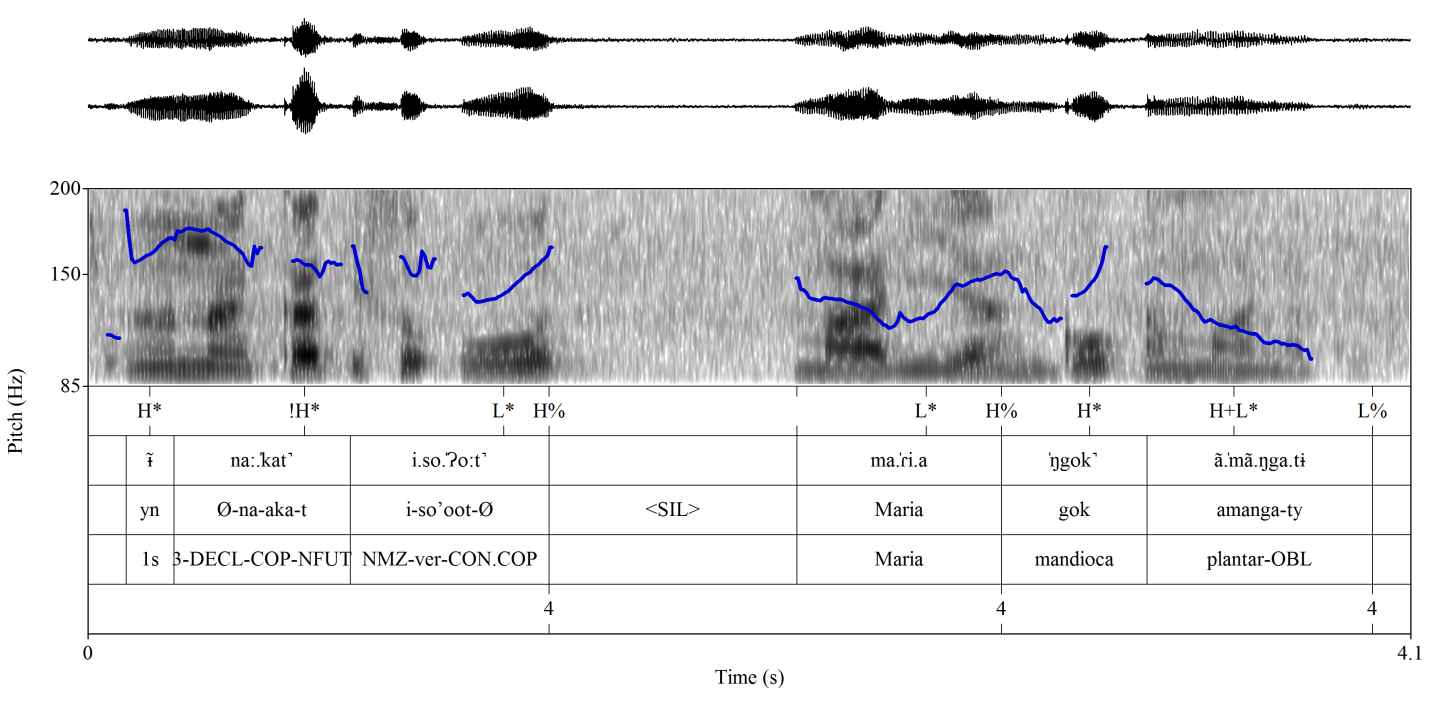

Figura 11 - Curva intonacional para "Yn naakat iso'oot... Maria gok amangaty."

Crucialmente, esse padrão emerge tanto em exemplos elicitados como na sentença acima quanto em dados naturalísticos como abaixo, em que 'dez dias iakat,...' é uma sentença subordinada adverbial: 


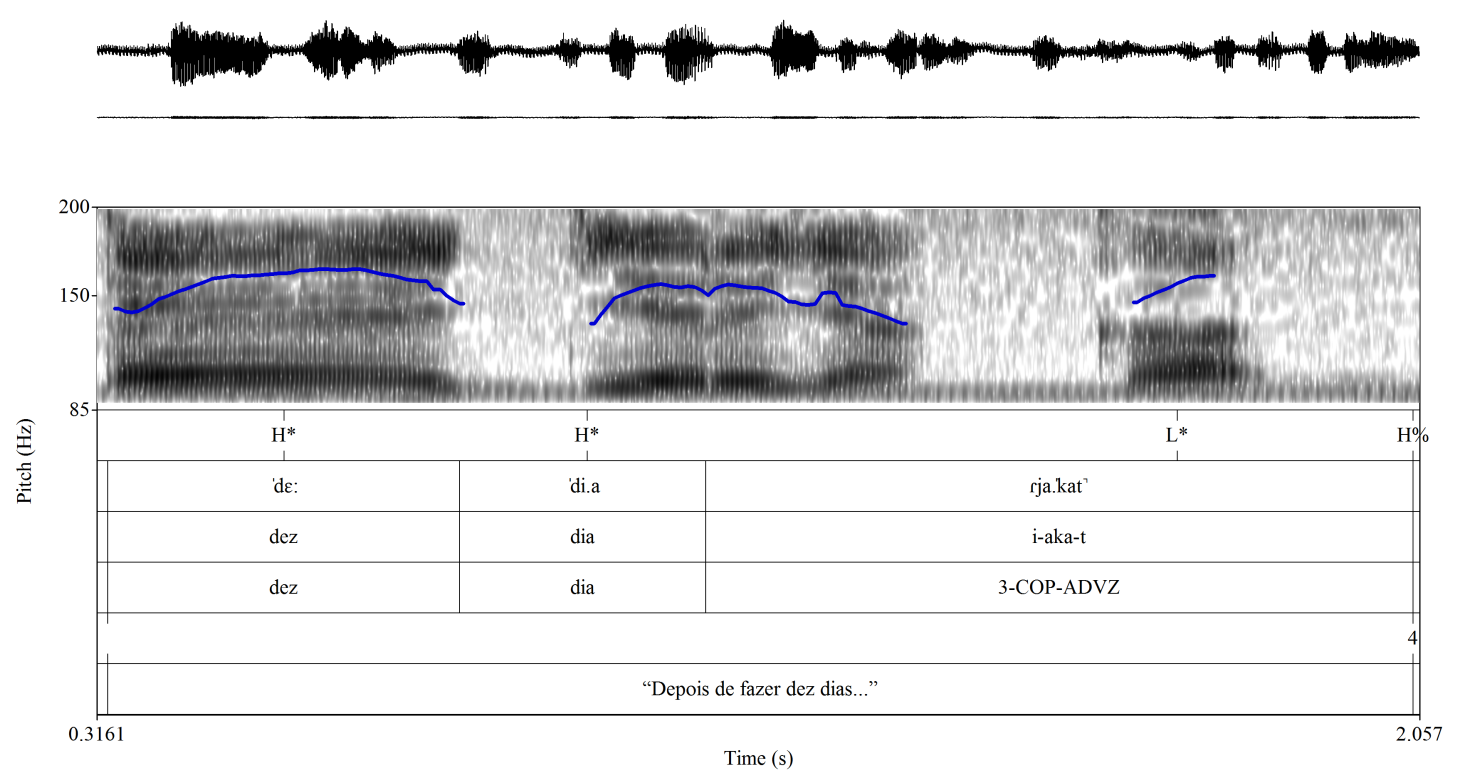

Figura 12 - Curva intonacional para "Dez dias yjakat..."

As movimentações tonais antes da fronteira em 'iso'oot' na Figura 11 e 'yjakat' na Figura 12 parecem ser um outro fenômeno: primeiramente, temos um movimento descendente alinhando-se à sílaba tônica, seguido por um movimento ascendente no final da oração. Aqui, não temos um incremento de F0 tão óbvio na sílaba pré-tônica. Dessa forma, o acento tonal não parece ser um bitonal um $\mathrm{H}+\mathrm{L}^{*}$, mas sim um simples $\mathrm{L}^{*}$. Além disso, existe ainda um movimento ascendente alinhando-se borda direita do sintagma intonacional, o que parece indicar a presença de um tom de fronteira $\mathrm{H} \%$.

Esse padrão $L^{*} \mathrm{H} \%$ parece ser característico de sintagmas entoacionais que não são o último constituinte de um enunciado fonológico. Assim, além de aparecer em contextos de sentenças bi-oracionais, ele também emerge quando um constituinte não final é reestruturado em um único sintagma intonacional: em 13, ele aparece no sujeito 'ewosiip', que foi reestruturado e forma um único sintagma intonacional: 


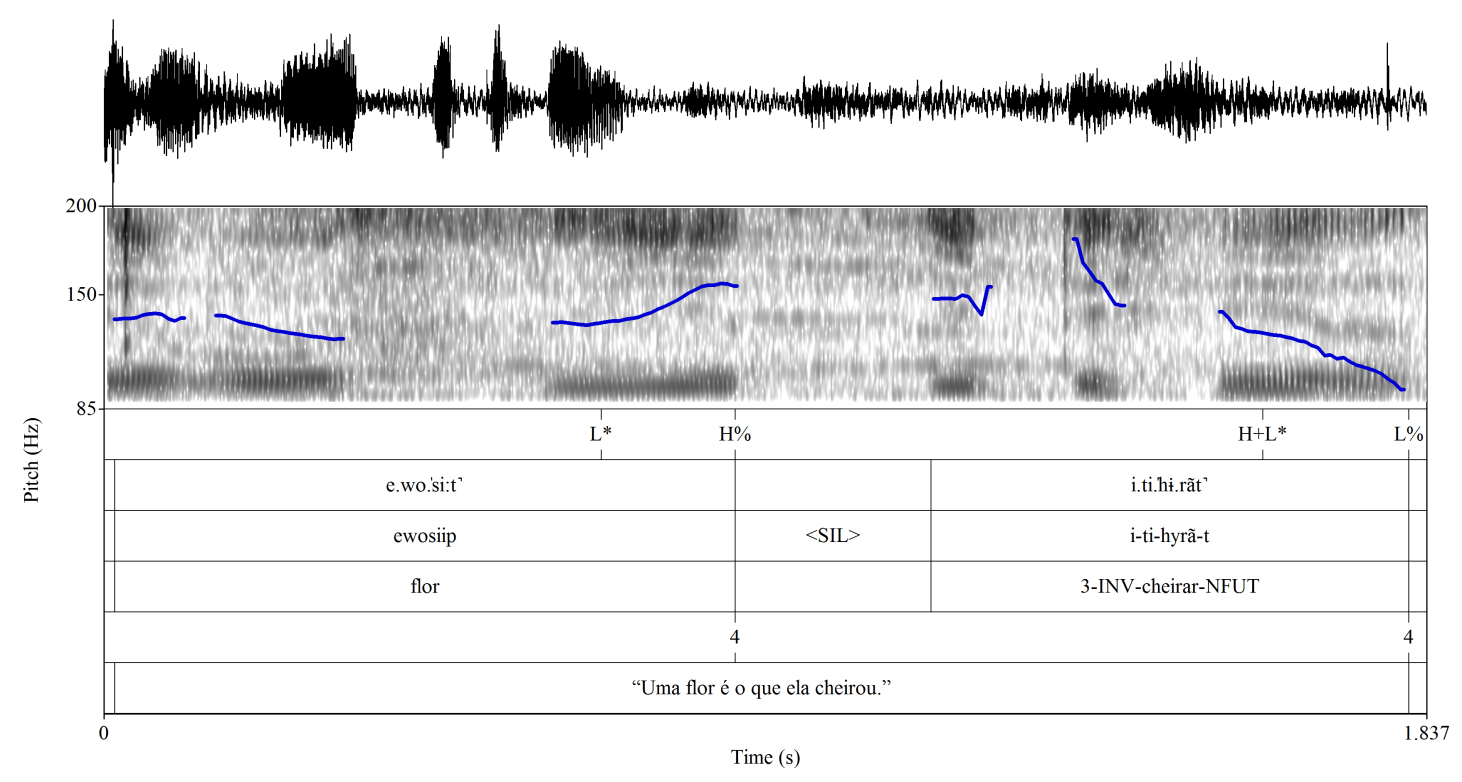

Figura 13 - Curva intonacional para "Ewosiit itihyrãt" (dado de Valin et al. (s.d.))

Por marcar a borda de sintagmas intonacionais não finais, chamaremos esse padrão de contorno ascendente de continuação, na medida em que ele sinalizaria a continuação de um enunciado para o interlocutor. Dessa forma, atualizamos o inventário de tons do Karitiana para incluir esse acento nuclear:

Tabela 14 - Sistema tonal do Karitiana

\begin{tabular}{lll}
\hline \multicolumn{2}{c}{ CONTORNO NUCLEAR } & USO PROTOTÍPICO \\
\cline { 1 - 2 } ACENTO NUCLEAR & TOM DE FRONTEIRA & \\
\hline H $+\mathrm{L}^{*}$ & $\mathrm{~L} \%$ & Declarativas, perguntas e imperativos negativos \\
$\mathrm{H}^{*}$ & $\mathrm{H} \%$ & Imperativos \\
$\mathrm{L}^{*}$ & $\mathrm{H} \%$ & Contorno ascendente de continuação \\
\hline
\end{tabular}

Este acento nuclear terá central importância na discussão que faremos a seguir, visto que ele é capaz de sinalizar a posição sintática dos elementos através de seu fraseamento prosódico.

\subsubsection{Entonação em relativas de objeto}

A discussão dos tons em Karitiana e principalmente a existência do contorno ascendente de continuação pode lançar luz sobre alguns fenômenos de alteração de ordem em ambientes subordinados. Especificamente, vimos em 1 que as relativas de objeto podem exibir tanto a ordem OSV quanto SOV, embora a primeira seja mais frequente e tipicamente encontrada em contextos potencialmente ambíguos (VIVANCO, 2014): 
(461) Relativa de objeto $O S V$

Yn $\emptyset$-na-aka-t i-pyting- $\emptyset \quad$ ['irip saara ti-'y]-ty.

1s 3-DECL-COP-NFUT NMZ-querer-CON.COP [anta jacaré INV-comer-OBL

"Eu quero a anta que o jacaré mordeu."

(VIVANCO, 2014)

(462) Relativa de objeto SOV

Yn $\emptyset$-na-aka-t i-pyting- $\emptyset$ [Luciana pykyp

1s 3-DECL-COP-NFUT NMZ-querer-CON.COP [Luciana roupa

ti-pipãram-a]-ty.

INV-costurar-EPEN-]OBL

"Eu quero a roupa que a Luciana costurou."

(VIVANCO, 2014)

A entonação das sentenças 461 e 462 pode ser vista nas figuras abaixo:
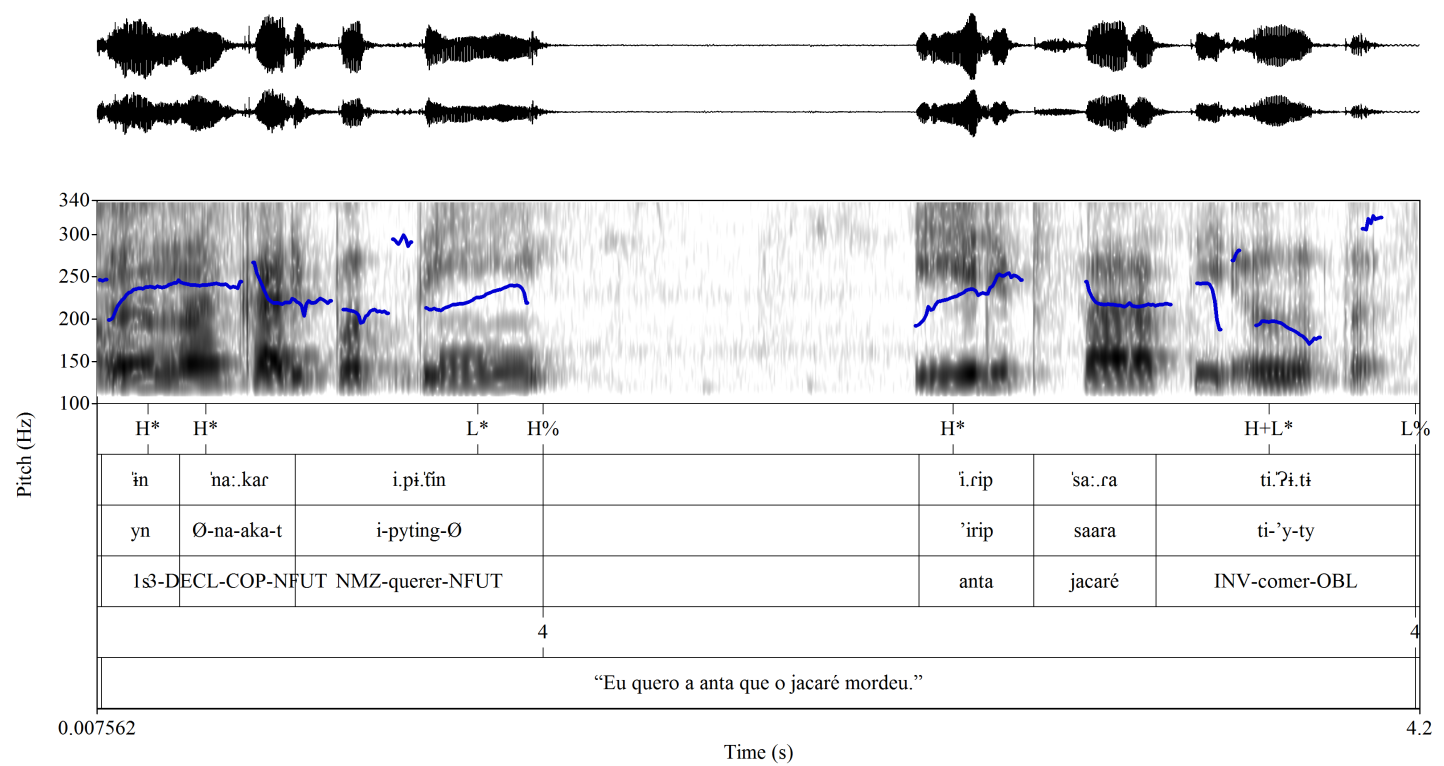

Figura 14 - Curva intonacional para "Yn naakat ipyting 'irip saara ti'yty" 


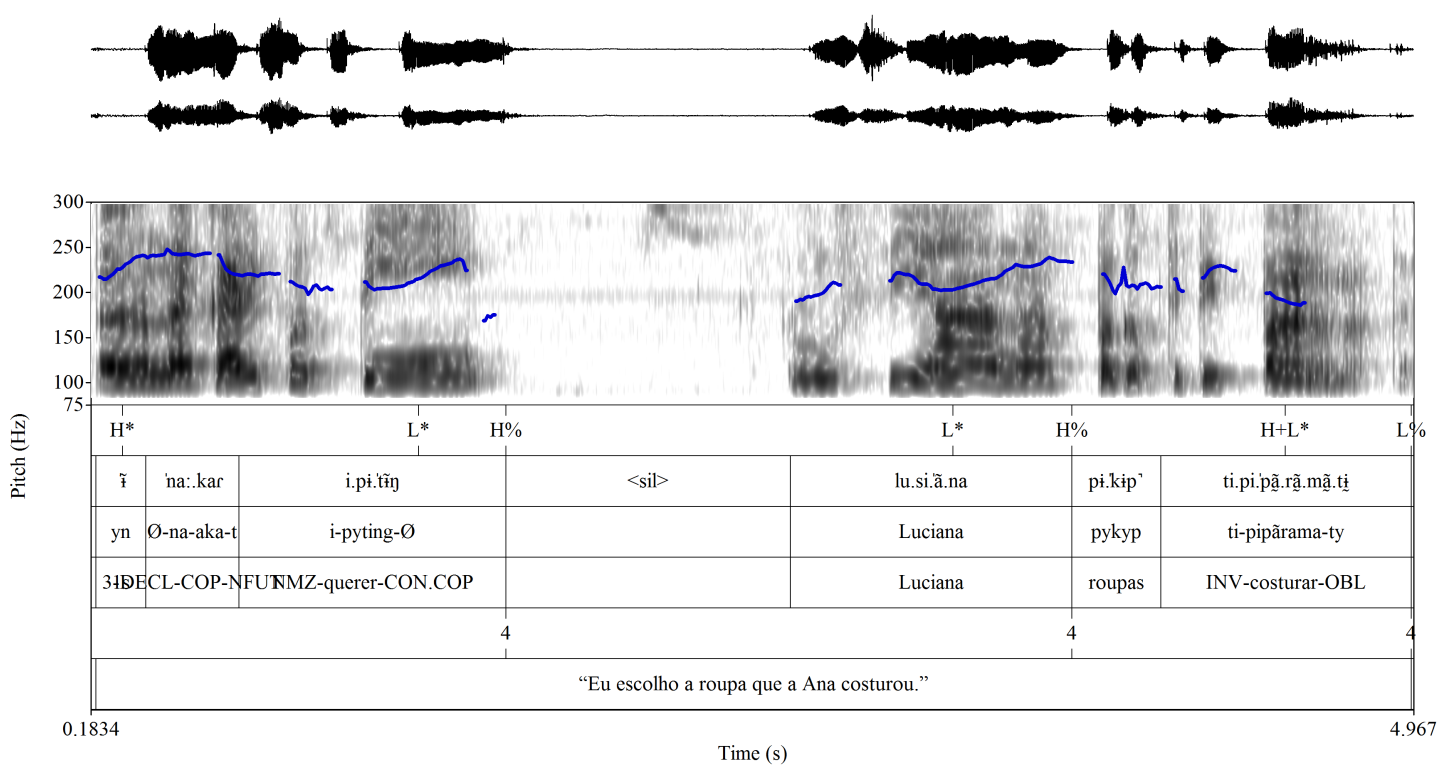

Figura 15 - Curva intonacional para "Yn naakt ipyting Luciana pykyp tipipãramaty"

Crucialmente, as relativas com a ordem SOV como na Figura 15 parecem ter um padrão prosódico mais ou menos fixo: existe um abaixamento de F0 alinhado à sílaba tônica do sujeito, seguido de um incremento no F0 em suas últimas sílabas. Diversos fatores sinalizam ainda uma fronteira de número 4 entre sujeito e objeto, isto é, uma fronteira entre dois sintagmas intonacionais. Primeiramente, a última sílaba do sujeito é alongada, um indicativo comum nas línguas de fronteira de sintagma intonacional (CRUTTENDEN, 1997). Isso pode ser visto em 'Luciana' na Figura 15, cujas sílabas finais são mais longas. Além disso, muitos exemplos contêm efetivamente uma pausa, como veremos à frente. Assim, o padrão prosódico no sujeito da relativa em 462 parece ser o o contorno ascendente de continuação, isto é, uma melodia $\mathrm{L}^{*} \mathrm{H} \%$. Isto, por sua vez, indicaria que o sujeito é obrigatoriamente reestruturado em um sintagma intonacional à parte em relativas de objeto SOV.

Na Figura 15, o contorno ascendente de continuação se inicia a partir da vogal acentuada [ã] de 'Luciana', o sujeito dessa oração relativa: o F0 primeiro declina (o tom L*) para ascender em seguida na sílaba seguinte [na] (o tom de fronteira H\%). Este exemplo é bastante ilustrativo por não envolver uma compressão tonal nas últimas sílabas. Como muitas palavras do Karitiana são oxítonas, os acentos tonais e os tons de fronteira podem ser difíceis de distinguir por serem frequentemente comprimidos em muitos enunciados. Por esta razão, casos como a Figura 15, nos quais o acento da palavra recai numa sílaba não final, mostram o alinhamento de cada tom mais claramente.

Vejamos dois outros exemplos. Na Figura 16, o sujeito é 'sosy'. Neste NP, existe um vale curto seguido por uma linha ascendente no final. O fato de haver um pequeno pico quando o F0 começa a ascender não é importante, pois o que realmente importa aqui é o movimento global ascendente seguindo o tom L, que indicaria a presença do tom $\mathrm{H} \%$. 

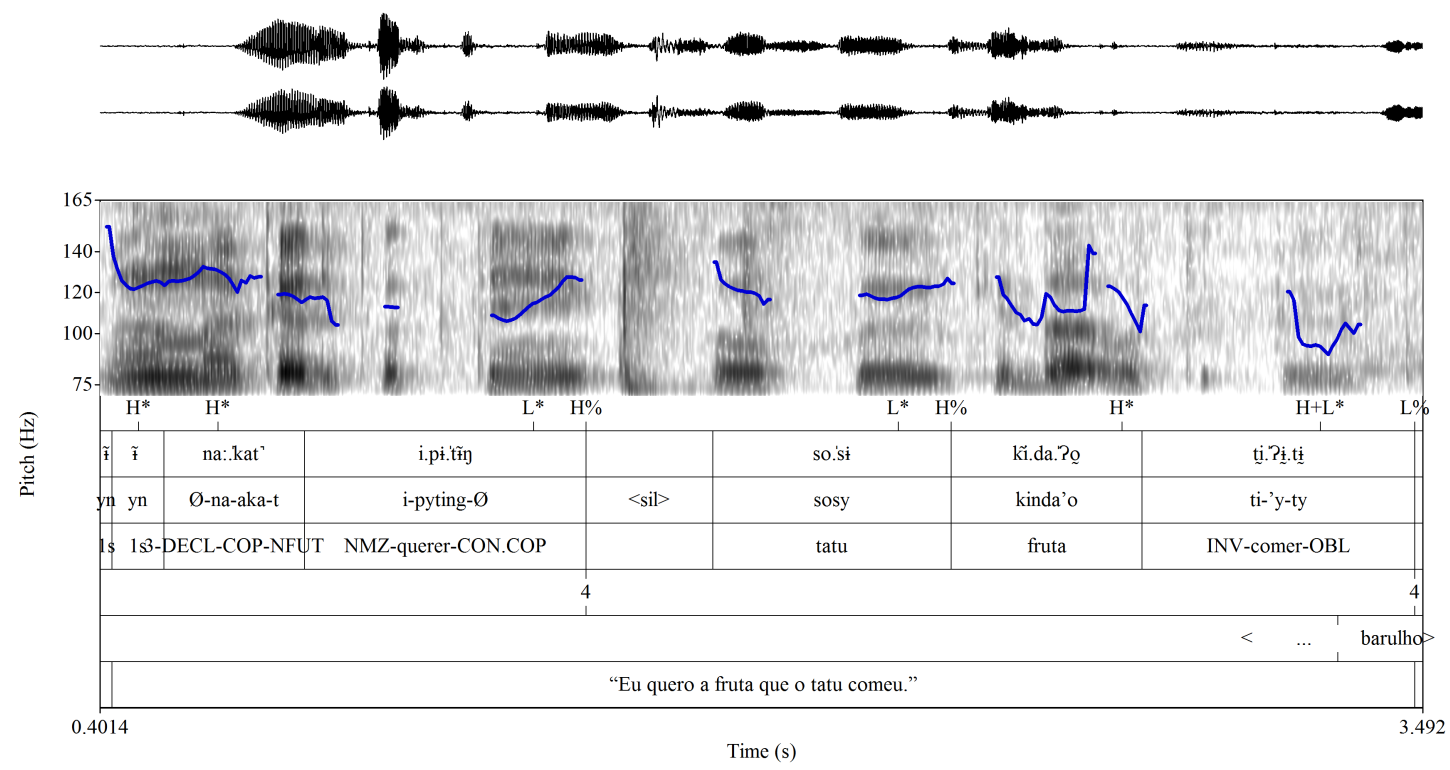

Figura 16 - Curva intonacional para "Yn naakt ipyting sosy kinda'o ti'yty"

Finalmente, o tom L* pode também ser detectado na Figura 17, já que existe um movimento descendente seguido por uma subida de F0 alinhada à sílaba tônica [so] do sujeito 'jonsõ'. Embora a subida de F0 seja um pouco irregular, o que conta para a análise intonacional é o movimento global de orientação ascendente:

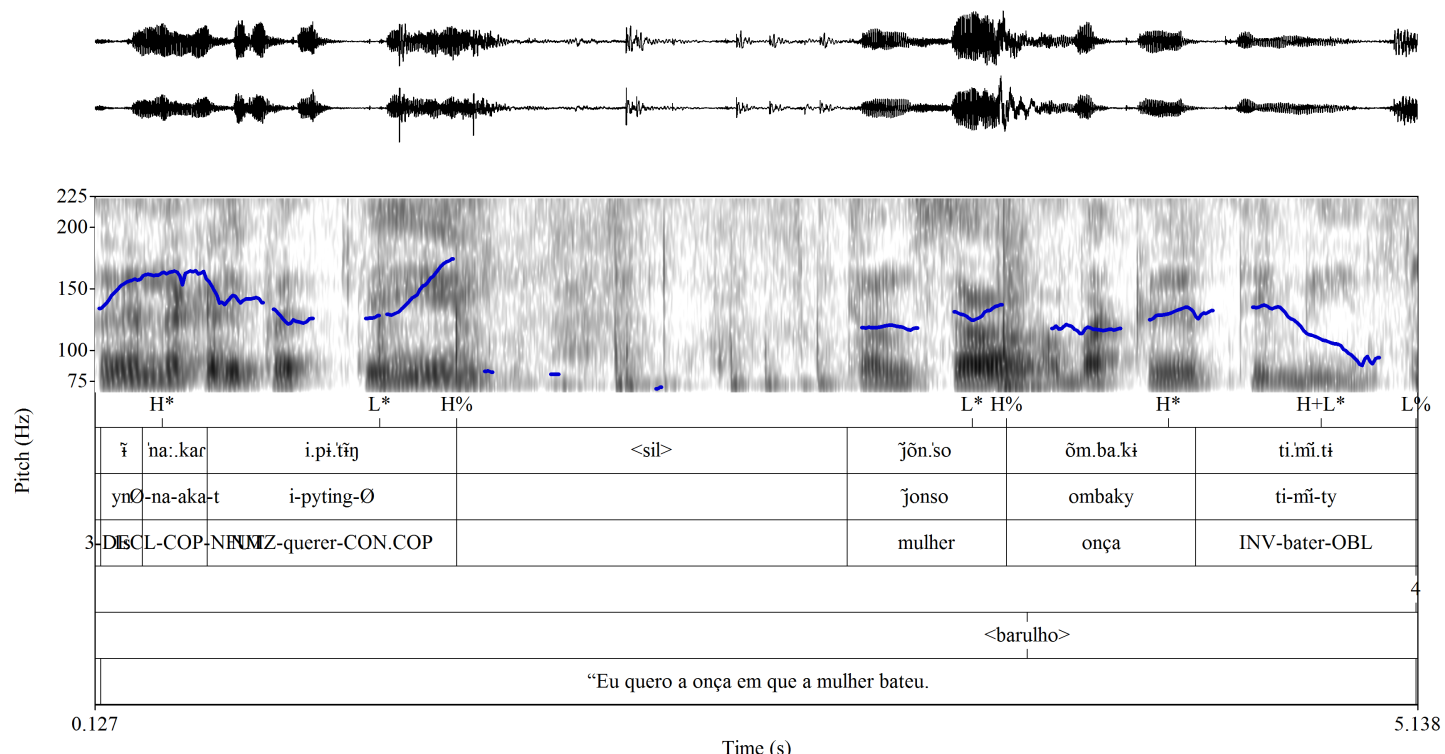

Figura 17 - Curva intonacional para "Yn naakat ipyting jonso ombaky timíty"

Todos estes exemplos mostram que as relativas de objeto SOV têm um padrão intonacional relativamente fixo, pois elas exibiriam um contorno $\mathrm{L}^{*} \mathrm{H} \%$ no argumento sujeito. Por sua vez, esse padrão prosódico indicaria que, nessa ordem específica, o sujeito compõe obrigatoriamente um sintagma intonacional reestruturado à parte. 
Em relativas de objeto OSV como 461, não existe a obrigatoriedade de um determinado padrão melódico. Nesta ordem, a melodia associada a argumentos é muito mais livre do que no caso das suas contrapartes SOV. No dado a seguir, por exemplo, nota-se um pico de F0 na sílaba tônica [bi] de 'ambi', novamente indicando a presença de um alvo tonal do tipo $\mathrm{H}^{*}$. Perceba ainda que, neste exemplo, o falante pronuncia a sentença inteira em um único sintagma intonacional, ou seja, sem reestruturação. Assim, além de não haver o contorno ascendente de continuação em 'pyting' e 'ambi', há uma sequência de tons $\mathrm{H}^{*}$ que vão tendo seus valores relativos abaixados progressivamente até o final da sentença: ${ }^{2}$

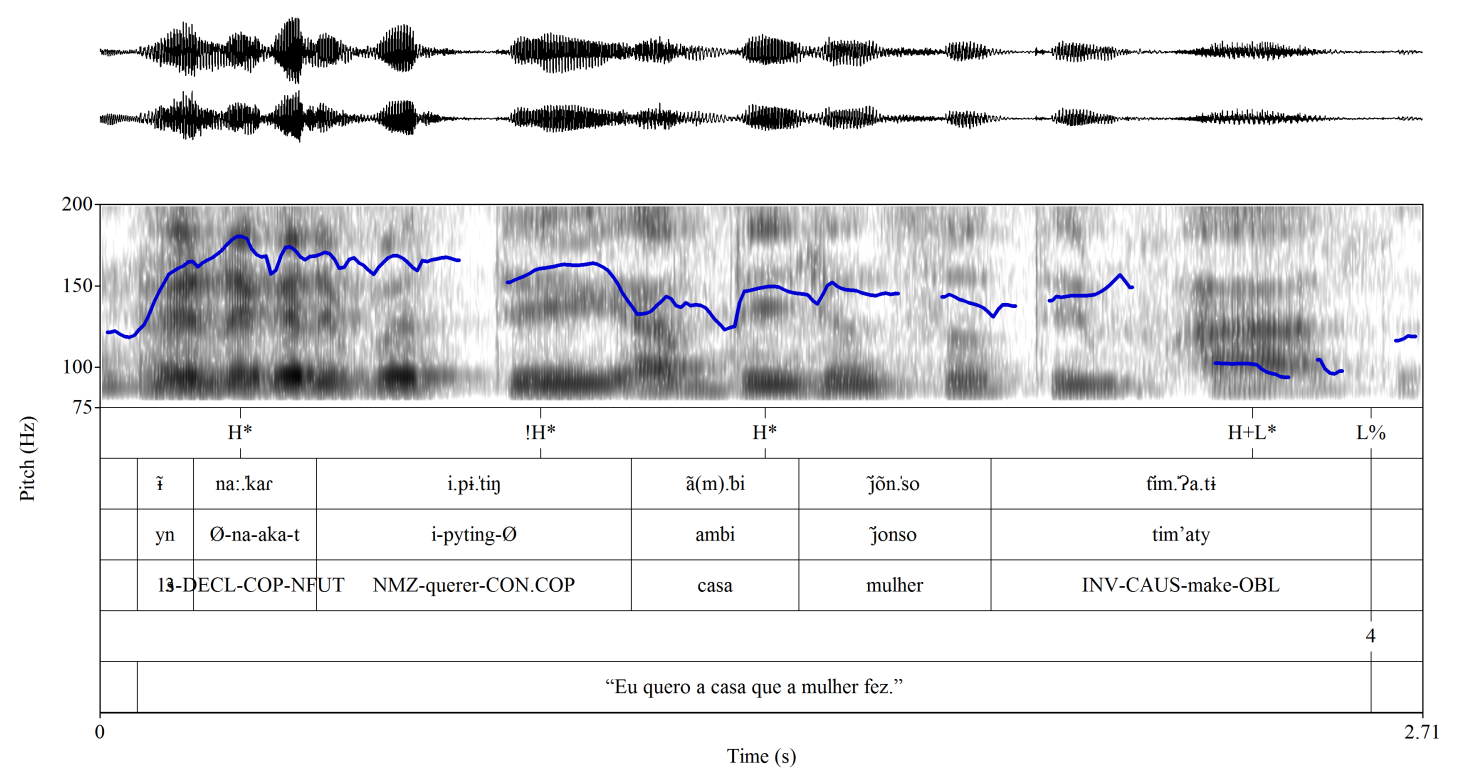

Figura 18 - Curva intonacional para "Yn naakat ipyting ambi jonso tim'aty."

No exemplo abaixo, repetimos o contorno para a relativa OSV em 461. Nele, observa-se uma ascensão de F0 no início da sílaba tônica [i] de 'irip', sinalizando o acento tonal $\mathrm{H}^{*}$. Crucialmente, não existe aqui nenhum tipo de movimentação tonal descendente que poderia indicar a presença de um $\mathrm{L}^{*}$.

2 Este fenômeno é conhecido como downstepping e, assim como proposto para o inglês por Pierrehumbert (1980), será indicado aqui pelo símbolo ‘!’. 

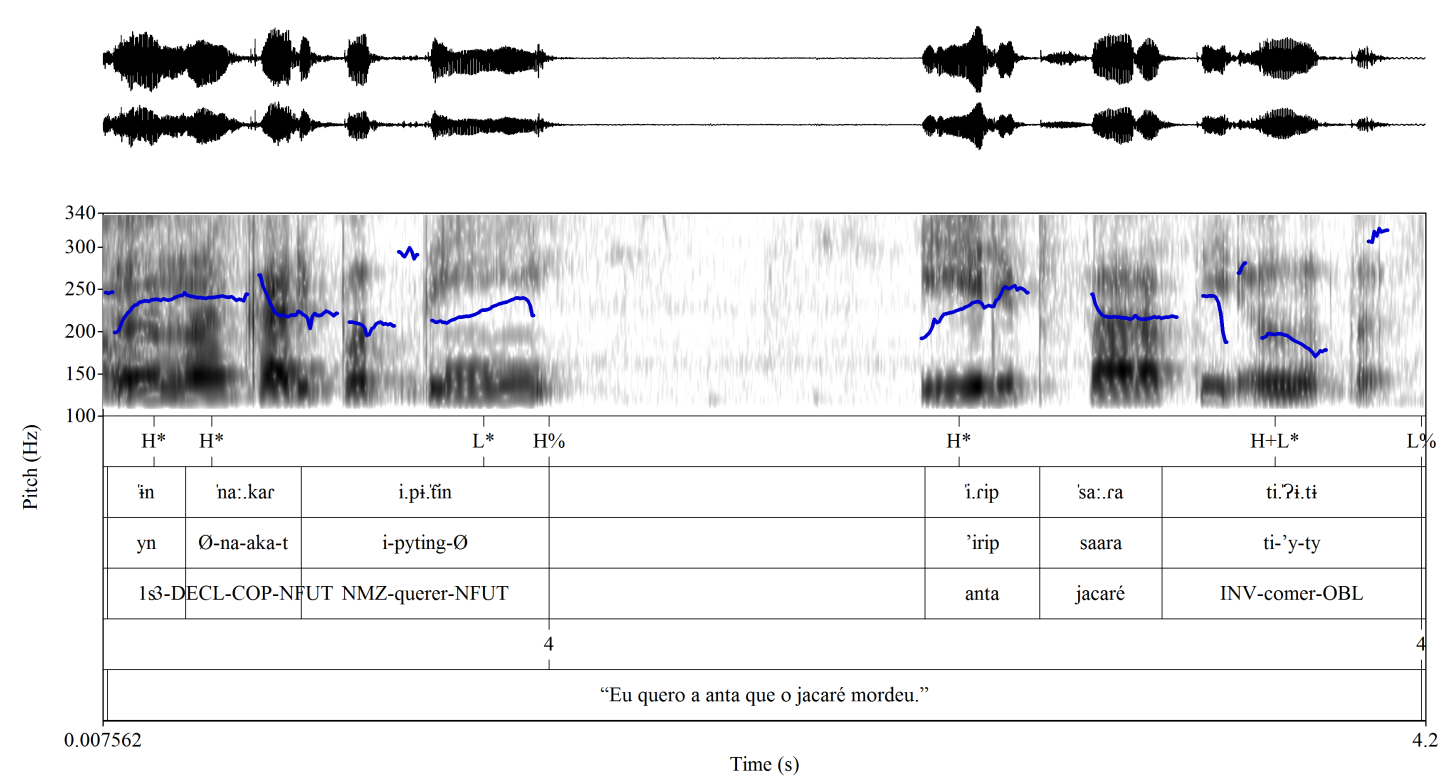

Figura 19 - Curva intonacional para "Yn naakat ipyting 'irip saara ti'yty"

Finalmente, é preciso pontuar que a melodia $\mathrm{L}^{*} \mathrm{H} \%$ presente em relativas de objeto SOV pode ser igualmente encontrada em sua contraparte OSV se o objeto constituir um único sintagma intonacional. É o caso do exemplo abaixo, no qual se detecta uma fronteira 4 através da pausa entre objeto e sujeito:

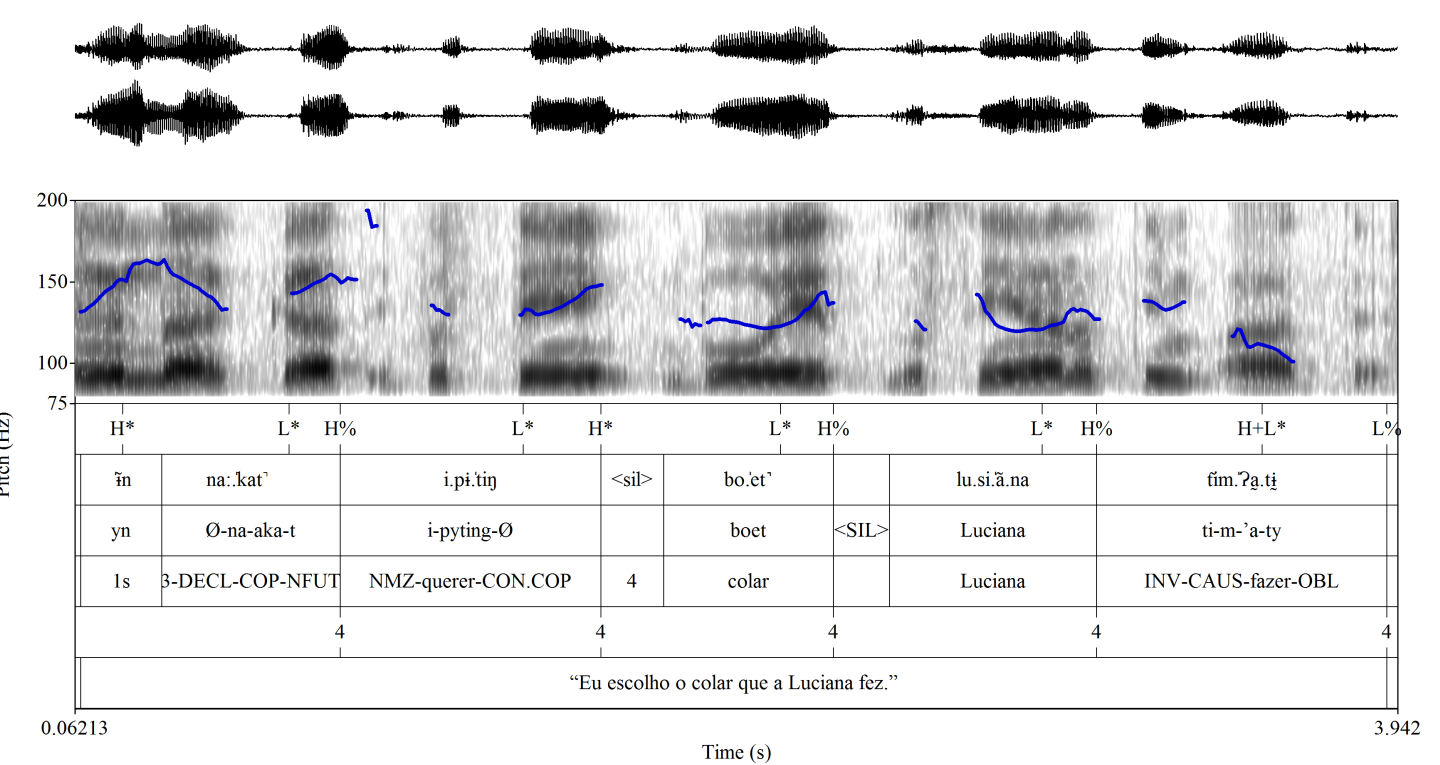

Figura 20 - Curva intonacional para "Yn naakat ipyting boet Luciana tim'aty"

Em resumo, existe em relativas de objeto com a ordem SOV uma exigência de que o sujeito seja reestruturado em seu próprio sintagma intonacional. Em contrapartida, relativas com a ordem OSV não exibem essa restrição, e seus argumentos podem ser mapeados em um único sintagma ou então reestruturados - provavelmente devido a questões 
de velocidade de fala. Na próxima seção, argumentaremos que o requerimento desse fraseamento prosódico nas relativas com a ordem SOV pode ser acomodado de levarmos em consideração a nossa proposta para o morfema ti- desenvolvida o capítulo 6 .

\subsubsection{Prosódia e argumentos em relativas de objeto}

Gostaríamos de sugerir aqui que o padrão prosódico observado acima pode ser explicado por uma análise de relativas de objeto que integra a proposta para o morfema ti- desenvolvida no capítulo 6 . Nela, o tema seria gerado como complemento de $\mathrm{V}$ dentro de uma projeção com ti- e, devido a necessidades afixais deste morfema, este constituinte se moveria para a borda do $v \mathrm{P}$ :

(463) Relativa de objeto com ti- - ordem OSV

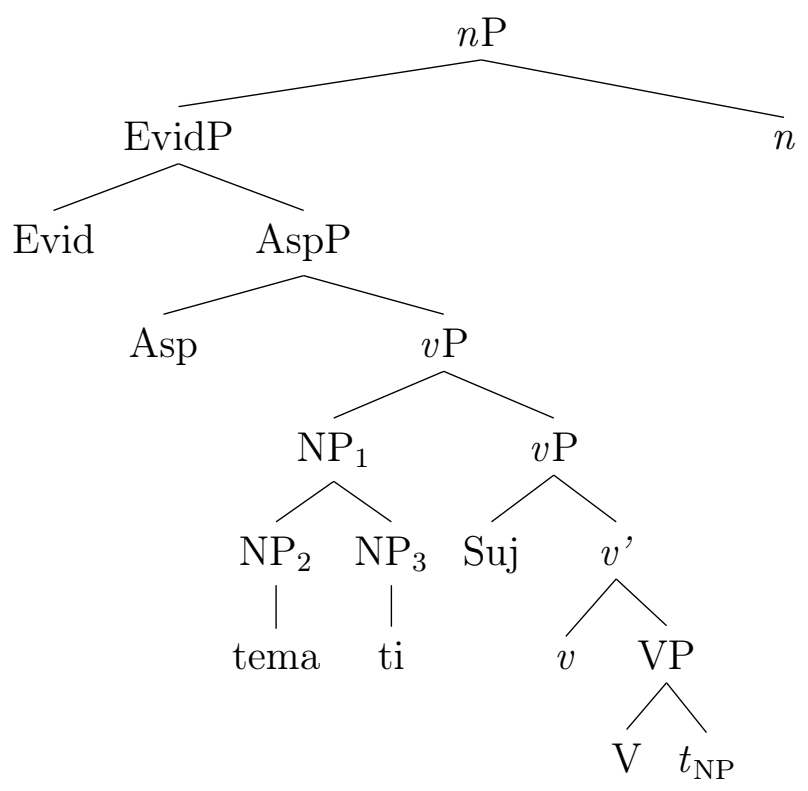

Essa estrutura captura a ordem das relativas de objeto OSV como 461, pois o objeto localiza-se acima do sujeito nesta estrutura. Contudo, como podemos derivar as relativas de objeto com a ordem SOV como 462? Neste caso, possivelmente o sujeito se moveria além do objeto, adjungindo-se a uma posição superior a ele: 
(464) Relativa de objeto com ti- - ordem SOV

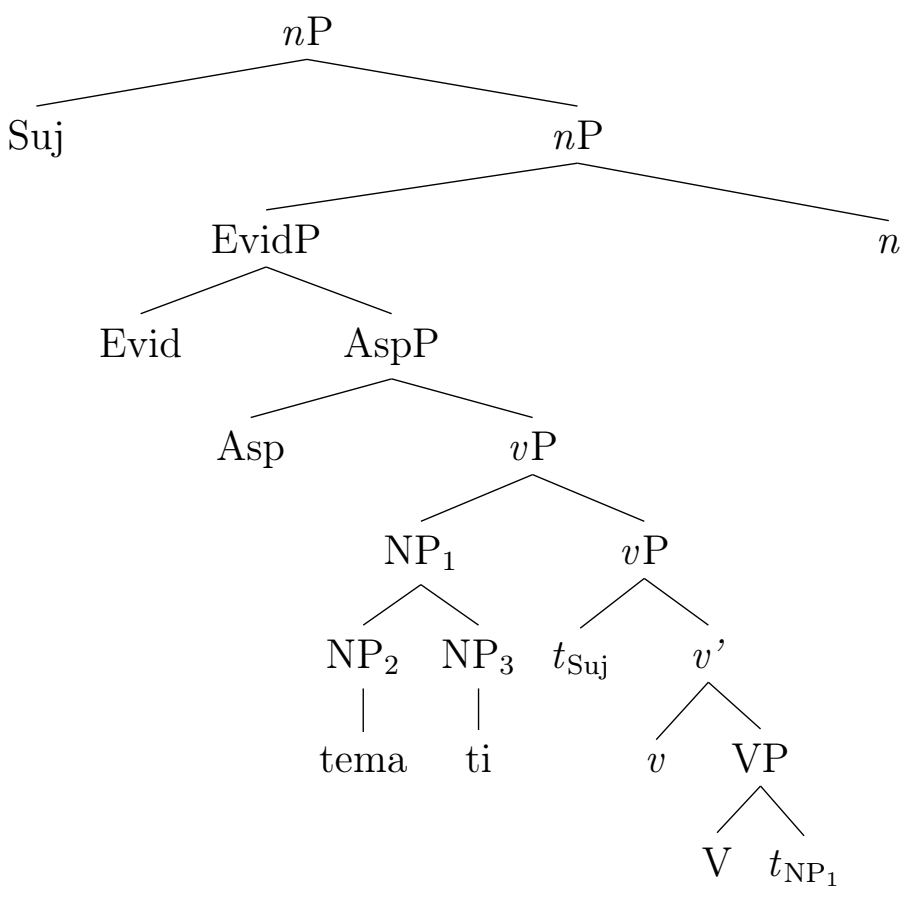

Por enquanto, as razões para o deslocamento do sujeito para além do $v \mathrm{P}$ permanecem desconhecidas. É notório que ele só pode ocorrer em situações relativamente não ambíguas, nas quais a identificação de sujeito e objeto se dá por outras estratégias que não a ordem em si. Por exemplo, é possível que exista uma hierarquia de animacidade operativa, atuando como uma dessas estratégias de identificação. Sobre isso, é importante relembrar que a animacidade parece ter um certo impacto no reconhecimento de funções sintáticas em subordinadas simples (veja o capítulo 1), então isso de fato é uma possibilidade.

Para a intonação destas construções, um dos aspectos mais importantes da estrutura em 464 é a posição do sujeito como um adjunto bastante alto. Nossa sugestão aqui é que essa posição explicaria o padrão prosódico observado na seção §7.3.3 - mais especificamente, o fato do sujeito ser sempre estruturado como um sintagma intonacional à parte. Crucialmente, esse mesmo padrão de fraseamento prosódico pode ser encontrado com advérbios, que, segundo Storto (1999), ocupam a primeira posição na maioria das orações subordinadas. Como se vê no exemplo abaixo, ao menos em dados elicitados o advérbio é reestruturado em um sintagma intonacional à parte: 


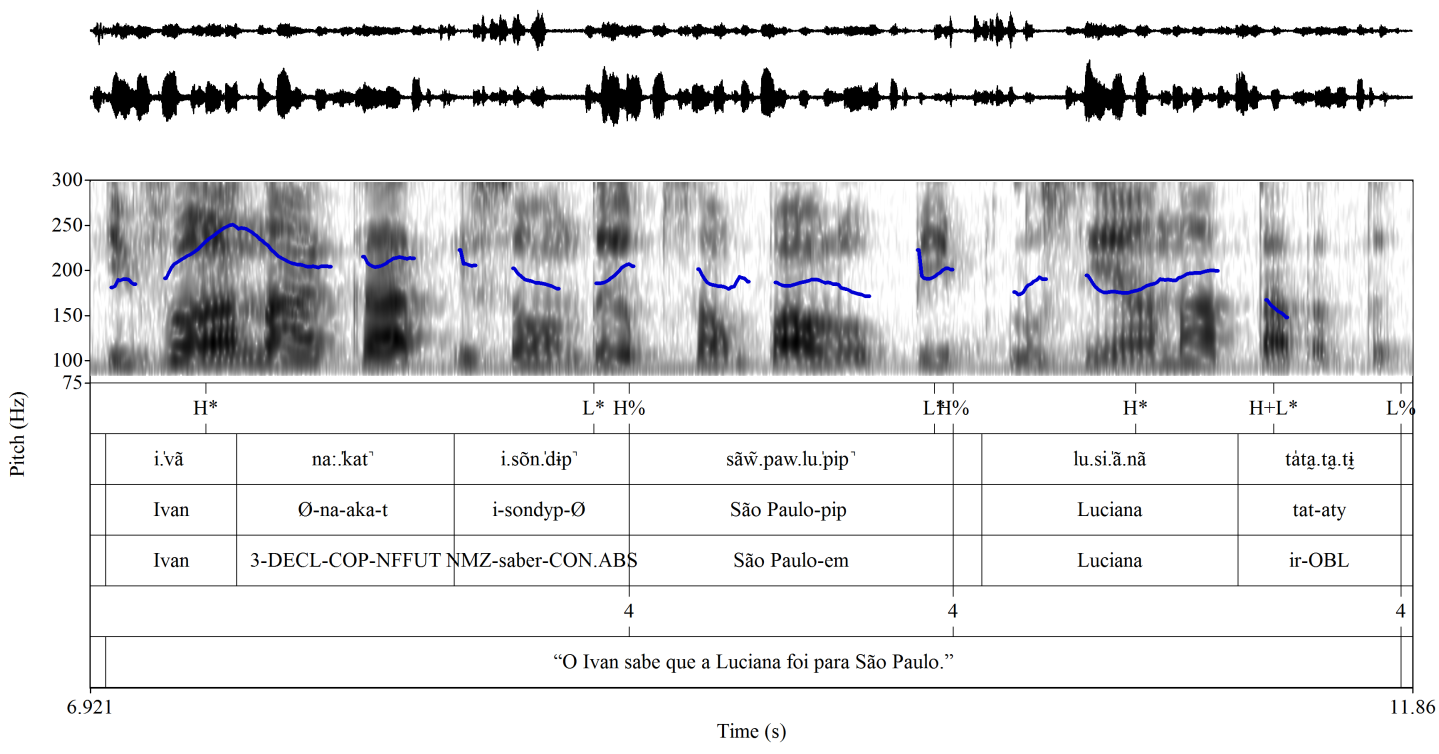

Figura 21 - Curva intonacional para "Ivan naakat isondyp São Paulopip Luciana titataty"

Perceba ainda que o padrão melódico que encontramos no advérbio 'São Paulopip' é o contorno ascendente de continuação, assim como vimos no sujeito de relativas SOV. Isso comprovaria que, em ambos os casos, estes elementos se encontrariam em posições sintáticas similares.

O mapeamento de advérbios em um único sintagma intonacional nos leva então a postular a seguinte regra de mapeamento sintaxe-fonologia na gramática do Karitiana (baseado em Nespor e Vogel (2007, p.189)):

(465) Mapeamento de sintagmas intonacionais

a. Dominio do sintagma intonacional (E)

Um domínio de E consiste em:

i. Uma sentença raiz (i.e., não nominalizada) e todos os sintagmas fonológicos ligados a ela no nível de estrutura-S;

ii. $\mathrm{O} v \mathrm{P}$ de uma oração nominalizada;

iii. Qualquer sintagma fonológico que não pertença aos domínios acima.

b. Construção do sintagma intonacional

Ligue em um único sintagma intonacional todos os sintagmas fonológicos incluídos em uma cadeia delimitada pela definição de domínio de sintagma intonacional.

Pela constituição do sintagma intonacional fazer referência ao estatuto sintático de seus elementos, o fraseamento prosódico é uma pista para diagnosticar suas posições sintáticas. Assim, o fraseamento obrigatório de sujeitos em relativas de objeto SOV como um único sintagma intonacional os aproximaria de advérbios, o que, por conseguinte, evidenciaria sua posição como um adjunto da oração subordinada. 


\subsection{Resumo do capítulo}

Neste capítulo, examinamos dois fenômenos fonológicos que seriam argumentos independentes para as propostas dos capítulos 4 e 6 . Primeiramente, vimos que a ocorrência da vogal -o dentro de orações subordinadas sinalizaria seu estatuto diferenciado em relação às orações matrizes. Além disso, no caso de relativas de objeto SOV, vimos como o padrão prosódico de certos elementos oferece pistas importantes de sua posição sintática .

Obviamente, os dados discutidos aqui requerem uma investigação bem mais profunda; porém, acreditamos que pesquisas futuras devem preencher as lacunas que surgiram no decorrer da análise. Por fim, acreditamos que o estudo de fenômenos nas interfaces é capaz de iluminar diversos aspectos de nossas propostas, visto que certos fenômenos sintáticos podem ser rastreados a partir de processos semântico-fonológicos que eles condicionam. 


\section{Resumo da tese e considerações finais}

Esta tese descreve e analisa diversos fenômenos relacionados à formação de perguntas QU- complexas, orações subordinadas e ordem de palavras. Iniciamos nossa discussão com dados de perguntas QU- bi-oracionais, como as perguntas indiretas e perguntas de longa-distância. No capítulo 2, argumentamos que o Karitiana não possui perguntas indiretas strictu sensu, pois a língua não permite elementos QU- funcionando como quantificadores em orações subordinadas. Nestes ambientes, pronomes interrogativos (quando presentes) adquirem uma leitura de indefinido. Este comportamento estaria relacionado à ausência da camada CP em orações encaixadas, pois, em Karitiana, apenas elementos QU- que ocupam a posição de Spec, CP e que são regidos por C podem atuar como quantificadores.

No capítulo 3, apresentamos dados de perguntas QU- de longa distância. Vimos que, para construí-las, a língua frontaliza a oração subordinada inteira contendo o elemento QU-, uma estratégia conhecida como pied-piping de larga-escala. Dado que a língua também emprega essa mesma estratégia para focalizar os constituintes dentro de orações subordinadas, sugerimos que estes ambientes sejam domínios opacos para a extração - ou seja, ilhas sintáticas.

A estrutura das subordinadas foi discutida com maior detalhamento no capítulo 4. Nele, apresentamos a proposta de Storto (1999) de que as orações subordinadas não teriam certas projeções funcionais, modificando-a ligeiramente para incluir um núcleo de natureza nominal $n$. Esta arquitetura mista capturaria o comportamento ambíguo destas construções, que exibem concomitantemente diversas propriedades oracionais e nominais. Argumentamos que essa proposta também é capaz de explicar a ausência de perguntas indiretas na língua ao admitir que subordinadas não teriam a projeção CP, além de fazer uma ligação entre a existência do pied-piping de larga-escala com o caráter nominal destas construções. Também mostramos que essa proposta iluminaria diversos outros fenômenos da língua, como a ausência de tough-constructions, a possibilidade de extração com verbos factivos, a suposta cliticização em subordinadas e a presença de relativas de núcleo interno. Também apresentamos uma nova interpretação do fenômeno V2, que aproximaria as subordinadas do Karitiana não de orações encaixadas de línguas como o Alemão, mas sim de construções nominalizadas como action nominals.

Propusemos no capítulo 5 que, em alguns casos, um sufixo - a seria uma manifestação fonética do núcleo - a presente em estruturas subordinadas. Uma das evidências seria de que ele frequentemente emerge em sintagmas nominais, como verbos nominalizados e compostos. Além disso, propusemos também que ele teria conexões históricas com o sufixo nominalizador - $a$ de outras línguas Tupi, pois ambos emergem nos mesmos ambi- 
entes. Como já fora proposto que o morfema - $a$ teria dado origem ao sufixo de enfático -o em Karitiana, apresentamos evidências a favor de uma conexão e de uma origem comum para estes dois morfemas.

Também discutimos neste trabalho um morfema que emerge em certos ambientes subordinados, o sufixo $t i$-. Nossa análise é de que $t i$ - seria um clítico pronominal e que as construções em que ele aparece seriam configurações de redobro de clítico. Argumentamos que essa proposta consegue capturar o comportamento diversificado de $t i$-, como sua presença em diversas construções, a mudança no padrão de concordância e a leitura pressuposicional do tema. Por fim, também argumentamos contra alguns testes propostos por Baker e Kramer (2016) para diagnosticar o redobro de clítico, propondo que eles detectariam na realidade a posição do tema e não a configuração de redobro em si.

Finalmente, apresentamos no capítulo 7 dois fenômenos na interface entre sintaxe e morfologia que poderiam constituir evidências adicionais para as análises desenvolvidas no capítulos 4 e 6 . Primeiramente, teríamos o sufixo -o, que emerge em certos NPs dentro de orações subordinadas. Apresentamos duas possíveis propostas de análise para essa vogal, uma como epêntese e outra como um sufixo de enfático - o. Concluímos que, independente de qual seja a análise mais correta, este sufixo -o poderia constituir um argumento adicional para a análise de nominalização em subordinadas, pois nos dois casos ele guarda semelhanças com o comportamento de possessivos em sintagmas nominais.

O último fenômeno analisado é um padrão intonacional em orações subordinadas com $t i$. Vimos que relativas de objeto SOV com $t i$ - têm um padrão prosódico fixo, sinalizado pelo contorno ascendente de continuação L* H\%. Argumentamos que esse padrão pode ser capturado pela análise para ti-desenvolvida no capítulo 6 , visto que o sujeito nestas relativas parece se comportar sintaticamente e fonologicamente como um adjunto.

Em suma, buscamos neste trabalho elucidar diversos pontos da gramática do Karitiana. Embora os fenômenos contemplados aqui tenham sido numerosos e, em alguns casos, aparentemente não relacionados, vimos que existem diversas conexões que perpassam essas construções e que impedem que elas sejam investigadas em separado. Por exemplo, o comportamento de $t i$ - pressupõe mecanismos como movimento QU- e a subordinação. O funcionamento da subordinação oracional, por sua vez, só pode ser capturado em sua totalidade se investigarmos sua interação com movimento QU-. Por fim, até um fenômeno fonológico como a epêntese faz referência a diversos outros mecanismos morfossintáticos que subjazem muitas outras construções da língua. Em última instância, isso nos mostra que, embora comecemos a estudar uma língua em uma escalada de domínios aparentemente mais simples para outros supostamente mais complexos, sua arquitetura só pode ser efetivamente apreendida se consideramos a constelação de operações que a compõe. 


\section{Bibliografia}

ADAMS, Marianne. Government of empty subjects in factive clausal complements. Linguistic Inquiry 16 (2), 1985.

AISSEN, Judith. Pied-piping, abstract agreement, and functional projections in Tzotzil.

Natural Language and Linguistic Theory, Springer, v. 14, n. 3, 1996.

ALDRIDGE, Edith. Phase-based account of extraction in Indonesian. Lingua, v. 118, n. 10, 2008.

ALEXANDRE, Thiago Chaves. Os evidenciais do Karitiana. 2016. Diss. (Mestrado) - Universidade de São Paulo, São Paulo.

ALEXIADOU, Artemis; ANAGNOSTOPOUlOU, Elena. Clitic-doubling and (non-) configurationality. Proceedings of NELS, v. 30, 2000.

ARAÚJO, Íris. Osikirip: os especiais Karitiana e a noção de pessoa ameríndia. 2014. Tese (Doutorado) - Universidade de São Paulo.

ARREGI, Karlos. Clausal pied-piping. Natural Language Semantics, v. 11, n. 2, 2003.

BAIER, Nico. A Survey of Anti-Agreement Effects, 2016.

BAKER, Mark. Degrees of nominalization: Clause-like constituents in Sakha. Lingua 121 (7), 2011.

BAKER, Mark; JOHNSON, Kyle; ROBERTS, Ian. Passive arguments raised. Linguistic inquiry, v. 20, n. 2, 1989.

BAKER, Mark; KRAMER, Ruth. Doubling Clitics are Pronouns: Reduce and Interpret. [S.1.: s.n.], 2016. Manuscript.

BASILICO, David. Head position and internally headed relative clauses. Language, p. 498-532, 1996.

BECKMAN, Mary; HIRSCHBERG, Julia. The ToBI annotation conventions. Ohio State University, 1994.

BECKMAN, Mary; PIERREHUMBERT, Janet. Intonational structure in Japanese and English. Phonology, v. 3, 1986.

BÉJAR, Susana; REZAC, Milan. Cyclic agree. Linguistic Inquiry, v. 40, n. 1, 2009.

BENNETT, William; AKINLABI, Akinlabiyi; CONNEL, Bruce. Two subject asymmetries in Defaka focus constructions. v. 29. [S.l.: s.n.], 2012.

BHAT, D.N.S. Introduction. In: PRONOUNS. Oxford: Oxford University Press on Demand, 2004. 
BOBALIJK, Jonathan; BRANIGAN, Phil. Eccentric Agreement and Multiple Case Checking. In: JOHNS, Alana; MASSAM, Diane; NDAYIRAGIJE, Juvenal (Ed.). Ergativity: emerging issues. Dordrecht: Springer, 2006.

BORSLEY, Robert. Mixed extended projections. In: The nature and function of syntactic categories. Edição: Robert Borsley. Nova Iorque: Academic Press, 2000 .

BOSKOVIC, Zeljko. From the Complex NP Constraint to everything: On deep extractions across categories. The Linguistic Review 32, 2015.

BRASIL. Decreto no 93.068, de 6 e AGOSTO de 1986. [S.l.: s.n.]. Diário Oficial da União - Seção 1 - 7/8/1986. Disponível em www2.camara.leg.br/legin/fed/decret/19801987/decreto-93068-6-agosto-1986-443142-publicacaooriginal-1-pe.html. Acessado em 4 de julho de 2018.

BROADWELL, George Aaron. Optimal order and pied-piping in San Dionicio Zapotec. Formal and empirical issues in optimality theory. Stanford: CSLI, 2001.

BURZIO, Luigi. Italian syntax: A government-binding approach. Dordrecht: Springer, 1986.

CABLE, Seth. Against the existence of pied-piping: Evidence from Tlingit. Linguistic Inquiry, v. 41, n. 4, 2010.

CARVAlHO, Andrea Marques de. O auxiliar aspectual Tyka do Karitiana. 2010. Diss. (Mestrado) - Universidade de São Paulo.

CHOE, Jae. LF movement and pied-piping. Linguistic Inquiry, 1987.

CHOMSKY, Noam. Barriers. Cambridge: MIT press, 1986.

. Derivation by Phase. In: KENSTOWICZ, Michael (Ed.). Kenneth Hale: A Life is Language. Cambrdige: MIT Press, 2001.

Knowledge of language: Its nature, origin, and use. New YorNew Yor: Praeger, 1986.

On WH- movement. In: CULICOVER, Peter; WASOW, Thomas; AKMAJIAN, Adrian (Ed.). Formal syntax. Nova Iorque: Academic Press, 1977.

CINQUE, Guglielmo. The movement nature of left dislocation. Linguistic inquiry, v. 8, n. 2, 1977.

COLE, Peter. Imbabura quechua. Amsterdam: North-Holland Publishing Company, 1982.

The structure of internally headed relative clauses. Natural Language and Linguistic Theory 5 (2), 1987. 
COLLINS, Chris. A smuggling approach to the passive in English. Syntax, v. 8, n. 2, 2005.

COMRIE, Bernard; THOMPSON, Sandra. Lexical nominalization. In: SHOPPEN, Timothy (Ed.). Language Typology and Syntactic Description vol. III: Grammatical Categories and the Lexicon. Cambridge: Cambridge University Press, 2007.

COON, Jessica. Interrogative possessors and the problem with pied-piping in Chol. Linguistic Inquiry, v. 40, n. 1, 2009.

COUTINHO-SILVA, Thiago. Aspectos dos sintagmas nominais em karitiana: a quantificação universal. 2008. Diss. (Mestrado) - Universidade de São Paulo, São Paulo.

CROWLEY, Terry. Field linguistics: A beginner's guide. Oxford: Oxford University Press, 1993.

CRUTTEnDEN, Alan. Intonation. Cambridge: Cambridge University Press, 1997.

CULY, Christopher. The syntax and semantics of internally headed relative clauses. 1990. Tese (Doutorado) - Stanford University.

DIESING, Molly. Indefinites. Cambridge, EUA: MIT Press, 1992.

DIESING, Molly; JELINEK, Eloise. Distributing arguments. Natural Language Semantics, 1995.

DIETRICH, Wolf. Correspondências fonológicas e lexicais entre Karitiána (Arikém, Tupi) e Tupi-Guarani. Revista Brasileira de Linguística Antropológica, v. 1, n. 2, 2009.

DIXON, Robert; AIKHENVALD, Alexandra. Introduction. In: The Amazonian Languages. Edição: Robert Dixon e Alexandra Aikhenvald. Cambridge: Cambridge University Press, 1999.

DOBROVIE-SORIN, Carmen. Clitic doubling, wh-movement, and quantification in Romanian. Linguistic inquiry, v. 21, n. 3, 1990.

EVERETT, Caleb. Constituent focus in Karitiâna, 2008.

. Patterns in Karitiana: Articulation, perception, and grammar. 2006. Tese (Doutorado) - Rice University, Houston.

FERREIRA, Luiz Fernando. Modo em Karitiana. 2017. Diss. (Mestrado) - Universidade de São Paulo, São Paulo.

FODOR, Janet; SAG, Ivan. Referential and quantificational indefinites. Linguistics and philosophy, v. 5, n. 3, 1982.

GALUCIO, Ana Vilacy. Relativização na língua Sakurabiat (Mekens). Boletim do Museu Paraense Emílio Goeldi Ciências Humanas, v. 1, n. 1, 2006. 
GIJN, Rik van; GALÚCIO, Ana Vilacy; NOGUEIRA, Antônia Fernanda. Subordination strategies in Tupian languages. Boletim do Museu Paraense Emilio Goeldi. Ciências Humanas 10 (2), 2015.

GIJN, Rik van; HAUDE, Katharina; MUYSKEN, Pieter. Subordination in native SouthAmerican languages: an overview. In: Subordination in native SouthAmerican languages. Edição: Rik van Gijn, Katharina Haude e Pieter Muysken. [S.l.]: John Benjamins Publishing, 2011.

HALE, Kenneth; JELINEK, Eloise; WILLIE, Mary Ann. Topic and focus scope positions in Navajo. In: KARIMI, Simin (Ed.). Word order and scrambling. New Jersey EUA: John Wiley e Sons, 2012.

HALE, Kenneth; KEYSER, Samuel Jay. Prolegomenon to a theory of argument structure. Cambridge: MIT press, 2002.

HALE, Kenneth; STORTO, Luciana. Agreement and spurious antipassives. Boletim da Associacao Brasileira de Linguistica (ABRALIN) 20-Homenagem a Aryon Dall'igna Rodrigues, 1997.

HASPELMATH, Martin. Indefinite pronouns. Nova Iorque: Oxford University Press, 1997.

HECK, Fabian. On certain properties of pied-piping. Linguistic Inquiry, v. 40, n. 1, 2009. 2008.

On pied-piping: Wh-movement and beyond. Berlin: Walter de Gruyter,

HEIM, Irene. The Semantics of Definite and Indefinite Noun Phrases. 1982. Tese (Doutorado) - UniUniversity of Massachusetts, Amherst.

HEIM, Irene; KRAZTER, Angelika. Semantics in generative grammar. Oxford: Blackwell, 1998.

HOLMBERG, Anders. Verb second. Edição: Tibor Kiss e Artemis Alexiadou. Syntax Theory and Analysis. An International Handbook of Contemporary Syntactic Research, Mouton de Gruyter, Berlim, 2015.

HORVATH, Julia. Pied-piping. In: EVERAERTAND, Martin; RIEMSDIJK, Henk Van (Ed.). The Blackwell Companion to Syntax. Oxford: Blackwell Publishing, 2006. v. III.

IATRIDOU, Sabine. Clitics and island effects. University of Pennsylvania working papers in linguistics, v. 2, n. 1, 1995.

INSTITUTE, Max Planck. The Leipzig glossing rules. [S.l.: s.n.], 2015. Manuscrito.

ISA. TI Karitiana. [S.l.: s.n.]. Disponível em terrasindigenas.org.br/es/terras-indigenas/3725.

Acessado em 4 de julho de 2018. 
KARIMI, Simin. On object positions, specificity, and scrambling in Persian. In: WORD order and scrambling. Oxford: Blackwell Publishing, 2003.

KARITIAnA, Edelaine Maria Om Etepãrãrã. Kerep Õwã Aopika: a educação Karitiana antes da criação da escola. 2017. Diss. (Mestrado) - Universidade Federal de Rondônia, Ji-Paraná.

KARITIANA, Inácio. Processos próprios de educação do povo Karitiana. 2015. Diss. (Mestrado) - Universidade Federal de Rondônia, Ji-Paraná.

KARITIAnA, João Batista Kyjengã. Pensando a escola indígena Karitiana diferenciada. 2015. Diss. (Mestrado) - Universidade Federal de Rondônia, Ji-Paraná.

KARITIANA, Luiz Carlos. Saberes e fazeres matemáticos do povo Karitiana. 2015. Diss. (Mestrado) - Universidade Federal de Rondônia, Ji-Paraná.

KEMMER, Susn. Middle voice, transitivity, and the elaboration of events. In: FOX, Barbara; HOPPER, Paul (Ed.). Voice: Form and Function. Amsterdam/Philadelphia: John Benjaminss, 1994.

KIPARSKY, P.; KIPARSKY, C. Fact. In: STEINBERG, D.; JAKOBOVITS, L. (Ed.). Semantics: and interdisciplinary reader. Cambridge, EUA: Cambridge University Press, 1971.

KISHIMOTO, Hideki. Wh-in-situ and movement in Sinhala questions. Natural Language and Linguistic Theory, v. 23, n. 1, 2005.

KOOPMAN, Hilda; SPORTICHE, Dominique. Variables and the bijection principle. The Linguistic Review, v. 2, n. 2, 1982.

KOPTJEVSKAJA-TAMM, Maria. Nominalizations. New York: Routledge, 2002.

KRAMER, Ruth. Clitic doubling or object agreement: the view from Amharic. Natural Language and Linguistic Theory, 2014.

KRATZER, Angelika; SHIMOYAMA, Junko. Indeterminate pronouns: The view from Japanese. Springer, p. 123-143, 2017.

KUPULA, Mikko. Clitic lef-dislocation as agreement - a movement approach. In: KIMMELMAN, Vadim; KOROTKOVA, Natalia; YANOVICH, Igor (Ed.). Proceedings of MOSS 2: Moscow Syntax and Semantics. Cambridge: MIT Working Papers in Linguistics \#75, 2014.

LADD, Robert D. Intonational phonology. Cambridge: Cambridge University Press, 2008.

LADEFOGED, Peter. Phonetic data analysis: An Introduction to Fieldwork and Instrumental Techniques. Malden: Blackwell, 2003. 
LAMBRECHT, Knud. Information structure and sentence form: Topic, focus, and the mental representations of discourse referents. Cambridge: Cambridge University Press, 1994.

Information structure and sentence form: Topic, focus, and the mental representations of discourse referents. Cambridge: Cambridge university press, 1996.

LANDIN, David. An outline of the syntactic structure of Karitiana sentences. Estudos sobre línguas Tupi do Brasi, 1984.

Dicionário e léxico karitiana/português. Sociedade Internacional de Linguística, 2005 .

LANDIN, Rachel. Word order variation in karitiana. Arquivo Linguístico 149, 1982.

LEGATE, Julie Anne. Warlpiri Wh-Scope Marking. Syntax, v. 14, n. 2, 2011.

LEITE, Yonne. Para uma tipologia ativa do Tapirapé. Cadernos de estudos linguisticos, v. 18, 1990.

LONGOBARDI, Giuseppe. Extraction from NP and the proper notion of head government. In: GIORGI, Alessandra; LONGOBARDI, Giuseppe (Ed.). the Syntax of Noun Phrases: configuration, parameter, and empty categories. [S.1.]: Cambridge University Press, 1991.

MATTHEWSON, Lisa. On the methodology of semantic fieldwork. International journal of American linguistics 70 (4), 2004.

MCCLOSKEY, James. The morphosyntax of wh-extraction in Irish. Journal of Linguistics, v. 37, n. 1, 2001.

MEIRA, Sérgio. Mental state postpositions in Tiriyó and other Cariban languages. Linguistic Typology, no prelo.

MILSARK, Gary L. Toward an explanation of certain peculiarities of the existential construction in English. Linguistic analysis, v. 3, n. 1, 1977.

MITHUN, Marianne. How to avoid subordination. [S.l.: s.n.], 1984.

MOORE, Denny. Línguas indígenas: situação atual, levantamento e registro. Revista Eletrônica do IPHAN, v. 5, 2007.

MÜLLER, Ana. On the encoding of the definite/indefinite distinction in Karitiana. Proceedings of Sinn und Bedeutung, 2011.

MULLER, Ana; SANCHEZ-MENDES, Luciana. The meaning of pluractionality in Karitiana. In: PROCEEDINGS of the Semantics of Under-represented languages in the Americas. [S.l.]: University of Massachusetts Occasional Papers 35, 2007. v. 4. 
MÜLlER, Ana; STORTO, Luciana; COUTINHO-SILVA, Thiago. Number and the mass/count distinction in Karitiana. v. 11. [S.l.: s.n.], 2006.

NAVARRO, Eduardo. Dicionário de tupi antigo: a língua indígena clássica do Brasil. São Paulo: Global, 2013.

NESPOR, Marina; VOGEL, Irene. Prosodic phonology: with a new foreword. [S.l.]: Walter de Gruyter, 2007.

NEVINS, Andrew. Multiple agree with clitics: Person complementarity vs. omnivorous number. Natural Language and Linguistic Theory, v. 29, n. 4, 2011.

NEVINS, Andrew; SANDALO, Filomena. Markedness and morphotactics in Kadiwéu [+ participant] agreement. Morphology, v. 21, n. 2, 2011.

NIMUENDAJÚ, Curt. Wortlisten aus Amazonien. Journal de la Société des Américanistes, v. 24, n. 1, 1932.

O’DONNELL, Roy. Syntactic differences between speech and writing. American Speech 49, 1974.

OUHALLA, Jamal. Subject-extraction, negation and the antiagreement effect. Natural Language and Linguistic Theory, v. 11, n. 3, 1993.

PAYNE, Doris. The tupi-guarani inverse. In: FOX, Barbara; HOPPER, Paul (Ed.). Voice: Form and function. Amsterdam/Philadelphia: John Benjamins, 1994. v. 27.

PERLMUTTER, David; POSTAL, Paul. Toward a universal characterization of passivization. In: ANNUAL Meeting of the Berkeley Linguistics Society. [S.l.: s.n.], 1977.

PESETSKY, David. Wh-in-situ: Movement and unselective binding. In: REULAND, Eric; MEULEN, Alice ter (Ed.). The representation of (in)definiteness. [S.l.: s.n.], 1987.

PESETSKY, David; TORREGO, Ester. Case. In: BOECKX, Cedric (Ed.). The Oxford handbook of linguistic minimalism. Oxford: Oxford University Press, 2011.

PIERREHUMBERT, Janet. The phonology and phonetics of English intonation. 1980. Tese (Doutorado) - Massachusetts Institute of Technology, Cambridge, EUA.

PIERREHUMEBERT, Janet. Tonal elements and their alignment. In: HORNE, Merle (Ed.). Prosody: Theory and experiment. Dordrecht: Springer, 2010.

PRAÇA, Walkiria Neiva; MAGALHÃES, Marina Maria Silva; CRUZ, Aline da. Indicativo II da família Tupi Guarani: uma questão de modo? LIAMES: Línguas Indígenas Americanas, v. 17, n. 1, 2017.

QUEIXALÓS, Francesc. The primacy and fate of predicativity in Tupi-Guarani. In: LEXICAL categories and root classes in Amerindian languages. Bern: Peter Lang, 2006. ximena lois and valentina vapnarsky. 
RACKOWSKI, Andrea; RICHARDS, Norvin. Phase edge and extraction: A Tagalog case study. Linguistic Inquiry, v. 36, n. 4, 2005.

RICHARDS, Norvin. WH- questions. In: MIYAGAWA, Shigeru; SAITO, Mamoru (Ed.). The Oxford Handbook of Japanese Linguistics. OxfordOxford: Oxford University Press, 2008.

RIZZI, Luigi. The fine structure of the left periphery. In: HAEGEMAN, Liliane (Ed.). Elements of grammar. [S.l.]: Springer, 1997.

ROCHA, Ivan. A Estrutura Argumental da Língua Karitiana: desafios descritivos e teóricos. 2011. Diss. (Mestrado) - Universidade de São Paulo, São Paulo.

Causativization in karitiana. Boletim do Museu Paraense Emílio Goeldi. Ciências Humanas 9 (1), 2014.

. Não-finitude em Karitiana: subordinação versus nominalização. 2016. Tese (Doutorado) - Universidade de São paulo, São Paulo.

RODRIGUES, Aryon. Argumento e predicado em Tupinambá. Revista Brasileira de Linguística Antropológica 3 (1), 2013.

Línguas brasileiras: para o conhecimento das línguas indígenas. São Paulo: Edições Loyola, 1986.

. Sobre as línguas indígenas e sua pesquisa no Brasil. Ciência e cultura, Sociedade Brasileira para o Progresso da Ciências, v. 57, n. 2, 2005.

. Tarefas da linguística no Brasil. Estudos linguísticos, v. 1, n. 1, 1966.

. Tupí. In: DIXON, Robert; AIKHENVALD, Alexandra (Ed.). The Amazonian Languages. Cambridge: Cambridge University Press, 1999.

RODRIGUES, Aryon; CABRAL, Ana Suelly. Tupían. In: CAMPBELL, Lyle; GRONDONA, Verónica (Ed.). The indigenous languages of South America: a comprehensive guide. Berlin/Boston: Walter de Gruyter, 2012.

RODRIGUES, Aryon; CABRAL, Ana Suelly; SILVA, Beatriz da. Evidências Lingüísticas para a Reconstrução de um Nominalizador de Objeto**-Mi-Em Proto-Tupí. Estudos da Língua(gem) 4 (1), 2006.

ROOTH, Mats. Focus. In: LAPPIN, Shalom (Ed.). The handbook of contemporary semantic theory. Oxford: Blackwell, 1996.

ROSS, John. Constraints on variables in syntax. 1967. Tese (Doutorado) - Massachusetts Institute of Technology, Cambridge, EUA.

. Nouniness. In: AARTS, Bas et al. (Ed.). Fuzzy grammar: A reader. [S.1.]: Oxford University Press on Demand, 2004. 
SADDY, Douglas. Wh-scope mechanisms in Bahasa Indonesia. MIT working papers in linguistics, v. 15, 1991.

SANCHEZ-MENDES, Luciana. A modificação de grau em Karitiana. 2014. Tese (Doutorado) - Universidade de São Paulo.

A quantificação adverbial em Karitiana. 2009. Tese (Doutorado) - Universidade de São Paulo.

SELKIRK, Elisabeth. Sentence prosody: Intonation, stress, and phrasing. In: GOLDSMITH, John (Ed.). The handbook of phonological theory. Cambridge: Blackwell, 1995.

SIMPSON, Andrew; BHATTACHARYA, Tanmoy. Wh clausal pied piping in Bangla. Proceeding of NELS, v. 30, 2000.

STORTO, Luciana. Algumas categorias funcionais em Karitiana. [S.l.: s.n.], 2002. Anáfora ta- em Karitiana. [S.l.: s.n.], 2007. manuscrito.

. Aspects of a Karitiana grammar. 1999. Tese (Doutorado) - Massachusetts Institute of Technology, Cambridge, EUA.

Ausência de determinantes e complementizadores em Karitiana.s. [S.l.: s.n.], 2011.

. Caso e Concordância nas Línguas Tupi. Estudos Lingüísticos, 2005.

. Copular Constructions in Karitiana: a case against case movement. University of Massachusetts Occasional Papers 41, 2010.

. Information Structure and Constituent Order in Karitiana Clauses. In: GIJN, Rik van et al. (Ed.). Information Structure and Reference Tracking in Complex Sentences. Amsterdam/Philadelphia: John Benjamins Publishing, 2014.

. Livro de apoio ao aprendizado da ortografia Karitiana, 1996.

. Marcação Absolutiva em Algumas Construções Sintáticas em Karitiana. Ameríndia 32: La Structure des Langues Amazoniennes, 2008.

. Negation in Karitiana. Amazônicas, 2017.

. Reduplication in Karitiana (Tupi). In: GÓMEZ, Gale Goodwin; VOORT, Hein van der (Ed.). Reduplication in Indigenous Languages of South America. [S.l.]: Brill, 2014.

. Subordination in Karitiana. Ameríndia 35: La Structure des Langues Amazoniennes, 2012.

. Temporal and aspectual Interpretations in non-finite clauses. In: MOLSING, Karina Veronica; IBAÑOS, Ana Maria Tramunt (Ed.). Time and TAME in Language. Newcastle upon tyne: Cambridge scholars publishing, 2013. 
STORTO, Luciana; BALDI, P. The Proto-Arikem Vowel Shift. Apresentação oral. Linguistics Society of America, 1994.

STORTO, Luciana; DEMOLIN, Didier. Pitch Accent in Karitiana. In: KAJI, Shigeki (Ed.). Cross Linguistic Studies of Tonal Phenomena. Tokyo: ILCAA, 2005.

STORTO, Luciana; ROCHA, Ivan. Estrutura Argumental na Língua Karitiana. Sintaxe e semântica do verbo em línguas indígenas do brasil, Mercado de Letras, 2015. Inventário sociolinguístico da Língua Karitiana. [S.l.: s.n.], 2018. INDL (Inventário Nacional da Diversidade Linguística), IPHAN-MPEG.

STORTO, Luciana; THOMAS, Guillaume. The Clausal Nature of Universally Quantified Phrases in Karitiana. Proceedings of Semantics of Under-represented Languages in the Americas, v. 6, 2012.

STORTO, Luciana; VIVANCO, Karin; ROCHA, Ivan. Multiple embedding of relative clauses in karitiana. In: AMARAL, Luiz et al. (Ed.). Recursion across domains. Cambridge: Cambridge University Press, 2018.

SUDO, Yasutada. Wh-ka pronouns in Japanese and the semantics of indeterminate pronouns, p. 10-12, 2010.

SUÑER, Margarita. The role of agreement in clitic-doubled constructions. Natural Language and Linguistic Theory, v. 6, n. 3, 1988.

THORNTON, Rosalind. Elicited production. In: MCDANIEL, Dana; MCKEE, Cecile; CAIRNS, Helen Smith (Ed.). Methods for assessing children's syntax. Cambridge: The MIT Press, 1996.

URBINA, Jon Ortiz de. Feature percolation and clausal pied-piping. In: HUALDE, José Ignacio; URBINA, Jon Ortiz de (Ed.). Generative Studies in Basque Linguistics. [S.l.]: Walter de Gruyter, 1993.

URBINA, Jon Ortiz de; ETXEPARE, Ricardo. Focalization and Wh-movement in Basque. In: HUALDE, José Ignacio; URBINA, Jon Ortiz de (Ed.). A Grammar of Basque. Berlin: Mouton de Gruyter, 2003.

URIAGEREKA, Juan. Aspects of the syntax of clitic placement in Western Romance. Linguistic inquiry, v. 26, n. 1, 1995.

VALIN, Robert Van et al. Information Structure in Amazonian Languages. [S.l.: s.n.]. Disponível em http://www.acsu.buffalo.edu/ rrgpage/infostructure/Site/Intro.html. Acessado em 3 de agosto de 2018.

VELDEN, Felipe Ferreira Vander. Inquietas companhias: sobre os animais de criação entre os Karitiana. 2010. Tese (Doutorado) - Universidade Estadual de Campinas, Campinas. 
VIVANCO, Karin. Evidencialidade em Karitiana: aspectos morfológicos e sintáticos. Universidade de São Paulo": [s.n.], 2007. Relatório de Iniciação Científica.

. Orações relativas em karitiana. Revista LinguíStica, v. 10, 2015.

. Orações relativas em karitiana: um estudo experimental. 2014. Diss. (Mestrado) - Universidade de São Paulo, São Paulo.

. Some observations on word order and prosody in Karitiana relative Cclauses.

Diadorim: revista de estudos linguísticos e literários 19, 2017.

VRIES, Mark De. The Syntax of Relativization. Utrecht: LOT, 2002.

YANG, Charles. Computational models of syntactic acquisition. Wiley Interdisciplinary Reviews: Cognitive Science, v. 3, n. 2, 2012.

ZUBIZARRETA, Maria Luisa. Theoretical implications of subject extraction in Portuguese. The Linguistic Review 2(1), 1982. 